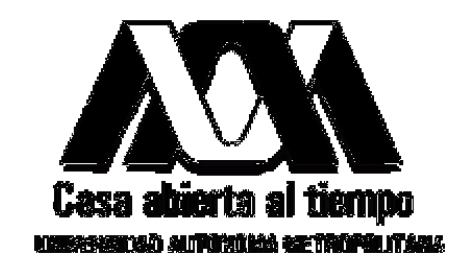

UNIVERSIDAD AUTÓNOMA METROPOLITANA

Unidad Iztapalapa

\title{
ESTUDIO DE LA BIOCONVERSIÓN DE NOOTKATON CON BIORREACTORES TRIFÁSICOS UTILIZANDO CÉLULAS COMPLETAS \\ STUDY OF BIOCONVERSION NOOTKATONE WITH THREE PHASE PARTITIONING BIOREACTORS USING WHOLE CELLS
}

TESIS PARA OBTENER EL GRADO DE DOCTORA EN BIOTECNOLOGÍA

PRESENTA

DULCE MARÍA PALMERÍN CARREÑO

DIRECTOR

DR. SERGIO HUERTA OCHOA

ASESORES

DRA. OLGA MIRIAM RUTIAGA QUIÑNONES

DR. JOSÉ RAMÓN VERDE CALVO

México D.F. Septiembre de 2015. 
El Doctorado en Biotecnología de la Universidad Autónoma Metropolitana está incluido en el Programa Nacional de Posgrados de Calidad (PNPC) Nivel Competencia Internacional del Consejo Nacional de Ciencia y Tecnología (CONACyT). Y se agradece al CONACyT por la beca otorgada (226912) para la realización de este trabajo. 
México, D.F., Septiembre de 2015.

El jurado designado por la División de Ciencias Biológicas y de la Salud de la Unidad Iztapalapa aprobó la tesis:

\section{ESTUDIO DE LA BIOCONVERSIÓN DE NOOTKATON CON BIORREACTORES TRIFÁSICOS UTILIZANDO CÉLULAS COMPLETAS \\ STUDY OF BIOCONVERSION NOOTKATONE WITH THREE PHASE PARTITIONING BIOREACTORS USING WHOLE CELLS}

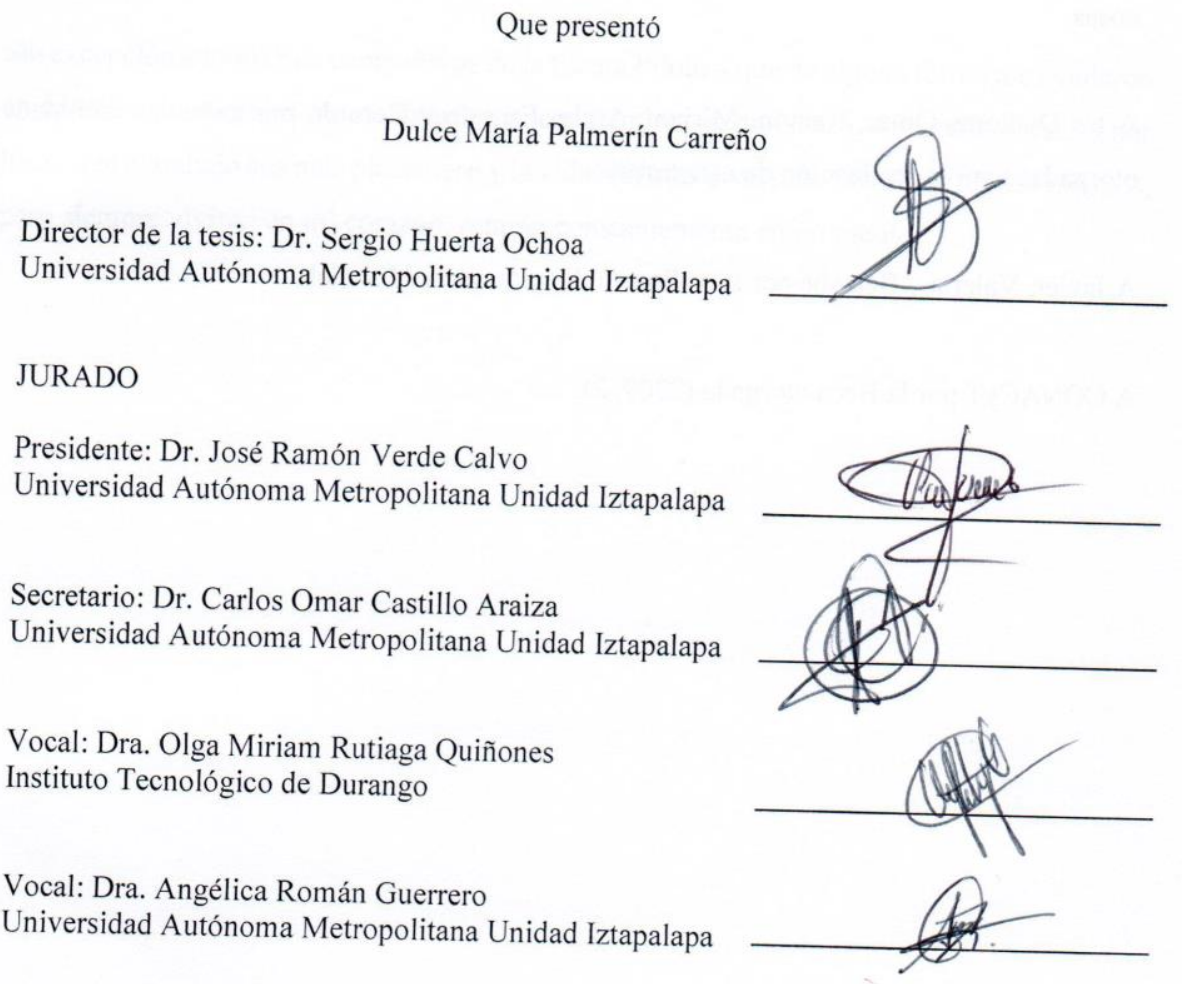


ESTUDIO DE LA BIOCONVERSION DE NOOTKATON CON

BIORREACTORES TRIFASICOS

UTILIZANDO CELULAS COMPLETAS.
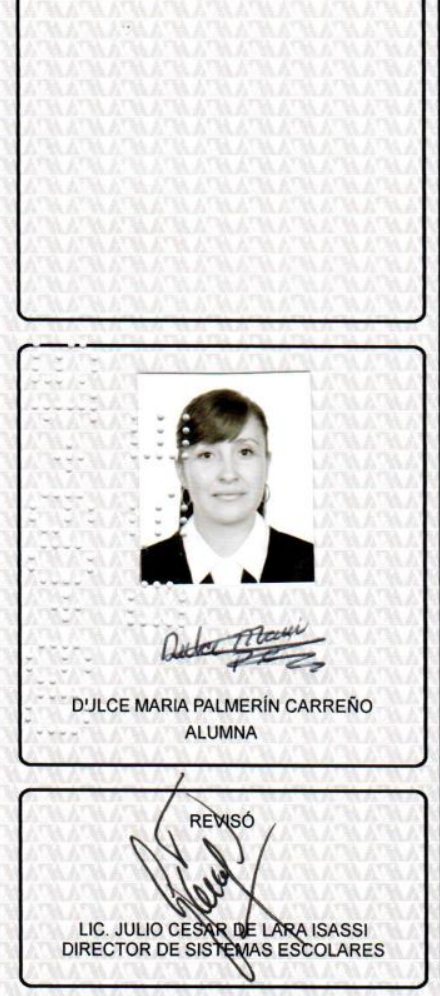

Bajo la Presidencia del primero y con carácter de Secretario el último, se reunieron a la presentación de la Disertación Pública cuya denominación aparece al margen, para la obtención del grado de:

DOCTORA EN BIOTECNOLOGIA

DE: DULCE MARIA PALMERIN CARREÑO

y de acuerdo con el artículo 78 fracción IV del Reglamento de Estudios Superiores de la Universidad Autónoma Metropolitana, los miembros del jurado resolvieron:

\section{AProbar}

Acto continuo, el presidente del jurado comunicó a la interesada el resultado de la evaluación $y$, en caso aprobatorio, le fue tomada la protesta.

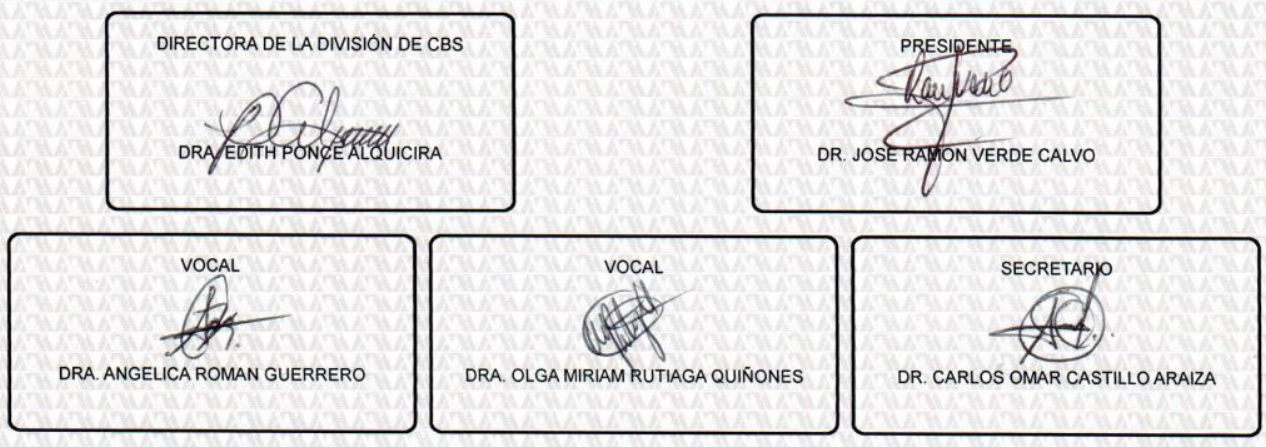




\section{AGRADECIMIENTOS}

A Dios....

A Sergio, por la enorme ayuda que me otorgó para realizar este trabajo, por confiar en mí a lo largo de todo este tiempo, por sus valiosos consejos, pero sobre todo por la gran amistad que hicimos.

A Abhishek por recibirme en la Universidad de KU Leuven, Bélgica y enseñarme grandes cosas.

A los Doctores Omar, Ramón, Miriam, Arely, Ernesto y Gerardo por todas las facilidades otorgadas para la realización de este trabajo.

A Javier, Valeria y Betzabe por su valioso trabajo de servicio social.

A CONACyT por la Beca otorgada (226912). 


\section{DEDICATORIAS}

A mis Padres por darme la Vida y enseñarme a disfrutarla. Los Amo.

A Santiago, por estar a mi lado a lo largo de este camino, por tu paciencia... Te Amo Simis.

A Kristelle, Carlos Jr. y Jesús (Mi pequeño angelito), por darme sonrisas inesperadas.

Para Christian, Carlos y David, hermanos que me apoyaron en todo momento. Los Amo.

Sin excepción a todos mis compañeros de la Planta Piloto 4 que de alguna forma me ayudaron en este trabajo. Gracias por compartir sus conocimientos, amistad y compañía. Gracias por hacer que el trabajo sea más placentero y la vida aún más divertida. Sus nombres son muchos, pero siempre vivirán en mi corazón, estarán constantemente en mi mente. 


\section{INDEX}

1. GENERAL INTRODUCTION 8

2. CHAPTER I 17

PROBLEM STATEMENT

3. CHAPTER II

SCREENING OF MICROORGANISMS FOR BIOCONVERSION OF (+)VALENCENE TO (+)-NOOTKATONE

\section{CHAPTER III}

BIOCONVERSION OF (+)-VALENCENE BY Botryodiplodia theobromae USING A MEMBRANE AERATED BIOFILM REACTOR

\section{CHAPTER IV}

ASSESSMENT OF (+)-VALENCENE BIOCONVERSION BY Yarrowia lipolytica USING A THREE PHASE PARTITIONING BIOREACTOR

6. CHAPTER V

WHOLE CELL BIOCONVERSION OF (+)-VALENCENE TO (+)NOOTKATONE BY Yarrowia lipolytica USING A THREE PHASE PARTITIONING BIOREACTOR

\section{CHAPTER VI}

EFFECT OF HYDRODYNAMIC STRESS AND BIOMASS CONCENTRATION IN BIOCONVERSION OF (+)-VALENCENE WITH Yarrowia lipolytica 
8. CHAPTER VII

WHOLE CELL (+)-NOOTKATONE BIOCONVERSION IN AN ORGANIC PHASE (ORANGE ESSENTIAL OIL) SYSTEM USING Yarrowia lipolytica

\section{CHAPTER VIII}

HYDRODYNAMIC AND OXYGEN MASS TRANSFER STUDIES IN A THREE-PHASE (AIR-WATER-ESSENTIAL ORANGE OIL) STIRRED TANK BIOREACTOR FOR THE BIOCONVERSION OF (+)-VALENCENE WITH Yarrowia lipolytica

\section{CHAPTER IX}

GENERAL CONCLUSIONS AND PERSPECTIVES

ANNEXES

PUBLISHING PAPERS 


\section{GENERAL INTRODUCTION}

(+)-Nootkatone is a sesquiterpenoid that has a pleasant grapefruit like aroma and is slightly bitter with a low odor threshold of $1 \mu \mathrm{g} \mathrm{L}{ }^{-1}$ water. Notwithstanding this property, (+)nootkatone is applied in pharmacology such as anti-platelet aggregation effects and antiproliferative activity towards cancer cell lines [1,2]. (+)-Nootkatone inhibits the activity of acetylcholinesterases (AChE), AChE inhibitors are used as medicines against Alzheimer's disease [3]; and also (+)-Nootkatone inhibits the activity of human cytochrome-P450monooxygenase. The cytochrome enzyme eliminates unwanted components from the body by oxidation [4]. (+)-Nootkatone has a stimulating effect on certain physiological conditions such as AMP-activated protein kinase (AMPK) activation in skeletal muscle and liver [5]. Furthermore, (+)-nootkatone is also used as an insecticide. It is useful because it kills insects by blocking the insects' receptors of their nerve cells for a neurotransmitter called octopamine. The insects become hyperactive and vibrate themselves to death $[6,7]$.

Nowadays, the world production of (+)-nootkatone is carried out in 32 industries. There are three reported methods for (+)-nootkatone production: Natural (from citrus fruits and plants), chemical, and biological (using whole-cells bioconversions). Figure 1 shows how the production methods are applied by industry. The leading companies that are currently producing this sesquiterpene with whole cells are Allylix Inc., Amyris, Evolva, Isobionics B.V., ACIB and Oxford Biotrans, respectively. In the natural method, (+)-nootkatone is obtained from different plants, but only in trace amounts [8], it takes around 400,000 kg of grapefruit to produce $1.0 \mathrm{~kg}$ of (+)-nootkatone (http://oxfordbiotrans.com/uk-researchprovides-taste-of-future-foods/). Therefore (+)-nootkatone demand is nowadays fulfilled by chemical synthesis [9], i.e., through the use of tert-butyl chromate for the Copper(I) mediated oxidation by alkyl hydroperoxides [10]. However, the main problem with chemical synthesis is that reactions include various reaction steps that require environmentally hazardous reagents, catalysts and solvents. In this sense, the use of unwanted or even toxic chemicals is not favorable and, thus, (+)-nootkatone cannot legally be marketed as a "natural" flavor [1]. 


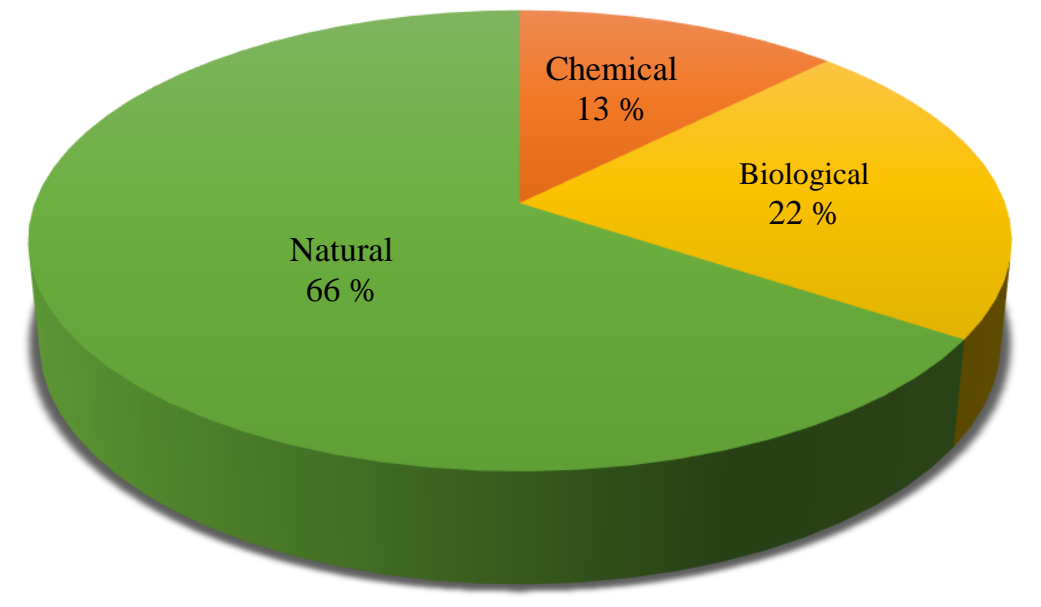

\author{
England, Asia \\ $\square$ England, EE.UU., Europe \\ - Canada, EE.UU., Asia, Europe
}

Figure 1. Distribution of industries by (+)-nootkatone production method

(http://www.radiantinsights.com/research/nootkatone-market-research-report-2015).

(+)-Valencene and (+)-Nootkatone are sesquiterpenes, natural terpenoids, that are commonly found in plant essential oils [11]. Several biotechnological processes have already been designed to achieve the oxidation of (+)-valencene to (+)-nootkatone on different microorganisms. Examples of these processes are the production of (+)-nootkatone with: green algae like Chlorella or Euglena; fungi such as Botryodiplodia theobromae [12] or Chaetomium globosum [13]; recombinant bacteria like E. coli [4]; a nucleic acid encoding valencene synthase is added into a host cell (Yarrowia lipolytica) that now will be able to encode nucleic acid sequence for sinthesizing (+)-nootkatone [13]; and, also there are some optimization methods with $Y$. lipolytica to produce or enhance the production of proteins or (+)-nootkatone metabolites [14]. Interest of industry and academia on (+)-nootkatone production during the last decade has, increased as; shown in Figure 2 through published articles and patents (SCOPUS, May 2015).

The main disadvantage of the use of recombinant microorganism is due to recombinant DNA technologies are very sophisticated and the recombinant strain conservation is stricter than the parental one. On the other hand, the use of plant cells, such as cells of Citrus species, for 
the bioconversion present some drawbacks, since plant cells have less resistance against shear stress during mixing and temporary extremes of $\mathrm{pH}$ and temperature in comparison to natural microorganisms [13]. Thus, the use of a natural microorganism for bioconversion purposes therefore seems to be an interesting alternative.

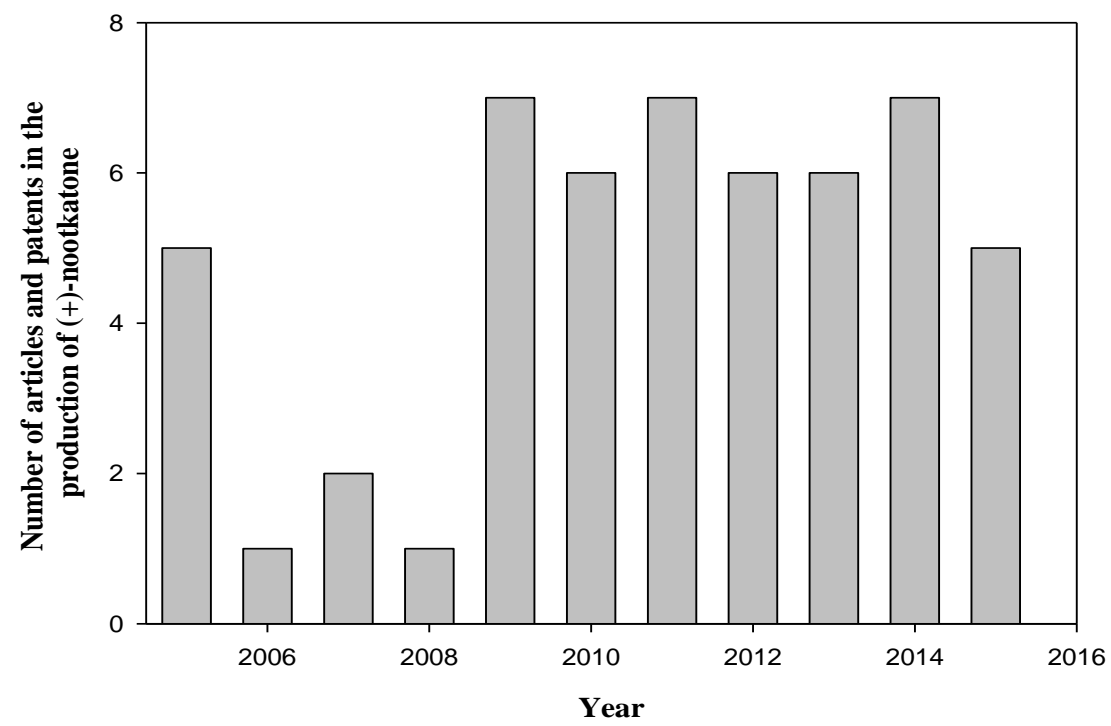

Figure 2. Number of published articles and patents for (+)-nootkatone production during the last decade (Scopus, May 2015).

The bioconversion of (+)-valencene to (+)-nootkatone is mainly due to the catalytic activity of Cytochrome P450 (CYP450), which is a superfamily of membrane-bound, haemcontaining monooxygenases responsible for the oxidation and reduction of a lot of drugs, steroid hormones and fatty acids. The CYP450's are expressed in many animal tissues and are found in relatively high quantities in the liver. The main function of CYP450 is to introduce an oxygen atom into the substrate i.e. to increase the hydrophilicity of the product, thereby the enzyme eases the elimination of the product from the cell [4]. Sowden et al [15] reported a bioconversion for (+)-nootkatone production using wild type and mutants P450cam from Pseudomonas putida and P450BM-3 from Bacillus megaterium. They noted that the mutant type P450cam oxidizes (+)-valencene, while the wild type does not. They also reported that wild type P450BM-3 and mutants have higher activities than P450cam but are less selective. 
Based on a literature review, two bioconversion reaction schemes from (+)-valencene to (+)nootkatone have been described (see Figure 3): a) one of them, where the enzyme Cytochrome-P450-Monooxygenase performs this reaction [16,17], or b) another where (+)nootkatone is produced from an intermediate, (+)-nootkatol, where this first product is formed by a second enzyme called dioxygenase [18]. In the literature, it is also mentioned that the bioconversion reaction presents inhibition by substrate, product, oxygen and intermediary $[13,2,16]$. Based on these findings, the mechanism proposed in this work is drawn in Figure 3c.

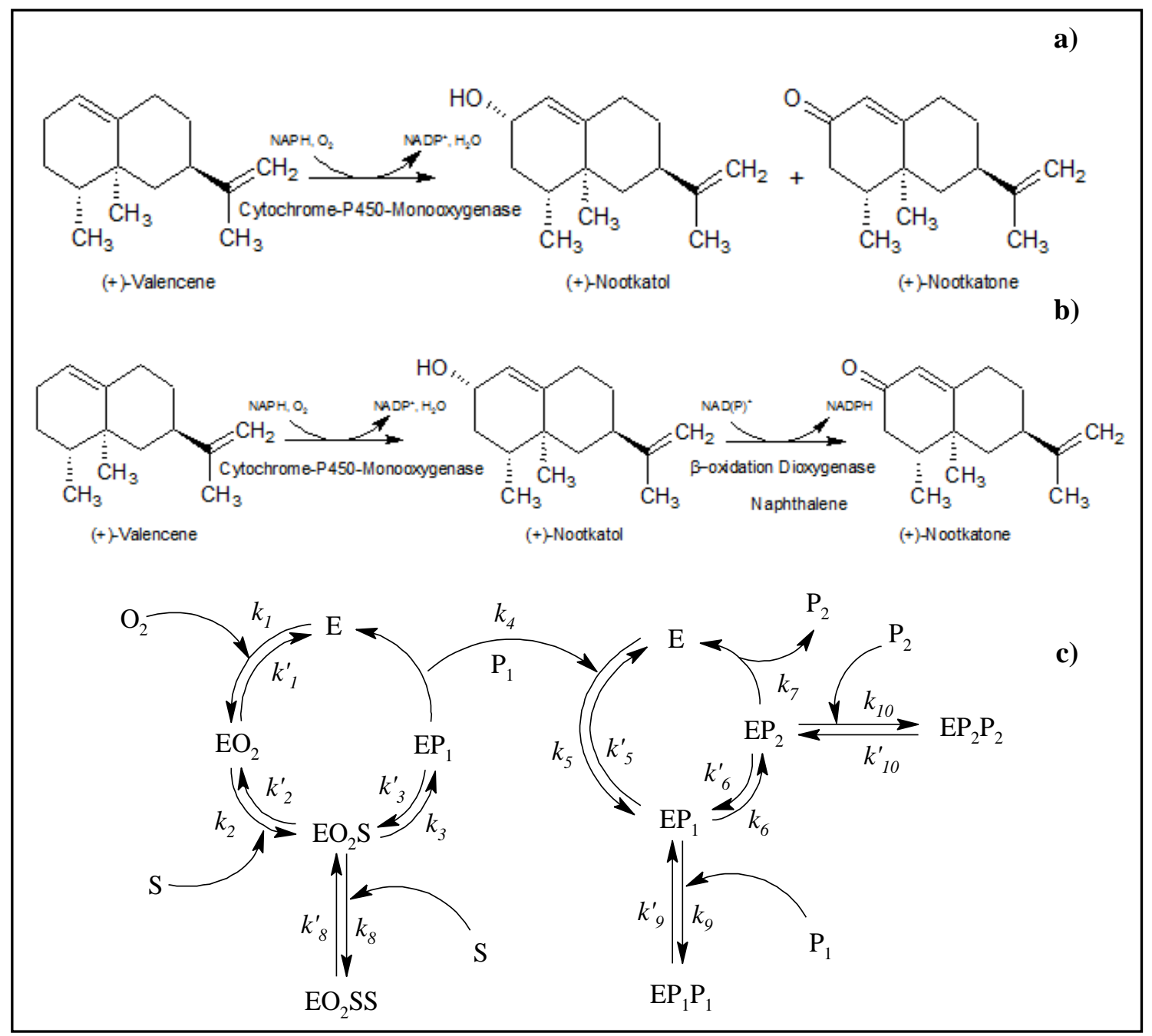

Figure 3. Possible enzyme bioconversion mechanisms performed with (a) one and (b) two enzymes. (c) Reaction mechanism proposed for (+)-nootkatone bioconversion under inhibition conditions. $E$ enzyme; $S$ substrate; $O_{2}$ oxygen; Products $P_{1}$ and $P_{2}$; and intermediaries $E O_{2}, E O_{2} S$, $E O_{2} S S, E P_{1}, E P_{1} P_{1}, E P_{2}, E P_{2} P_{2}$. 
The kinetics related to the bioconversion of (+)-valencene to (+)-nootkatone using various microorganisms have already been studied by several researchers. Kaspera et al [13] studied the kinetics using the ascomycete Chaetomium globosum. They observed that the fungal cells maintain viability in the presence of high $(+)$-valencene concentrations, however, there is a fast decrement in (+)-valencene concentration at early reaction times. Besides, it was reported by Palmerín-Carreño et al. [19] that Yarrowia lipolytica is capable of carrying out the mentioned bioconversion. In fact strain $Y$. lipolytica $2.2 \mathrm{ab}$ is used through this study. Palmerín-Carreño et al [19], also investigated the effects of substrate- and product inhibition on cell growth using $Y$. lipolytica 2.2ab. Fu et al [20] described the thermal deactivation of $Y$. lipolytica. They elucidated how this microorganism loses its functionality over $40^{\circ} \mathrm{C}$. Muniglia et al. [21] developed a macroscopic kinetic model for the microorganism $Y$. lipolytica. They were interested on the growth of the microorganism on glucose, obtaining a maximum specific growth rate of $0.25 \mathrm{~h}^{-1}$.

Pure enzymes or whole cells are used as biocatalysts [22]. Whole cells in comparision with the pure enzymes have more stability due to their cellular matrix, which allows the re-generation of cofactors and enzyme active sites, reducing production costs [23]. Besides, in whole cells biocatalysis the enzyme system of the cell is used to carry out reactions that are not part of the metabolism. In this way, enzymes are more stable due to the presence of its natural environment within the cell and the intracellular environment provides effective method for regeneration of the cofactors, i.e. mention these cofactors $[24,25]$.

The inhibition of the above reaction by (+)-valencene and (+)-nootkatone has been reported with various microorganisms [9,26]. A number of solutions have been recommended to decrease the substrate/product inhibition; for instance: the proposal of adsorbent resins [27]; in situ supply of the substrate and removal of product, maintaining both substrate and product concentrations at sub-inhibitory levels in the environment of the biocatalyst [28]; and encapsulation of biocatalyst to prevent enzyme oxidation [29]. However, one of the main limitations of these strategies is the difficulty in controlling mass transfer of substrate, product and oxygen that directly impacts on the productivity and the 
cost-benefit ratio. As background, this research group proposed the addition of a second liquid phase (essential orange oil) in a partitioning bioreactor, it can be a useful tool to reduce product inhibition due to the presence of a partition coefficient favorable to the second liquid phase [30].

This thesis is aimed to evaluate, enhance and predict the potential of (+)-nootkatone production from (+)-valencene on selected microorganisms in different three-phase (aqueous-organic-air) partitioning bioreactors using orange essential oil as a cheap source of (+)-valencene.

\section{REFERENCES}

1. Fraatz M., Riemer. S., Stöber R., Kaspera R., Nimtz M., Berger R., and Zorn H. A Novel Oxygenase from Pleurotus sapidus Transforms Valencene to Nootkatone. Journal of Molecular Catalysis B: Enzymatic, (2009b): 202-7.

2. Wriessnegger, T., Augustin P., Engleder M., Leitner E., Müller M., Kaluzna I., Schürmann M., Production of the Sesquiterpenoid (+)-Nootkatone by Metabolic Engineering of Pichia Pastoris. Metabolic Engineering, (2014): 18-29.

3. De Souza A., Cardoso Lopes E.M., da Silva M.C., Cordeiro I., Young M.C., Sobral M.E.G. and Moreno P.R.H. Chemical Composition and Acetylcholinesterase Inhibitory Activity of Essential Oils of Myrceugeniamyrcioides (Cambess.) O. Berg and Eugenia riedeliana O. Berg, Myrtaceae. Brazilian Journal of Pharmacognosy, (2009): 175-79.

4. Girhard M., Kazuhiro M., Masashi I., Schmid R., Arisawa A., and Urlacher V. Regioselective Biooxidation of (+)-Valencene by Recombinant E. coli Expressing CYP109BI from Bacillus subtilis in a Two-Liquid-Phase System.Microbial Cell Factories (2009): 1-12.

5. Murase T.i, Satoshi H., Yoshihiko M., and Tadashi H. Nootkatone, a Characteristic Constituent of Grapefruit, Stimulates Energy Metabolism and Prevents Diet-Induced Obesity by Activating AMPK. American Journal of Physiology - Endocrinology and Metabolism, (2010): 266-75.

6. Sujatha S. Essential Oil and Its Insecticidal Activity of Medicinal Aromatic Plant Vetiveria Zizanioides (L.) Against the Red Flour Beetle Tribolium castaneum (Herbst). Asian Journal of Agricultural Sciences, (2010): 84-88.

7. Knox R. Repelling Bugs with the Essence of Grapefruit. Npr Morning Edition subject, (2011). 
8. Del Rio J.A., Ortuño A., Garcia Puig D., Iborra J.L., and Sabater F. Accumulation of the Sesquiterpenes Nootkatone and Valencene by Callus Cultures of Citrus paradisi, Citrus limonia and Citrus aurantium. Plant Cell Reports (1991): 410-13.

9. Fraatz M., Berger R., and Zorn H. Nootkatone- a Biotechnological Challenge.Appl Microbiol Biotechnol (2009a): 35-41.

10. Salvador J.A., Melo M.L., and Neves A.S. Copper-Catalysed Allylic Oxidation of Delta(5)Steroids by T-Butyl Hydroperoxide.Tetrahedron Lett. (1997): 119-22

11. Gounaris Y. Biotechnology for the Production of Essential Oils, Flavours and Volatile Isolates. A Review. Flavour and Fragrance Journal (2010): 367-86.

12. Palmerín Carreño D.M., Rutiaga Quiñones O., Verde Calvo R., Huerta Ochoa S., Bioconversion of (+)-nootkatone by Botryodiplodia theobromae using a membrane aereated biofilm reactor. Revista Mexicana de Ingeniería Química (2014) 13: 757-764.

13. Kaspera R., Krings U., Nanzad T., and Berger R.G. Bioconversion of (+)-Valencene in Submerged Cultures of the Ascomycete Chaetomium globosum. Appl Microbiol Biotechnol (2005): 477-83.

14. Daniel Widmaier and David Breslauer. Cellular reprogramming for product optimization. US Patent Application 2014066374 A1. 066159. (2014).

15. Sowden R., Samina Y., Rees N., Bell S. and Wong L. Biotransformation of the Sesquiterpene (+)-Valencene by Cytochrome P450 (cam) and P450 (BM-3).Org. Biomol. Chem. (2014): $57-64$.

16. Sime J.T, Cheetham P.S.J, Gardley M.L. and Banister N.E. Use of Sesquiterpenes for Inhibiting Oxidative Enzymes. US 6054490 A. (2000).

17. De Montellano, Ortiz P.R. Cytochrome P450, Structure, Mechanism and Biochemistry. 3rd ed. Vol. 6 (2005).

18. Berger R.G., Krings U., Batt C.A. and Tortorello M.L. Fermentation (Industrial): Production of Colors and Flavors. Encyclopedia of Food Microbiology (2014): 785-91.

19. Palmerín-Carreño D.M., Castillo-Araiza C.O, Rutiaga-Quiñones O.M., Verde Calvo J.R., Trejo-Aguilar G.M., Dutta A., and Huerta-Ochoa S. Whole Cell Bioconversion of (+)Valencene to (+)-Nootkatone by Yarrowia lipolytica using a Three Phase Partitioning Bioreactor. Journal of Chemical Technology and Biotechnology (2015).

20. Fu D., Cong L., Rahman A., and Tan T. Relationship between Thermal Inactivation and Conformational Change of Yarrowia lipolytica Lipase and the Effect of Additives on Enzyme Stability. Journal of Molecular Catalysis B: Enzymatic (2010): 136-41. 
21. Muniglia, L., Chevalot I., Aggelis G. and Marc I. Yarrowia lipolytica as a Potential Producer of Citric Acid from Raw Glycerol. Journal of Applied Microbiology (2002): 737-47.

22. Ishige T, Honda K, Shimizu S. Whole organism biocatalysis. Current Opinion in Chemical Biology (2005) 9:174-180.

23. Bräutigam S, S. Bringer-Meyer, D. Weuster-Botz. Asymmetric whole cell biotransformations in biphasic ionic liquid/water-systems by use of recombinant Escherichia coli with intracellular cofactor regeneration. Tetrahedron: Asymmetry. (2007) 18:1883-7.

24. Nthangeni M.B. The Use of Yarrowia lipolytica for the Expression of Human Cytochrome P450 CYP1A1. Yeast (2004): 583-92.

25. Goldberg K, Schroer K, Lutz S, Liese A. Biocatalytic ketone reduction-a powerful tool for the production of chiral alcohols-part II: whole-cell reductions. Appl. Microb. Biotechnol. (2007). 76:249-255.

26. Robin-Hagen Leonhardt and Ralf G. Berger. Nootkatone. Adv Biochem Eng Biotechnol (2015) 148: 391-404.

27. Hilker I, C. Baldwin, V. Alphand, R. Furstoss, J. Woodley and R. Wohlgemuth. On the Influence of Oxygen and Cell Concentration in an SFPR Whole Cell Biocatalytic Baeyer-Villiger Oxidation Process. Biotechnology and Bioengineering. (2006) 93(6): 1138-1144.

28. Simpson H.D., V. Alphand, R. Furstoss. Microbiological biotransformations 49Asymmetric biocatalysed Baeyer-Villiger oxidation: improvement using a recombinant $E$. coli whole cell biocatalyst in the presence of an adsorbent resin. J. Mol. Catal. B Enzym. (2011) 6: 101-108.

29. Buĉko M., A. Schenkmayerová, P. Gemeinera, A. Vikartovská, M. Mihovilovibĉ, B. Lacíkc. Continuous testing system for Baeyer-Villiger bio oxidation using recombinant Escherichia coli expressing cyclohexanone monooxygenase encapsulated in polyelectrolyte complex capsules. Enzyme and Microbial Technology. (2011) 49: 284- 288.

30. Torres-Martínez D., R. Melgarejo-Torres, M. Gutiérrez-Rojas, L. Aguilera-Vázquez, M. Micheletti, G.J. Lye, S. Huerta-Ochoa, Hydrodynamic and oxygen mass transfer studies in a three-phase (air-water-ionic liquid) stirred tank bioreactor, Biochem. Eng. J. (2009) 45 (3): 209-217.

\section{Websites:}

http://www.radiantinsights.com/research/nootkatone-market-research-report-2015

http://oxfordbiotrans.com/uk-research-provides-taste-of-future-foods/

http://www.scopus.com/ 


\section{CHAPTER I}

\section{PROBLEM STATEMENT}




\section{HYPOTHESIS}

The addition of orange essential oil as second liquid phase as a substrate reservoir and in situ product extracting agent in a three phase partitioning bioreactor (TPPB) overcome substrate and product inhibition increasing the bioconversion performance of (+)-valencene to (+)nootkatone. This information would be useful to develop operating windows of a TPPB which in a further study, could be used to describe and understand this technology for a commercial exploitation at industrial scales.

\section{JUSTIFICATION}

Industry and academia are interested on (+)-nootkatone bioconversion using whole cells, which involves the selection of an optimal cellular enzyme, reaction engineering, product recovery and scaling-up. Different efforts have been focused to enhance whole cell bioconversion of (+)-valencene to (+)-nootkatone among them classical genetics approach or metabolic engineering using recombinant microorganism. However, information of bioreactor design and operating condition of (+)-nootkatone bioconversion is yet scarce. The use of TPPB with whole cells as biocatalyst allows an increment of the productivity in the bioprocess. Due to thermodynamic equilibrium, the dispersed phase maintains substrates, products or toxic secondary metabolites concentrations at sub-inhibitory levels. Since these systems present several mechanisms such as mass transfer, kinetics and deactivation of the biocatalyst, it is relevant to characterize them at different conditions with the aim to understand their effect on high value metabolite production and develop strategies of these bioreactors.

\section{GENERAL AIM}

This thesis is aimed to evaluate, enhance and predict the potential of (+)-nootkatone production from (+)-valencene on selected microorganisms in different three-phase (aqueous-organic-air) partitioning bioreactors using orange essential oil as a cheap source of (+)-valencene. 


\section{SPECIFIC AIMS}

1. Select a method for microorganism screening with the potential for the allylic oxidation of (+)-valencene to (+)-nootkatone using different bioconversion conditions.

2. Evaluate the bioconversion of (+)-valencene to (+)-nootkatone by Botryodiplodia theobromae using a Membrane Aerated Biofilm Reactor (MABR).

3. Assess physiological characterization of whole cell biocatalysis using Yarrowia lipolytica for the bioconversion of (+)-valencene to (+)-nootkatone in a partitioning bioreactor.

4. Enhance the bioconversion of (+)-valencene to (+)-nootkatone with Yarrowia lipolytica in a partitioning bioreactor using orange essential oil as the dispersed phase.

5. Determine hydrodynamic stress on the viability of the yeast Yarrowia lipolytica and the effect of biomass concentration on (+)-nootkatone bioconversion in a partitioning bioreactor.

6. Assess whole cell bioconversion of (+)-nootkatone in an organic phase (orange essential oil).

7. Evaluate hydrodynamic and oxygen mass transfer characteristics of a three phase gas-water-orange essential oil dispersion and determine the limiting step of the bioconversion process through a regime analysis. 


\section{GENERAL STRATEGY}

Figure 1.1 depicts the general strategy followed through this work: I) The first chapter contains the main aim, hypothesis, justification, and general and specific objectives of the project. II) The second chapter deals with the evaluation and selection of microorganisms with the potential of (+)-nootkatone bioconversion using different systems. III) In the third chapter B. theobromae, one of the selected microorganisms is evaluated in a membrane aerated biofilm reactor (MARB). IV) In the fourth chapter a physiological characterization of whole cell biocatalysis using Yarrowia lipolytica is assessed in a stirred tank partitioning bioreactor. V) In the fifth chapter, the strategies to increase bioconversion are tested in a three phase partitioning bioreactor using $Y$. lipolytica. VI) In the sixth chapter, the role of hydrodynamic stress on the viability of $Y$. lipolytica and the effect of the biomass concentration on bioconversion are evaluated during the bioconversion in the three phase partitioning bioreactor. VII) In the seventh chapter whole cell bioconversion of (+)-nootkatone is assessed in an organic phase (orange essential oil). VIII) Finally, in the eighth chapter substrate, product and oxygen mass transfer mechanisms in the TPPB are studied and a regime analysis is conducted to determine the limiting step of the bioconversion at the operating condition used.

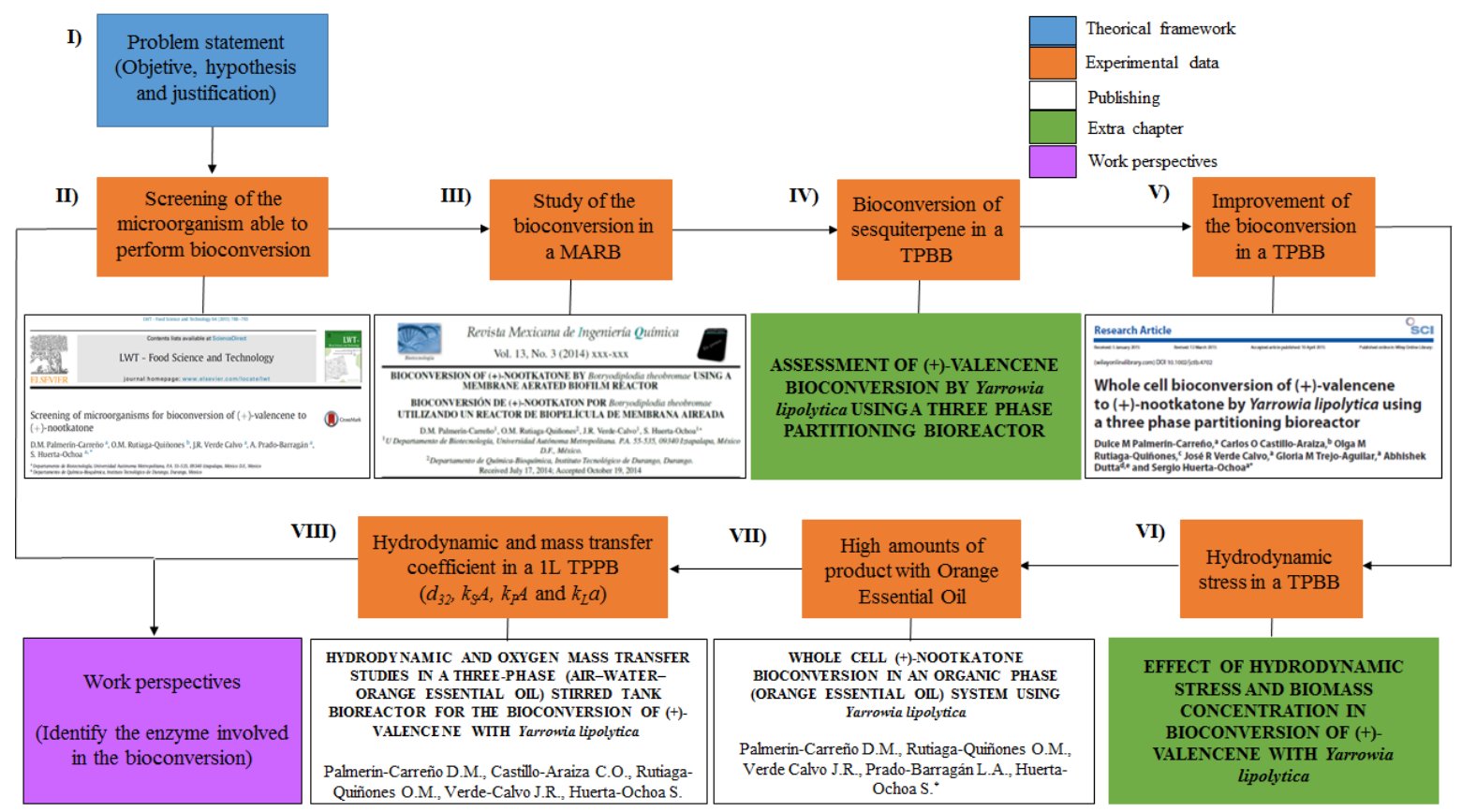

Figure 1.1. General strategy followed in this Thesis for the study of (+)-nootkatone bioconversion using whole cells in three phase partitioning bioreactors.

NOTE: Each chapter has its self-nomenclature, figures, tables and references. 


\title{
CHAPTER II
}

\section{SCREENING OF MICROORGANISMS FOR BIOCONVERSION OF (+)- VALENCENE TO (+)-NOOTKATONE}

\author{
Palmerín-Carreño D.M., Rutiaga-Quiñones O.M., Verde Calvo J.R., Prado-Barragán A., \\ Huerta-Ochoa S. \\ LWT- Food Science and Technology, 2015, Volume 64, Issue 2, Pages 788-793. \\ DOI: 10.1016/j.lwt.2015.06.065
}




\title{
SCREENING OF MICROORGANISMS FOR BIOCONVERSION OF (+)- VALENCENE TO (+)-NOOTKATONE
}

\author{
Palmerín-Carreño D.M. ${ }^{1}$, Rutiaga-Quiñones O.M. ${ }^{2}$, Verde Calvo J.R. ${ }^{1}$, Prado-Barragán A. ${ }^{1}$, \\ Huerta-Ochoa S. ${ }^{\text {* }}$ \\ ${ }^{I}$ Departamento de Biotecnología, Universidad Autónoma Metropolitana. \\ P.A. 55-535, 09340 Iztapalapa, México D.F., MÉXICO, e-mail: sho@xanum.uam.mx \\ ${ }^{2}$ Departamento de Química-Bioquímica, Instituto Tecnológico de Durango, Durango, e-mail: \\ omrutiaga@itdurango.edu.mx
}

\begin{abstract}
The production of (+)-nootkatone, highly appreciated by fragrance and flavour industries, can be performed by whole-cell bioconversion from the sesquiterpene (+)-valencene, a compound readily available in orange essential oil. The aim of this work was to screen for microorganisms that convert (+)-valencene to (+)nootkatone using different bioconversion systems. The screening was conducted using six different microorganisms, and bioconversion experiments were set up on surface culture using serological flasks containing PDA at $30{ }^{\circ} \mathrm{C}$. It was observed that Botryodiplodia theobromae 1368, Yarrowia lipolytica 2.2ab, and Phanerochaete chrysosporium oxidised (+)-valencene to (+)-nootkatone, reaching (+)-nootkatone concentrations of $231.7 \pm 2.1,216.9 \pm 5.8$ and $100.8 \pm 2.6 \mathrm{mg} \mathrm{L}^{-1}$, respectively. Different bioconversion conditions were also tested-aqueous, organic, and biphasic - all resulting in similar (+)-nootkatone production. Both $B$. theobromae 1368 and $Y$. lipolytica $2.2 \mathrm{ab}$ showed substrate inhibition above $4.2 \times 10^{-2}$ and $0.13 \mathrm{~g}$ of $(+)$-valencene ( $\mathrm{g}$ of biomass) $)^{-1}$, respectively, in aqueous phase experiments. Furthermore, $B$. theobromae 1368 and Y. lipolytica 2.2ab showed product inhibition when concentrations reached above 17.02 and $34.78 \mathrm{mg}$ of (+)-nootkatone ( $\mathrm{g}$ of biomass $)^{-1}$, respectively. The experimental method presented here allowed for the identification of microorganisms with the potential for the bioconversion of (+)-valencene to (+)nootkatone. This study will be useful for ongoing studies on the selection and operation of the proper bioreactor at different bioconversion conditions.
\end{abstract}

Keywords: Screening, surface culture, orange essential oil, bioconversion, (+)-nootkatone

\section{Chemical compounds studied in this article}

(+)-Valencene (PubChem CID: 9855795); (+)-Nootkatone (PubChem CID: 1268142); Ethyl acetate (PubChem CID: 8857); Glucose (PubChem CID: 53782692); Sucrose (PubChem CID: 5988); Tween 80 (PubChem CID: 5281955); Sodium chloride (PubChem CID: 5234); Potassium dihydrogen phosphate (PubChem CID: 516951); Magnesium sulphate (PubChem CID: 24083); Copper sulfate (PubChem CID: 24462) 


\subsection{Introduction}

Flavours and aromas are highly valued in food, cosmetic, chemical, and pharmaceutical industries. Most of the aromatic compounds available are obtained by chemical synthesis or solvent extraction. However, consumers' growing aversion towards synthetic chemicals added to foods, cosmetics, and other household products has encouraged research efforts towards the production of aromatic and flavouring compounds using biological organisms (Maróstica \& Pastore, 2007). The sesquiterpene molecules and their oxygenated derivatives are widely used in the aroma industry. Of particular interest is $(+)$-valencene $((2 \mathrm{R})-8,8,8 \mathrm{a}-$ trimethyl-2-prop-1-en-2-yl-1,2,3,4,6,7-hexahydronaphthalene), the main bicyclic sesquiterpene found in orange peel oil (Elston et al., 2005). Sesquiterpenes are low-priced compounds commonly used as substrates for the bioconversion of various aromas (Misawa et al., 2011). The production of (+)-nootkatone has been conducted by chemical synthesis mainly from the sesquiterpene (+)-valencene, but also through the use of oxidising agents known to be unsafe to the environment, such as tert-butyl peracetate (Wilson \& Shaw, 1978) or tert-butyl hydroperoxide in combination with metal catalysts supported on silica (Salvador \& Clark, 2002). As such, the (+)-nootkatone molecules obtained through the mentioned methods may not be considered natural products, and therefore, do not satisfy the increasing demand for natural aromatic compounds. In order to meet this demand, many efforts are underway to find a biotechnological process using bacteria, fungi, or plants (Fraatz et al., 2009).

Microorganisms, plants, or animal cells can make these new biotechnological products in natural forms at a relatively low cost. Microorganisms are of particular interest because of the multitude of naturally-occurring strains and their great metabolic diversity for modifying and upgrading a variety of complex organic molecules; consequently, it is expected that one of the many native strains may be responsible for catalysing any specific reaction (Tan \& Day, 1998). The use of diverse microorganisms as catalytic agents for the bioconversion of (+)-valencene to (+)-nootkatone (Fig. 2.1) has previously been studied (Kaspera et al., 2005). Fraatz et al. (2009) used Pleurotus sapidus to obtain $600 \mathrm{mg}$ of (+)-nootkatone $\mathrm{L}^{-1}$ in a fedbatch system. Sowden et al. (2005) used Pseudomonas putida and Bacillus megaterium for the same bioconversion process. Girhard et al. (2009) worked with enzymes from Bacillus 
subtilis inserted into Escherichia coli to convert $94.2 \mathrm{mg} \mathrm{L}^{-1}$ of the intermediate nootkatol and the product (+)-nootkatone. The yeast Saccharomyces cerevisiae (OGM) was also used as a catalyst for this bioconversion, producing a low concentration $\left(10 \mathrm{mg} \mathrm{L}^{-1}\right)$ of (+)nootkatone (Gavira et al., 2013). The aim of this work was to screen for microorganisms with the potential for the allylic oxidation of (+)-valencene using different bioconversion conditions.

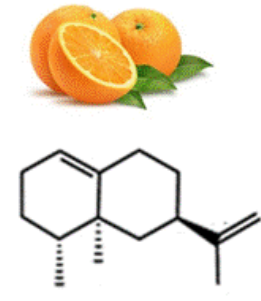

$(+)$-valencene

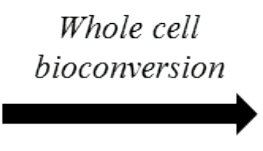

Fig. 2.1. Bioconversion of (+)-valencene to (+)-nootkatone using microbial whole cells

\subsection{Materials and methods}

\subsubsection{Chemicals}

Sesquiterpenes (+)-valencene (CAS 75-05-6) and (+)-nootkatone (CAS 93-78-5) with a purity of $>70 \%$ and $>85 \%$, respectively, were purchased from Fluka (Switzerland). Ethyl acetate (99.5\%) was purchased from Quimex (México). Orange essential oil (Citrus aurantium, var. Amara) was purchased from Cosmopolita Drugstore (Mexico DF) and used as the organic phase.

\subsubsection{Microorganisms}

The strains Botryodiplodia theobromae 1368, Aspergillus tamari V12307, Phanerochaete chrysosporium, Yarrowia lipolytica 2.2ab, Kluyveromyces marxianus NCYC 1429, and Rhyzomисоr sp. that were used came from the culture collection of the Solid State Fermentation Plant at the Autonomous Metropolitan University Iztapalapa. Y. lipolytica 2.2ab strain was previously sequenced in the Laboratory of Industrial Biotechnology of the National Polytechnic Institute (CBG-IPN), Mexico. The access in the National Centre for Biotechnology Information (NCBI) is EF643594.1 18S ribosomal RNA gene, partial sequence; internal transcribed spacer $1,5.8 \mathrm{~S}$ ribosomal RNA gene, and internal transcribed 
spacer 2, complete sequence; and 28S ribosomal RNA gene, partial sequence, identities 94 $\%$ with $Y$. lipolytica strain LN-13. The strains were propagated in Potato Dextrose Agar plates (PDA, Bioxon-Dickinson, México) incubated at $30{ }^{\circ} \mathrm{C}$ for $3-7$ days.

For the determination of substrate and product inhibition, microorganisms were grown in 250 $\mathrm{mL}$ baffled Erlenmeyer flasks containing $100 \mathrm{~mL}$ of culture medium. The culture medium for $Y$. lipolytica 2.2ab was composed of (in $\mathrm{g} \mathrm{L}^{-1}$ ): glucose, $30 ; \mathrm{Na}_{2} \mathrm{MoO}_{4}, 0.2 ; \mathrm{MnSO}_{4}, 0.4$; $\mathrm{FeCl}_{3}, 0.2 ; \mathrm{KI}, 0.1 ; \mathrm{CuSO}_{4}, 0.04 ; \mathrm{H}_{2} \mathrm{BO}_{3}, 0.5 ; \mathrm{CaCl}_{2}, 0.1 ; \mathrm{NaCl}, 0.1 ; \mathrm{MgSO}_{4} * 7 \mathrm{H}_{2} \mathrm{O}, 0.5$; $\mathrm{KH}_{2} \mathrm{PO}_{4}, 1.0 ; \mathrm{ZnSO}_{4}, 0.4 ;\left(\mathrm{NH}_{4}\right)_{2} \mathrm{SO}_{4}, 5$; yeast extract, 4.004. Prior to sterilisation, the $\mathrm{pH}$ of the culture medium was adjusted to 5.5 with $2 \mathrm{M} \mathrm{HCl}$ (Tsigie et al., 2012). The culture medium for $B$. theobromae 1368 was composed of (in $\mathrm{g} \mathrm{L}^{-1}$ ): sucrose, 50; $\mathrm{NaNO}_{3}, 7.5$; $\mathrm{KH}_{2} \mathrm{PO}_{4}, 2.0 ; \mathrm{KCl}, 0.3 ; \mathrm{MgSO}_{4} * 7 \mathrm{H}_{2} \mathrm{O}, 0.6 ; \mathrm{FeSO}_{4} * 7 \mathrm{H}_{2} \mathrm{O}, 0.6 ; \mathrm{ZnSO}_{4} * 7 \mathrm{H}_{2} \mathrm{O}, 0.03$; $\mathrm{MnSO}_{4} * 7 \mathrm{H}_{2} \mathrm{O}, 0.003 ; \mathrm{CuSO}_{4} * 7 \mathrm{H}_{2} \mathrm{O}, 0.003 ; \mathrm{Na}_{2} \mathrm{MoO}_{4} * 2 \mathrm{H}_{2} \mathrm{O}, 0.003$; yeast extract, 1.0. Prior to sterilisation, the $\mathrm{pH}$ of the culture medium was adjusted to 5.5 with $2 \mathrm{M} \mathrm{HCl}$ (Eng et al., 1998). Flasks were then inoculated with $1 \times 10^{6}$ cells $\mathrm{mL}^{-1}$ and incubated for 3 days ( $Y$. lipolytica $2.2 \mathrm{ab}$ ) or 7 days (B. theobromae 1368) at $200 \mathrm{rpm}$ and $30{ }^{\circ} \mathrm{C}$. After incubation, a concentrated solution of $(+)$-valencene was added to provide different initial concentrations of (+)-valencene: $0.05,0.1,0.2,0.3,0.4,0.6,0.8,1.0,1.5,2.0,3.2,4.5$ and $6.4 \mathrm{~g} \mathrm{~L}^{-1}$. To determine product inhibition on the bioconversion process, a concentrated solution of (+)nootkatone was added in other experimental units to ensure different initial concentrations of (+)-nootkatone: 50, 100, 200, 300, 400, 600 and $1000 \mathrm{mg} \mathrm{L}^{-1}$. The flasks were incubated for 4 days to carry out the bioconversion process, and samples $(2.0 \mathrm{~mL})$ were taken every 24 h. The concentrations of (+)-valencene and (+)-nootkatone were determined. Control experiments containing sterile broth without inoculum were also conducted. All the experiments were conducted in triplicate. Every day, three Erlenmeyer flasks were taken and centrifuged at $5000 \mathrm{rpm}$ for $10 \mathrm{~min}$. Biomass determination was carried out by measuring the dry weight of cells. Sesquiterpenes were extracted from the supernatant by adding 500 $\mu \mathrm{L}$ of ethyl acetate to $500 \mu \mathrm{L}$ of sample. The mixture was vortexed twice for $20 \mathrm{~s}$ and allowed to settle until phase separation occurred, after which $1 \mu \mathrm{L}$ of the ethyl phase was injected into a GC (Sowden et al., 2005; Girhard et al., 2009). 


\subsubsection{Partition coefficients determination}

Partition coefficients of (+)-valencene and (+)-nootkatone between a buffer solution (aqueous phase) and orange essential oil (organic phase) were determined taking into account the phase ratio $(1: 1 \mathrm{v} / \mathrm{v})$ and the initial $(+)$-valencene concentration conditions used in the serological flasks. During the bioconversion process, (+)-valencene is transferred from the organic phase to the aqueous phase, and (+)-nootkatone is transferred from the aqueous phase to the organic phase. Therefore, the aqueous phase was prepared as follows: $3.2 \mathrm{~g} \mathrm{~L}^{-1}$ of nootkatone was dissolved in a $0.1 \mathrm{M}$ phosphate buffer adjusted to $\mathrm{pH} 7.5$. Also, the organic phase was orange essential oil containing $3.2 \mathrm{~g} \mathrm{~L}^{-1}$ of (+)-valencene. Then, equal amounts of both solutions were mixed, yielding a final emulsion with a total volume of $6 \mathrm{~mL}$. The emulsion was subjected to mechanical agitation for $6 \mathrm{~h}$ at $30{ }^{\circ} \mathrm{C}$ in order to reach thermodynamic equilibrium. The phases were then separated by centrifugation. (+)valencene and (+)-nootkatone were extracted from the aqueous and organic phases, respectively, using $500 \mu \mathrm{L}$ of ethyl acetate. Both phases were analysed quantitatively by GC and the partition coefficient $\left(K_{p}\right)$ was subsequently determined. The partition coefficient was calculated as the ratio of the solute concentration in the organic phase divided by the solute concentration in the aqueous phase at equilibrium.

\subsubsection{Sesquiterpene analysis}

Concentrations of (+)-valencene and (+)-nootkatone were determined by gas chromatography (GC-FID) using a Perkin Elmer Auto System XL gas chromatographer equipped with a flame ionisation detector (Cyclosil-B capillary column; $30 \mathrm{~m} \mathrm{x} 0.32 \mathrm{~mm}$ x $0.25 \mu \mathrm{m} ; \mathrm{J} \& \mathrm{~W}$ Scientific). The temperature of the injector and detector was constant at 250 ${ }^{\circ} \mathrm{C}$ to $270{ }^{\circ} \mathrm{C}$, respectively. One $\mu \mathrm{L}$ of sample was automatically injected with a split ratio of 1:4, using helium gas as a carrier. The column temperature was initially set to $120{ }^{\circ} \mathrm{C}$ for 4 min then ramped up to $250{ }^{\circ} \mathrm{C}$ at a rate of $10{ }^{\circ} \mathrm{C}$ per min and maintained at $250{ }^{\circ} \mathrm{C}$ for $5 \mathrm{~min}$, using the technique reported by Girhard et al. (2009). Analyses were performed in triplicate. GC/MS spectra were obtained using a GC/MS-HP6890 (Agilent) gas chromatograph equipped with a HP-5 column (30 m x $250 \mu \mathrm{m}$ x $0.25 \mu \mathrm{m}$, Agilent). The same conditions of separation as the GC-FID analysis were used. Compounds in the samples were identified by comparison of mass spectra to that of pure compounds. 


\subsubsection{Microorganism pre-selection experiments}

Inoculum from each strain was obtained in $250 \mathrm{~mL}$ Erlenmeyer flasks containing $50 \mathrm{~mL}$ of PDA incubated at $30^{\circ} \mathrm{C}$ for 3-7 days. Cells (yeast) or spores (fungi) were harvested with 5.0

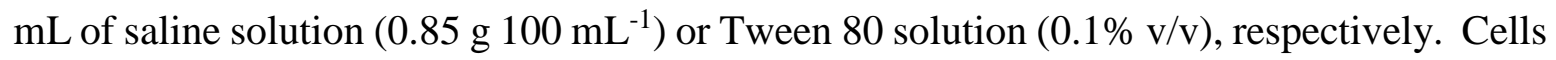
or spores were counted (Neubauer chamber). Bioconversion studies were conducted in serological flasks following the method reported by Castellanos (2007) with some modifications. Serological flasks containing $5 \mathrm{~mL}$ of PDA medium were inoculated with $1 \mathrm{x}$ $10^{6}$ cells or spores $\mathrm{mL}^{-1}$. After incubation periods mentioned previously at $30^{\circ} \mathrm{C}$, a solution of $0.1 \mathrm{M}$ phosphate buffer adjusted to $\mathrm{pH} 7.5$ was dissolved with a (+)-valencene concentration of $3.2 \mathrm{~g} \mathrm{~L}^{-1}$ and then added.

\subsubsection{Microorganism selection experiments}

Serological flasks containing $5 \mathrm{~mL}$ of PDA medium were inoculated with 1 x $10^{6}$ cells or spores $\mathrm{mL}^{-1}$ of Botryodiplodia theobromae 1368, Yarrowia lipolytica 2.2ab, or Phanerochaete chrysosporium. After strain growth, either a (+)-valencene solution or orange essential oil was added, covering the surface of the culture. Three different conditions were prepared as follows: (a) $3.0 \mathrm{~mL}$ of $0.1 \mathrm{M}$ phosphate buffer solution with a (+)-valencene concentration of $3.2 \mathrm{~g} \mathrm{~L}^{-1}$; (b) $3.0 \mathrm{~mL}$ of a mixture in equal volumes of orange essential oil and a phosphate buffer solution, forming a biphasic system; and finally (c) $3.0 \mathrm{~mL}$ of orange essential oil (3.2 $\mathrm{g} \mathrm{L}^{-1}$ of valencene). The bases of all serological flasks were filled with water and placed in a desiccator, to avoid volatilisation of the aromatic compounds. The flasks were closed with a plug and incubated at $30{ }^{\circ} \mathrm{C}$. All experiments were conducted in triplicate, and controls without microorganisms at the same reaction conditions were also performed. Aliquots $(500 \mu \mathrm{L})$ were taken every 24 h for 12 days.

\subsection{Results and discussion}

\subsubsection{Sesquiterpenes present in orange essential oil (Citrus aurantium, var. amara)}

Orange essential oil contained (+)-valencene and (+)-nootkatone concentrations of $3.2 \mathrm{~g} \mathrm{~L}^{-1}$ and $0.94 \mathrm{mg} \mathrm{L}^{-1}$, respectively. A similar (+)-valencene concentration (2.99 $\mathrm{g} \mathrm{L}^{-1}$ of (+)valencene) with the same kind of orange oil was reported by Del Rio et al. (1991). Sesquiterpene concentration varies for different species of the Citrus genus depending on the 
time of harvest of the fruit and its variety (Elston et al., 2005; Espina et al., 2010). The highest (+)-valencene concentration $\left(6 \mathrm{~g} \mathrm{~L}^{-1}\right)$ has been reported for Citrus sinensis (Sharon-Asa et al., 2003). Essential oil contains a large number of sesquiterpene compounds and can be potentially used as a broad spectrum green pesticide (Koul et al., 2008). The largest compound present in orange essential oil is limonene, a terpene with high antimicrobial activity (Mustafa et al., 2012).

\subsubsection{Partition coefficient determination}

Partition coefficients of valencene and nootkatone between orange essential oil (Citrus aurantium var. amara) and a phosphate buffer solution were determined (Table 2.1). The partition coefficient $\left(K_{P}\right)$ of $(+)$-valencene was 6.37 , which is 3.5 times lower than that obtained for (+)-nootkatone (22.5). This high value of $K_{P}$ for nootkatone indicates a high affinity of the product for orange essential oil (organic phase), which would be useful as a potential recovery in situ technique.

Table 2.1. Partition coefficient values of (+)-valencene and (+)-nootkatone between orange essential oil and culture medium at $30^{\circ} \mathrm{C}$.

\begin{tabular}{ll}
\hline Sesquiterpenes & Value \\
\hline (+)-valencene & 6.37 \\
(+)-nootkatone & 22.50 \\
\hline
\end{tabular}

\subsubsection{Selection of the microorganisms in a monophasic system}

Selection experiments of six strains (Botryodiplodia theobromae 1368, Phanerochaete chrysosporium, Yarrowia lipolytica 2.2ab, Aspergillus tamari V12307, Rhyzomucor sp. and Kluyveromyces marxianus NCYC1429) were conducted to observe their ability to oxidise (+)-valencene on surface cultures in serological flasks at $30{ }^{\circ} \mathrm{C}$. In order toper form the screening of microorganisms, we proceeded to use a simple technique with solid culture medium. The results of this selection are shown in Table 2.2. The highest (+)-nootkatone production was obtained by Botryodiplodia theobromae 1368, Phanerochaete chrysosporium, and Yarrowia lipolytica 2.2ab with a bioconversion percentage of 2.21, 1.71, and $1.6 \%$, respectively. The low bioconversion percentage obtained was probably due to (+)- 
valencene volatility, as it was also observed in the control. Furusawa et al. (2005) also reported the ability of Botryodiplodia theobromae to convert (+)-valencene to (+)-nootkatone in an enriched Czapeck-peptone culture medium. However, to the best of our knowledge, our research group is the first one reporting of the use of $Y$. lipolytica for this bioconversion process.

Table 2.2. Screening results for the biotransformation of (+)-valencene to (+)-nootkatone.

\begin{tabular}{llc}
\hline Microorganism & Maximum Nootkatone $\left(\mathrm{mg} \mathrm{L}^{-1}\right)^{\mathrm{ii}}$ & Bioconversion $(\%)^{\mathrm{i}}$ \\
\hline Kluyveromyces marxianus NCYC1429 & $14.51 \pm 0.83(\mathrm{~d})$ & $1.76 \pm 1.09$ (a) \\
Aspergillus tamarii V12307 & $4.70 \pm 0.56(\mathrm{e})$ & $0.46 \pm 0.32(\mathrm{~b})$ \\
Botryodiplodia theobromae 1368 & $29.03 \pm 1.33$ (c) & $2.21 \pm 1.13$ (a) \\
Yarrowia lipolytica 2.2ab & $42.35 \pm 0.91$ (a) & $1.60 \pm 0.23$ (a) \\
Phanerochaete chrysosporium & $32.78 \pm 1.23$ (b) & $1.71 \pm 0.32$ (a) \\
Rhyzomucor sp. & $0.315 \pm 0.23$ (f) & $0.91 \pm 0.56$ (b) \\
\hline
\end{tabular}

${ }^{\mathrm{i}}$ Percentage of (+)-nootkatone produced relative to (+)-valencene consumed.

${ }^{i i} \mathrm{mg}$ of maximum nootkatone $\mathrm{L}^{-1}$ produced after 12 days.

Values represent mean \pm standard deviation.

Same letters represent no significant differences ( $\mathrm{p} \leq 0.05$; Tukey, SAS System Version 9).

2.3.4. Microorganism screening for the bioconversion of $(+)$-valencene to $(+)$-nootkatone in a single aqueous phase system.

The bioconversion kinetics of (+)-valencene to (+)-nootkatone for 12 days for the three selected strains (B. theobromae 1368, P. chrysosporium and Y. lipolytica 2.2ab) are shown in Fig. 2.2. It was observed that (+)-nootkatone production began between the second and fourth day and finished after the ninth day. Among them, B. theobromae 1368 produced the highest (+)-nootkatone concentration of $223.7 \mathrm{mg} \mathrm{L}^{-1}$. Comparing these results with previous experiments (section 2.3.3), it was observed that (+)-nootkatone production increased 7.7 and 4.1 times for B. theobromae 1368 and Y. lipolytica 2.2ab, respectively (see Tables 2.1 and 2.2), most likely due to the lack of evaporation of substrate and product. 


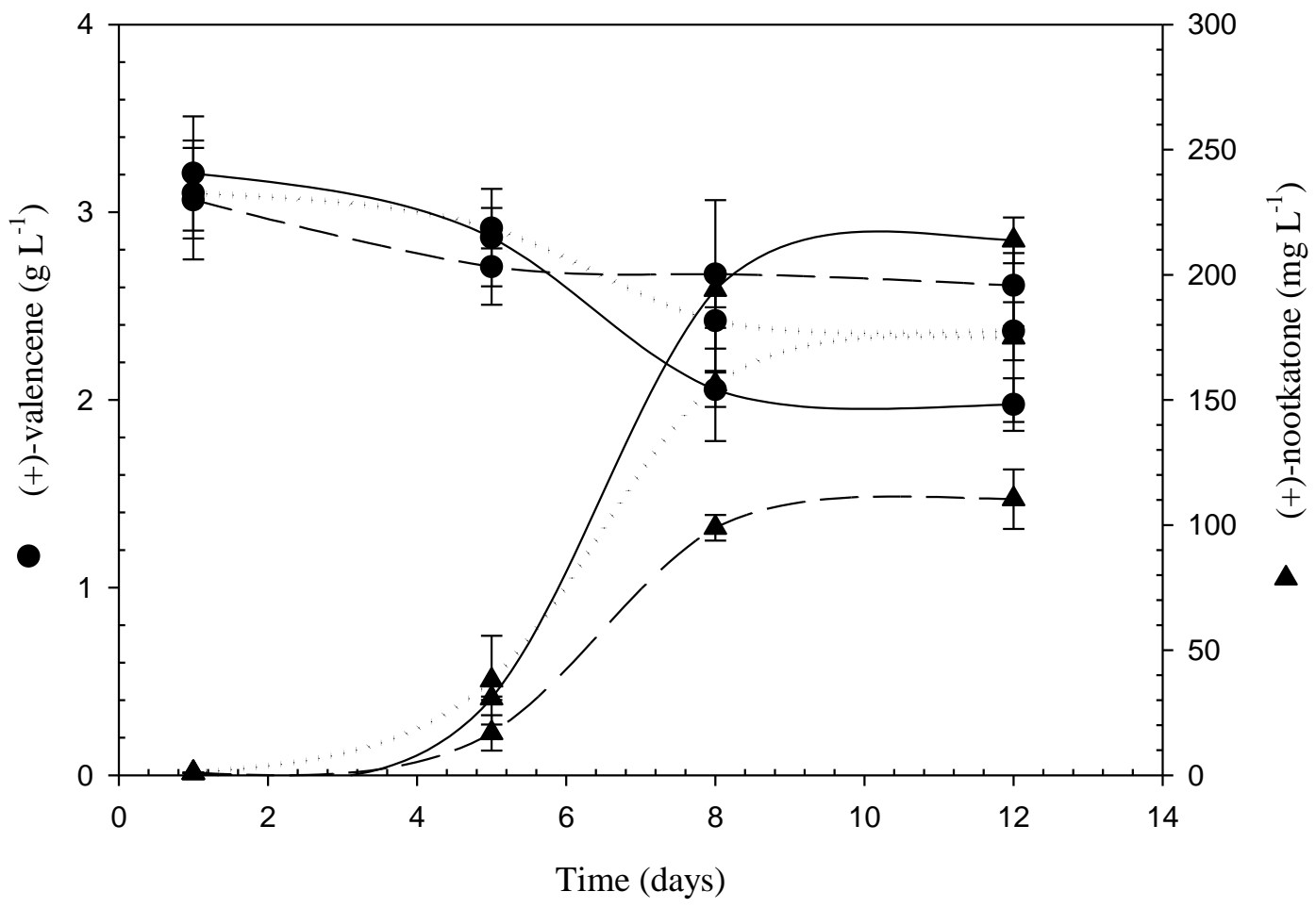

Fig. 2.2. Bioconversion kinetics of (+)-valencene to (+)-nootkatone in a monophasic system: $(-) B$. theobromae 1368, (…) Y. lipolytica 2.2ab, (---) P. chrysosporium. Experiments were carried out in triplicate.

\subsubsection{Microorganism screening for the bioconversion of $(+)$-valencene to $(+)$-nootkatone} in a biphasic system.

The bioconversion kinetics of the selected strains (B. theobromae 1368, P. chrysosporium and $Y$. lipolytica 2.2ab) using the biphasic system is shown in Fig. 2.3. The (+)-valencene and (+)-nootkatone concentrations were determined from the organic phase (orange essential oil). It was also observed that B. theobromae 1368 and Y. lipolytica 2.2ab had the highest (+)-nootkatone production, 239.7 and $216.9 \mathrm{mg} \mathrm{L}^{-1}$, respectively. For both strains, no significant difference in maximum nootkatone concentration was observed when comparing these results to those obtained with the single aqueous phase. A two-phase bioconversion process was studied by Girhard at al. (2009) using recombinant E. coli with a $10 \%$ dodecane organic phase in a stirred tank bioreactor. These authors reported a (+)-nootkatone concentration of $94.2 \mathrm{mg} \mathrm{L}^{-1}$ after growth for $8 \mathrm{~h}$. Recently, Wriessnegger et al. (2014) 
reported the production of (+)-nootkatone by metabolic engineering of Pichia pastoris obtaining $208 \mathrm{mg} \mathrm{L}^{-1}$ in $48 \mathrm{~h}$ using a $20 \%$ n-dodecane organic phase. Our results show the potential for a (+)-nootkatone production in situ extraction system using an orange essential oil organic phase. A biphasic bioprocess for the production of high concentrations of R-(+)$\alpha$-terpineol from R-(+)-limonene was described by Bicas et al. (2010). The system used consisted of a biphasic medium in which the aqueous phase contained a high concentration of Sphingobium sp. resting cells and a sunflower oil organic phase.

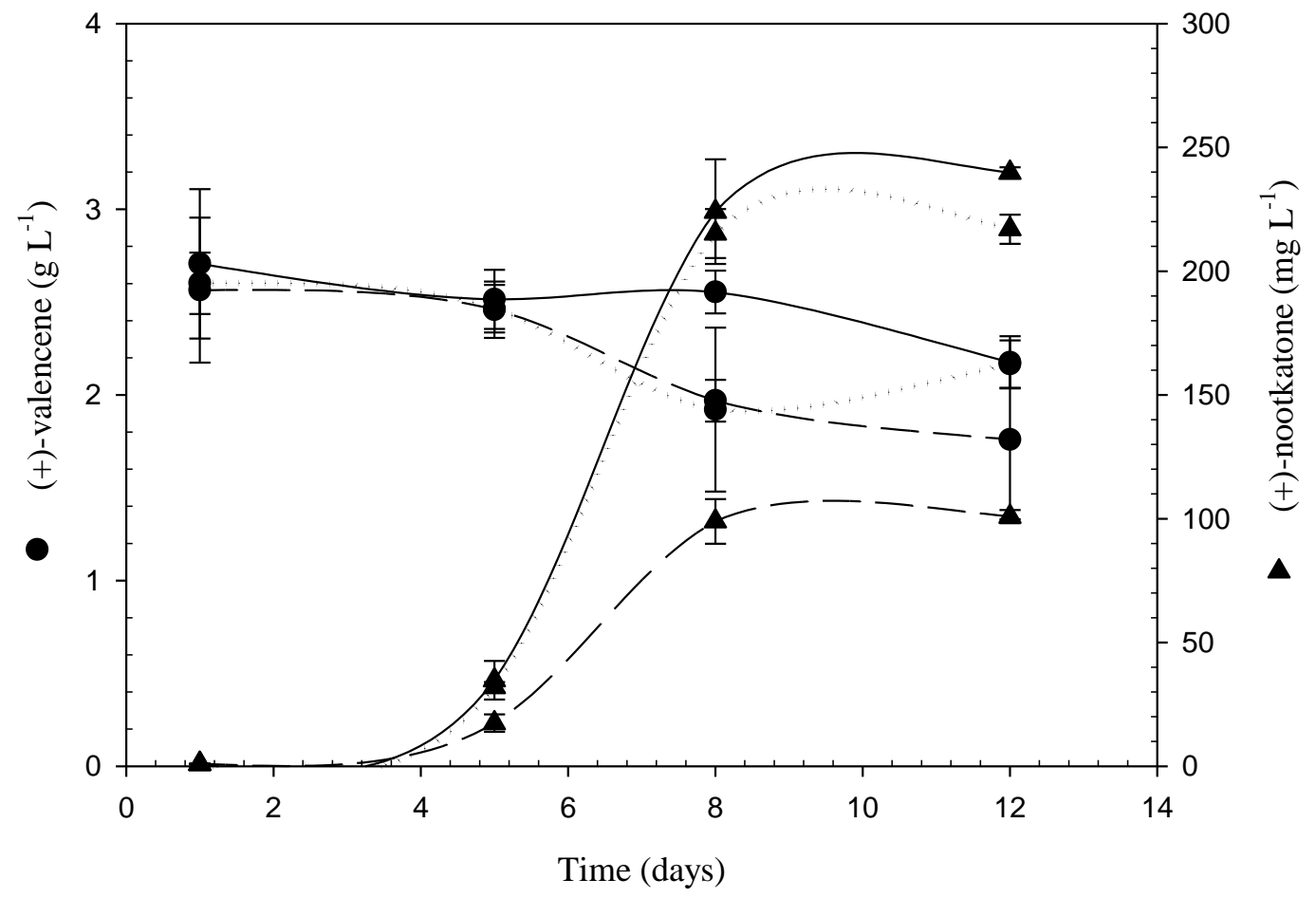

Fig. 2.3. Bioconversion kinetics of (+)-valencene to (+)-nootkatone in a biphasic system: $(-) B$. theobromae 1368, (….) Y. lipolytica 2.2ab, (---) P. chrysosporium. Experiments were carried out in triplicate.

\subsubsection{Microorganism screening for the bioconversion of (+)-valencene to (+)-nootkatone} in a single organic phase system.

The bioconversion kinetics of (+)-valencene to $(+)$-nootkatone in a single organic phase using orange essential oil is shown in Fig. 2.4. Interestingly, similar (+)-nootkatone production was observed. Recently, Brault et al. (2014) reported the synthesis of a short-chain ester flavour in organic media using an E. coli whole-cell biocatalyst expressing a newly characterised 
heterologous lipase. The whole-cell biocatalyst showed excellent tolerance to alcohol and short-chain fatty acid denaturation in a micro-aqueous media. Therefore, further studies should focus on the regioselectivity of the bioconversion.

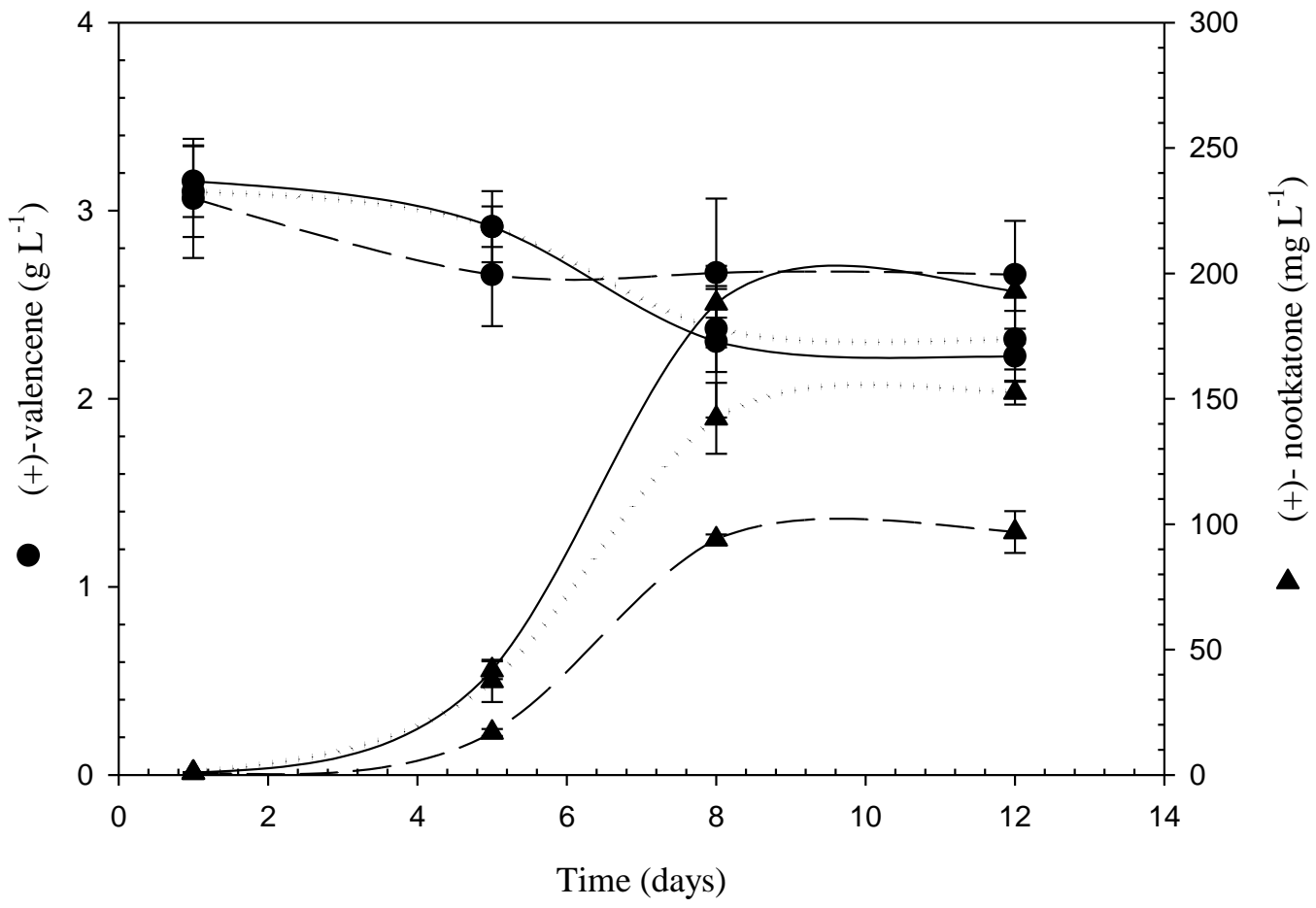

Fig. 2.4. Bioconversion kinetics of (+)-valencene to (+)-nootkatone in a single organic phase: $(-) B$. theobromae 1368, (….) Y. lipolytica 2.2ab, (---) P. chrysosporium. Experiments were carried out in triplicate.

For each strain, a similar percentage of bioconversion and maximum (+)-nootkatone concentration using three different bioconversion conditions-aqueous, organic, and biphasic phase - were obtained, probably due to the following: a) in the aqueous phase, substrate and product concentration were under non-inhibition conditions; b) in the biphasic phase, unknown components in orange essential oil might not be as toxic as expected; and c) in the organic phase, the hydrophobic characteristic of the strain (Table 2.3). Differences in percentage of bioconversion and maximum (+)-nootkatone concentration between strains might be due to cell catalytic activity, differences in $\mathrm{g}$ of biomass per $\mathrm{cm}^{2}$ on the agar surface, different tolerance to orange essential oil components, or hydrophobic characteristic of the strain. Girhard et al. (2009) studied this bioconversion process using recombinant E. coli in 
a stirred tank bioreactor. A similar bioconversion of $24.7 \%$ for the monophasic system and $23 \%$ for the biphasic system, under optimised conditions with $10 \%$ dodecane as an organic phase, was observed in this study.

Table 2.3. Maximum (+)-nootkatone production and percentage of bioconversion of (+)-valencene for the three systems studied.

\begin{tabular}{|c|c|c|c|}
\hline Microorganism & $\begin{array}{l}\text { Maximum } \\
\text { Nootkatone }\left(\mathrm{mg} \mathrm{L}^{-1}\right)^{\mathrm{ii}}\end{array}$ & $\begin{array}{l}\text { Bioconversion } \\
(\%)^{\mathrm{i}}\end{array}$ & System \\
\hline & $223.7 \pm 9.1(a, b)$ & $18.17 \pm 3.0(\mathrm{a})$ & Single aqueous phase \\
\hline \multirow[t]{3}{*}{ B. theobromae 1368} & $239.7 \pm 2.1(b)$ & $23.25 \pm 7.5$ (a) & Biphasic \\
\hline & $237.7 \pm 7.6(a)$ & $25.53 \pm 5.1(\mathrm{a})$ & Single organic phase \\
\hline & $174.9 \pm 33.7$ (a) & $27.19 \pm 3.3(\mathrm{a})$ & Single aqueous phase \\
\hline \multirow[t]{3}{*}{ Y. lipolytica $2.2 \mathrm{ab}$} & $216.9 \pm 5.8(a)$ & $29.50 \pm 13.9$ (a) & Biphasic \\
\hline & $217.4 \pm 4.7$ (a) & $27.68 \pm 14.7$ (a) & Single organic phase \\
\hline & $110.3 \pm 11.8(\mathrm{a})$ & $24.21 \pm 11.2$ (a) & Single aqueous phase \\
\hline \multirow[t]{2}{*}{ P. chrysosporium } & $100.8 \pm 2.6(a)$ & $22.13 \pm 0.03$ (a) & Biphasic \\
\hline & $96.8 \pm 8.3$ (a) & $23.87 \pm 1.3(\mathrm{a})$ & Single organic phase \\
\hline
\end{tabular}

i Percentage of (+)-nootkatone produced relative to (+)-valencene consumed.

ii $\mathrm{mg}$ of maximum nootkatone $\mathrm{L}^{-1}$ produced after 12 days.

Values represent mean \pm standard deviation.

Same letters represent no significant differences ( $\mathrm{p} \leq 0.05$; Tukey, SAS System Version 9).

The strains B. theobromae 1368 and Y. lipolytica 2.2ab were selected for further study, as they provided the highest (+)-nootkatone production and percentage of bioconversion. The screening of microorganisms was conducted using a technique in serological flasks with spores or cells on a surface culture. There are few references on bioconversion using surface cultures. For instance, Demyttenaere et al. (2000) studied the biotransformation of cetrol, geraniol, and citral oils by Aspergillus niger and Penicillium sp. on surface cultures. The biotransformation was monitored by dynamic headspace, and the main product obtained linalool yield values up to $8.57 \mu \mathrm{L}$ from $200 \mu \mathrm{L}$ of nerol. 
In all the kinetic profiles, a stationary phase of (+)-nootkatone production was observed after 8 days when inhibition by substrate, product, or oxygen limitation could be involved. The results of the control without addition of inoculum showed no bioconversion. Therefore, in order to elucidate the cause of the stationary phase, a new set of bioconversion experiments was performed.

\subsubsection{Substrate and product inhibition}

Biomass was previously produced in liquid media in baffled Erlenmeyer flasks. Growth kinetics for the two strains was obtained and biomass concentrations chosen were $23.5 \pm 0.71$ $\mathrm{g} \mathrm{L}^{-1}$ at 7 days for $B$. theobromae 1368 and $11.5 \pm 1.41 \mathrm{~g} \mathrm{~L}^{-1}$ at 3 days of culture for $Y$. lipolytica 2.2ab. Subsequently, different amounts of a concentrated solution of (+)-valencene were added to ensure different initial concentrations, and experimental units were incubated at $30^{\circ} \mathrm{C}$. Fig. $2.5 \mathrm{~A}$ shows that the maximum concentration of (+)-nootkatone for $Y$. lipolytica 2.2ab from an initial concentration of $1.5 \mathrm{~g} \mathrm{~L}^{-1}$ of (+)-valencene $(0.13 \mathrm{~g}$ of valencene per $\mathrm{g}$ of biomass) reached a bioconversion maximum of $34.7 \%$. On the other hand, $B$. theobromae 1368 presented a lower tolerance at $1 \mathrm{~g} \mathrm{~L}^{-1}$ of (+)-valencene $(0.042 \mathrm{~g}$ of valencene per $\mathrm{g}$ of biomass), but a greater bioconversion of $45.8 \%$. An inhibitory effect above these concentrations was evident. It has been reported that sesquiterpenes present antifungal activities, and their biosynthesis is often induced after fungal infection (Manter et al., 2007; Huffaker et al., 2011). Recently, Liu et al. (2012) demonstrated that (+)-valencene contained in sweet orange essential oil resulted in inhibition of fungal growth in five different microorganisms. 

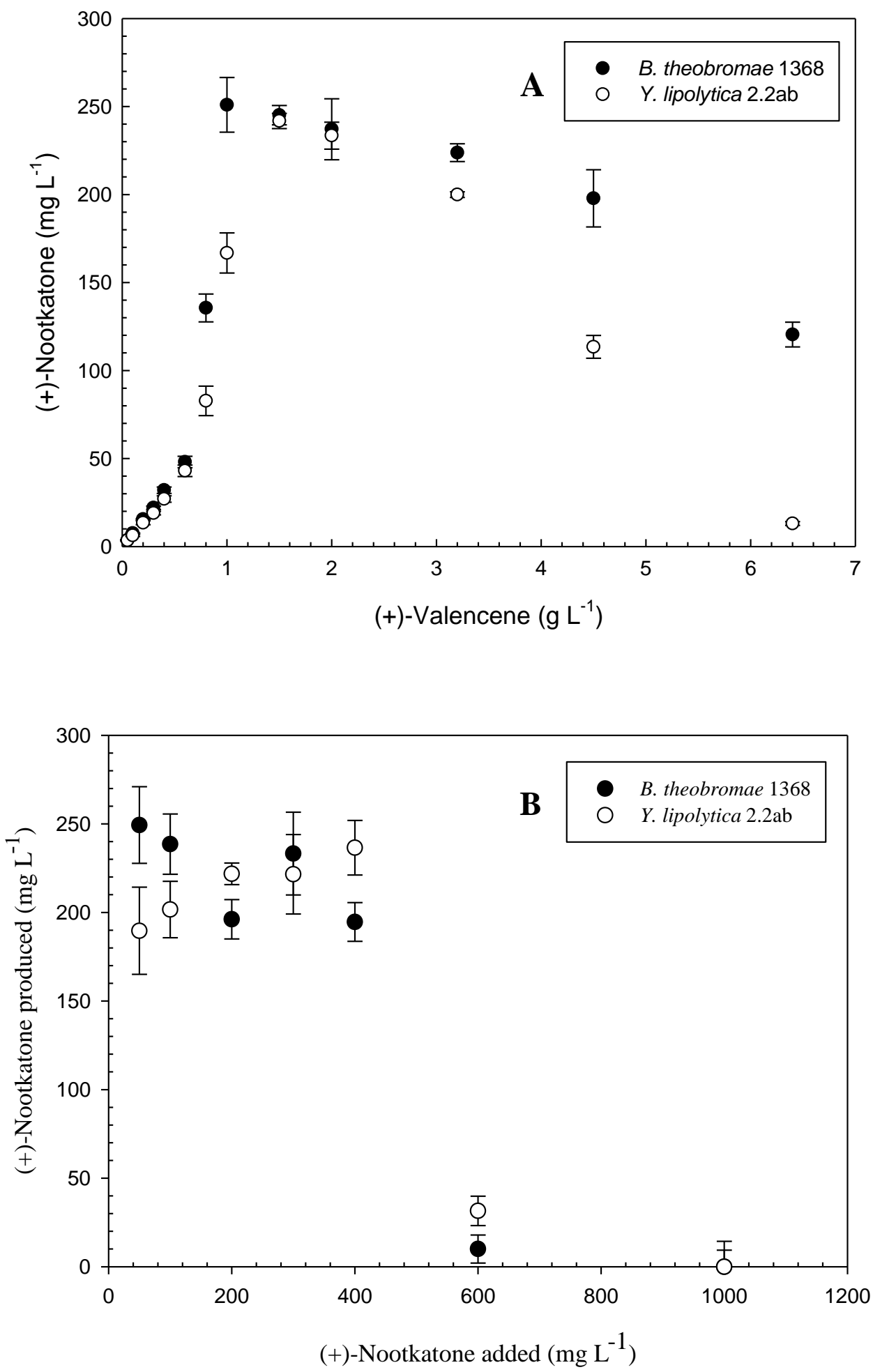

Fig. 2.5. Effect of (A) Substrate and (B) Product inhibition on (+)-Nootkatone bioconversion for $(\bullet)$ B. theobromae 1368 and (०) Y. lipolytica 2.2ab in an aqueous phase system using baffled Erlenmeyer flasks. 
In order to determine product inhibition, further experiments were carried out by adding different amounts of a concentrated solution of (+)-nootkatone to culture medium, resulting in different initial concentrations. Fig. 2.5B shows a decrease in (+)-nootkatone produced when the initial (+)-nootkatone added was above $600 \mathrm{mg} \mathrm{L}^{-1}$, indicating that $B$. theobromae 1368 and $Y$. lipolytica 2.2ab present product inhibition above 17.0 and $52.17 \mathrm{mg}$ of (+)nootkatone (g of biomass) ${ }^{-1}$. Studies performed by Gavira et al. (2013) with S. cerevisiae showed that a concentration of $1.0 \mathrm{~g} \mathrm{~L}^{-1}$ of $(+)$-nootkatone results in product inhibition and a loss of cell viability.

Therefore, the results obtained using this screening methodology are useful for the bioconversion process design. Consequently, it is possible to visualise studies focused on multiphasic systems in order to avoid substrate and product inhibition during the bioconversion process.

\subsection{Conclusions}

The screening method that was used evaluated the potential ability of the strains studied to biotransform $(+)$-valencene to $(+)$-nootkatone. This regioselective synthesis was performed naturally via surface culture, which provided greater versatility using different bioconversion systems. Remarkably, similar (+)-nootkatone concentrations in the single organic phase were observed compared to both the aqueous and biphasic systems. The addition of a second liquid phase (orange essential oil) presents a potential application for the production and in situ extraction of the sesquiterpene (+)-nootkatone. Due to the different physiological and morphological characteristics of the selected strains, further work must focus on the use of a membrane-aerated biofilm reactor for the fungus $B$. theobromae 1368 and a stirred tank bioreactor for the yeast $Y$. lipolytica $2.2 \mathrm{ab}$, using a single aqueous phase or partitioning bioreactors with whole cells.

\section{References}

Bicas, J.L., Fontanille, P., Pastore, G.M., Larroche, C. (2010). A bioprocess for the production of high concentrations of R-(+)- $\alpha$-terpinol from R-(+)-limonene. Process Biochemistry, 45, 481486. 
Brault, G., Shareck, F., Hurtubise, Y., Lépine, F., Doucet, N. (2014). Short-chain flavor ester synthesis in organic media by an $E$. coli whole-cell biocatalyst expressing a newly characterized heterologous lipase. PLOS ONE, 9, 1-9.

Castellanos, M.F.E. (2007). Biotransformación de limoneno, $\alpha$-pineno y aceites de naranja y mandarina, empleando Aspergillus niger "Biotransformation of limonene, $\alpha$-pinene and oils from orange and tangerine, using Aspergillus niger". Tesis Mag Química. Universidad Industrial de Santander, Facultad de Ciencias, Escuela de Química; Bucaramanga 54-58.

Del Río, J.A., Ortuño, A., Puig, D.G., Iborra, J.L., Sabater, F. (1991). Accumulation of the sesquiterpenos nootkatone and valencene by callus cultures of Citrus paradisi, Citrus limonia and Citrus aurantium. Plant Cell Rep., 10, 410-413.

Demyttenaere, J.C.R., Herrera, M.C., De Kimpe, N. (2000). Biotransformation of geraniol, nerol and citral by sporulated surface cultures of Aspergillus niger and Penicillium sp. Phytochemistry, 55, 363-373.

Eng, F., Gutiérrez, R.M., Favela, T.E. (1998). Culture conditions for jasmonic acid and biomass production by Botryodiplodia theobromae in submerged fermentation. Process Biochemistry, $33,715-720$.

Elston, A., Lin, J., Rouseff, R. (2005). Determination of the role of valencene in orange oil as a direct contributor to aroma quality. Flavour Frag. J., 20, 381-386.

Espina, L., Somolinos, M., Loreen, S., Conchello, P., Garcia, D., Pageen, R. (2010). Chemical composition of commercial citrus fruit essential oils and evaluation of their antimicrobial activity acting alone or in combined processes. Food Control, 22, 896-902.

Fraatz, M.A., Berger, R.G., Zorn, H. (2009). Nootkatone-a biotechnological challenge. Appl. Microbiol. Biotechnol., 83, 35-41.

Furusawa, M., Hashimoto, T., Noma, Y., Asakawa, Y. (2005). Highly efficient production of nootkatone, the grapefruit aroma from valencene, by biotransformation. Chem. Pharm. Bull., 53, 1513-1514.

Gavira, G., Höfer, R., Lesot, A., Lambert, F., Zucca, J., Werck-Reichhart, D. (2013). Challenges and pitfalls of P450-dependent (+)-valencene bioconversion by Saccharomyces cerevisiae. Metab Eng., 18, 25-35.

Girhard, M., Machida, K., Itoh, M., Schmid, R., Arisawa, A., Urlacher, V. (2009). Regioselective biooxidation of (+)-valencene by recombinant E. coli expressing CYPI09BI from Bacillus subtilis in a two-liquid-phase system. Microbial Cell Factories, 8, 1-12. 
Huffaker, A., Kaplan, F., Vaughan, M.M., Dafoe, N.J., Ni, X., Rocca, J.R., Alborn, H.T., Teal, P.E.A., Schmelz, E.A. (2011). Novel acidic sesquiterpenoids constitute a dominant class of pathogeninduced phytoalexins in maize. Plant Physiol., 156, 2082-2097.

Kaspera, K., Krings, U., Nanzad, T., Berger, R.G. (2005). Bioconversion of (+)-valencene in submerged cultures of the ascomycete Chaetomium globosum. Appl. Microbiol. Biotechnol., 67, 477-483.

Koul, O., Walia, S., Dhaliwal, G.S. (2008). Essential oils as green pesticides: potential and constraints. Biopestic., Int. 4, 63-84.

Liu, K., Chen, Q., Liu, Y., Zhou, X., Wang, X. (2012). Isolation and biological activities of decanal, linalool, valencene, and octanal from sweet orange oil. J. Food Sci., 77, C1156-1161.

Manter, D.K., Kelsey, R.G., Karchesy, J.J. (2007). Antimicrobial activity of extractable conifer heart wood compounds to ward Phytophthora aramorum. J. Chem. Ecol., 33, 2133-2147.

Maróstica, M.R., Pastore, G.M. (2007). Production of R-(+)- $\alpha$-terpineol by the biotransformation of limonene from orange essential oil, using cassava waste water as medium. Food Chemistry, 101, 345-350.

Misawa, N., Nodate, M., Otomatsu, T., Shimizu, K., Kaido, C., Kikuta, M., Ideno, A., Ikenaga, H., Ogawa, J., Shimizu, S., Shindo, K. (2011). Bioconversion of substituted naphthalenes and $\beta$ eudesmol with the cytochrome P450 BM3 variant F87V. Appl. Microbiol. Biotech., 90, 147-157.

Mustafa, U., Filiz, U., Aysun, S., Sadik, D. (2012). Research on antifungal and inhibitory effects of DL-limonene on some yeasts. Turk. J. Agric. For., 36, 576-582.

Salvador, J.A.R., Clark, J.H. (2002). The allylic oxidation of unsaturated steroids by tert-butyl hydroperoxide using surface functionalized silica supported metal catalysts. Green Chem., 4, 352-356.

Sharon-Asa, L., Shalit, M., Frydman, A., Bar, E., Holland, D., Or, E., Lavi, U., Lewinsohn, E., Eyal, Y. (2003). Citrus fruit flavor and aroma biosynthesis: isolation, functional characterization, and developmental regulation of Cstps1, a key gene in the production of the sesquiterpene aroma compound valencene. Plant J. 36, 664-674.

Sowden, R.J., Yasmin, S., Rees, N.H., Bell, S.G., Wong, L.L. (2005). Biotransformation of the sesquiterpene (+)-valencene by cytochromeP450cam and P450BM-3. Org. Biomol. Chem., 3, 57-64.

Tan, Q., Day, D.F. (1998). Organic co-solvent effects on the bioconversion of (R)-(+)-limonene to (R)-(+)- $\alpha$-terpineol. Process Biochemistry, 33, 755-761. 
Tsigie, Y.A., Wang, C.Y., Kasim, N.S., Diem, Q.D., Huynh, L.H., Ho, Q.P., Truong, C.T., Ju, Y.H. (2012). Oil production from Yarrowia lipolytica Po1g using rice bran hydrolysate. J. Biomed. Biotechnol., 1, 1-10.

Wilson, C.W., Shaw, P.E. (1978). Synthesis of nootkatone from valencene. J. Agric. Food Chem., 26, 1430-1432.

Wriessnegger, T., Augustin, P., Engleder, M., Leitner, E., Müler, M., Kaluzna, I., Schümann, M., Mink, E., Zellnig, G., Schwab, H., Pichler, H. (2014). Production of the sesquiterpenoid (+)nootkatone by metabolic engineering of Pichia pastoris. Metabolic Engineering, 24, 18-29. 


\section{CHAPTER III}

BIOCONVERSION OF (+)-VALENCENE BY Botryodiplodia theobromae USING A MEMBRANE AERATED BIOFILM REACTOR

Palmerín-Carreño D.M., Rutiaga-Quiñones O.M., Verde Calvo J.R., Huerta-Ochoa S.

Revista Mexicana de Ingeniería Química, (2014), Vol. 13, No. 3. Pages: 1-8

http://rmiq.org/new\%20page/Pdfs/Vol.\%2013,\%20No.\%203/Bio5/RMIQTemplate.pdf 


\title{
BIOCONVERSION OF (+)-VALENCENE BY Botryodiplodia theobromae USING A MEMBRANE AERATED BIOFILM REACTOR
}

\author{
Palmerín-Carreño D.M. ${ }^{1}$, Rutiaga-Quiñones O.M. ${ }^{2}$, Verde Calvo J.R. ${ }^{1}$, Huerta-Ochoa S..$^{*}$ \\ 1*Departamento de Biotecnología, Universidad Autónoma Metropolitana. \\ P.A. 55-535, 09340 Iztapalapa, México D.F., MÉXICO, e-mail: sho@xanum.uam.mx \\ ${ }^{2}$ Departamento de Química-Bioquímica, Instituto Tecnológico de Durango, Durango, e-mail: \\ omrutiaga@itdurango.edu.mx
}

\begin{abstract}
The aim of this work was to evaluate the bioconversion of (+)-valencene to (+)-nootkatone by B. theobromae using a membrane aerated biofilm reactor (MABR) in a two liquid phase system with orange essential oil as organic phase. In an aqueous phase system, a (+)-nootkatone production rate up to $3.98 \mathrm{mg} \mathrm{L}^{-1} \mathrm{~h}^{-1}$ was achieved obtaining a final product concentration of $398.08 \mathrm{mg} \mathrm{L}^{-1}$ with a conversion rate: $62 \%$. Also, a two-phase liquid system, using orange essential oil as dispersed phase was studied and a final (+)-nootkatone concentration of $310.37 \mathrm{mg} \mathrm{L}^{-1}$ in the organic phase, with $30.5 \%$ of bioconversion and production rate of $2.46 \mathrm{mg} \mathrm{L}^{-1} \mathrm{day}^{-1}$ was achieved. The present work is the first report of a MABR for the bioconversion of (+)-valencene (+)-nootkatone. Further studies of bioconversion products and optimization of biofilm reactor operations are needed to enhance bioconversion.
\end{abstract}

Keywords: Bioconversion, (+)-nootkatone, Botryodiplodia theobromae, Membrane aerated biofilm reactor

\subsection{Introduction}

Bioconversions play an increasingly important role in organic synthesis for the production of fine chemicals, such as the synthesis of chiral precursors (Faber, 2004). However, an important number of substrates and products of bioconversions are poorly soluble in water, the medium in which most biocatalysts have optimal biological performance. Additionally, substrate and product above critical concentrations are known to inhibit biocatalytic activity (D’Arrigo et al., 2000; Held et al., 2000). Therefore, a significant obstacle to the application of bioconversions in industry is the limiting loading of substrate and product allowed in the reactor. Partitioning bioreactors overcome this limitation since favorable partitioning coefficients of substrates and products toward the organic phase allow the use of high concentrations in this phase, while maintaining low concentrations in the aqueous phase. However, there might be some drawbacks such as the intensive mixing of medium and organic phases can cause strong emulsions that make downstream separation a practical 
constraint. And the presence of the organic solvent might inhibit or even stop the biocatalyst activity (D’Arrigo et al., 2000; Held et al., 2000).

MABR's have been applied for the degradation of volatile contaminants in waste water (Qureshi et al., 2005; Judd, 2008) but has not been used yet in oxidative bioconversion. MABR showed to be a suitable method to decrease the loss of volatile substances during a transformation process (Casey et al., 1999; Lilly and Woodley, 1996). Onken and Berger (1999) studied the use of a MABR for the biotransformation of the citronellol by basidiomycete Cystoderma carcharias, production rates up to $150 \mathrm{mg}$ of citronellol L ${ }^{-1}$ day

${ }^{1}$ were reached and led to a product concentration of $866 \mathrm{mg} \mathrm{L}^{-1}$ with a conversion rate of $52 \%$. The total loss of the added volatile substrate via the exhaust air was $4.5 \%$ when this aeration method was used. In addition, González-Brambila and López-Isunza (2007) reduced oxygen transfer limitations across the biofilm supplying oxygen from inside the membrane and simultaneous sparing of air to the residual water improving the MABR performance.

The aim of this work was to evaluate the bioconversion of (+)-valencene to (+)-nootkatone by $B$. theobromae using a MABR. The bioconversion was tested in both a single liquid phase system and a two liquid phase system using orange essential oil as organic phase.

\subsection{Materials and methods}

\subsubsection{Chemicals}

(+)-valencene (CAS 75-05-6) and (+)-nootkatone (CAS 93-78-5) with a purity $>70 \%$ and $>85 \%$, respectively, were purchased from Fluka (Switzerland) and used as standards. Ethyl acetate (99.5\%) was purchased from Quimex (México). Analytical grade orange essential oil (Citrus aurantium, var. Amara) was purchased from Cosmopolita Drugstore (Mexico, DF) and used as organic dispersed phase to carry out bioconversion studies.

\subsubsection{Microorganism}

Botryodiplodia theobromae 1368 from the Instituto Nacional de Investigaciones Fundamentales de la Agricultura Tropical (La Habana, Cuba) isolated from Cuban Citrus cinensis Osbeck cv Valencia, was used. The strain was stored on dextrose potato agar slants 
at $4{ }^{\circ} \mathrm{C}$ and sub-cultured every month at $30{ }^{\circ} \mathrm{C}$ for 7 days. Spores were harvested with 5.0 $\mathrm{mL}$ of Tween-80 $(0.01 \% \mathrm{v} / \mathrm{v})$ and were used as inoculum $\left(1 \times 10^{6}\right.$ spores $\left.\mathrm{mL}^{-1}\right)$.

\subsubsection{Culture media}

Culture media with the following basal salt composition were used (in $\mathrm{g} \mathrm{L}^{-1}$ ): sucrose, 50; $\mathrm{NaNO}_{3}, 7.5 ; \mathrm{KH}_{2} \mathrm{PO}_{4}, 2.0 ; \mathrm{KCI}, 0.3 ; \mathrm{MgSO}_{4} .7 \mathrm{H}_{2} \mathrm{O}, 0.6 ; \mathrm{FeSO}_{4} .7 \mathrm{H}_{2} \mathrm{O}, 0.6 ; \mathrm{ZnSO}_{4} .7 \mathrm{H}_{2} \mathrm{O}$, $0.03 ; \mathrm{MnSO}_{4} .7 \mathrm{H}_{2} \mathrm{O}, 0.003 ; \mathrm{CuSO}_{4} .7 \mathrm{H}_{2} \mathrm{O}, 0.003 ; \mathrm{Na}_{2} \mathrm{MoO}_{4} .2 \mathrm{H}_{2} \mathrm{O}, 0.003$; yeast extract, 1.0 (Eng et al., 1998). After autoclaving initial pH was adjusted to 5.5-5.6 with $\mathrm{HCl} 2 \mathrm{M}$.

\subsubsection{Suspended biomass determination}

Samples of known volume were dried until a constant weight in metal plates which had been previously weighed after being left in an oven at $90{ }^{\circ} \mathrm{C}$ overnight. All analyses were performed in triplicate.

\subsubsection{Sucrose consumption}

Sucrose consumption of $B$. theobromae was estimated by analyzing the sucrose concentration in the medium using the technique described by Miller et al. (1960). Analyses were performed in triplicate.

\subsubsection{Cell viability}

Cell viability during growth and the bioconversion process was determined by measuring the concentration of living cells using the methylene blue technique, as described by Bonora and Mares (1982). Analyses were performed in triplicate.

\subsubsection{Membrane Aerated Biofilm reactor (MABR)}

The MABR used was previously described by González-Brambila and López-Isunza (2007). The Pyrex tube-bioreactor had the following dimensions: $200 \mathrm{~mL}$ volume, $300 \mathrm{~mm}$ height, $30 \mathrm{~mm}$ outside diameter, and $2 \mathrm{~mm}$ thickness. An oxygen permeable membrane of silicon rubber (290 $\mathrm{mm}$ length, $1.5 \mathrm{~mm}$ inner radius, and $0.3 \mathrm{~mm}$ thick) was used. The membrane tube was placed inside the glass bioreactor. One side of the tube was connected to the air supply valve, and the other side was partially blocked to force oxygen to flow through the 
wall membrane. The system operated continuously at $30{ }^{\circ} \mathrm{C}$ and $\mathrm{pH}$ 5.5. Atmospheric air was filtered through a sterile filter of $0.22 \mu \mathrm{m}$ and was pumped through the membrane at a flow rate of $135 \mathrm{~mL} \mathrm{~min}$. The culture medium was fed up ward with hydraulic retention time (HRT) of $0.756 \mathrm{~h}^{-1}$.

\subsubsection{Bioconversion processes}

The MABR was inoculated using a concentration of $1 \times 10^{6}$ spores of $B$. theobromae $\mathrm{mL}^{-1}$. After 7 days of growth a biofilm was formed outside of the membrane. Then, bioconversion studies were conducted by: (a) adding a concentrated solution of (+)-valencene to reach a final concentration of $1.0 \mathrm{~g} \mathrm{~L}^{-1}$ or (b) dropping a total volume of $135 \mathrm{~mL}$ of orange essential oil through the MABR during of bioconversion process (Figure 3.1). In order to determine the effect of adding valencene and other components of orange essential oil to the culture medium, a control without the addition of (+)-valencene was included using $50 \mathrm{~g}$ of sucrose $\mathrm{L}^{-1}$, which was performed in duplicate. Every day, $2 \mathrm{~mL}$ of sample was taken and centrifuged at $5000 \mathrm{rpm}$ for $10 \mathrm{~min}$. Sesquiterpenes extraction was carried out using $500 \mu \mathrm{L}$ of sample and $500 \mu \mathrm{L}$ of ethyl acetate. The mixture was vortexed twice for $20 \mathrm{~s}$ in a vortex, and settled until phase separation occurred, after that $1 \mu \mathrm{L}$ of the ethyl acetate phase was injected to GC (Girhard et al., 2009; Kaspera et al., 2005).

\subsubsection{Sesquiterpenes analysis}

The concentrations of (+)-valencene and (+)-nootkatone were determined by gas chromatography (GC-FID) using a Perkin Elmer Auto System XL Gas Chromatograph equipped with a flame ionization detector (Cyclosil-B capillary column; $30 \mathrm{~m} \mathrm{x} 0.32 \mathrm{~mm}$ x $0.25 \mu \mathrm{m} ; \mathrm{J} \& \mathrm{~W}$ Scientific). The temperatures of the injector and detector were constant at $250{ }^{\circ} \mathrm{C}$ to $270{ }^{\circ} \mathrm{C}$, respectively. $1 \mu \mathrm{L}$ of sample was automatically injected with a split ratio of 1:4, using helium gas as a carrier. The column temperature was initially set to $120^{\circ} \mathrm{C}$ for 4 min then ramped up to $250{ }^{\circ} \mathrm{C}$ at a rate of $10{ }^{\circ} \mathrm{C}$ per min and maintained at $250{ }^{\circ} \mathrm{C}$ for 5 min, using the technique reported by Girhard et al. (2009). Analyses were performed in triplicate. GC/MS spectra were obtained using a GC/MS-HP6890 (Agilent) gas chromatograph equipped with a HP-5 column (30 m x $250 \mu \mathrm{m}$ x $0.25 \mu \mathrm{m}$, Agilent). The same 
conditions of separation as the GC FID analysis were used. Compounds in the samples were identified by comparison of mass spectra to that of pure compounds.

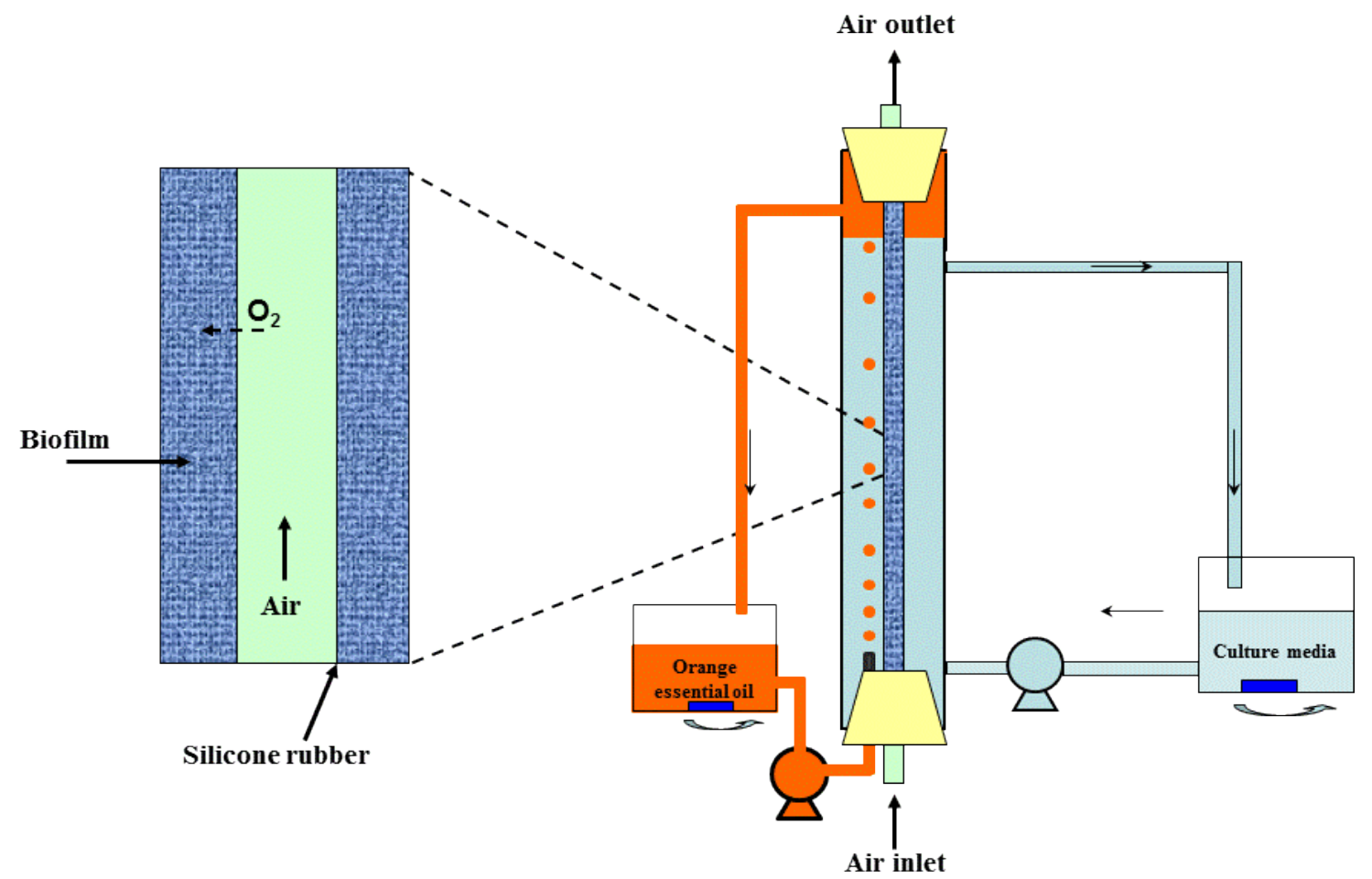

Figure 3.1. Diagram of the membrane aerated biofilm reactor for the bioconversion of (+)valencene to (+)-nootkatone by $B$. theobromae.

\subsection{Results and discussion}

\subsubsection{Sesquiterpenes in orange essential oil (Citrus aurantium, var. amara)}

Orange essential oil used in this work was analysed by GC coupled to mass spectrometry. Concentrations of (+)-valencene and (+)-nootkatone were determined to be $3.2 \mathrm{~g} \mathrm{~L}^{-1}$ and 0.94 $\mathrm{mg} \mathrm{L}^{-1}$, respectively. The (+)-valencene concentration obtained was similar to that reported by Del Rio et al. (1991) at $2.99 \mathrm{~g} \mathrm{~L}^{-1}$ for the same variety of orange. Depending on the harvest of the fruit and its specific variety, the concentration of sesquiterpenes varies for different species of the Citrus genus (Espina et al., 2010; Elston and Rouseff 2005). The highest concentration reported for (+)-valencene was $6.0 \mathrm{~g} \mathrm{~L}^{-1}$ for the species sinensis (Sharon-Asa et al., 2003). In orange essential oil, there are a large number of compounds used in the food and beverage industry as antimicrobial agents. Limonene, a terpene with the highest antimicrobial activity, is largest compound in abundance (Mustafa et al., 2012). 


\subsubsection{Membrane aerated biofilm reactor during the bioconversion in a monophasic system}

To investigate the effect of (+)-valencene on the whole bioconversion process in the MABR, an aqueous phase system was studied. The MABR was inoculated with $1 \times 10^{6}$ spores suspended in $250 \mathrm{~mL}$ of mineral medium with $50 \mathrm{~g}$ of sucrose $\mathrm{L}^{-1}$ as a carbon source. The biofilm was allowed to develop for 7 days at $30{ }^{\circ} \mathrm{C}$. However, suspended biomass was observed reaching a maximum biomass concentration of $23.5 \mathrm{~g} \mathrm{~L}^{-1}$ after approximately $90 \%$ sucrose consumption. At this point, a stock solution of valencene was added to reach an initial (+)-valencene concentration of $1.0 \mathrm{~g} \mathrm{~L}^{-1}$ in the MABR to initiate the bioconversion process. The reactor was operated with a recycle rate of $12.6 \mathrm{~mL} \mathrm{~min}^{-1}$ and an overall HRT of 0.185 $\mathrm{h}$, and the ascending liquid velocity parallel to the membrane was $0.5 \mathrm{~m} \mathrm{~h}^{-1}$. The bioconversion of (+)-valencene was measured by GC. Kinetics of cell growth, sucrose consumption, and cell viability during the bioconversion process are plotted in Figure 3.2. It was observed that cell viability decreased linearly to roughly $30 \%$ between 8 and 12 days. Final cell viability might indicate that (+)-valencene or an intermediary may induce the inhibition of (+)-nootkatone bioconversion.

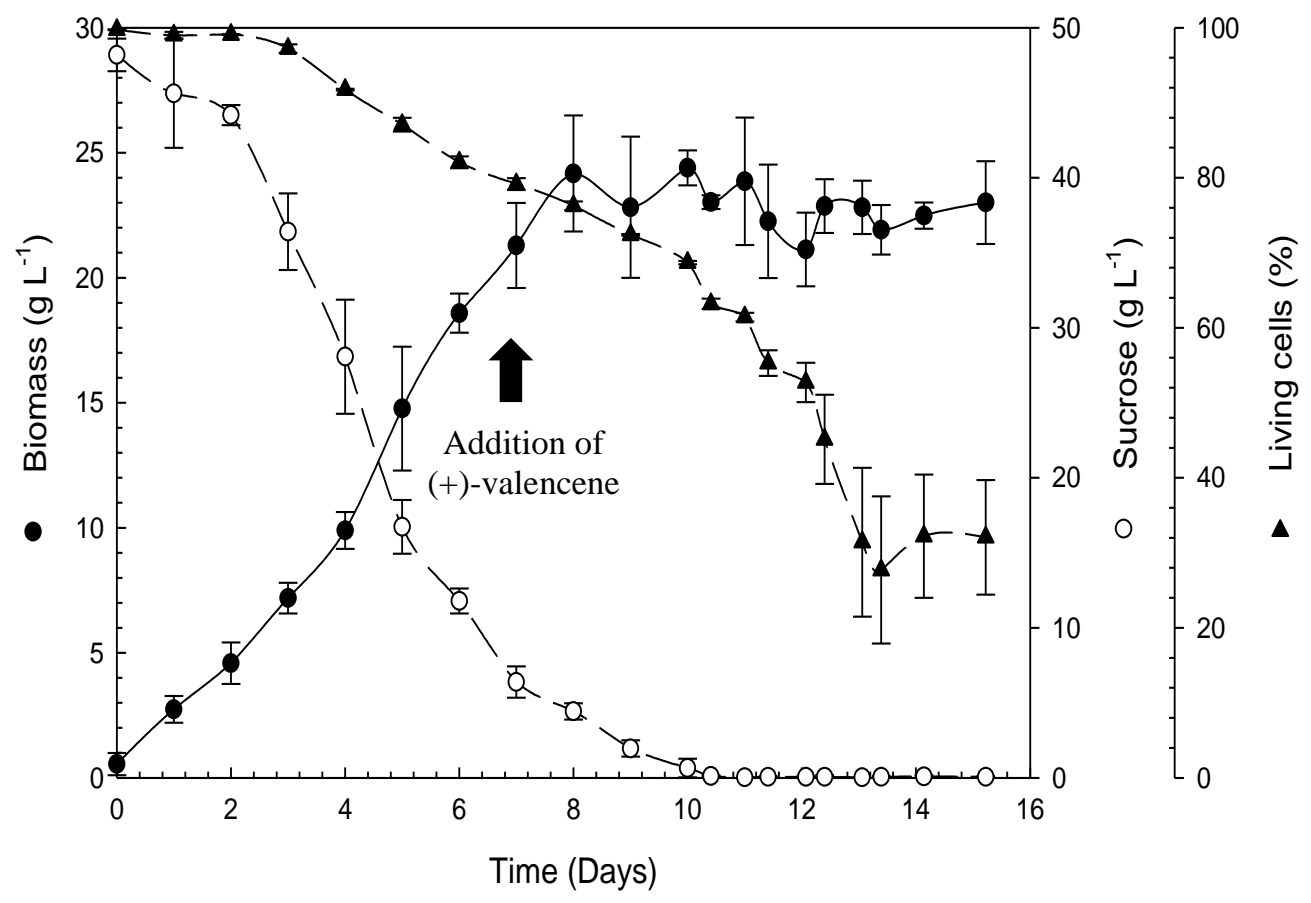

Figure 3.2. Kinetics of suspended biomass, sucrose consumption, and cell viability in the aqueous phase system. $1.0 \mathrm{~g} \mathrm{~L}^{-1}$ of (+)-valencene was added to initiate the bioconversion process. 
Kinetics of (+)-valencene consumption and (+)-nootkatone production during the bioconversion process are plotted in Figure 3.3. After $96 \mathrm{~h}$, a concentration of $398.08 \mathrm{mg} \mathrm{L}^{-}$ ${ }^{1}$ of (+)-nootkatone was reached, converting $0.526 \mathrm{~g} \mathrm{~L}^{-1}$ of valencene (i.e. bioconversion of $62 \%)$. It was observed that the initial (+)-valencene concentration $\left(1.0 \mathrm{~g} \mathrm{~L}^{-1}\right)$ decreased in about $50 \%$ after $96 \mathrm{~h}$ of bioconversion at $30^{\circ} \mathrm{C}$. After this period, no further changes in (+)valencene concentration were observed. However, after $56 \mathrm{~h}$ no statistically significant difference from the (+)-nootkatone produced by B. theobromae is observed. The production of (+)-nootkatone from (+)-valencene has been reported by Furusawa et al. (2005), using to Botryosphaeria dothidea and Botryodiplodia theobromae, fungi cells. The authors reported that the biotransformation yielded 93 and $72 \%$ respectively of enantiomerically pure (+)-nootkatone. In this system, $\operatorname{NADP}(\mathrm{H})$, the reduced form of the cofactor, is used to provide the reaction reduction potential and is regenerated by the cells.

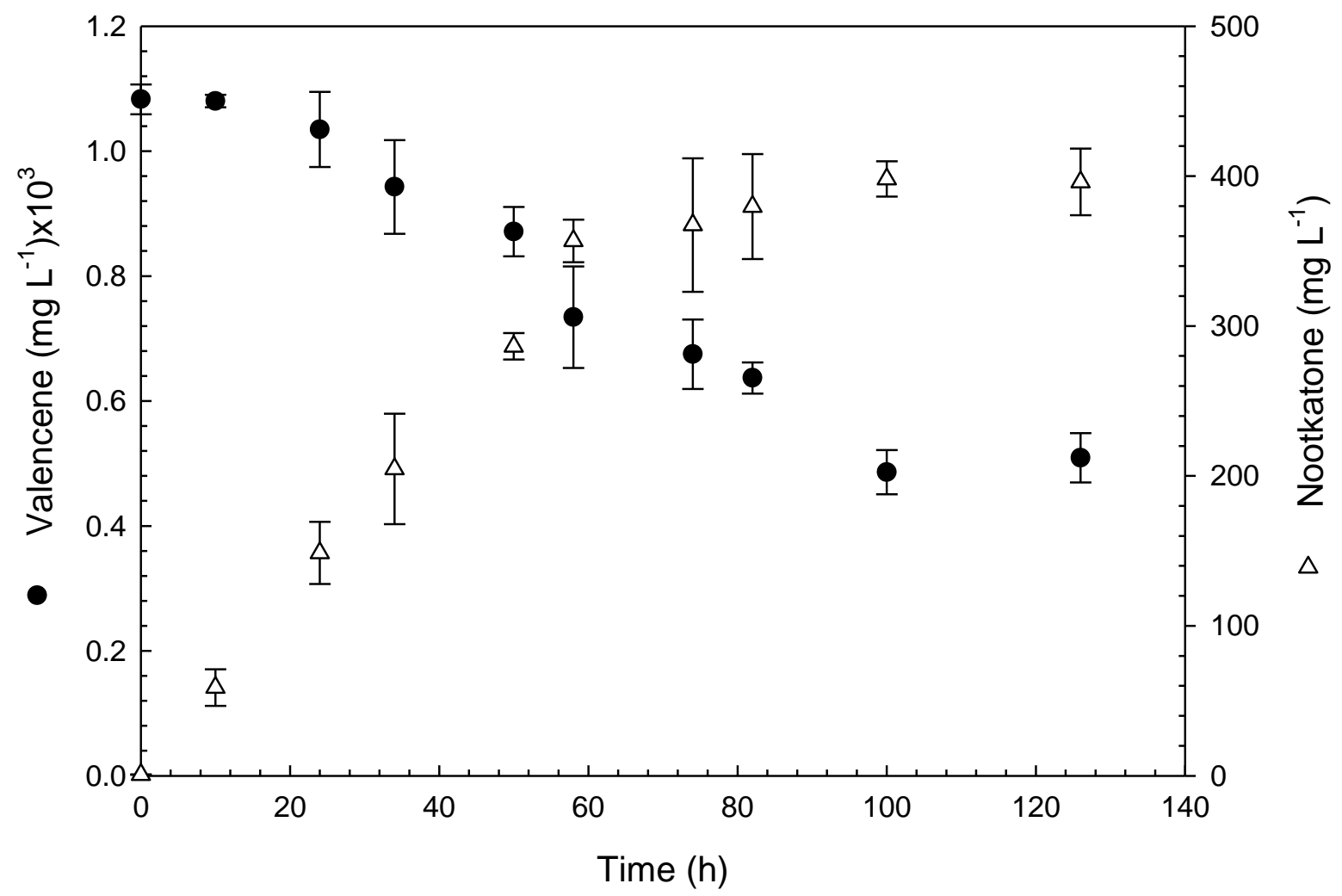

Figure 3.3. Bioconversion of (+)-valencene to (+)-nootkatone in an aqueous phase system using $B$. theobromae. Zero time corresponds to 7 days of growth. 


\subsubsection{Membrane aerated biofilm reactor during the bioconversion in a biphasic system}

Bioconversion experiments were conducted in a two-phase system using orange essential oil as a source of (+)-valencene for bioconversion to (+)-nootkatone. First, the biofilm was allowed to develop for 7 days at $30{ }^{\circ} \mathrm{C}$ using $50 \mathrm{~g}$ of sucrose $\mathrm{L}^{-1}$ as a carbon source. Then, orange essential oil was added. Figure 3.4 shows the results of the growth kinetics, sucrose concentration and cell viability during the bioconversion process. At 10 days, approximately $90 \%$ sucrose consumption and a suspended biomass concentration of $23.25 \mathrm{~g} \mathrm{~L}^{-1}$ was observed. After the addition of orange essential oil, cell viability decreased linearly between 8 and 12 days.

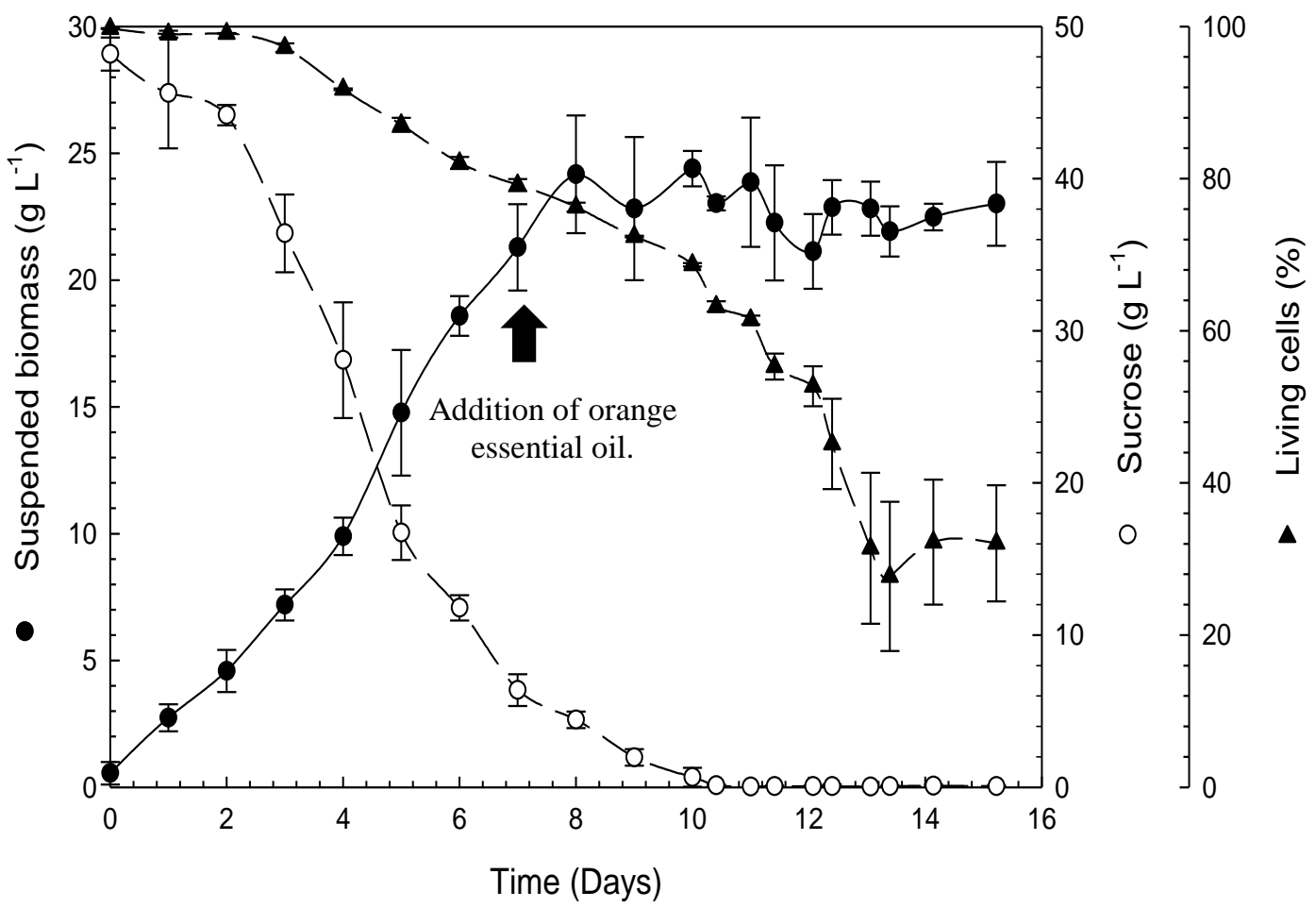

Figure 3.4. Kinetics of suspended biomass, sucrose consumption, and cell viability in the biphasic system. Orange essential oil was added to initiate the bioconversion process.

(+)-Valencene and (+)-nootkatone concentrations in the organic phase during the bioconversion process are plotted in Figure 3.5. At $80 \mathrm{~h}$, a concentration of $310.37 \pm 13.4 \mathrm{mg}$ $\mathrm{L}^{-1}$ of (+)-nootkatone and an approximate consumption of $0.716 \mathrm{~g} \mathrm{~L}^{-1}$ of (+)-valencene was observed (i.e. bioconversion of $30.5 \%$ ). During the bioconversion process in the partitioning 
bioreactor, the (+)-valencene present in orange essential oil was transferred by partition $\left(K_{p}\right.$ $=6.37$ ) to the aqueous phase based on the equilibrium and the metabolic demand of the cells. Also, the (+)-nootkatone produced in the aqueous phase was mainly transferred by partition $\left(K_{p}=22.5\right)$ into the organic phase for an in situ extraction. The relatively low nootkatone concentrations in the organic phase, observed during the bioconversion in the MABR might be due to lipophilic compounds, such as terpenoids, are preferentially dissolved in the lipophilic membrane systems of fungal cells (Abraham et al. 1997). The terpenoids, but also other lipophilic compounds, such as polycyclic aromatic hydrocarbons, alkanes and phenols, induce changes of the membrane properties and, thus, cause toxic effects. The fungi counteract these effects by co-metabolizing the poorly water-soluble compounds to watersoluble ones or to carbon dioxide and water, using easily metabolizable substrates (e.g. sucrose) as the main source of energy. The enzyme systems involved in these detoxification processes are comparable to those of other eucaryotic cells, e.g. mammals (Wackett and Gibson, 1982). In the first step, catalyzed by cytochrome P-450 mono-oxygenases, the molecule is oxyfunctionalised and, in the second step, hydrolysis (e.g. by epoxide hydrolases) or conjugation (e.g. by glutathione-S-transferases or UDP-glucuronosyltransferases) leads to water-soluble products, which are excreted into the medium.

The bioreactor experiments were performed in dead-end mode to provide a trans-membrane flow to diminish blocking of membrane pores by growth of the fungus or by extra-cellular products which provoke a partial blocking of the membrane pores causing a decreased oxygen transfer. The aeration of fungal cultures in bioreactors using hydrophobic microporous membranes offers attractive perspectives for bioconversions of volatile sesquiterpenes substrates. Further work has to focus on the long-term supply of sufficient amounts of oxygen through the aeration membrane to make this approach more applicable to the bioconversion of lipophilic compounds by submerged fungal cultures. This method of regioselective synthesis was performed naturally by microbial pathway converting the product of commercial interest, presenting a better versatility, so this method is to find alternatives in the industrial production of nootkatone. 


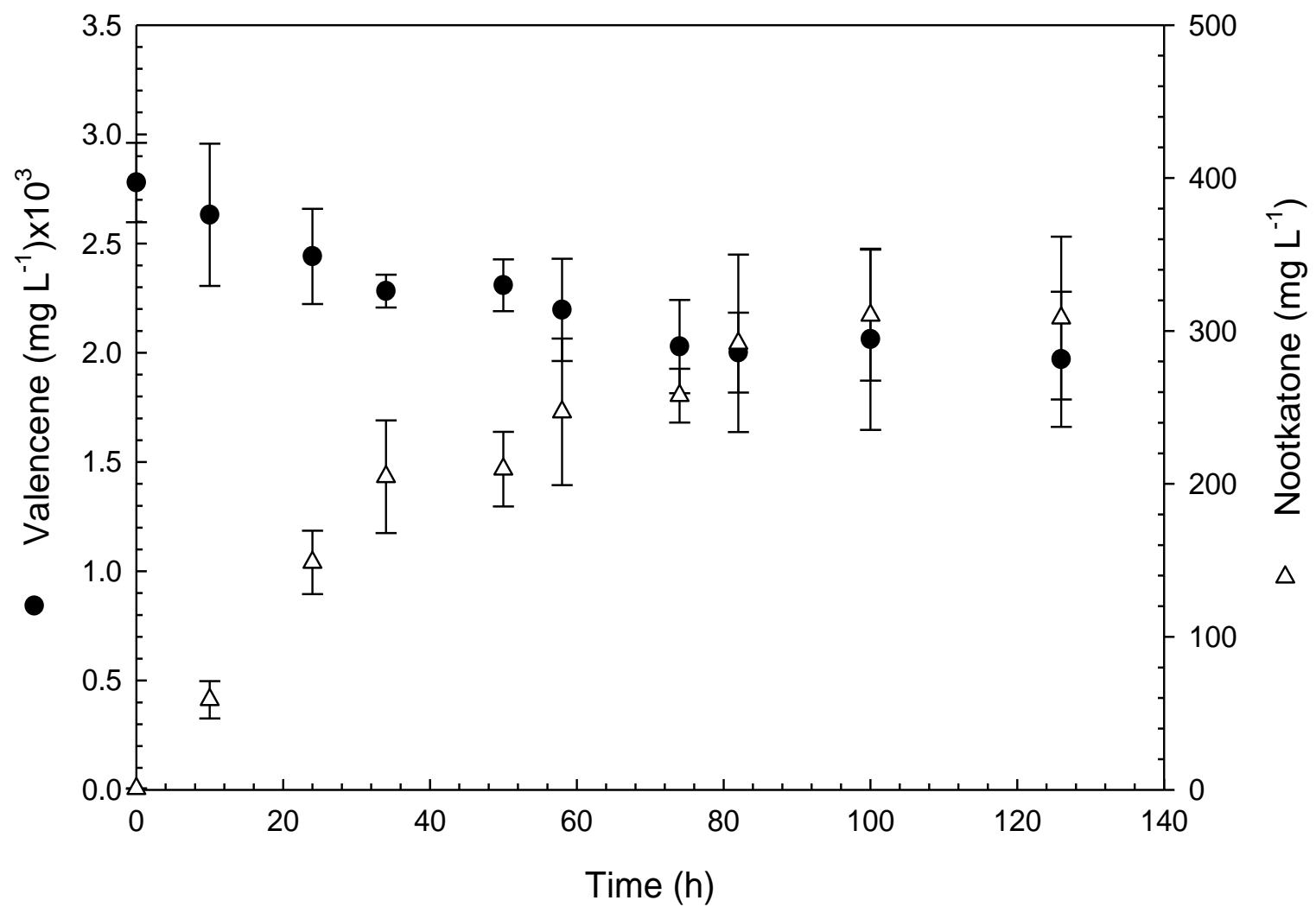

Figure 3.5. Bioconversion of (+)-valencene to (+)-nootkatone in a biphasic system using $B$.

theobromae. Zero time corresponds to 7 days of growth.

\subsection{Conclusions}

In a biphasic system using $B$. theobromae, a (+)-nootkatone concentration of $310.37 \mathrm{mg} \mathrm{L}^{-1}$ was recovered in the organic phase. The addition of a second liquid phase (orange essential oil) presents a potential application for the production and in-situ extraction of the sesquiterpene (+)-nootkatone. However, further bioconversion studies and optimization of the MABR operation are needed to enhance this process.

\section{References}

Abraham B, Onken J, Reil G, Berger RG. (1997). Strategies toward an efficient biotechnology of aromas. In: Kruse H-P, Rothe M (eds). Flavour perception-aroma evaluation. (Proceedings of the 5th Wartburg Aroma Symposium, Eisenach). Eigenverlag Universitaat Potsdam, 357-373. 
Bonora A., D. Mares. (1982). A Simple Colorimetric Method for Detecting Cell Viability in Cultures of Eukaryotic Microorganisms. Curr. Microbiol. 7, 217-222.

Casey, E., Glennon, B., Hamer, G. (1999). Oxygen Mass Transfer Characteristics in a membraneAerated Biofilm Reactor. Biotechnology \&Bioengineering 62 (2), 183-192.

D’Arrigo P., G. Pedrocchi-Fantoni, S. Servi. (2000). Stereoselective synthesis of chiral compounds using whole-cell biocatalysts, in: R.N. Patel (Ed.), Stereoselective Biocatalysis, M. Dekker, New York, 365-396.

Del Río J.A., A. Ortuño, D.G. Puig, J.L. Iborra, F. Sabater. (1991). Accumulation of the sesquiterpenos nootkatone and valencene by callus cultures of Citrus paradisi, Citrus limonia and Citrus aurantium. Plant Cell Rep. 10, 410-413.

Elston A., Lin, J., Rouseff, R. (2005). Determination of the role of valencene in orange oil as a direct contributor to aroma quality. J. Flavour and Fragrance. 20, 381-386.

Eng F., M. Gutiérrez-Rojas y E. Favela-Torres. (1998). Culture conditions for jasmonic acid and biomass production by Botryodiplodia theobromae in submerged fermentation. Process Biochemistry. 33, 7, 715-721.

Espina L., M. Somolinos, S. Loreen, P. Conchello, D. Garcia, R. Pageen. (2010). Chemical composition of commercial Citrus fruit essential oils and evaluation of their antimicrobial activity acting alone or in combined processes. Food Control, 22, 896-902.

Esquivel V., Ponce F., Esponda P., Prado A., Gutiérrez M., Lye G. and Huerta S. (2009). Biodegradation of [bmim][PF6] using Fusarium sp. Revista Mexicana de Ingeniería Química. $8,163-168$.

Faber K. (2004). Biotransformations in Organic Chemistry, Spinger-Verlag, Berlin.

Furusawa M., T. Hashimoto, Y. Noma, Y. Asakawa. (2005). Highly efficient production of nootkatone, the grapefruit aroma from valencene, by biotransformation. Chem Pharm Bull (Tokyo) 53, 1513-1514.

Girhard M., K. Machida, M. Itoh, R. Schmid, A. Arisawa y V. Urlacher. (2009). Regioselective biooxidation of (+)-valencene by recombinant E. coli expressing CYPI09BI from Bacillus subtilis in a two-liquid-phase system. Microbial Cell Factories. 8, 1-12.

González-Brambila M. and López-Isunza F. (2007). Mass Transport and reaction in a biofilm. Revista Mexicana de Ingeniería Química 6, 127-136.

Held M., A. Schmid, J.B. Van Beilen, B. Witholt. (2000). Biocatalysis. Biological systems for the production of chemicals, Pure Appl. Chem. 72 (7), 1337-1343.

Judd S. (2008). The status of membrane bioreactor technology. Trends in Biotechnology. 26, 109116. 
Kaspera R., U Krings, T Nanzad, Berger RG. (2005). Bioconversion of (+)-valencene in submerged cultures of the ascomycete Chaetomium globosum Appl Microbiol Biotechnol. 67, 477 - 483.

Lilly MD, Woodley JM. (1996). A structured approach to design and operation of biotransformation processes. J Ind Microbiol. 17, 24-29.

Miller G. L., R. Blum, W.E. Glennon, y A.L. Burton. (1960). Measurement of Carboxymethylcellulase Activity. Anal. Biochem. 2, 127-132.

Mustafa U., U. Filiz, S. Aysun, D. Sadık. (2012). Research on antifungal and inhibitory effects of DL-limonene on some yeasts, Turk. J. Agric. For. 36, 576-582.

Onken J. and Berger R. G. (1999). Biotransformation of citronellol by the basidiomycete Cystoderma carcharias in an aerated-membrane bioreactor. Appl. Microbial. Biotechnol. 51, 158-163.

Qureshi N., Annous B.A., Ezeji T.C., Karcher P. and Maddox I.S. (2005). Biofilm reactors for industrial bioconversion processes: employing potential of enhanced reaction rates. Microbial Cell Factories 4, 24.

Sharon-Asa L., M. Shalit, A. Frydman, E. Bar, D. Holland, E. Or, U. Lavi, E. Lewinsohn, Y. Eyal. (2003). Citrus fruit flavor and aroma biosynthesis: isolation, functional characterization, and developmental regulation of Cstps1, a key gene in the production of the sesquiterpene aroma compound valencene. Plant J. 36, 664-674.

Wackett LP, Gibson DT. (1982). Metabolism of xenobiotic compounds by enzymes in cell extracts of the fungus Cunningham-ella elegans. Biochem J. 205: 117-122. 


\title{
CHAPTER IV
}

\author{
ASSESSMENT OF (+)-VALENCENE BIOCONVERSION BY Yarrowia lipolytica
} USING A THREE PHASE PARTITIONING BIOREACTOR 


\title{
ASSESSMENT OF (+)-VALENCENE BIOCONVERSION BY Yarrowia lipolytica USING A PARTITIONING BIOREACTOR
}

\begin{abstract}
The aim of this work was to perform the physiological characterization of Yarrowia lipolytica 2.2ab during the bioconversion of (+)-valencene to (+)-nootkatone in a partitioning bioreactor using orange essential oil as the dispersed phase. When the exponential growth phase finished after $33 \mathrm{~h}$ of cell cultivation, orange essential oil $(50 \% \mathrm{v} / \mathrm{v})$ was added. A (+)-nootkatone concentration of $326.34 \mathrm{mg} \mathrm{L}^{-1}$ in the organic phase was obtained after 4 days, reaching a volumetric productivity of $3.40 \mathrm{mg} \mathrm{L}^{-1} \mathrm{~h}^{-1}$ and a bioconversion of $38.82 \%$. At the end of the process, a loss of $70 \%$ of viable cells was observed, likely due to the accumulation of an intermediary. To the best of our knowledge, our research group is the first one reporting the wild type Y. lipolytica strain as a microorganism with the enzymatic machinery to carry out the oxidation of $(+)$-valencene. The bioconversion system based on the addition of an organic phase presents an attractive way to produce and recover $(+)-$ nootkatone in situ.
\end{abstract}

Keywords: Bioconversion, Partitioning bioreactor, (+)-nootkatone, Yarrowia lipolytica

\subsection{Introduction}

The compound (+)-nootkatone is a sesquiterpenoid that possesses an intense grapefruit-like taste and other valuable properties that are exploited by the fragrance and flavour industries [1]. The production of (+)-nootkatone is performed via chemical synthesis, mainly from the sesquiterpene (+)-valencene, which is readily available from the orange industry and also through the use of environmentally unfriendly oxidizing agents, such as tert-butyl peracetate [2] and tert-butyl hydroperoxide in combination with catalytic metal supported on silica [3]. However, the resulting (+)-nootkatone produced via chemical synthesis cannot be marketed as a "natural" product and does not satisfy increasing market demands for natural aromatic compounds. In order to meet this demand, many efforts have focussed on the use of biotechnological processes with bacteria, fungi or plants [4]. Some researchers have investigated genetically modified microorganisms, and several published reviews $[5,6]$ have provided an overview of recently acquired knowledge about whole cell bioconversions and future industrial applications. A biocatalysis process in whole cells involves the selection of an optimal cellular enzyme, reaction engineering, product recovery and scaling-up. However, 
to date, there is a lack of literature related to the appropriate selection of a bioreactor for biosynthesis of (+)-nootkatone.

Gavira et al. [7] reported a bioconversion process for (+)-nootkatone production using plant enzymes expressed in $S$. cerevisiae, the process was inhibited by substrate $\left(>4 \mathrm{~g} \mathrm{~L}^{-1}\right)$ and product $\left(1.0 \mathrm{~g} \mathrm{~L}^{-1}\right)$. Alternatives are needed to overcome this inhibition by the substrate and product, as well as the over-oxidation of (+)-valencene. For instance, essential oils can be used as both a substrate reservoir and an in situ extraction agent in a partitioning bioreactor, thereby increasing the efficiency of the process [8]. Oppermann et al. [9] previously reviewed the use of biocompatible organic solvents in biphasic systems and their application in purification, extraction and bioconversion. However, bioconversion productivity of sesquiterpenes in a multi-phase system can be limited by low mass transfer rates at interfaces (gas-liquid or liquid-liquid). Partitioning bioreactors have shown significant potential for improving the productivity of many biological processes by overcoming problems related to low solubility or the toxicity of substrates and products [10].

The aim of this work was to perform the physiological characterisation of Yarrowia lipolytica $2.2 \mathrm{ab}$ during the bioconversion of (+)-valencene to (+)-nootkatone in a partitioning bioreactor.

\subsection{Materials and methods}

\subsubsection{Chemicals}

(+)-valencene (CAS 75-05-6) and (+)-nootkatone (CAS 93-78-5) with a purity $>70 \%$ and $>85 \%$, respectively, were purchased from Fluka (Switzerland) and used as standards. Ethyl acetate $(99.5 \%)$ was purchased from, Quimex (México). Analytical grade orange essential oil (Citrus aurantium, var. Amara, Cosmopolita Drugstore, Mexico DF) was used as organic dispersed phase. This orange essential oil was used to carry out thermodynamic, hydrodynamic, mass transfer, and bioconversion studies.

\subsubsection{Microorganism, culture media and inoculum}

Yarrowia lipolytica 2.2ab was previously selected for its capability to convert (+)-valencene to (+)-nootkatone from a screening between 6 selected strains (fungi and yeasts). Yarrowia 
lipolytica 2.2ab was isolated from copra meal that was provided by the Laboratory of BioProcess of the University of Guadalajara ( $U$ de G), Mexico. The strain was maintained in potato dextrose agar (PDA) at $4{ }^{\circ} \mathrm{C}$, and cultures were propagated in 125 -mL Erlenmeyer conical flasks containing $30 \mathrm{~mL}$ of PDA, before being incubated at $30{ }^{\circ} \mathrm{C}$ for 4 days. Cells were harvested with $25 \mathrm{~mL}$ 0.01\% Tween-80 and used as inoculum (stock solution). Culture medium for $Y$. lipolytica was composed of $\left(\mathrm{g} \mathrm{L}^{-1}\right)$ : Glucose, $20 ; \mathrm{Na}_{2} \mathrm{MoO}_{4}, 0.2 ; \mathrm{MnSO}_{4}, 0.4$; $\mathrm{FeCl}_{3}, 0.2 ; \mathrm{KI}, 0.1 ; \mathrm{CuSO}_{4}, 0.04 ; \mathrm{H}_{2} \mathrm{BO}_{3}, 0.5 ; \mathrm{CaCl}_{2}, 0.1 ; \mathrm{NaCl}, 0.1 ; \mathrm{MgSO}_{4} * 7 \mathrm{H}_{2} \mathrm{O}, 0.5$; $\mathrm{KH}_{2} \mathrm{PO}_{4}, 1 ; \mathrm{ZnSO}_{4}, 0.4 ;\left(\mathrm{NH}_{4}\right)_{2} \mathrm{SO}_{4}, 5$; and Yeast extract, 4.004 [11]. Prior to sterilization, the $\mathrm{pH}$ of culture medium was adjusted to 5.5 using $2 \mathrm{M} \mathrm{HCl}$. For experiments in baffled conical flasks, $100 \mu \mathrm{L}$ of $Y$. lipolytica $2.2 \mathrm{ab}$ cell suspension $\left(1 \times 10^{6}\right.$ cells $\left.\mathrm{mL}^{-1}\right)$ was added as inoculum to $100 \mathrm{~mL}$ of culture medium. Flasks were incubated at $30^{\circ} \mathrm{C}$ for 3 days on a rotary shaker at $200 \mathrm{rpm}$. For bioreactor experiments, $700 \mu \mathrm{L}$ of inoculum was added to $350 \mathrm{~mL}$ of sterile medium.

\subsubsection{Growth kinetics and biomass determination}

To increase the biomass of $Y$. lipolytica $2.2 \mathrm{ab}$, and thus, to obtain a greater yield of (+)nootkatone, it was carried out an analysis of growth kinetics with different concentrations of glucose $\left(20-60 \mathrm{~g} \mathrm{~L}^{-1}\right)$ in the culture medium. Baffled Erlenmeyer flasks of $250 \mathrm{~mL}$ containing $100 \mathrm{~mL}$ of culture media were used. Each baffled Erlenmeyer flask was inoculated with $1 \times 10^{6}$ cells $\mathrm{mL}^{-1}$ and incubated at $30{ }^{\circ} \mathrm{C}$ for 3 days on a rotary shaker at $200 \mathrm{rpm}$. Biomass determination was carried out by measuring the dry weight of cells. Samples of known volume were dried to a constant weight in metal plates which had been previously weighed after being left in an oven at $90{ }^{\circ} \mathrm{C}$ overnight. All analyses were performed in triplicate.

\subsubsection{Glucose consumption}

Glucose consumption of $Y$. lipolytica $2.2 \mathrm{ab}$ was estimated by analysing the glucose concentration in the medium using the technique described by Miller [12]. Analyses were performed in triplicate. 


\subsubsection{Cell viability}

Cell viability during growth and the bioconversion process was determined by measuring the concentration of living cells using the methylene blue technique, described by Bonora and Mares [13]. Analyses were performed in triplicate.

\subsubsection{Partitioning bioreactor}

A 1.0 L glass stirred tank bioreactor (model ADI 1025, Applikon) was used for hydrodynamic characterisation, mass transfer and bioconversion processes. The bioreactor had an inside diameter of $9.5 \mathrm{~cm}$ and an operation volume of $0.7 \mathrm{~L}\left(\mathrm{H}_{\mathrm{L}} / \mathrm{D}_{\mathrm{T}}=0.96\right)$. The bioreactor was equipped with a single Rushton turbine with 6 paddles, $\mathrm{D}_{\mathrm{i}}=4.53 \mathrm{~cm}(\mathrm{Di} / \mathrm{DT}$ $=0.46$ ), located $4.53 \mathrm{~cm}$ from the base of the container. The bioreactor had 2 equidistant deflectors of $1.0 \mathrm{~cm}$ in width to improve liquid-liquid mixing. Temperature and agitation were maintained at $30^{\circ} \mathrm{C}$ and $300 \mathrm{rpm}$, respectively. The $\mathrm{pH}$ was monitored using an AppLiSens Z001023511 pH electrode (Applikon) and controlled at 5.5 using 2M NaOH. Atmospheric air entering the system was filtered through a sterile $0.22 \mu \mathrm{m}$ filter. The air flow rate in the bioreactor was $1 \mathrm{vvm}$ through a perforated "L" tube with seven holes of $1.0 \mathrm{~mm}$ in diameter.

\subsubsection{Bioconversion processes}

Bioconversion studies were conducted after the growth phase of Y. lipolytica 2.2ab (33 h), by adding (a) a concentrated solution of (+)-valencene to reach a final concentration of $1.5 \mathrm{~g}$ $\mathrm{L}^{-1}$ or (b) adding $350 \mathrm{~mL}$ of orange essential oil (phase ratio of $1: 1 \mathrm{v} / \mathrm{v}$ ) to the culture medium to reach a final concentration of $2.7 \mathrm{~g}$ of $(+)$-valencene $\mathrm{L}^{-1}$ in the organic phase and $0.4 \mathrm{~g}$ of (+)-valencene $\mathrm{L}^{-1}$ in the aqueous phase. Every day, $5 \mathrm{~mL}$ of sample from the bioconversion media was taken and centrifuged at $5000 \mathrm{rpm}$ for $10 \mathrm{~min}$. Then, sesquiterpene extraction was carried out using $500 \mu \mathrm{L}$ of the aqueous or organic phase and $500 \mu \mathrm{L}$ of ethyl acetate. The mixture was vortexed twice for $20 \mathrm{~s}$ in a vortex, and settled until phase separation occurred, after that $1 \mu \mathrm{L}$ of the ethyl phase was injected to $\mathrm{GC}[14,15]$. 


\subsubsection{Sesquiterpenes analysis}

The concentrations of (+)-valencene and (+)-nootkatone were determined by gas chromatography (GC-FID) using a Perkin Elmer Auto System XL Gas Chromatograph equipped with a flame ionization detector (Cyclosil-B capillary column; $30 \mathrm{~m}$ x $0.32 \mathrm{~mm}$ x $0.25 \mu \mathrm{m} ; \mathrm{J} \& \mathrm{~W}$ Scientific). The temperatures of the injector and detector were constant at $250{ }^{\circ} \mathrm{C}$ to $270{ }^{\circ} \mathrm{C}$, respectively. $1 \mu \mathrm{L}$ of sample was automatically injected with a split ratio of 1:4, using helium gas as a carrier. The column temperature was initially set to $120^{\circ} \mathrm{C}$ for 4 min then ramped up to $250{ }^{\circ} \mathrm{C}$ at a rate of $10{ }^{\circ} \mathrm{C}$ per min and maintained at $250{ }^{\circ} \mathrm{C}$ for 5 min, using the technique reported by Girhard et al. [14]. Analyses were performed in triplicate, and concentrations were determined using external calibration curves of $(+)$ valencene and (+)-nootkatone. GC/MS spectra were obtained using a GC/MS-HP6890 (Agilent) gas chromatograph equipped with a HP-5 column (30 m x $250 \mu \mathrm{m} \times 0.25 \mu \mathrm{m}$, Agilent). The same conditions of separation as for the GC-FID analysis were used. Compounds in the samples were identified by comparison of mass spectra to that of pure compounds.

\subsection{RESULTS AND DISCUSIONS}

\subsubsection{Bioconversion of (+)-valencene in a biphasic system with Y. lipolytica}

In order to investigate the effect of (+)-valencene on the whole bioconversion process in the bioreactor, a biphasic bioreactor was studied. Kinetics of cell growth, glucose consumption, and cell viability during the bioconversion process are plotted in Figure 4.1. After $33 \mathrm{~h}$ of growth, a maximum biomass concentration of $9.36 \mathrm{~g} \mathrm{~L}^{-1}$ was reached after approximately $90 \%$ glucose consumption. At this point, a stock solution of valencene was added to a final

concentration of $1.5 \mathrm{~g}$ of $(+)$-valencene $\mathrm{L}^{-1}$ in the bioreactor to initiate the bioconversion process. Cell viability decreased linearly to roughly $30 \%$ between 30 and $80 \mathrm{~h}$. Final cell viability might indicate that (+)-valencene or an intermediary may induce the inhibition of (+)-nootkatone bioconversion. 


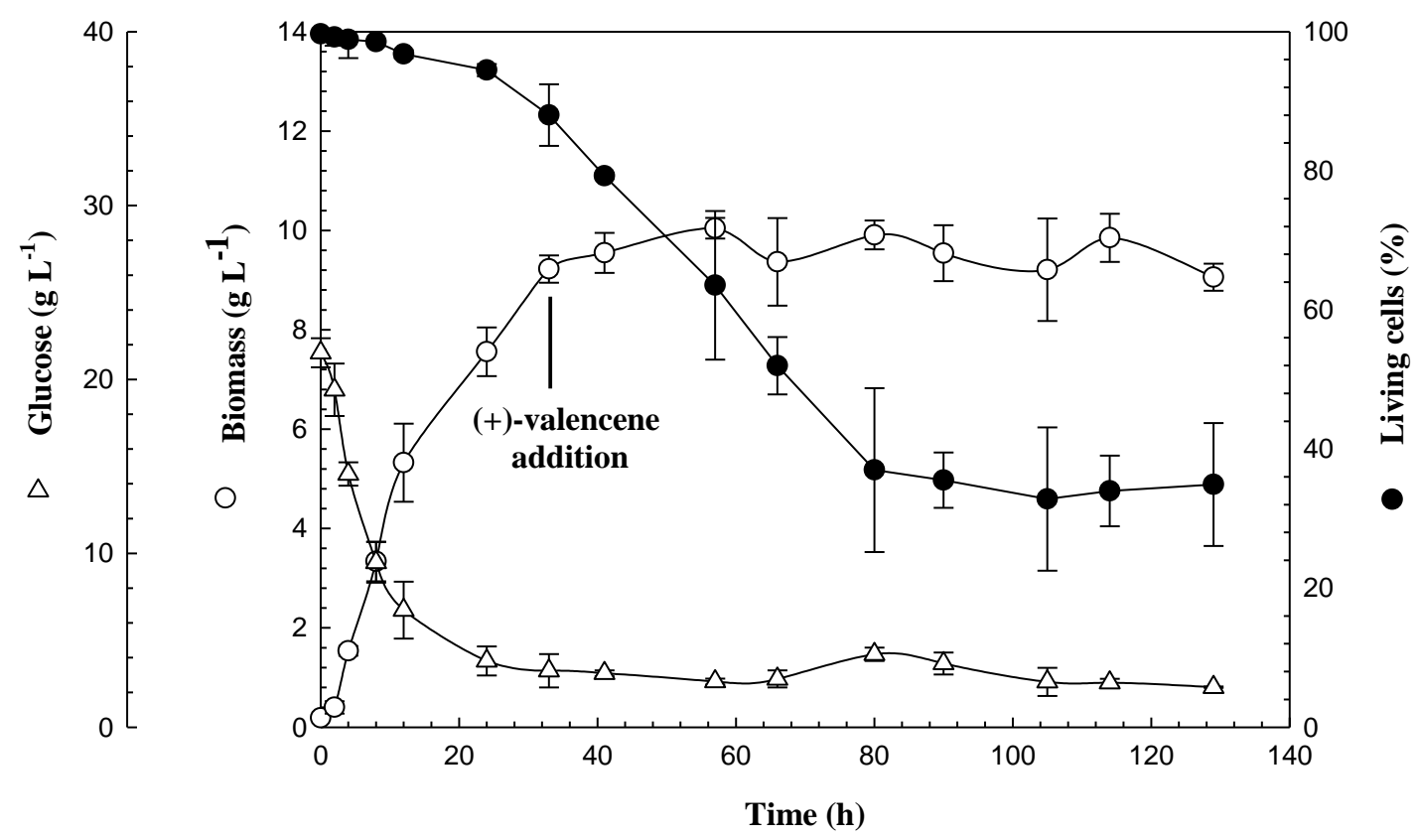

Figure 4.1. Kinetics of cell growth, glucose consumption, and cell viability in the biphasic system. $1.5 \mathrm{~g}$ of $(+)$-valencene $\mathrm{L}^{-1}$ was added to initiate the bioconversion process.

Besides, kinetics of (+)-valencene consumption and (+)-nootkatone production during the bioconversion process are plotted in Figure 4.2. After $96 \mathrm{~h}$, a concentration of $302.65 \mathrm{mg}$ of (+)-nootkatone $\mathrm{L}^{-1}$ was reached, converting $0.866 \mathrm{~g}$ of valencene $\mathrm{L}^{-1}$ (i.e. bioconversion of $32.7 \%$ ). However, a stationary phase was observed after $70 \mathrm{~h}$, likely due to: loss of cell viability; alteration in the transport mechanism through the cell membrane; accumulation of intermediaries of the bioconversion reaction in the endo-membranes; or excessive product formation to potentially toxic levels. 


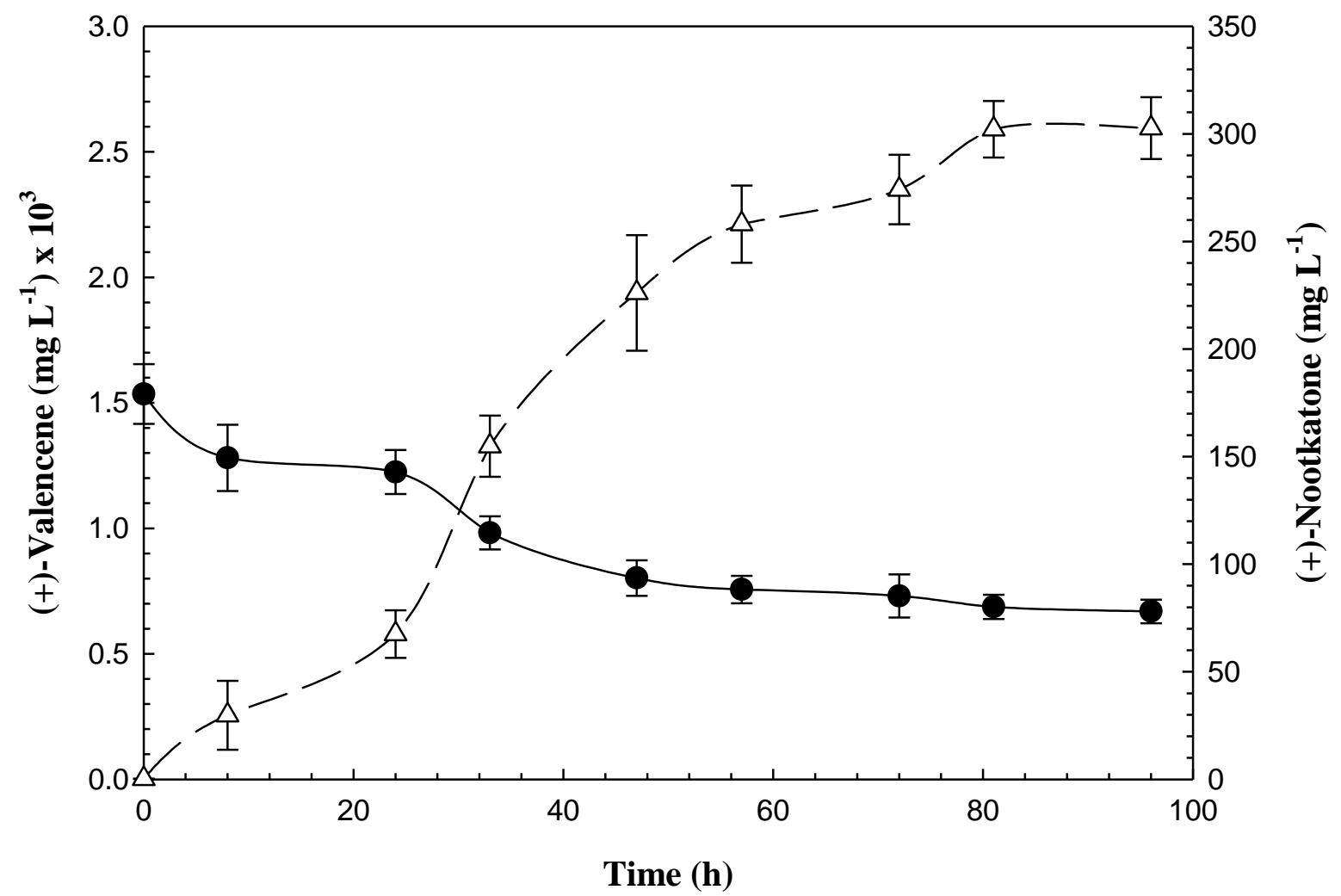

Figure 4.2. Bioconversion of (+)-valencene to (+)-nootkatone in a biphasic system using $Y$. lipolytica. Zero time corresponds to $33 \mathrm{~h}$ of growth.

\subsubsection{Bioconversion of $(+)$-valencene in a three-phase system with $Y$. lipolytica}

Bioconversion experiments were conducted in a three-phase system using orange essential oil as a source of (+)-valencene for bioconversion to (+)-nootkatone. First, Y. lipolytica was grown using $20 \mathrm{~g}$ of glucose $\mathrm{L}^{-1}$ as a carbon source. Then, after $33 \mathrm{~h}$, orange essential oil $(50 \% \mathrm{v} / \mathrm{v})$ was added as a source of $(+)$-valencene to produce $(+)$-nootkatone. Figure 4.3 shows the results of the growth kinetics, glucose concentration and cell viability during the bioconversion process. At $33 \mathrm{~h}$, approximately $90 \%$ glucose consumption and a biomass of $9.28 \mathrm{~g} \mathrm{~L}^{-1}$ were observed. After this time, when orange essential oil was added, cell viability decreased linearly between 30 and $80 \mathrm{~h}$. 


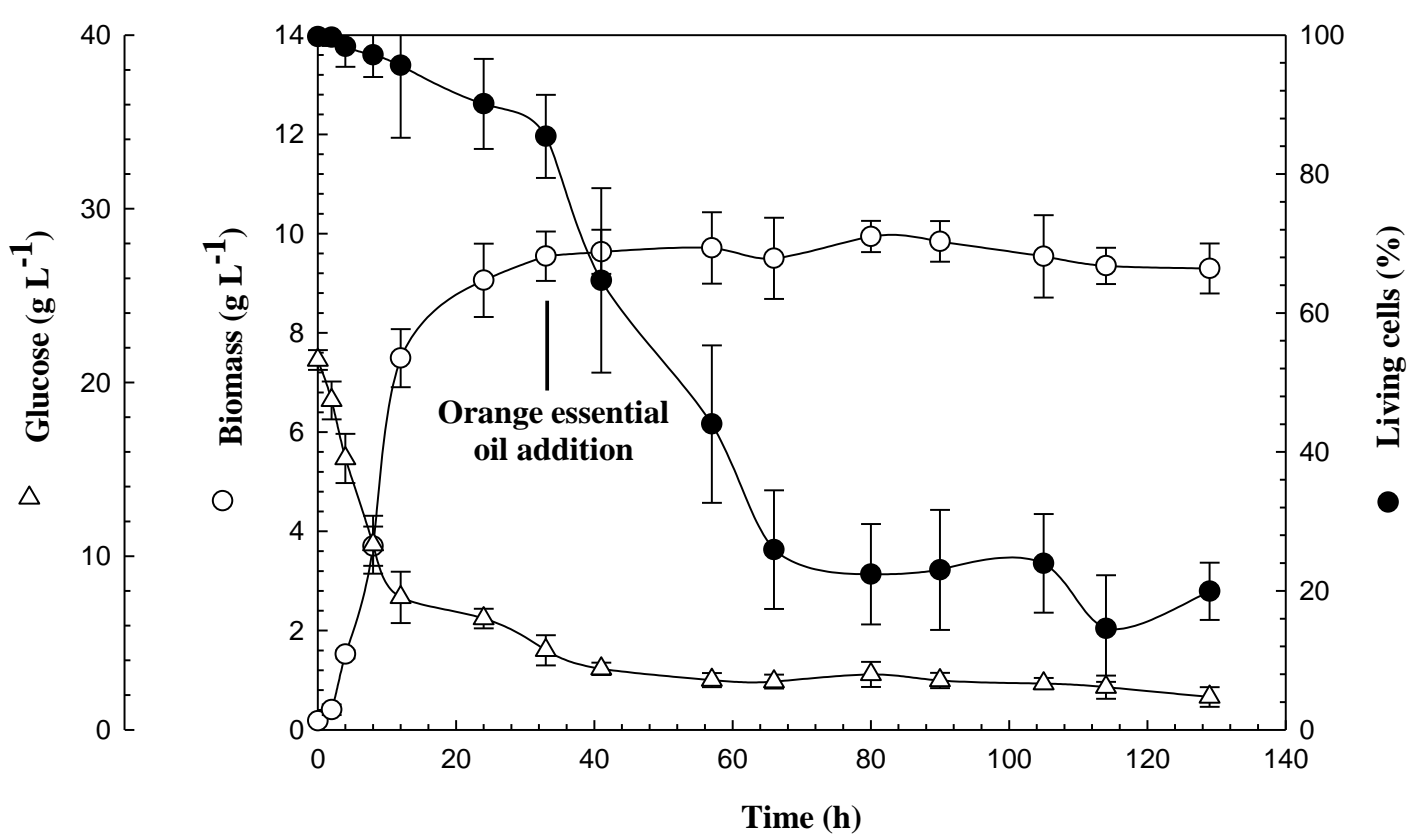

Figure 4.3. Kinetics of cell growth, glucose consumption, and cell viability in the three-phasic system. Up to $50 \% \mathrm{v} / \mathrm{v}$ orange essential oil $\left(3.2 \mathrm{~g}\right.$ of $(+)$-valencene $\left.\mathrm{L}^{-1}\right)$ were added to initiate the bioconversion process.

Cell viability value is half to the value observed from the control experiment (see Section 5.3.4) and 10\% lower than the value observed in the biphasic system (Figure 4.1), likely due to unknown components in the orange essential oil.

During the bioconversion process in the partitioning bioreactor, the $(+)$-valencene present in orange essential oil was transferred by partition $\left(K_{p}=6.37\right)$ to the aqueous phase based on the equilibrium and the metabolic demand of the cells. Also, the (+)-nootkatone produced in the aqueous phase was mainly transferred by partition $\left(K_{p}=22.5\right)$ into the organic phase for an in situ extraction. Substrate ((+)-valencene) and product ((+)-nootkatone) concentrations in the organic phase during the bioconversion process are plotted in Figure 4.4. At $96 \mathrm{~h}$, a concentration of $280.27 \mathrm{mg}$ of (+)-nootkatone $\mathrm{L}^{-1}$ and an approximate consumption of 1.016 $\mathrm{g}$ of (+)-valencene $\mathrm{L}^{-1}$ were observed (i.e. bioconversion of $31.93 \%$ ). However, after $70 \mathrm{~h}$, the bioconversion process reached a stationary phase, indicating that there was a limiting factor in the production of (+)-nootkatone. 


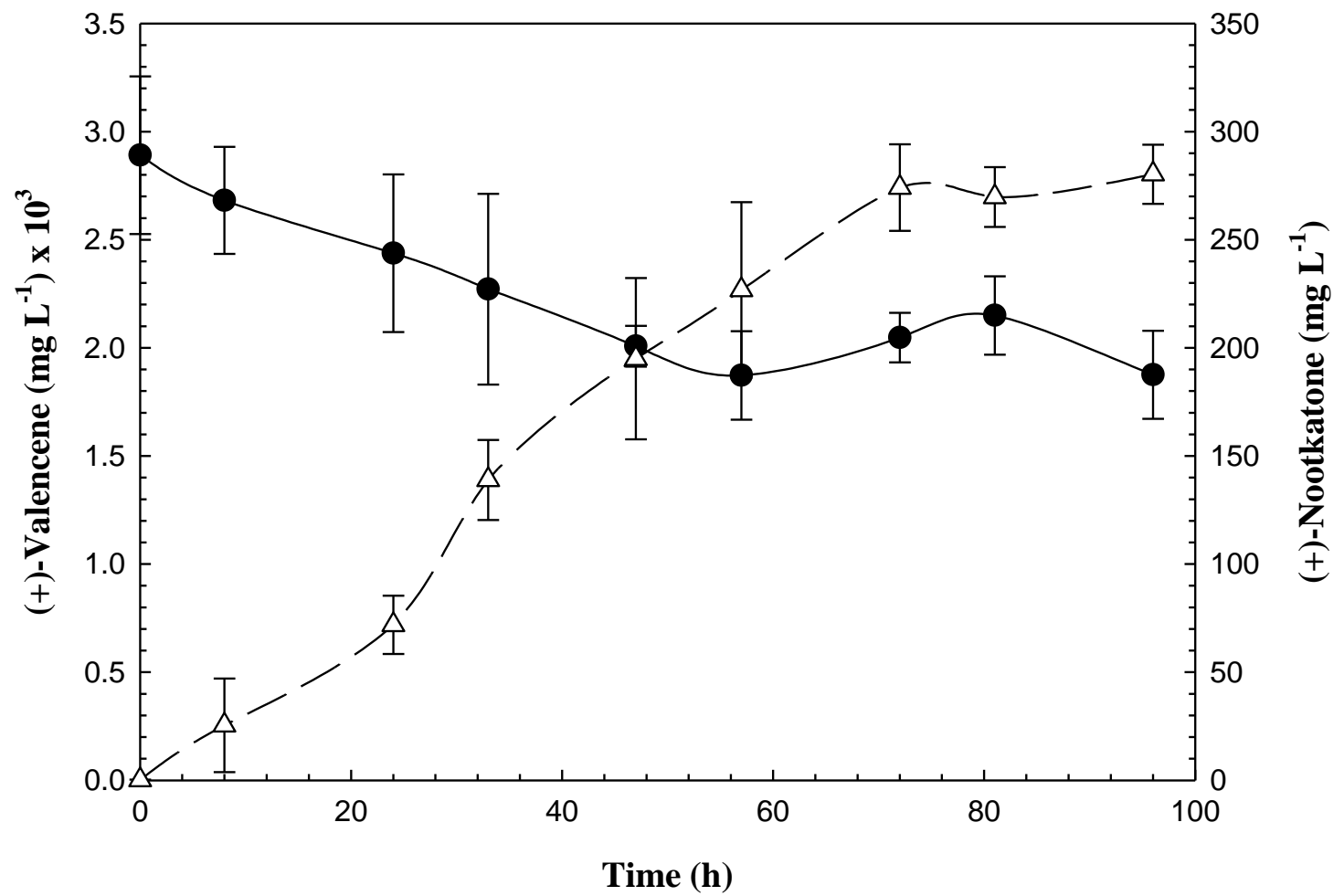

Figure 4.4. Bioconversion of (+)-valencene to (+)-nootkatone in a three-phasic system using $Y$. lipolytica. Zero time corresponds to $33 \mathrm{~h}$ of growth.

Based on these results, the first strategy to increase the yield of (+)-nootkatone involved increasing the amount of biomass during the bioconversion process. To this end, growth kinetics in shaken, baffled Erlenmeyer flasks were measured using various initial glucose concentrations (20 to $60 \mathrm{~g} \mathrm{~L}^{-1}$ ) in order to determine the concentration with the greatest biomass production (Figure 4.5). Substrate inhibition was observed at concentrations of $40 \mathrm{~g}$ of glucose $\mathrm{L}^{-1}$ and greater. 


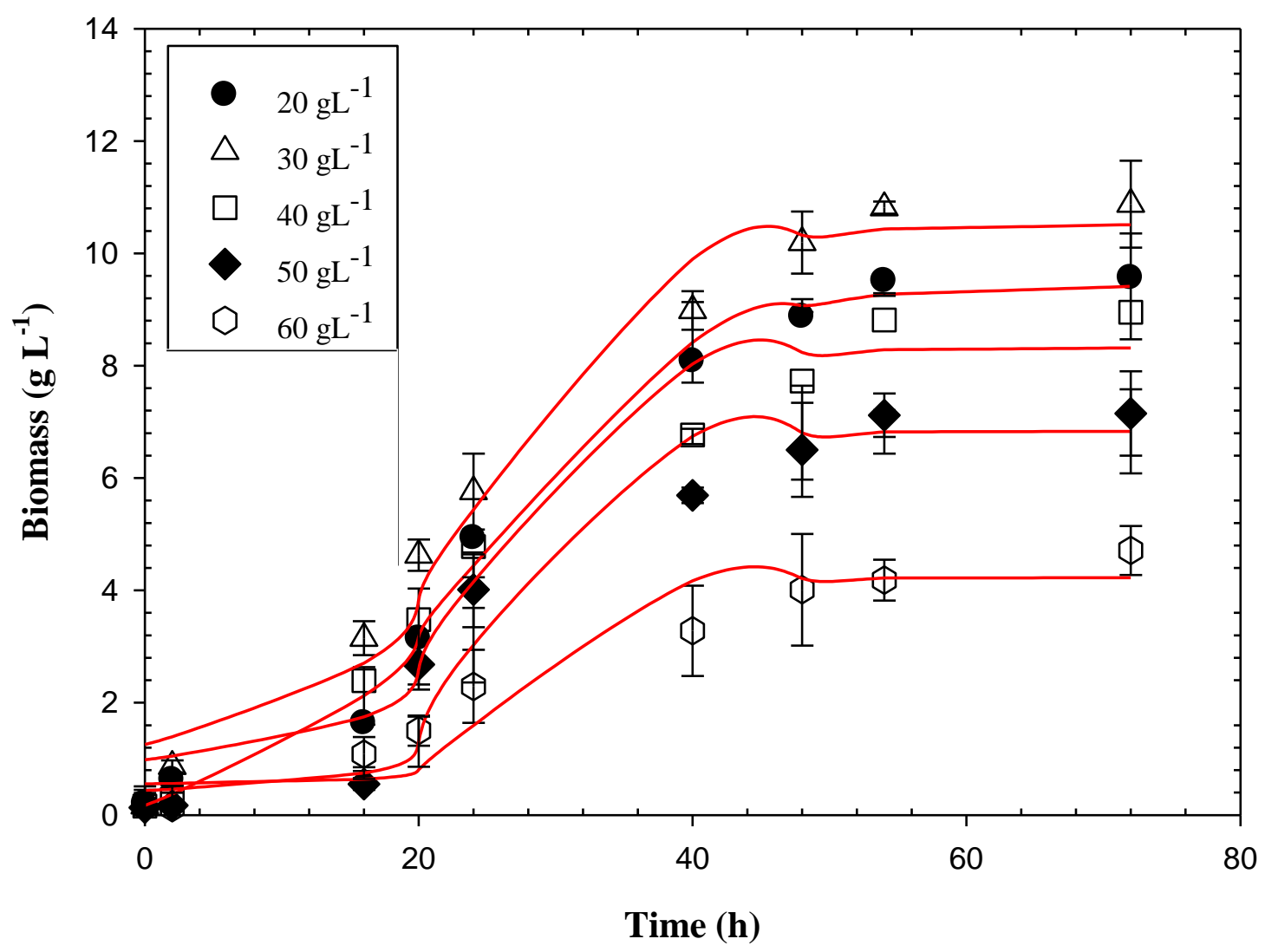

Figure 4.5. Kinetics of $Y$. lipolytica growth at different initial glucose concentration in baffled Erlenmeyer flasks at $200 \mathrm{rpm}$ and $30{ }^{\circ} \mathrm{C}$. Experimental (symbols), logistic (-). Error bars represent the standard deviation of triplicate experiments.

Experimental values of biomass production were adjusted to the integral form of the logistic model [16] using Excel Solver function (Equation 1).

$X(t)=\frac{X \max }{1+\left(C * e^{-\mu t}\right)}$

Where $X$ is the biomass production calculated at time $\mathrm{t}\left(\mathrm{g} \mathrm{L}^{-1}\right) ; X_{\max }$ is the maximum biomass production and it is achieved at the end of the culture $\left(\mathrm{g} \mathrm{L}^{-1}\right) ; \mu$ is specific biomass production rate $\left(\mathrm{h}^{-1}\right)$ and $\mathrm{t}$ is the time (h). Figure 4.5 displays biomass production fitted through logistic model. 
In Table 4.1 the kinetic parameters estimated by the diverse growth kinetics are observed.

Table 4.1. Kinetic parameters estimated by the logistic model with different glucose concentrations.

\begin{tabular}{llllll}
\hline Parameter & $\mathbf{2 0} \mathbf{g ~ L}^{-\mathbf{1}}$ & $\mathbf{3 0} \mathbf{g ~ L}^{-\mathbf{1}}$ & $\mathbf{4 0} \mathbf{g ~ L}^{-\mathbf{1}}$ & $\mathbf{5 0} \mathbf{g ~ L}^{-\mathbf{1}}$ & $\mathbf{6 0} \mathbf{g ~ L}^{-\mathbf{1}}$ \\
\hline $\mathbf{X o}\left(\mathbf{g ~ L}^{-\mathbf{1}}\right)$ & 0.28 & 1.20 & 0.58 & 0.21 & 0.46 \\
$\mathbf{X}_{\max }\left(\mathbf{g ~ L}^{-\mathbf{1}}\right)$ & 9.42 & 11.78 & 9.34 & 7.22 & 6.09 \\
$\boldsymbol{\mu}\left(\mathbf{h}^{-\mathbf{1}}\right)$ & 0.14 & 0.45 & 0.45 & 0.76 & 0.48 \\
$\mathbf{Y}_{(\mathrm{x} / \mathrm{s})}$ & 0.48 & 0.43 & 0.23 & 0.15 & 0.08 \\
\hline
\end{tabular}

The maximum concentration of biomass $\left(11.5 \mathrm{~g} \mathrm{~L}^{-1}\right)$ was obtained using a concentration of $30 \mathrm{~g}$ of glucose $\mathrm{L}^{-1}$ with a biomass/substrate yield, $\mathrm{Y}_{\mathrm{X} / \mathrm{S}}$, of 0.48 . This yield was major than that obtained with $20 \mathrm{~g}$ of glucose $\mathrm{L}^{-1}\left(\mathrm{Y}_{\mathrm{X} / \mathrm{S}}=0.43\right)$. Hence, further experiments were carried out using $30 \mathrm{~g}$ of glucose $\mathrm{L}^{-1}$. Tsigie et al. [11] worked with $Y$. lipolytica for maximum biomass production using fermentable sugars as a carbon source in shaken flasks at $150 \mathrm{rpm}$, $26^{\circ} \mathrm{C}$ and a $\mathrm{pH}$ of 6.5 . The authors obtained $8.76 \mathrm{~g}$ of biomass $\mathrm{L}^{-1}$ using $20 \mathrm{~g}$ of sugars $\mathrm{L}^{-1}$ after three days, and the concentration of biomass was increased up to $10.75 \mathrm{~g}$ of biomass $\mathrm{L}^{-}$ ${ }^{1}$ when using $30 \mathrm{~g}$ of sugars $\mathrm{L}^{-1}$. Above this concentration of sugars, substrate inhibition was observed. It is well known that glucose has important effects on the regulation of carbon metabolism and other properties in yeast cells. In the presence of glucose, inductors and individual genes are subject to repression.

The effect of biomass concentration on the bioconversion process in the three-phase partitioning bioreactor was observed using $30 \mathrm{~g}$ of glucose $\mathrm{L}^{-1}$. Maximum biomass production (11.70 $\left.\mathrm{g} \mathrm{L}^{-1}\right)$ was reached at $33 \mathrm{~h}$ of growth (Figure 4.6). At this time, orange essential oil $(50 \% \mathrm{v} / \mathrm{v})$ was added to the bioreactor when approximately $10 \mathrm{~g}$ of glucose $\mathrm{L}^{-1}$ still remained in the culture medium. It was also observed that the percentage of viable cells decreased, reaching $50 \%$ after $60 \mathrm{~h}$ and $30 \%$ at the end of the bioconversion process. 


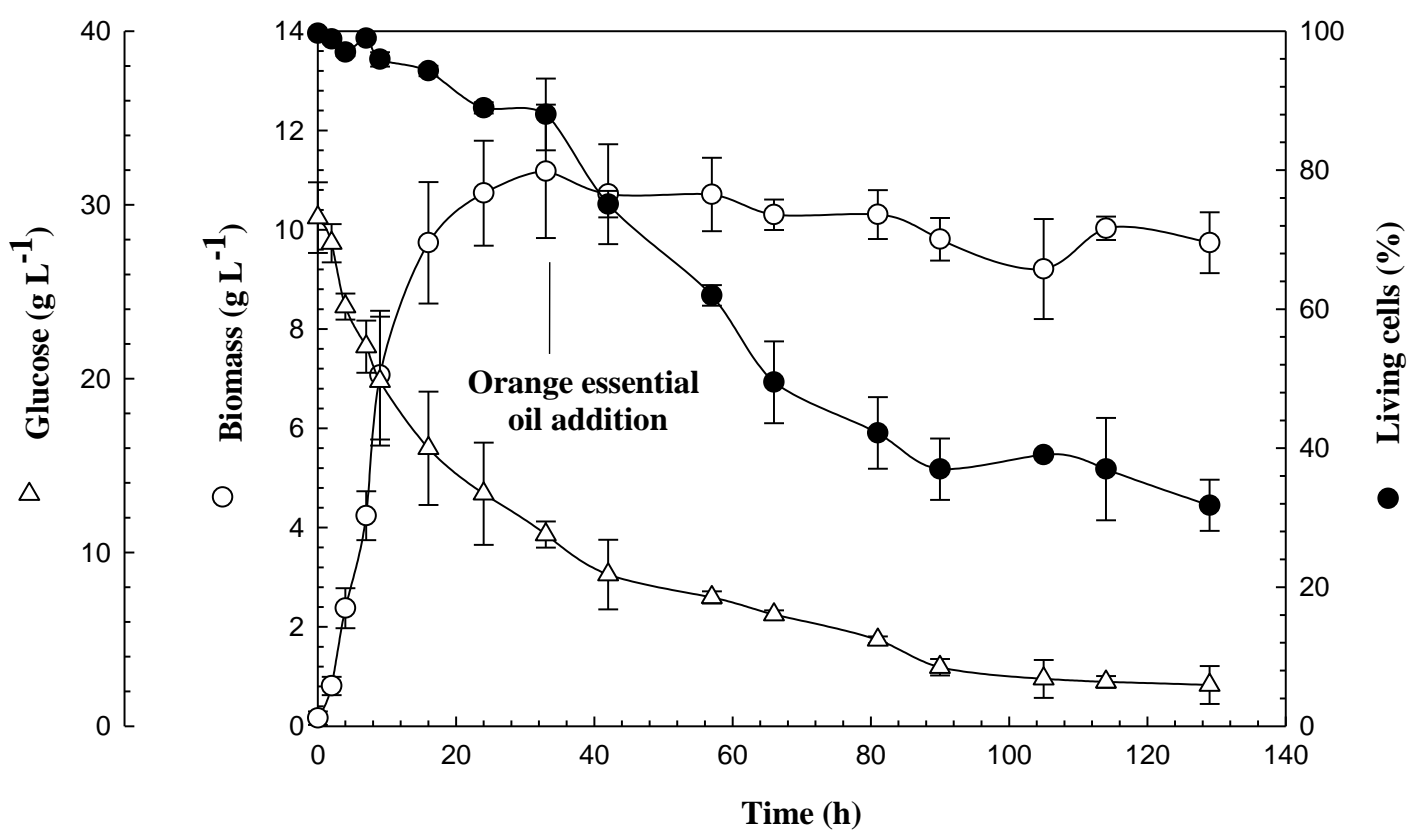

Figure 4.6. Kinetics of cell growth, glucose consumption, and cell viability in the three phasic system. $50 \% \mathrm{v} / \mathrm{v}$ orange essential oil (3.2 $\mathrm{g}$ of $(+)$-valencene $\left.\mathrm{L}^{-1}\right)$ were added for the bioconversión.

Once again, this slight increase in the percentage of viable cells was not statistically different to the value obtained when $20 \mathrm{~g}$ of glucose $\mathrm{L}^{-1}$ was used. However, the production of (+)nootkatone (Figure 4.7) peaked at $326.34 \mathrm{mg} \mathrm{L}^{-1}$ in the organic phase at $96 \mathrm{~h}$, with a bioconversion of $39.08 \%$, showing a statistical difference with respect to maximum (+)nootkatone concentration. 


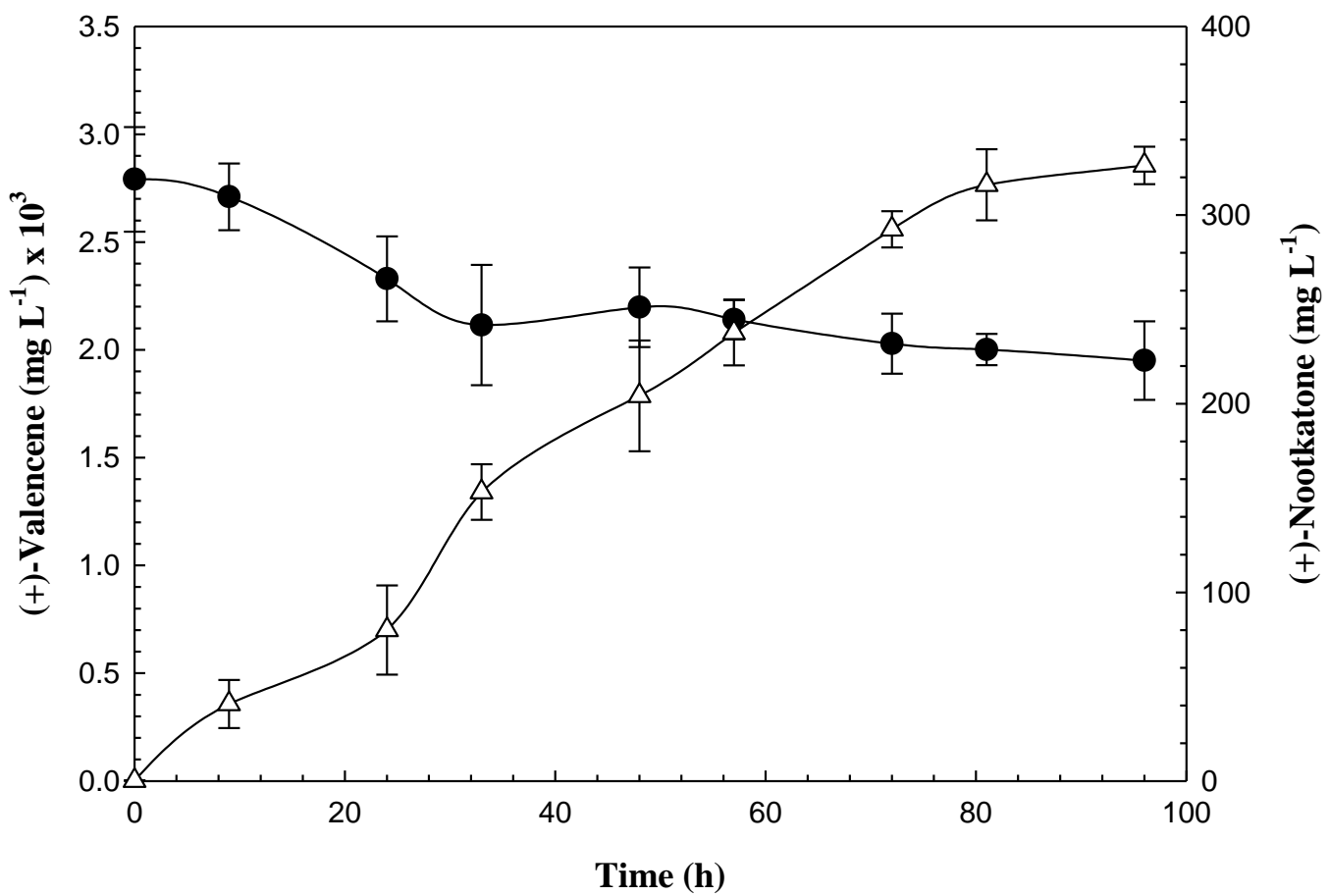

Figure 4.7. Bioconversion of (+)-valencene to (+)-nootkatone in a three phasic system using $Y$. lipolytica. Zero time corresponds to the 33 hours of growth.

Besides, it was observed that cell viability value in the three-phasic system was $10 \%$ lower than the value observed in the biphasic system (Figure 4.1); however, there was no statistical difference. Therefore, unknown components in the orange essential oil might not be as toxic as expected at the concentration used.

Specifically, in both biphasic and three-phasic systems studied in this work, after $48 \mathrm{~h}$, the bioconversion process reached a stationary phase, indicating that there was a limiting factor in the production of (+)-nootkatone. Likely due to the loss of cell viability, alteration in the transport mechanism through the cell membrane, accumulation of intermediaries of the bioconversion reaction in the endo-membranes, or excessive product formation to potentially toxic levels. On the other hand, it has been reported that (+)-nootkatone production is inhibited by the intermediary nootkatol, which is an inhibitor of the P450 enzymes [18]. This phenomenon may explain the low efficiency of bioconversion. It was observed a plateau in all bioconversions after $72 \mathrm{~h}$ of process. Recently, several authors have reported on microbial 
bioconversion of (+)-valencene to (+)-nootkatone using genetically modified yeast strains of Saccharomyces cerevisiae [7] and Pichia pastoris [19]. Gavira et al. [7] performed optimization of a bioconversion process using a recombinant yeast expressing CYP71D51v2 from tobacco and a P450 reductase from Arabidopsis. Yeast cells were cultivated for $24 \mathrm{~h}$ in the presence of increasing concentrations of $(+)$-valencene, $\beta$-nootkatol and (+)-nootkatone. The authors claimed that (+)-valencene was tolerated at concentrations up to $4 \mathrm{~g} \mathrm{~L}^{-1}$, with a recovery of $73 \%$ of viable cells after $24 \mathrm{~h}$. On the other hand, $\beta$-nootkatol and (+)-nootkatone led to a loss of cell viability at $1 \mathrm{~g} \mathrm{~L}^{-1}$, with $45 \%$ viability already lost at $100 \mathrm{mg} \mathrm{L}^{-1}$ in the case of $\beta$-nootkatol. The possible reasons for the observed bioconversion efficiency to (+)nootkatone include: a) the toxicity of products formed, b) accumulation of $\beta$-nootkatol in the endo-membranes of yeast, c) inhibition of the CYP71D51v2 hydroxylation reaction by the products, and d) the fact that the formation of nootkatone from $\beta$-nootkatol is not dependent from cytochrome P450, but it is catalysed by an unidentified enzyme in yeast [7]. There are few reports characterizing the process in a multiphasic partitioning bioreactor.

Wriessnegger et al. [20] generated by metabolic engineering a strain of Pichia pastoris coexpressing the premnaspirodiene oxygenase of Hyoscyamus muticus (HPO) and the Arabidopsis thaliana cytochrome $\mathrm{P} 450$ reductase (CPR) that hydroxylated extracellularly added (+)-valencene. Intracellular production of $(+)$-valencene by co-expression of valencene synthase from Callitropsis nootkatensis resolved the phase-transfer issues of (+)valencene. Biphasic cultivations of $P$. pastoris resulted in the production of trans-nootkatol, which was oxidized to (+)-nootkatone by an intrinsic $P$. pastoris activity. The over expression of a $P$. pastoris alcohol dehydrogenase and truncated hydroxy-methylglutarylCoA reductase (tHmg1p) enhanced, significantly, the (+)-nootkatone yield to $208 \mathrm{mg} \mathrm{L}^{-1}$ with $0.5 \mathrm{~g} \mathrm{~L}^{-1}$ of (+)-valencene in fed-batch cultivations after $108 \mathrm{~h}$. The (+)-nootkatone was recovered in situ using $10 \%(\mathrm{v} / \mathrm{v})$ of n-dodecane as organic phase. Girhard at al. [14] also studied this bioconversion process using a two-phase system with $10 \%$ dodecane as the organic phase in a stirred tank bioreactor with a recombinant strain of Escherichia coli. An initial concentration of $409 \mathrm{mg}$ of (+)-valencene $\mathrm{L}^{-1}$ was used in a relatively short time (8 h), $94.2 \mathrm{mg}$ of (+)-nootkatone $\mathrm{L}^{-1}$ was produced with a total bioconversion of $23 \%$. As much as $80 \%$ cell death was also observed using other organic solvents, such as isooctane and n- 
octane, due to the significant toxicity of these solvents. In contrast, cell viability remained at $90 \%$ during the bioconversion process upon use of the organic solvent dodecane.

Fungi extracellular enzymes have been described for the bioconversion of (+)-valencene. Fraatz et al. [4] confirmed the dioxygenase nature of the enzyme of Pleurotus sapidus that catalyze (+)-valencene oxidation. The isolation and identification of two allylic (+)valencene derived hydroperoxides together with homology data from amino acid sequencing suggested a lipoxygenase-like type of enzyme [21].

To our knowledge our research group is the first one reporting a wild type $Y$. lipolytica with the enzymatic machinery to carry out this bioconversion. It has been shown that, the alkaneassimilating yeast Yarrowia lipolytica degrades very efficiently hydrophobic substrates such as n-alkanes, fatty acids, fats and oils for which it has specific metabolic pathways [22]. In this regard, cell hydrophobicity must be considered as a key criterion to select effective microorganisms for three-phase partitioning bioreactors devoted to transform hydrophobic substrates [23].

After (+)-valencene bioconversion in biphasic and three-phasic system, analysis by GC revealed several new peaks as well as the substrate peak (Figure 4.8). Based on predicted fragmentation and comparison to authentic reference compounds, three peaks were identified as $(+)$-valencene (retention time, $\left.t_{R}=8.9 \mathrm{~min}\right)$, nootkatol $\left(t_{R}=10.9 \mathrm{~min}\right)$ and $(+)$-nootkatone $\left(t_{R}=12.8 \mathrm{~min}\right)$. In the chromatogram of the three-phasic system, it is observed that some peaks present in the orange essential oil increased after bioconversion, and new peaks were observed with different retention times to those existing in the orange essential oil, possibly representing products of over-oxidation.

The performance of the bioconversion process in both biphasic and three-phasic systems was analysed in terms of reaction rate, volumetric productivity and product/biomass yield, and nootkatone maximum concentration (Table 4.2). At similar biomass concentrations using 20 $\mathrm{g}$ of glucose $\mathrm{L}^{-1}$, there was a non-significant statistical difference for all of the values obtained. The highest mean values were obtained in the biphasic system when non-inhibitory 
initial concentrations of (+)-valencene were used. Girhard et al. [14] observed a similar trend in bioconversion per cent and volumetric productivity; for instance: for the biphasic system, $24.7 \%$ and $12.97 \mathrm{mg}$ of nootkatone $\mathrm{L}^{-1} \mathrm{~h}^{-1}$, and for the triphasic system, $23 \%$ and $11.77 \mathrm{mg}$ of nootkatone $\mathrm{L}^{-1} \mathrm{~h}^{-1}$, respectively. These volumetric productivity values are as much as 4fold greater than those observed in the current work. However, volumetric productivity reported by Girhard et al. [14] accounted for the production of both nootkatol and (+)nootkatone, while the current study only investigated (+)-nootkatone concentration.

In the three-phasic system, volumetric productivity $\left(3.58 \mathrm{mg} \mathrm{L}^{-1} \mathrm{~h}^{-1}\right)$ was only $15 \%$ lower than that of the biphasic system $\left(4.19 \mathrm{mg} \mathrm{L}^{-1} \mathrm{~h}^{-1}\right)$. Nevertheless, adding $50 \% \mathrm{v} / \mathrm{v}$ of orange essential oil with an initial $30 \mathrm{~g}$ of glucose $\mathrm{L}^{-1}$, resulted in a $7.3 \%$ reduction in volumetric productivity after $96 \mathrm{~h}$ of bioconversion due to the increase in $Y$. lipolytica 2.2ab biomass. Alcohol and ketone sesquiterpenes differ from acids, such as artemisinic acid, which get trapped in the outer surface of the cell wall of yeast under conditions of acid fermentation [24], in that they do not accumulate in the endo-membranes or exhibit considerable toxicity to yeast [18]. Accumulation of $\beta$-nootkatol in yeast membranes and binding to the active site of the enzyme CYP71D51v2 by differential spectrophotometry strongly support that inhibition of the enzyme during the process of bioconversion [7].

Comparing both three-phasic systems (20 and $30 \mathrm{~g}$ of glucose $\left.\mathrm{L}^{-1}\right)$, it can be observed that by using an initial amount of $30 \mathrm{~g}$ of glucose $\mathrm{L}^{-1}$, an increment of $16.44 \%$ in volumetric productivity after $96 \mathrm{~h}$ of bioconversion was evident due to the increase in $Y$. lipolytica biomass. A similar tendency was observed with maximum nootkatone concentration obtained. Despite the fact that the nootkatone/biomass yield was lower in the three-phasic system using $30 \mathrm{~g}$ of glucose $\mathrm{L}^{-1}\left(27.89 \mathrm{mg} \mathrm{g}^{-1}\right)$, this yield was 21.8 times higher than that (1.28 $\left.\mathrm{mg} \mathrm{g}^{-1}\right)$ observed by Girhard et al. [14] under optimized conditions using recombinant E. coli with $10 \%$ dodecane and $409 \mathrm{mg}$ of $(+)$-valencene $\mathrm{L}^{-1}$. A primary drawback mentioned by the authors was the accumulation of high concentrations of $\beta$-nootkatol in cellular membranes, leading to alterations in membrane permeability, as well as the function of integral proteins, similar to that which has been observed with other hydrocarbons that are concentrated in membranes [25,26]. Accumulation of products, in particular $\beta$-nootkatol is thus likely to be an important factor limiting rates and yields during the process of bioconversion [7]. 


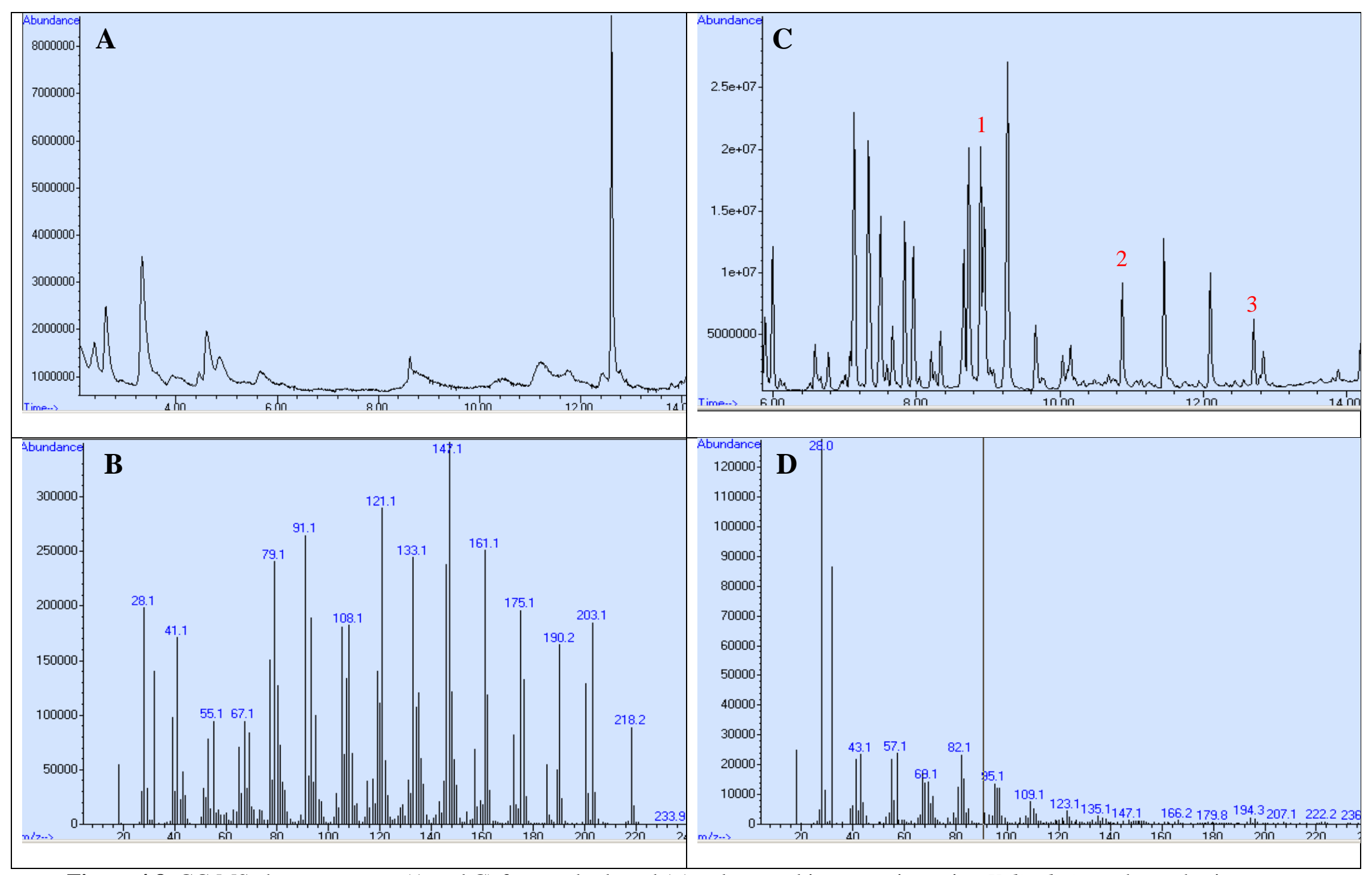

Figure 4.8. GC-MS chromatograms (A and C) for standards and (+)-valencene bioconversion using Y. lipolytica a three-phasic system, respectively. And mass fragmentation patterns (B and D) for (+)-nootkatone as a standard and after the bioconversion. (+)-valencene (1), (+)nootkatone (2), nootkatol (3). 
Table 4.2. Bioconversion performance of (+)-valencene to (+)-nootkatone by $Y$. lipolytica at $30^{\circ} \mathrm{C}$

\begin{tabular}{|c|c|c|c|c|c|c|}
\hline System & $\begin{array}{c}\text { Biomass } \\
\left(\mathrm{g} \mathrm{L}^{-1}\right)\end{array}$ & $\begin{array}{c}\text { Reaction rate } \\
\left(\mathrm{mg} \text { nootkatone } \mathrm{L}^{-1} \mathrm{~h}^{-1}\right)^{\mathrm{iii}}\end{array}$ & $\begin{array}{c}\text { Bioconversion } \\
(\%)^{\mathrm{ii}}\end{array}$ & $\begin{array}{l}\text { Volumetric } \\
\text { productivity } \\
\left(\mathrm{mg} \mathrm{L}^{-1} \mathrm{~h}^{-1}\right)^{\mathrm{iii}}\end{array}$ & $\begin{array}{c}\text { Nootkatone/Biomass } \\
\text { Yield } \\
\left(\mathrm{mg} \mathrm{g}^{-1}\right)\end{array}$ & $\begin{array}{l}\text { Maximum } \\
\text { Nootkatone } \\
\left(\mathrm{mg} \mathrm{L}^{-1}\right)^{\mathrm{iv}}\end{array}$ \\
\hline $\begin{array}{l}\text { Biphasic } \\
\left(30 \mathrm{~g} \mathrm{~L}^{-1}\right)^{\mathrm{i}, \mathrm{v}}\end{array}$ & $11.40 \pm 0.98$ (a) & $3.90 \pm 0.20(b)$ & $35.67 \pm 6.77(a, b)$ & $3.63 \pm 0.13(a, b)$ & $30.63 \pm 1.3(\mathrm{a}, \mathrm{b})$ & $348.5 \pm 13.06$ (a) \\
\hline $\begin{array}{l}\text { Three-phasic } \\
\left(20 \mathrm{~g} \mathrm{~L}^{-1}\right)^{\mathrm{i}, \mathrm{v}}\end{array}$ & $9.28 \pm 0.06(b)$ & $5.23 \pm 1.90(\mathrm{a})$ & $31.93 \pm 18.0(a, b)$ & $2.92 \pm 0.14(\mathrm{a})$ & $30.20 \pm 1.6(\mathrm{a}, \mathrm{b})$ & $280.3 \pm 13.7(b)$ \\
\hline $\begin{array}{l}\text { Three-phasic } \\
\left(30 \mathrm{~g} \mathrm{~L}^{-1}\right)^{\mathrm{i}, \mathrm{v}}\end{array}$ & $11.70 \pm 1.41$ (a) & $4.99 \pm 1.75$ (a) & $39.08 \pm 12.23$ (a) & $3.40 \pm 0.10(\mathrm{a})$ & $27.89 \pm 3.1(b)$ & $326.3 \pm 9.9(\mathrm{a})$ \\
\hline
\end{tabular}

${ }^{\mathrm{i}}$ Concentration of initial glucose in the growth medium of $Y$. lipolytica.

ii Percentage of (+)-nootkatone produced relative to (+)-valencene consumed based on molecular masses.

iii $\mathrm{mg}$ of nootkatone $\mathrm{L}^{-1}$ produced between 24 and $48 \mathrm{~h}$.

${ }^{\text {iv }} \mathrm{mg}$ of maximum nootkatone $\mathrm{L}^{-1}$ produced after $96 \mathrm{~h}$.

${ }^{\mathrm{v}}$ values represent mean \pm standard deviation.

Same letters in the same column represent no significant differences $(\mathrm{p} \leq 0.05$; Tukey, SAS System Version 9). 
Based on the aforesaid, some strategies to improve the bioconversion process have been revised and could be studied in future investigations. Some of them include expressing a specific dehydrogenase in $Y$. lipolytica to oxidize nootkatol to nootkatone, thus regenerating $\mathrm{NADH}$, which can also reduce metabolic stress in the strain [7]. Another alternative is to increase the permeability of the cell membrane using a solvent and a selective transporter of nootkatol and (+)-nootkatone in order to avoid toxic product accumulation in the endomembranes.

\subsection{CONCLUSIONS}

The addition of a second liquid phase (orange essential oil) for the oxidation of (+)-valencene to (+)-nootkatone by the yeast $Y$. lipolytica $2.2 \mathrm{ab}$ in a stirred tank partitioning bioreactor represents a potential application for in situ extraction of (+)-nootkatone. A higher concentration of biomass $\left(11.5 \mathrm{~g} \mathrm{~L}^{-1}\right)$ and final cell viability (30\%) was achieved by using a concentration of $30 \mathrm{~g}$ of glucose $\mathrm{L}^{-1}$ as carbon source. Under this conditions, a (+)-nootkatone production of $285 \mathrm{mg} \mathrm{L}^{-1}$ with $33.6 \%$ of bioconversion, was observed. The three phase bioconversion system used provides easy control and scalability, presenting an attractive approach for production and in situ recovery of (+)-nootkatone.

\section{References}

[1] T.A. Haring., F. Rijkens, H. Boelens, A. Van der Gen, Olfactory studies on enantiomeric eremophilane sesquiterpenoids, J. Agric. Food Chem. 20 (1972) 1018-1021.

[2] C.W. Wilson III, P.E. Shaw, Synthesis of nootkatone from valenceno. J. Agric. Food Chem. 26 (1978) 1430-1432.

[3] J.A.R. Salvador, J.H. Clark, The allylic oxidation of unsaturated steroids by tert-butyl hydroperoxide using surface functionalized silica supported metal catalysts, Green Chem. 4 (2002) 352-356.

[4] M.A. Fraatz, R.G. Berger, H. Zorn, Nootkatone-a biotechnological challenge, Appl. Microbiol. Biotechnol. 83 (2009) 35-41.

[5] A. Schmid, J.S. Dordick, B. Hauer, A. Kiene, M. Wubbolts, B. Witholt, Industrial biocatalysis today and tomorrow, Nature 409 (2001) 258-266.

[6] P. Tufvesson, W. Fu, J.J. Skibsted J.M. Woodley, Process considerations for the scale-up and implementation of biocatalysis, Food Bioprod. Process. 88 (2010) 3-11. 
[7] C. Gavira, R. Höfer, A. Lesot, F. Lambert, J. Zucca, D. Werck-Reichhart, Challenges and pitfalls of P450-dependent (+)-valencene bioconversion by Saccharomyces cerevisiae, Metab. Eng. 18 (2013) 25-35.

[8] G. De Gonzalo, C. Rodriguez, A. Rioz-Martinez, V. Gotor, Improvement of the biocatalytic properties of one phenylacetone monooxygenase mutant in hydrophilic organic solvents, Enzyme Microb. Technol. 50 (2012) 43-49.

[9] S. Oppermann, F. Stein, U. Kragl, Ionic liquids for two-phase systems and their application for purification, extraction and biocatalysis, Appl. Microbiol. Biotechnol. 89 (2011) 493-499.

[10] D. Torres-Martinez, R. Melgarejo-Torres, M. Gutierrez-Rojas, L. Aguilera-Vazquez, M. Micheletti, G.J. Lye, S. Huerta-Ochoa, Hydrodynamic and oxygen mass transfer studies in a three-phase (air-water-ionic liquid) stirred tank bioreactor, Biochem. Eng. J. 45 (3) (2009) 209217.

[11] Y.A. Tsigie, Ch-Y. Wang, N.S. Kasim, Quy-Do Diem, Lien-Huong Huynh, Quoc-Phong Ho, Chi-Thanh Truong and Yi-Hsu Ju, Oil Production from Yarrowia lipolytica Po1g Using Rice Bran Hydrolysate, J. Biomed. Biotechnol. 1 (2012) 1-10.

[12] G.L. Miller, R. Blum, W.E. Glennon, and A.L. Burton, Measurement of Carboxymethylcellulase Activity, Anal. Biochem. 2 (1960) 127-132.

[13] A. Bonora, D. Mares, A Simple Colorimetric Method for Detecting Cell Viability in Cultures of Eukaryotic Microorganisms, Curr. Microbiol. 7 (1982) 217-222.

[14] M. Girhard, K. Machida, M. Itoh, R. Schmid, A. Arisawa and V. Urlacher, Regioselective biooxidation of (+)-valencene by recombinant E. coli expressing CYPI09BI from Bacillus subtilis in a two-liquid-phase system, Microbial Cell Factories, 8 (2009) 1-12.

[15] Kaspera R, Krings U, Nanzad T, Berger RG. Bioconversion of (+)-valencene in submerged cultures of the ascomycete Chaetomium globosum. Appl Microbiol Biotechnol 2005;67:477483.

[16] Hamidi-Esfahani, Z., Shojaosadati, S.A. and Rinzema, A. Modelling of simultaneous effect of moisture and temperature on A. níger growth in solid-state fermentation. Biochem. Eng. J. 2004; $21: 265$.

[17] Ghezelbash GR, Nahvi I, Rabbani M. Study of polyols production by Y. lipolytica in batch culture and optimization of growth condition for maximum production. Jundishapur J Microbiol 2012;5:546-549.

[18] D.K. Ro, M. Ouellet, E.M. Paradise, H. Burd, D. Eng, C.J. Paddon, J.D. Newman, J.D., Keasling, Induction of multiple pleiotropic drug resistance genes in yeast engineered to produce an increased level of anti-malarial drug precursor, artemisinic acid, BMC Biotechnol. 8 (2008) 83. 
[19] Liu Y, Li F, Hu W, Wiltberger K, Ryll T. Effects of bubble-liquid two-phase turbulent hydrodynamics on cell damage in sparged bioreactor. Biotechnol Prog 2014;30:48-58.

[20] Tassaneeyakul W, Guo LQ, Fukuda K, Ohta T, Yamazoe Y. Inhibition selectivity of grape fruit juice components on human cytochromes P450. Arch Biochem Biophys 2000;378:356-363.

[21] Wriessnegger T, Augustin P, Engleder M, Leitner E, Müler M, Kaluzna I, Schümann M, Mink E, Zellnig G, Schwab H, Pichler H. Production of the sesquiterpenoid (+)-nootkatone by metabolic engineering of Pichia pastoris. Metabolic Engineering. 2014;24:18-29.

[22] Krügener S, Krings U, Zorn H, Berger RG. A dioxygenase of Pleurotus sapidus transforms (+)valencene regio-specifically to (+)-nootkatone via a stereo-specific allylic hydroperoxidation. Bioresour Technol 2010;101:457-462.

[23] Fickers P, Benetti PH, Waché Y, Marty A, Mauersberger S, Smit MS, Nicaud JM. Hydrophobic substrate utilisation by the yeast Yarrowia lipolytica, and its potential applications. FEMS Yeast Res 2005;5:527-543.

[24] Muñoz R, Daugulis AJ, Hernández M, Quijano G. Recent advances in two-phase partitioning bioreactors for the treatment of volatile organic compounds. Biotech Adv 2012;30:1707-1720.

[25] Sikkema J, De Bont JA, Poolman B. Interactions of cyclic hydrocarbons with biological membranes. J Biol Chem 1994;269:8022-8028.

[26] Sikkema J, De Bont JA, Poolman B. Mechanisms of membrane toxicity of hydrocarbons. Microbiol Rev 1995;59:201-222. 


\section{CHAPTER V}

WHOLE CELL BIOCONVERSION OF (+)-VALENCENE TO (+)-NOOTKATONE BY YARROWIA LIPOLYTICA USING A THREE PHASE PARTITIONING BIOREACTOR

D.M. Palmerín-Carreño, C.O. Castillo-Araiza, O.M. Rutiaga-Quiñones, J.R. Verde Calvo, G.M. Trejo-Aguilar, Abhishek Dutta, S. Huerta-Ochoa*

Journal of Chemical Technology and Biotechnology (2015), http://onlinelibrary.wiley.com/doi/10.1002/jctb.4702/pdf 


\title{
WHOLE CELL BIOCONVERSION OF (+)-VALENCENE TO (+)-NOOTKATONE BY YARROWIA LIPOLYTICA USING A THREE PHASE PARTITIONING BIOREACTOR
}

\author{
D.M. Palmerín-Carreño ${ }^{a}$, C.O. Castillo-Araiza ${ }^{\mathrm{b}}$, O.M. Rutiaga-Quiñones ${ }^{\mathrm{c}}, \mathrm{J}^{\mathrm{R}}$.R. Verde \\ Calvo $^{\mathrm{a}}$, G.M. Trejo-Aguilar ${ }^{\mathrm{a}}$, Abhishek Dutta $^{\mathrm{d}, \mathrm{e}}$, S. Huerta-Ochoa ${ }^{\mathrm{a}^{*}}$ \\ aDepartamento de Biotecnología, Universidad Autónoma Metropolitana. \\ P.A. 55-535, 09340 Iztapalapa, México D.F., MÉXICO, sho@xanum.uam.mx \\ ${ }^{\text {b }}$ Grupo de Procesos de Transporte y Reacción en Sistemas Multifásicos. Dpto. de IPH, Universidad \\ Autónoma Metropolitana. P.A. 55-535, 09340 Iztapalapa, México D.F., México. coca@ xanum.uam.mx \\ 'Departamento de Química-Bioquímica, Instituto Tecnológico de Durango, Durango. e-mail: \\ omrutiaga@itdurango.edu.mx \\ ${ }^{\mathrm{d}}$ Faculteit Industriële Ingenieurswetenschappen, KU Leuven, Campus Groep T Leuven, \\ Andreas Vesaliusstraat 13, B-3000 Leuven, Belgium. \\ ${ }^{\text {e}}$ Departement Materiaalkunde, KU Leuven, Kasteelpark Arenberg 44 bus 2450, B-3001 Heverlee-Leuven, \\ Belgium.
}

\begin{abstract}
Low permeability of substrates across the cell membrane, cofactor regeneration and product inhibition are some drawbacks during (+)-nootkatone bioconversion. The aim of this work was to evaluate and enhance the bioconversion of (+)-valencene to (+)-nootkatone with Yarrowia lipolytica in a partitioning bioreactor using orange essential oil as the dispersed phase. Preliminary experiments in shake flasks allowed enhancing (+)nootkatone bioconversion to obtain favorable operating conditions $(0.2 \% \mathrm{w} / \mathrm{v}$ of CTAB and $2.0 \mathrm{mM}$ of niacin and $11.5 \mathrm{~g} \mathrm{~L}^{-1}$ of biomass) to produce $420.9 \mathrm{mg} \mathrm{L}^{-1}$. Bioreactor experiments in a two-phase system using $0.2 \%$ $(\mathrm{w} / \mathrm{v})$ of CTAB, $2.0 \mathrm{mM}$ of niacin and $22.5 \mathrm{~g} \mathrm{~L}^{-1}$ of biomass produced a maximum (+)-nootkatone concentration of $619.8 \mathrm{mg} \mathrm{L}^{-1}$ which was around the product inhibition concentration. Nevertheless, the partitioning threephase system using orange essential oil, overcome product inhibition obtaining concentrations of $852.3 \mathrm{mg} \mathrm{L}^{-}$ ${ }^{1}$. This is the first report of a wild type Y. lipolytica with the enzymatic machinery to carry out this bioconversion. Multiphase partitioning bioreactor conception seems to have a good potential in enhancing the productivity of $(+)$-nootkatone. The bioconversion approach presents an attractive way to produce and recover (+)-nootkatone in situ using a natural (+)-valencene source.
\end{abstract}

Keywords: Bioconversion, Partitioning bioreactor, (+)-nootkatone, orange essential oil, Yeast, Product inhibition 


\subsection{INTRODUCTION}

The compound (+)-nootkatone is a sesquiterpenoid which possesses an intense grapefruitlike taste and other valuable properties that are exploited by the fragrance and flavour industries. ${ }^{1}$ The production of (+)-nootkatone is performed via chemical synthesis, mainly from the sesquiterpene (+)-valencene, which is readily available from the orange industry and also through the use of environmentally unfriendly oxidising agents, such as tert-butyl peracetate $^{2}$ and tert-butyl hydroperoxide in combination with catalytic metal supported on silica. ${ }^{3}$ However, the resulting (+)-nootkatone produced via chemical synthesis cannot be marketed as a "natural" product and does not satisfy increasing market demands for natural aromatic compounds. In order to meet this demand, many efforts have been focussed on the use of biotechnological processes with bacteria, fungi or plants. ${ }^{4}$ Some researchers have investigated genetically modified microorganisms, and several published reviews ${ }^{5,6}$ have provided an overview of recently acquired knowledge about whole cell bioconversions and future industrial applications. Particularly, industry and academia are interested on a biocatalytic process using whole cells which involves the selection of an optimal cellular enzyme, reaction engineering, product recovery and scaling-up.

Gavira et al. ${ }^{7}$ reported a bioconversion process for (+)-nootkatone production using plant enzymes expressed in Saccharomyces cerevisiae. Nevertheless, the process was inhibited by both the substrate $\left(>4 \mathrm{~g} \mathrm{~L}^{-1}\right)$ and the product $\left(1.0 \mathrm{~g} \mathrm{~L}^{-1}\right)$ as well over-oxidation of (+)valencene. Wriessnegger et al. ${ }^{8}$ resolved the phase-transfer issues caused by the external addition of (+)-valencene using intracellular production of (+)-valencene by co-expression of valencene synthase from Callitropsis nootkatensis through two-phase cultivations of Pichia pastoris. Oppermann et al. ${ }^{9}$ reviewed the use of biocompatible organic solvents in two-phase systems and their application in purification, extraction and bioconversion. However, it must be noted that bioconversion productivity of sesquiterpenes in a multi-phase system can be limited by low mass transfer rates at interfaces (gas-liquid or liquid-liquid). Partitioning three-phase bioreactors (gas-liquid-liquid) for oxidative bioconversions ${ }^{10}$ have shown significant potential for improving the productivity of many biological processes by overcoming problems related to low solubility or the toxicity of substrates and products. ${ }^{11}$ In this regard, essential oils can be used as both substrate reservoir (dispersed phase) and in situ 
extraction agent in a partitioning bioreactor, thereby increasing the efficiency of the process. ${ }^{12}$ Essential oils are dominated by monoterpene hydrocarbons, which are regarded as process waste, mainly because of their low sensory activity, low water solubility and tendency to autoxidise and polymerise, ${ }^{13}$ which turns terpene hydrocarbons, such as limonenes, pinenes and sesquiterpinenes, into ideal starting materials for microbial transformations. Maróstica and Pastore ${ }^{14}$ previously used industrial waste orange essential oil as a source of R-(+)-limonene, in the biotransformation of $\mathrm{R}-(+)-\alpha$-terpineol with Fusarium oxysporum, obtaining a final yield of $450 \mathrm{mg} \mathrm{L}^{-1}$.

This work is aimed to evaluate the enhancement of (+)-nootkatone production from (+)valencene on a non-previously studied Yarrowia lipolytica yeast in a three-phase (aqueousorganic-air) partitioning bioreactor using orange essential oil as a cheap source of (+)valencene. As a first evaluation of the process, experiments using $1.0 \mathrm{~L}$ partitioning bioreactor were conducted in a three-phase system using orange essential oil as disperse phase. To enhance the bioconversion, experiments using baffled Erlenmeyer flasks were conducted to study the effect of cell membrane permeability and NADPH cofactor regeneration on (+)-nootkatone production. Then, the three-phase partitioning bioreactor was once more operated but at optimal operating conditions with the aim of elucidating the potential role of the essential oil overcoming bioconversion inhibition from either (+)nootkatone or (+)-valencene. Finally, in order to highlight results obtained from the three phase partitioning technology, $(+)$-nootkatone production is compared to that obtained from a conventional two-phase (aqueous-air) reactor wherein yeast inhibition takes place.

\subsection{MATERIALS AND METHODS}

\subsubsection{Chemicals}

(+)-valencene (CAS 75-05-6) and (+)-nootkatone (CAS 93-78-5) with a purity $>70 \%$ and $>85 \%$, respectively were purchased from Fluka (Switzerland) and used as standards. Ethyl acetate (99.5\%) used for sesquiterpene extraction was purchased from Quimex (México). Analytical grade orange essential oil (Citrus aurantium, var. Amara) was purchased from a local drugstore in Mexico DF) and used as an organic dispersed phase to carry out threephase bioconversion studies. 


\subsubsection{Microorganism, culture media and inoculum}

Yarrowia lipolytica was previously selected for its capability to convert (+)-valencene to (+)nootkatone from a screening among 6 selected strains (fungi and yeasts). Y. lipolytica was isolated from copra meal that was provided by the Laboratory of Bio-Process of the University of Guadalajara ( $\mathrm{U}$ de $\mathrm{G}$ ), Mexico. To the best of our knowledge, Y. lipolytica is used for the first time to study this bioconversion. This strain was previously sequenced in the Laboratory of Industrial Biotechnology of the National Polytechnic Institute (CBG-IPN), Mexico. The access in the National Center for Biotechnology Information (NCBI) is EF643594.1 18S ribosomal RNA gene, partial sequence; internal transcribed spacer 1, 5.8S ribosomal RNA gene, and internal transcribed spacer 2, complete sequence; and $28 \mathrm{~S}$ ribosomal RNA gene, partial sequence, identities $94 \%$ with $Y$. lipolytica strain LN-13. The strain was maintained in potato dextrose agar (PDA) at $4{ }^{\circ} \mathrm{C}$, and its cultivation was propagated in $125-\mathrm{mL}$ Erlenmeyer conical flasks containing $30 \mathrm{~mL}$ of PDA before being incubated at $30{ }^{\circ} \mathrm{C}$ for 4 days. Cells were harvested with $25 \mathrm{~mL} 0.01 \%$ Tween- 80 and used as inoculum during bioconversion experiments (stock solution). Culture medium for $Y$. lipolytica was composed of $\left(\mathrm{g} \mathrm{L}^{-1}\right)$ : Glucose, $30 ; \mathrm{Na}_{2} \mathrm{MoO}_{4}, 0.2 ; \mathrm{MnSO}_{4}, 0.4 ; \mathrm{FeCl}_{3}, 0.2 ; \mathrm{KI}$, $0.1 ; \mathrm{CuSO}_{4}, 0.04 ; \mathrm{H}_{2} \mathrm{BO}_{3}, 0.5 ; \mathrm{CaCl}_{2}, 0.1 ; \mathrm{NaCl}, 0.1 ; \mathrm{MgSO}_{4} * 7 \mathrm{H}_{2} \mathrm{O}, 0.5 ; \mathrm{KH}_{2} \mathrm{PO}_{4}, 1 ; \mathrm{ZnSO}_{4}$, 0.4; $\left(\mathrm{NH}_{4}\right)_{2} \mathrm{SO}_{4}, 5$; and yeast extract, 4.0. ${ }^{15}$ Prior to sterilization, the $\mathrm{pH}$ of culture medium was adjusted to 5.5 using $2 \mathrm{M} \mathrm{HCl}$. For experiments in baffled conical flasks, $100 \mu \mathrm{L}$ of $Y$. lipolytica cell suspension $\left(1 \times 10^{6}\right.$ cells $\left.\mathrm{mL}^{-1}\right)$ was added as inoculum to $100 \mathrm{~mL}$ of culture medium. Flasks were incubated at $30^{\circ} \mathrm{C}$ for 4 days on a rotary shaker at $200 \mathrm{rpm}$. For bioreactor experiments, $700 \mu \mathrm{L}$ of inoculum was added to $350 \mathrm{~mL}$ of sterile culture medium.

\subsubsection{Inhibition experiments}

To study the inhibition effect of (+)-valencene and (+)-nootkatone on the bioconversion process, experiments were carried out using baffled Erlenmeyer flasks at different initial concentrations of these components.

\subsubsection{Substrate inhibition}

Baffled Erlenmeyer flasks containing $100 \mathrm{~mL}$ of culture media were used during inhibition experiments. Each baffled Erlenmeyer flask was inoculated with $1 \times 10^{6}$ cells $\mathrm{mL}^{-1}$ and 
incubated for 4 days at $30{ }^{\circ} \mathrm{C}$. After these days, flasks were supplied with different concentrations of $(+)$-valencene $(0.05,0.1,0.2,0.3,0.4,0.6,0.8,1.0,1.5,2.0,3.2,4.5$ and 6 $\mathrm{g} \mathrm{L}^{-1}$ ) then incubated at $30^{\circ} \mathrm{C}$ for 4 days to allow time for the bioconversion process to occur. Every day, three baffled Erlenmeyer flasks were taken and centrifuged at $5000 \mathrm{rpm}$ for 10 min. All the experiments were conducted in triplicate. From the supernatant, sesquiterpene extraction was carried out by adding $500 \mu \mathrm{L}$ of ethyl acetate to $500 \mu \mathrm{L}$ of sample. The mixture was vortexed twice for $20 \mathrm{~s}$ in a vortex, and settled until phase separation occurred, after that $1 \mu \mathrm{L}$ of the ethyl phase was injected to Gas Chromatography (GC) in order to determine the concentration of (+)-valencene and (+)-nootkatone. ${ }^{16,17}$

\subsubsection{Product inhibition}

Baffled Erlenmeyer flasks containing $100 \mathrm{~mL}$ of culture media were used during inhibition experiments. Each baffled Erlenmeyer flask was inoculated with $1 \times 10^{6}$ cells $\mathrm{mL}^{-1}$ and incubated for 4 days at $30{ }^{\circ} \mathrm{C}$. After 4 days, flasks were supplemented with different initial concentrations of (+)-nootkatone: 50, 100, 200, 300, 400, 600 and $1000 \mathrm{mg} \mathrm{L}^{-1}$. The flasks were incubated for 4 days to carry out the bioconversion process. Control experiments containing sterile broth without inoculum were also conducted. Samples $(2.0 \mathrm{~mL})$ were taken every $24 \mathrm{~h}$, and the concentrations of (+)-valencene and (+)-nootkatone were determined. All the experiments were conducted in triplicate. Every day, three Erlenmeyer flasks were taken and centrifuged at $5000 \mathrm{rpm}$ for $10 \mathrm{~min}$. From the supernatant, (+)-valencene and (+)nootkatone were extracted and analysed as explained above.

\subsubsection{Cell membrane permeabilization and cofactor regeneration}

Two types of experiments were considered to enhance bioconversion and bio-selectivity of the desired product. On one hand, experiments of cell membrane permeabilization using Triton X-100 (0.05-1.0\% v/v), ${ }^{18}$ Cetyl trimethylammonium bromide (CTAB) $(0.1-0.4 \%$ $\mathrm{w} / \mathrm{v}),{ }^{19}$ and by sonication $(0.25-1.5 \mathrm{~h})^{20}$ were conducted in $250 \mathrm{~mL}$ Erlenmeyer flasks. On the other hand, experiments for the cofactor NADPH regeneration adding glycerol (0.05$1.0 \% \mathrm{v} / \mathrm{v})^{21}$ and vitamin $\mathrm{B}_{3}$ niacin $(0.5-10 \mathrm{mM})^{22}$ were conducted in Erlenmeyer flasks. Besides, two addition times were studied: when $Y$. lipolytica was inoculated and after 3 days of growth. The bioconversion began when $1.5 \mathrm{~g} \mathrm{~L}^{-1}$ of (+)-valencene (CAS 75-05-6) was 
added. Each experiment was performed in triplicate, with their respective positive control only adding (+)-valencene. The results were analyzed by the Tukey's HSD (Honestly Significant Difference) test $(\mathrm{p} \leq 0.05)$ using the SAS software (Version 9). A qualitative analysis was performed by GC/MS to determine the $\%$ of the intermediate (+)-nootkatol excreted to the reaction medium during the bioconversion.

\subsubsection{Analytical techniques}

\subsubsection{Biomass determination}

Biomass determination was carried out by measuring the dry weight of cells. Samples of 5.0 $\mathrm{mL}$ were dried to a constant weight in metal plates which had been previously weighed after being left in an oven at $90{ }^{\circ} \mathrm{C}$ overnight.

\subsubsection{Glucose consumption}

Glucose consumption of $Y$. lipolytica was determined by analyzing the glucose concentration in the medium using the dinitrosalicylic acid method described by Miller et al ${ }^{23}$ for reducing sugar, and a UV spectrophotometer at a wavelength of $550 \mathrm{~nm}$.

\subsubsection{Cell viability}

Cell viability during process including growth was determined by measuring the concentration of living cells using the methylene blue (MB) dye, as described by Bonora and Mares. ${ }^{24}$ Culture samples (around $5 \mathrm{~mL}$ ) were aseptically centrifuged at 8,000 rpm for 10 min. Cells were suspended and centrifuged in an equal amount of phosphate buffered saline pH 8 (PBS). PBS was used as a diluent. The MB dye was added to sample during 6 min and suspended again in PBS in the same conditions. The living cells were calculated using time course measurement mode at $640 \mathrm{~nm}$.

\subsubsection{Protein quantification}

Protein concentration released into the medium due to cell lysis was determined according to the procedure of Bradford, ${ }^{25}$ using bovine albumin serum as the standard. Maximum protein concentration was quantified via a cell rupture mechanical method as follow: a $5 \mathrm{~mL}$ stainless steel shaking flask (Sartorius Göttingen, Germany) containing $0.5 \mathrm{~g}$ of biomass with $0.2 \mathrm{~g}$ of 
glass pearls of $0.25 \mathrm{~mm}$ diameter was placed in a Mikro-Dismembrator U (Sartorius 37070 Göttingen, Germany) and agitation was kept for $10 \mathrm{~min}$, according to the technique described in Becerra et al. ${ }^{26}$

All the analyses were performed in triplicate

\subsubsection{Sesquiterpene analysis}

The concentrations of (+)-valencene and (+)-nootkatone were determined by gas chromatography (GC-FID) using a Perkin Elmer Auto System XL Gas Chromatograph equipped with a flame ionization detector (Cyclosil-B capillary column; $30 \mathrm{~m}$ x $0.32 \mathrm{~mm}$ x $0.25 \mu \mathrm{m} ; \mathrm{J}-\&-\mathrm{W}$ Scientific Inc., CA). The temperatures of the injector and detector were constant at $250{ }^{\circ} \mathrm{C}$ to $270{ }^{\circ} \mathrm{C}$, respectively. During the analysis $1 \mu \mathrm{L}$ of sample was automatically injected with a split ratio of 1:4, using helium gas as a carrier. The oven temperature was initially set to $120^{\circ} \mathrm{C}$ for 4 min then ramped up to $250{ }^{\circ} \mathrm{C}$ at a rate of $10^{\circ} \mathrm{C}$ per min and maintained at $250{ }^{\circ} \mathrm{C}$ for $5 \mathrm{~min}$, using the technique reported by Girhard et al. ${ }^{16}$ Analyses were performed in triplicate, and concentrations were determined using external calibration curves of (+)-valencene and (+)-nootkatone. GC/MS spectra were obtained using a GC/MS-HP6890 (Agilent) equipped with a HP-5 column (30 m x $250 \mu \mathrm{m}$ x $0.25 \mu \mathrm{m}$, Agilent). The same conditions of separation as for the GC-FID analysis were used. Compounds in the samples were identified by comparison of mass spectra with that of pure compounds.

\subsubsection{Stirred tank bioreactor for two-phase and three-phase bioconversions}

A glass 1.0 L stirred tank bioreactor (model ADI 1025, Applikon) was used for bioconversion processes. The bioreactor had an inside diameter of $9.5 \mathrm{~cm}$ and an operation volume of 0.7 $\mathrm{L}\left(\mathrm{H}_{\mathrm{L}} / \mathrm{D}_{\mathrm{T}}=0.96\right)$. The bioreactor was equipped with a single Rushton turbine with 6 paddles, $\mathrm{D}_{\mathrm{i}}=4.53 \mathrm{~cm}(\mathrm{Di} / \mathrm{DT}=0.46)$, located $4.53 \mathrm{~cm}$ from the base of the container. The bioreactor had 2 equidistant deflectors of $1.0 \mathrm{~cm}$ in width to improve liquid-liquid mixing. Agitation for yeast growth and bioconversion were maintained at 300 and $200 \mathrm{rpm}$, respectively. Temperature was maintained at $30^{\circ} \mathrm{C}$. The $\mathrm{pH}$ was monitored using an AppLiSens Z001023511 pH electrode (Applikon) and controlled at 5.5 using $2 \mathrm{M} \mathrm{HCl}$. Atmospheric air entering the system was filtered through a sterile $0.22 \mu \mathrm{m}$ filter. From previous experiments, 
the air flow rate in the bioreactor for yeast growth and bioconversion were maintained at 1.0 and $0.5 \mathrm{vvm}$, respectively, through a perforated "L" tube with seven holes of $1.0 \mathrm{~mm}$ in diameter. A refrigerant was located at the air exit to avoid sesquiterpenes evaporation from the bioreactor.

\subsubsection{Two-phase (aqueous-air) and three-phase (aqueous-organic-air) bioconversions}

Bioconversion studies were conducted after the growth phase of $Y$. lipolytica (33 h), by (a) adding a concentrated solution of (+)-valencene to reach a final concentration of $1.5 \mathrm{~g} \mathrm{~L}^{-1}$ or (b) adding $350 \mathrm{~mL}$ of orange essential oil (phase ratio of $1: 1 \mathrm{v} / \mathrm{v}$ ) to the culture medium to reach by partition a final concentration of $2.7 \mathrm{~g}$ of $(+)$-valencene $\mathrm{L}^{-1}$ in the organic phase and $0.4 \mathrm{~g}$ of (+)-valencene $\mathrm{L}^{-1}$ in the aqueous phase. Similar phase ratio was used during the screening in serological flasks. A control without the addition of (+)-valencene was included using $30 \mathrm{~g}$ of glucose $\mathrm{L}^{-1}$, which was performed in duplicate, in order to determine the effect of adding valencene and other components of orange essential oil to the culture medium. Every day, $5 \mathrm{~mL}$ of sample from the bioconversion media was taken and centrifuged at 5000 rpm for $10 \mathrm{~min}$. Then, sesquiterpene extraction was carried out using $500 \mu \mathrm{L}$ of sample from either aqueous or organic phase and $500 \mu \mathrm{L}$ of ethyl acetate. The mixture was vortexed twice for $20 \mathrm{~s}$ in a vortex, and settled until phase separation occurred, after that $1 \mu \mathrm{L}$ of the ethyl phase was injected to GC. ${ }^{16,17}$

\subsubsection{Determination of partition coefficients}

Partition coefficients of (+)-valencene and (+)-nootkatone between a buffer solution (aqueous phase) and orange essential oil (organic phase) were determined taking into account the phase ratio $(1: 1 \mathrm{v} / \mathrm{v})$ and the initial (+)-valencene concentration conditions used in the three-phase partitioning bioreactor. Therefore, the aqueous phase was prepared as follows: $3.2 \mathrm{~g} \mathrm{~L}^{-1}$ of nootkatone was dissolved in a $0.1 \mathrm{M}$ phosphate buffer adjusted to $\mathrm{pH}$ 7.5. Also, the organic phase was orange essential oil containing $3.2 \mathrm{~g} \mathrm{~L}^{-1}$ of (+)-valencene. Then equal amounts of both solutions were mixed, yielding a final solution with a total volume of $6 \mathrm{~mL}$. The mixture was subjected to mechanical agitation for $6 \mathrm{~h}$ at $30^{\circ} \mathrm{C}$ in order to reach thermodynamic equilibrium. The phases were then separated by centrifugation. (+)valencene and (+)-nootkatone were extracted from the aqueous and organic phases, 
respectively using $500 \mu \mathrm{L}$ of ethyl acetate. Both phases were analysed quantitatively by GC and the partition coefficient $\left(K_{p}\right)$ was subsequently determined. The partition coefficient was calculated as the ratio of the solute concentration in the organic phase divided by the solute concentration in the aqueous phase at equilibrium.

\subsection{RESULTS AND DISCUSSION}

\subsubsection{Sesquiterpenes in orange essential oil (Citrus aurantium, var. amara)}

GC-MS analysis were performed for (+)-valencene and (+)-nootkatone standards and orange essential oil to verify the presence of (+)-valencene in orange essential oil. Concentrations of (+)-valencene and (+)-nootkatone in orange essential oil were determined to be $3.2 \mathrm{~g} \mathrm{~L}^{-1}$ and $0.94 \mathrm{mg} \mathrm{L}^{-1}$, respectively. The (+)-valencene concentration obtained was similar to that reported by Del Rio et al. ${ }^{27}$ being $2.99 \mathrm{~g} \mathrm{~L}^{-1}$ for the same variety of orange oil. Depending on the harvest of the fruit and its specific variety, the concentration of sesquiterpenes varies for different species of the Citrus genus. ${ }^{28}$ The highest concentration reported for (+)-valencene was $6 \mathrm{~g} \mathrm{~L}^{-1}$ for the species sinensis. ${ }^{29}$

\subsubsection{Partition coefficients}

The (+)-valencene partition coefficient $\left(K_{p}\right)$ obtained was 6.37 , which was 3.5 times lower than the partition coefficient obtained for (+)-nootkatone. During the bioconversion process, (+)-valencene is transferred from the organic phase to the aqueous phase based solely on partition and metabolic demands of the cells transferring the substrate to the cell at subinhibitory levels. On the other hand, (+)-nootkatone is transferred from the aqueous phase to the organic phase. The high (+)-nootkatone $K_{p}$ value implies a good affinity of (+)nootkatone for orange essential oil (organic phase), which is advantageous for in situ recovery in a three-phase partitioning bioreactor and hence avoiding (+)-nootkatone inhibition.

\subsubsection{Inhibition experiments}

\subsubsection{Substrate inhibition}

Recently, Liu et al. ${ }^{30}$ showed that (+)-valencene contained in sweet orange essential oil inhibited the growth of five different microorganisms. The inhibition effect of initial (+)- 
valencene concentration on the bioconversion process was evaluated in baffled Erlenmeyer flasks (Figure 5.1A). Maximum final (+)-nootkatone concentration was observed using 1.5 $\mathrm{g} \mathrm{L}^{-1}$ of (+)-valencene. Above this concentration, an inhibitory effect was evident. In order to determine the maximum (+)-valencene concentration per gram of biomass to be under non-inhibitory conditions during the bioconversion process in the bioreactor, the biomass concentration in the Erlenmeyer flasks was determined. The average concentration obtained was $10.5 \mathrm{~g} \mathrm{~L}^{-1}$ of biomass. This leads to a value of $0.14 \mathrm{~g}$ of (+)-valencene per $\mathrm{g}$ of biomass, which was similar to the concentrations used in the stirred thank bioreactor experiments. In orange essential oil, there are a large number of compounds used in the food and beverage industry as antimicrobial agents. ${ }^{31}$ Limonene, a terpene with the highest antimicrobial activity, is the most abundant compound. Besides, it has been reported that sesquiterpenes have antifungal activity, ${ }^{32,33}$ and their biosynthesis is often induced after fungal infection. ${ }^{34,35,36}$

\subsubsection{Product inhibition}

In order to determine product inhibition, further experiments were carried out by adding different amounts of concentrated solution of (+)-nootkatone to culture medium, resulting in different initial concentrations. Figure 5.1B shows a decrease in (+)-nootkatone produced when initial (+)-nootkatone added was above $400 \mathrm{mg} \mathrm{L}^{-1}$, indicating that $Y$. lipolytica present product inhibition above $34.8 \mathrm{mg}$ of $(+)$-nootkatone ( $\mathrm{g}$ of biomass) ${ }^{-1}$. Studies performed by Gavira et al. ${ }^{7}$ with $S$. cerevisiae show that a concentration of $1.0 \mathrm{~g}$ of (+)-nootkatone $\mathrm{L}^{-1}$ results in product inhibition and loss of cell viability. Nevertheless, as observed, the studied yeast starts to present product inhibition at a lower (+)-nootkatone concentration. Therefore,

further studies in partitioning system are necessary in order to avoid both substrate and product inhibition during the bioconversion process. 

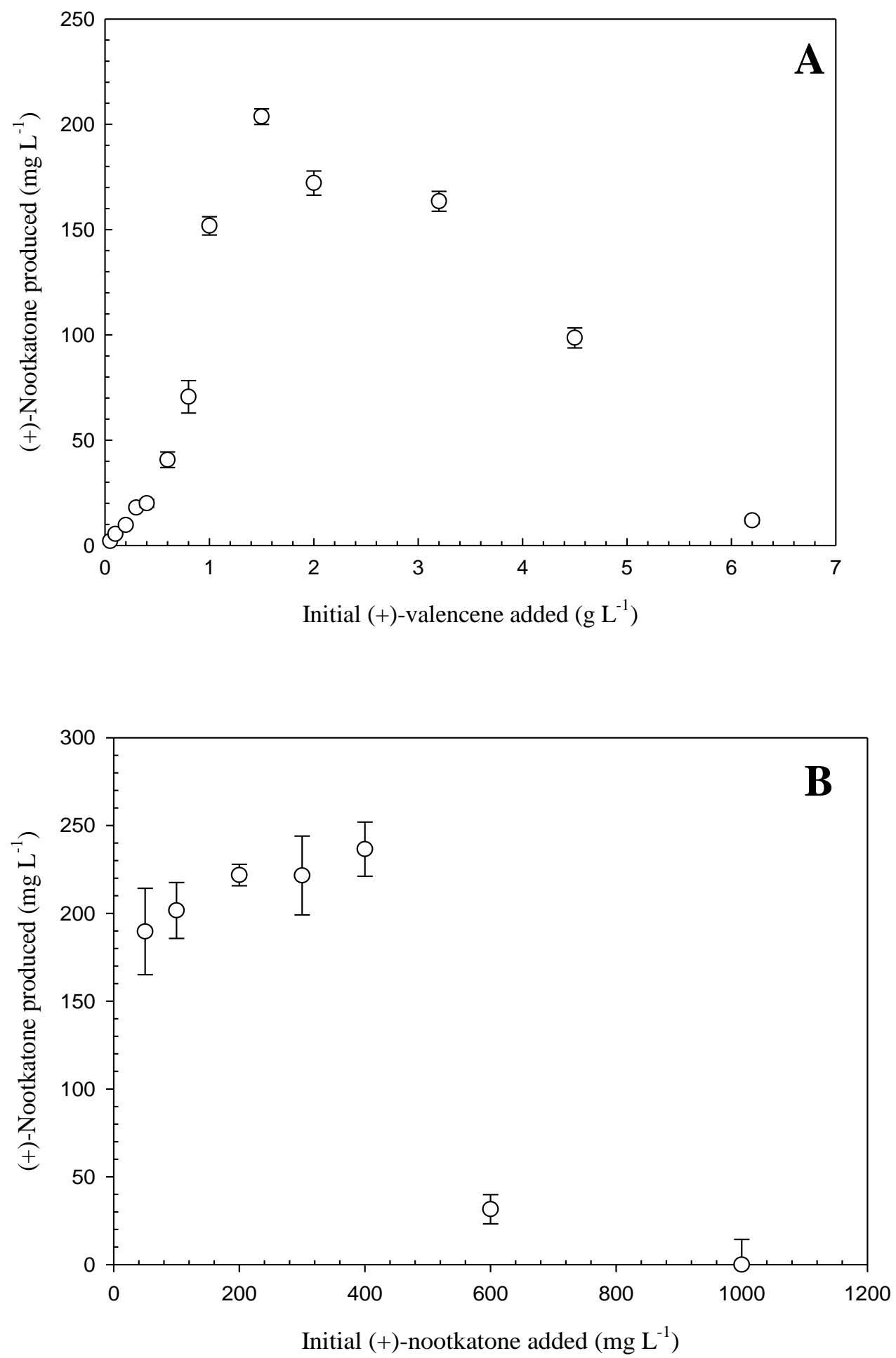

Figure 5.1. A) Effect of initial (+)-valencene concentration during the bioconversion process of $Y$. lipolytica. B) Effect of initial (+)-nootkatone concentration during the bioconversion process of $Y$. lipolytica. 


\subsubsection{Bioconversion of (+)-valencene in a three-phase system}

Firstly, in order to investigate the possible effect of reaction media on viable cells a control experiment without the addition of (+)-valencene or orange essential oil was carried out in the bioreactor. Biomass, substrate concentrations and cell viability were monitored for $129 \mathrm{~h}$ (Figure 5.2.). After $48 \mathrm{~h}$ of growth, $Y$. lipolytica remained in the stationary phase. Loss of cell viability was observed just as the stationary phase began dropping to $40 \%$, probably due to the nearly complete depletion of total glucose and cell lysis. Cell lysis is due to older cells that become weaker and less active with age, and cellular membranes eventually deteriorate and begin to release proteolytic enzymes. ${ }^{37}$ To evaluate cell lysis of $Y$. lipolytica, soluble protein released into culture medium was measured relative to the concentration of protein released after complete cell lysis via sonication and mechanical rupture. ${ }^{38}$ Results indicated that approximately $60 \%$ of protein was released into the culture medium during the bioconversion process. Becerra et al. ${ }^{26}$ previously reported that cell lysis of Kluyveromyces lactis resulted in the release of $52 \%$ of total protein.

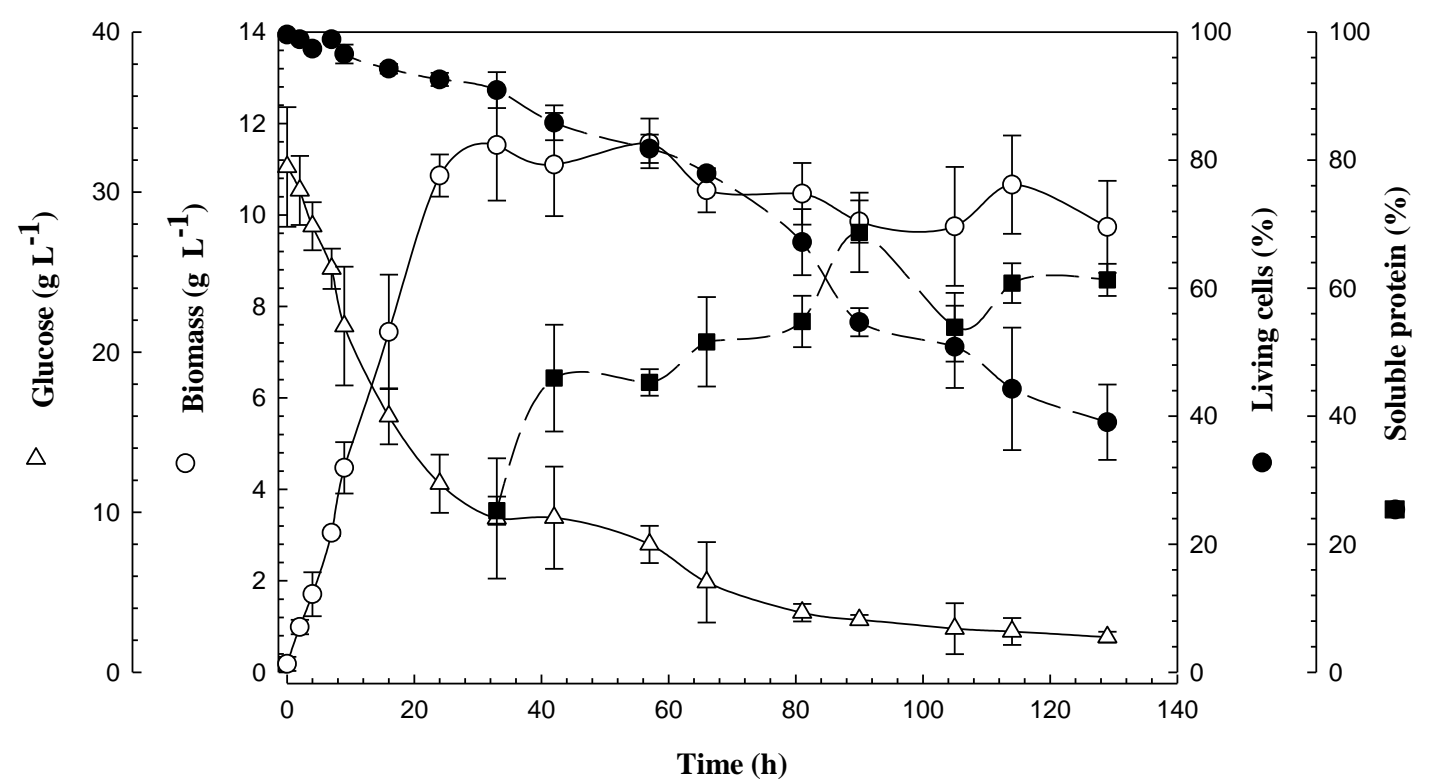

Figure 5.2. Kinetics of cell growth, glucose consumption, cell viability and soluble protein during the bioprocess. Y. lipolytica was grown and incubated for $129 \mathrm{~h}$ without the addition of (+)valencene, maintaining the same conditions of the bioconversion experiments. 
Secondly, bioconversion experiments were then conducted in a three-phase system using orange essential oil as a source of (+)-valencene for bioconversion to (+)-nootkatone. In this type of experiments $Y$. lipolytica was grown using $30 \mathrm{~g} \mathrm{~L}^{-1}$ of glucose. Maximum biomass production (11.7 $\mathrm{g} \mathrm{L}^{-1}$ ) was reached at $33 \mathrm{~h}$ of growth (Figure 5.3.). At this time, orange essential oil ( $50 \% \mathrm{v} / \mathrm{v})$ was added to the bioreactor when approximately $10 \mathrm{~g} \mathrm{~L}^{-1}$ of glucose still remained in the culture medium. It was also observed that the percentage of viable cells decreased, reaching $50 \%$ after $60 \mathrm{~h}$ and $30 \%$ at the end of the bioconversion process $(96 \mathrm{~h})$.

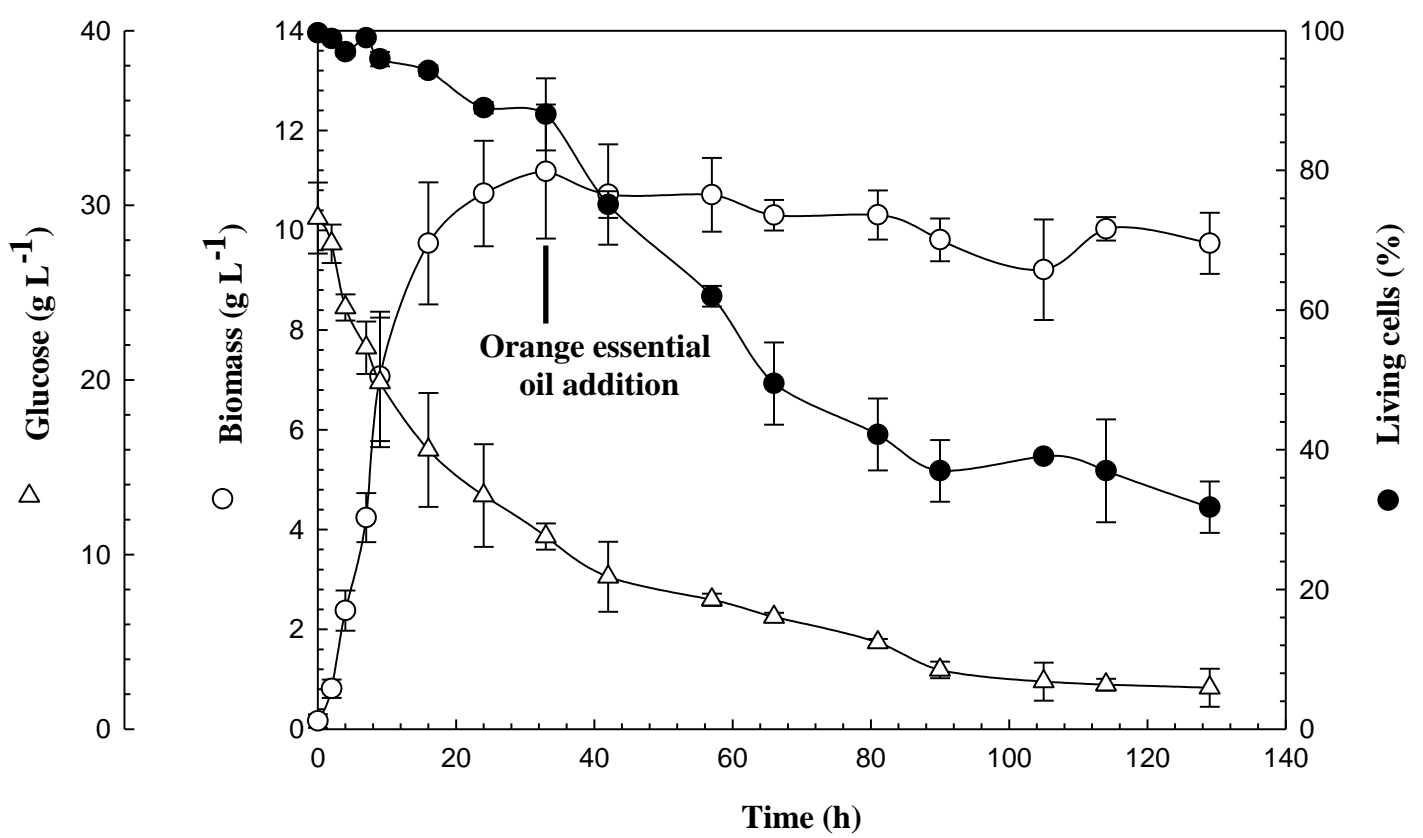

Figure 5.3. Kinetics of cell growth, glucose consumption, and cell viability in the tri-phasic system. Up to $50 \% \mathrm{v} / \mathrm{v}$ orange essential oil $\left(3.2 \mathrm{~g} \mathrm{~L}^{-1}\right.$ of $(+)$-valencene) were added to initiate the bioconversion process.

The production of (+)-nootkatone (Figure 5.4.) peaked at $326.3 \mathrm{mg} \mathrm{L}^{-1}$ in the organic phase at $96 \mathrm{~h}$, with a bioconversion of $39.1 \%$. In comparison, Gavira et al. ${ }^{7}$ cultured for $24 \mathrm{~h}$ using $4 \mathrm{~g} \mathrm{~L}^{-1}$ of (+)-valencene and reported production of (+)-nootkatone not more than $10 \mathrm{mg} \mathrm{L}^{-1}$. Papanikolaou et al. ${ }^{39}$ investigated the effect of citrus essential oil addition on the physiological behaviour of $Y$. lipolytica. Sugar uptake rate and maximum specific growth rate were not affected by oil addition. However, a loss of cell viability up to $50 \%$ was 
observed when oil concentration increased up to $1.5 \mathrm{~mL} \mathrm{~L}^{-1}$. Our results show that cells of $Y$. lipolytica rapidly lost viability even if no orange essential oil was added, suggesting that our strain was sensitive to mechanical and/or oxidative stress. ${ }^{40,41}$ Besides, it was observed that cell viability in three-phase system was $10 \%$ lower than that observed in the control system; although, there was no significant statistical difference $(\mathrm{p}=0.279)$. Therefore, unknown components in orange essential oil might not be as toxic as expected at the concentration used. Figure 5.4 also depicts that after 48 h, the bioconversion process reached a stationary phase, indicating that there was a limiting factor in the production of (+)-nootkatone.

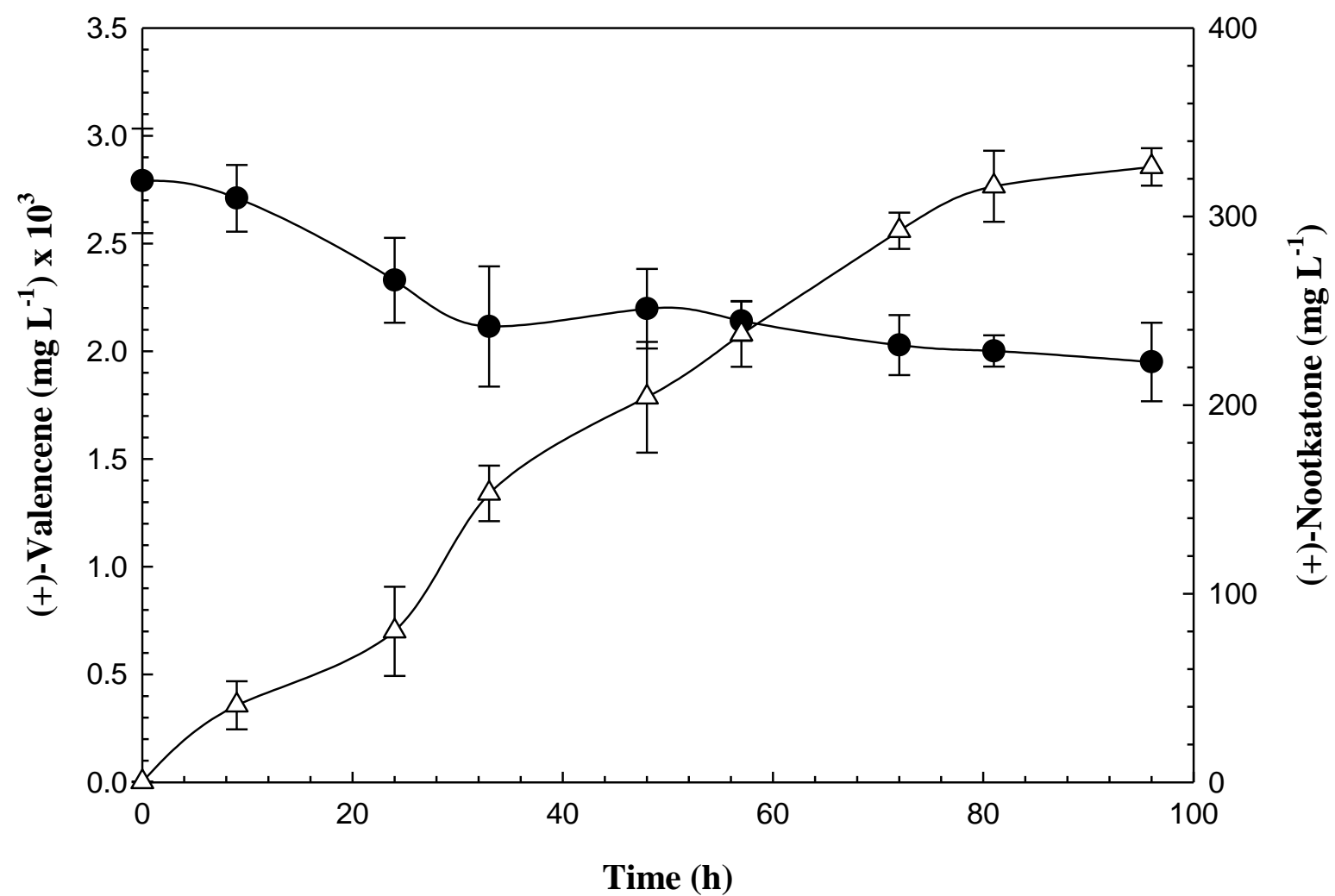

Figure 5.4. Bioconversion of (+)-valencene to (+)-nootkatone in a tri-phasic system using $Y$. lipolytica. Zero time corresponds to $33 \mathrm{~h}$ of growth.

Gavira et al. ${ }^{7}$ performed optimization of a bioconversion process using a recombinant yeast expressing CYP71D51v2 from tobacco and a P450 reductase from Arabidopsis. Yeast cells were cultivated for $24 \mathrm{~h}$ in the presence of increasing concentrations of $(+)$-valencene, $\beta$ nootkatol and (+)-nootkatone. The authors claimed that (+)-valencene was tolerated at 
concentrations up to $4 \mathrm{~g} \mathrm{~L}^{-1}$, with a recovery of $73 \%$ of viable cells after $24 \mathrm{~h}$. On the other hand, $\beta$-nootkatol and (+)-nootkatone led to a loss of cell viability at $1 \mathrm{~g} \mathrm{~L}^{-1}$, with $45 \%$ viability already lost at $100 \mathrm{mg} \mathrm{L}^{-1}$ in the case of $\beta$-nootkatol. The possible reasons for the observed bioconversion efficiency to (+)-nootkatone include: a) product toxicity, b) accumulation of $\beta$-nootkatol in the endo-membranes of yeast, c) inhibition of the CYP71D51v2 hydroxylation reaction by the products, and d) the fact that the formation of nootkatone from $\beta$-nootkatol is not dependent on cytochrome $\mathrm{P} 450$, but is catalysed by an unidentified enzyme in yeast. ${ }^{7}$ Fraatz et al. ${ }^{4}$ confirmed the dioxygenase nature of the enzyme of Pleurotus sapidus that catalyze (+)-valencene oxidation. The isolation and identification of two allylic (+)-valencene derived hydroperoxides together with homology data from amino acid sequencing suggested a lipoxygenase-like type of enzyme. ${ }^{42}$ To our knowledge, this report is the first one using a wild type $Y$. lipolytica with the enzymatic machinery to carry out the bioconversion.

The nootkatone/biomass yield in the three-phase system using $30 \mathrm{~g} \mathrm{~L}^{-1}$ of glucose was 27.9 $\mathrm{mg} \mathrm{g}^{-1}$, this yield was 21.8 times higher than that $\left(1.28 \mathrm{mg} \mathrm{g}^{-1}\right)$ observed by Girhard et al. ${ }^{16}$ under optimized conditions using recombinant $E$. coli with $10 \%$ dodecane and $409 \mathrm{mg} \mathrm{L}^{-1}$ of (+)-valencene. A primary drawback mentioned by the authors was the accumulation of high concentrations of $\beta$-nootkatol in cellular membranes, leading to alterations in membrane permeability, as well as the function of integral proteins, similar to that which has been observed with other hydrocarbons that are concentrated in membranes. ${ }^{43,44}$ Accumulation of products, in particular $\beta$-nootkatol, is thus likely to be an important factor limiting rates and yields during the process of bioconversion. ${ }^{7}$ As such some strategies to improve the bioconversion process was revised by the authors such as increasing the permeability of cell membrane using a solvent and a selective transporter of nootkatol and nootkatone in order to avoid toxic product accumulation in the endo-membranes. 


\subsubsection{Effect of cellular membrane permeabilization on the bioconversion of (+)- valencene to $(+)$-nootkatone}

\subsubsection{Membrane permeabilization experiments with Triton $X-100$}

Cellular membrane permeabilization experiments were conducted with Triton X-100 using washed and unwashed cells. A final concentration of $347.7 \mathrm{mg} \mathrm{L}^{-1}$ of (+)-nootkatone was reached at a concentration of $0.1 \%(\mathrm{v} / \mathrm{v})$ of Triton $\mathrm{X}-100$. However, this effect was not statistically significant with respect to that obtained by the control without the addition of Triton $(\mathrm{p}=0.183)$. Above $0.1 \%(\mathrm{v} / \mathrm{v})$, it was observed that the bioconversion decreased, probably due to the high concentrations of this compound. It has been reported for $Y$. lipolytica ${ }^{45}$ that the increment in cell membrane permeability depends on the detergent concentration: a greater concentration of Triton indicated greater permeability.

\subsubsection{Membrane permeabilization experiments with CTAB}

Cellular membrane permeabilization experiments with CTAB were carried out. A statistically significant difference was observed at a concentration of $0.2 \%(\mathrm{w} / \mathrm{v})$ (see Figure A1 in Annexes), obtaining $420.9 \mathrm{mg} \mathrm{L}^{-1}$ of nootkatone and $55.1 \pm 18.9 \%$ of bioconversion at $96 \mathrm{~h}$ using washed cells. Similar results were achieved by Naina et al. ${ }^{46}$ as they observed greater substrate, product and cofactors transport across the cell membranes of $S$. cerevisiae and Kluyveromyces fragilis using a concentration of $0.2 \%(\mathrm{w} / \mathrm{v})$ of this cationic surfactant. The authors reported that yeast cells can replace the purified ADH and GGPDH for the production of $\mathrm{NADH}$ and $\mathrm{NADPH}$, respectively. However, the cells require membrane permeabilization to increase cell ADH and the GGPDH achieved through the treatment with CTAB. In this study, CTAB was used to help the cells of $Y$. lipolytica to expel the intermediary nootkatol culture medium during the bioconversion process.

\subsubsection{Membrane permeabilization experiments by sonication}

Finally, using sonication as a mechanical method, with the equipment and operation conditions tested, there was no statistically significant difference of bioconversion compared to the control without sonication, in both cells washed and unwashed $(p=0.147)$. 


\subsubsection{Effect of cofactor regeneration (NADPH) on the bioconversion of (+)-valencene}

to (+)-nootkatone using glycerol and Niacin (vitamin $B_{3}$ )

\subsubsection{Cofactor regeneration experiments using glycerol}

It was observed that the addition of glycerol either when the culture medium was inoculated or after 3 days of growth, did not present a statistically significant increase in (+)-nootkatone, resulting in a maximum concentration of $337.6 \pm 19.2 \mathrm{mg} \mathrm{L}^{-1}$. It was also observed that the bioconversion using glycerol with washed cells was not statistically significant $(p=0.259)$ in comparison to cells without washing.

\subsubsection{Cofactor regeneration experiments using niacin (vitamin $B_{3}$ )}

In experiments using niacin (vitamin $\mathrm{B}_{3}$ ) for the regeneration of the cofactor $\mathrm{NADPH}^{+}$, significant differences on (+)-nootkatone production were observed (see Figure A2 in Annexes) when niacin at a concentration of $2 \mathrm{mM}$ was added after 3 days of $Y$. lipolytica growth. Under these conditions a (+)-nootkatone production of $380.4 \mathrm{mg} \mathrm{L}^{-1}$ with a $51.5 \%$ of bioconversion was reached. This $(+)$-nootkatone concentration was higher than that observed when niacin was added at the same time when culture media was inoculated. In spite of several authors reporting bioconversion of (+)-valencene to (+)-nootkatone, very few reports on the improvement of this reaction are available. . $^{7,16,47}$

\subsubsection{Identification of the intermediate nootkatol by GC-MS}

The presence of the intermediary nootkatol during the bioconversion was analyzed by GCMS using percentages of abundance in the control, $2 \mathrm{mM}$ of niacin and $0.2 \%(\mathrm{w} / \mathrm{v})$ of CTAB (Figure 5.5.).

An increment of nootkatol was observed when CTAB was added confirming that cells were permeabilized. Table 5.1 shows our results compared to those obtained by other authors using other microorganisms. At optimal CTAB concentration the intermediary was expelled to the culture medium obtaining an improvement in (+)-nootkatone production. In addition, the control results show similarities with other authors (see Table 5.1.) in terms of the percentage found of the intermediary. 


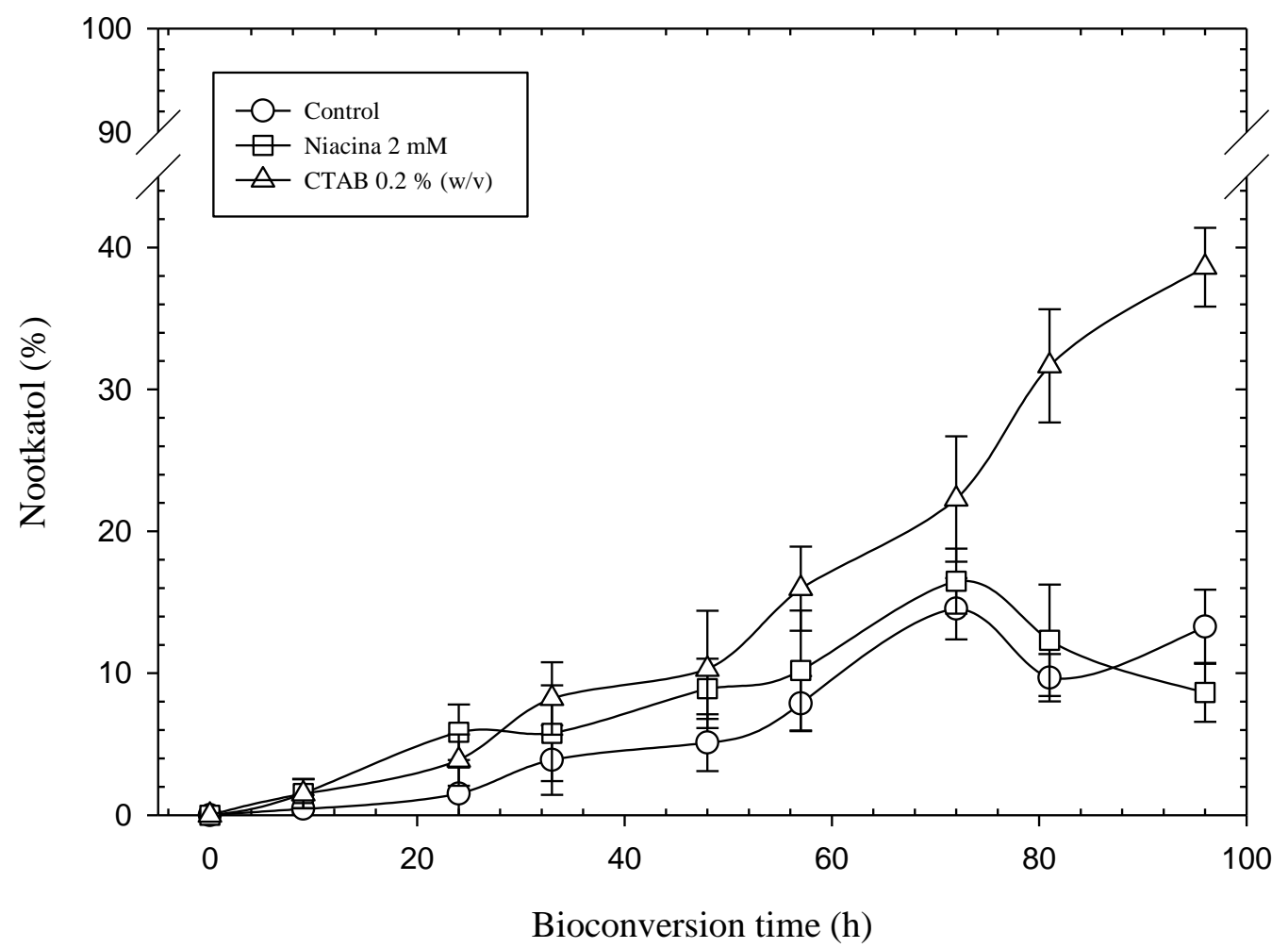

Figure 5.5. Nootkatol release during to the bioconversion process using $Y$. lipolytica.

Table 5.1. Presence of the intermediary nootkatol during the (+)-valencene bioconversion using $Y$. lipolytica in a monophasic system adding $2 \mathrm{mM}$ of niacin and $0.2 \%(\mathrm{w} / \mathrm{v})$ of CTAB.

\begin{tabular}{|c|c|c|c|c|}
\hline System & $\begin{array}{c}\text { (+)-Valencene } \\
\left(\mathrm{g} \mathrm{L}^{-1}\right)\end{array}$ & $\begin{array}{c}\text { Nootkatol } \\
(\%)\end{array}$ & $\begin{array}{c}\text { (+)-Nootkatone } \\
\left(\mathrm{mg} \mathrm{L}^{-1}\right)\end{array}$ & Reference \\
\hline $\begin{array}{l}\text { Monophasic } \\
\text { (Control) }\end{array}$ & 1.50 & $13.27 \pm 2.61$ & $325.3 \pm 17.3$ & This work \\
\hline $\begin{array}{l}\text { Monophasic + } \\
2.0 \mathrm{mM} \text { Niacin }\end{array}$ & 1.50 & $8.65 \pm 2.07$ & $380.4 \pm 31.1$ & This work \\
\hline $\begin{array}{l}\text { Monophasic }+ \\
0.2 \% \text { w/v CTAB }\end{array}$ & 1.50 & $38.61 \pm 2.77$ & $420.9 \pm 33.4$ & This work \\
\hline Monophasic & 0.46 & $4.00 \pm \mathrm{nr}$ & $170.1 \pm \mathrm{nr}$ & Kaspera et al. ${ }^{17}$ \\
\hline Biphasic & 0.40 & $12.90 \pm \mathrm{nr}$ & $5.65 \pm \mathrm{nr}$ & Sowden et al. ${ }^{47}$ \\
\hline Monophasic & 0.40 & $10.00 \pm \mathrm{nr}$ & $15.00 \pm \mathrm{nr}$ & $\begin{array}{c}\text { Furusawa et } \\
\text { al. }^{48}\end{array}$ \\
\hline Biphasic & 0.40 & $7.40 \pm \mathrm{nr}$ & $94.20 \pm 1.8$ & Girhard et al. ${ }^{16}$ \\
\hline
\end{tabular}

$\mathrm{nr}=$ Data not reported 
However, it was observed that the results using Niacin showed a similarity with respect to the results of the control. This demonstrates that this compound was only used as a cofactor regenerator during the bioconversion. Our results were particularly improved by membrane permeabilization with CTAB causing expel of intermediary nootkatol, cofactor NADH regeneration by the vitamin niacin.

\subsubsection{Bioconversion of (+)-valencene to (+)-nootkatone in a two-phase bioreactor using}

\section{Y. lipolytica with CTAB and Niacin}

After $24 \mathrm{~h}$ of growth $11.5 \mathrm{~g} \mathrm{~L}^{-1}$ of additional biomass, washed and permeabilized using $0.2 \%$ (w/v) de CTAB, and $2.0 \mathrm{mM}$ of niacin were added to the bioreactor. Then a concentration of $1.5 \mathrm{~g} \mathrm{~L}^{-1}$ of valencene was also added to start the bioconversion. Cell viability decreased up to $40 \%$ at $96 \mathrm{~h}$ of the bioconversion process was observed. A nootkatone production of 619.8 $\mathrm{mg} \mathrm{L}^{-1}$ was obtained at $120 \mathrm{~h}$, with an approximate consumption of $0.8 \mathrm{~g} \mathrm{~L}^{-1}$ of (+)-valencene (Figure 5.6).

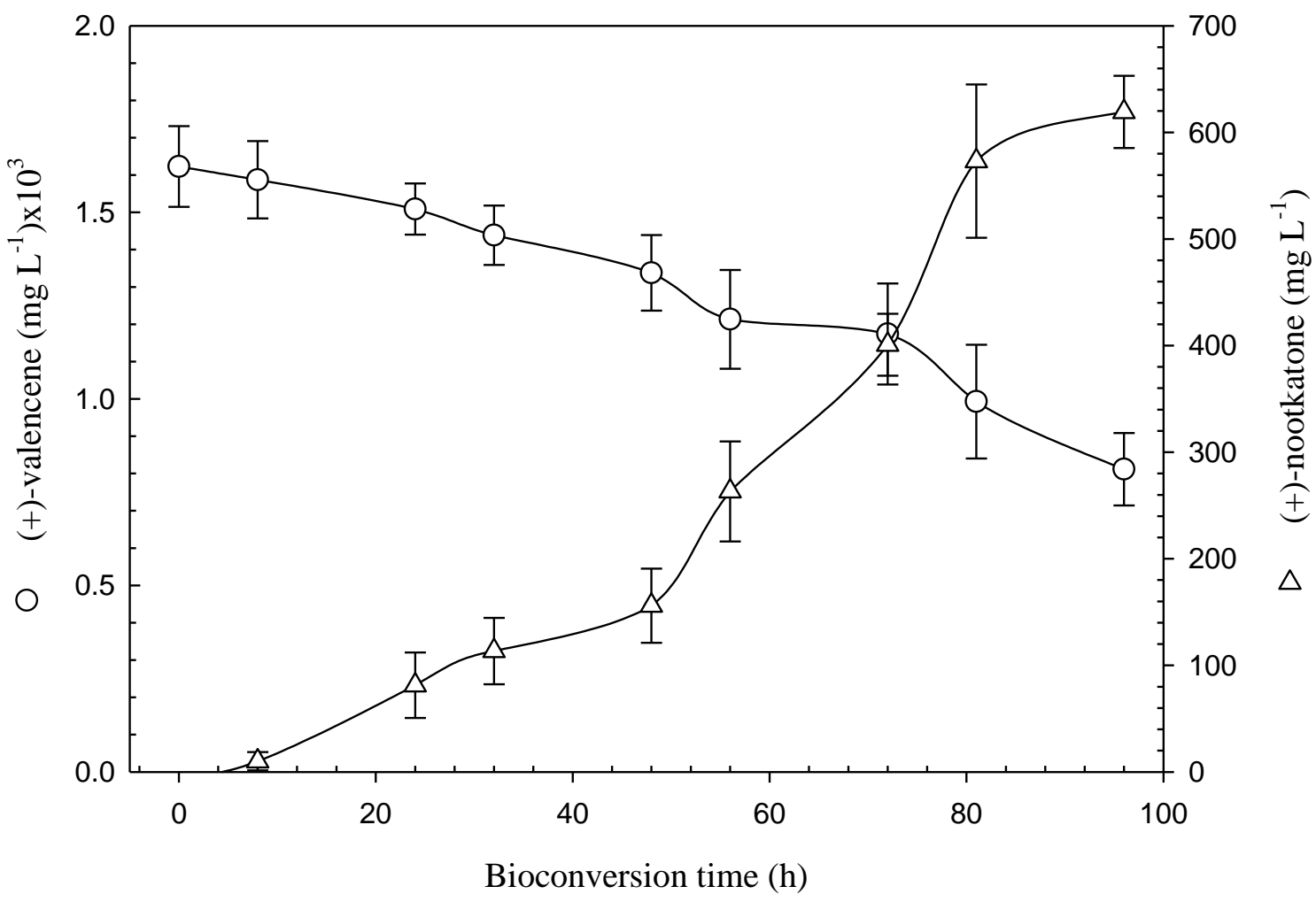

Figure 5.6. Bioconversion of (+)-valencene to (+)-nootkatone in a two-phase system using $Y$. lipolytica. Zero time corresponds to $33 \mathrm{~h}$ of growth. 
After this time, a limitation of (+)-nootkatone production was observed, since the product concentration reached above the product inhibition determined previously (see Figure 5.1B). Fraatz et al. ${ }^{4}$ obtained a final concentration of $600 \mathrm{mg}$ of nootkatone $\mathrm{L}^{-1}$, with the strain of Pleurotus sapidus in a fed-batch system, adding valencene pulses up to a concentration of 11 $\mathrm{g} \mathrm{L}^{-1}$.

\subsubsection{Bioconversion of (+)-valencene to (+)-nootkatone in a three-phase partitioning} bioreactor using Y. lipolytica with CTAB and Niacin

Experiments in a three-phase system were carried out to obtain higher production. After 24 $\mathrm{h}$ of growth, additional biomass up to $22 \mathrm{~g} \mathrm{~L}^{-1}$ washed and permeabilized using $0.2 \%(\mathrm{w} / \mathrm{v})$ de CTAB and $2.0 \mathrm{mM}$ of Niacin were added to the bioreactor. After 30 minutes, $50 \%$ (v/v) of orange essential oil was added. Cell viability decreased to $30 \%$ at $96 \mathrm{~h}$ of the bioconversion process. A (+)-nootkatone production of $852.3 \mathrm{mg} \mathrm{L}^{-1}$ in the organic phase was obtained at $120 \mathrm{~h}$ (Figure 5.7).

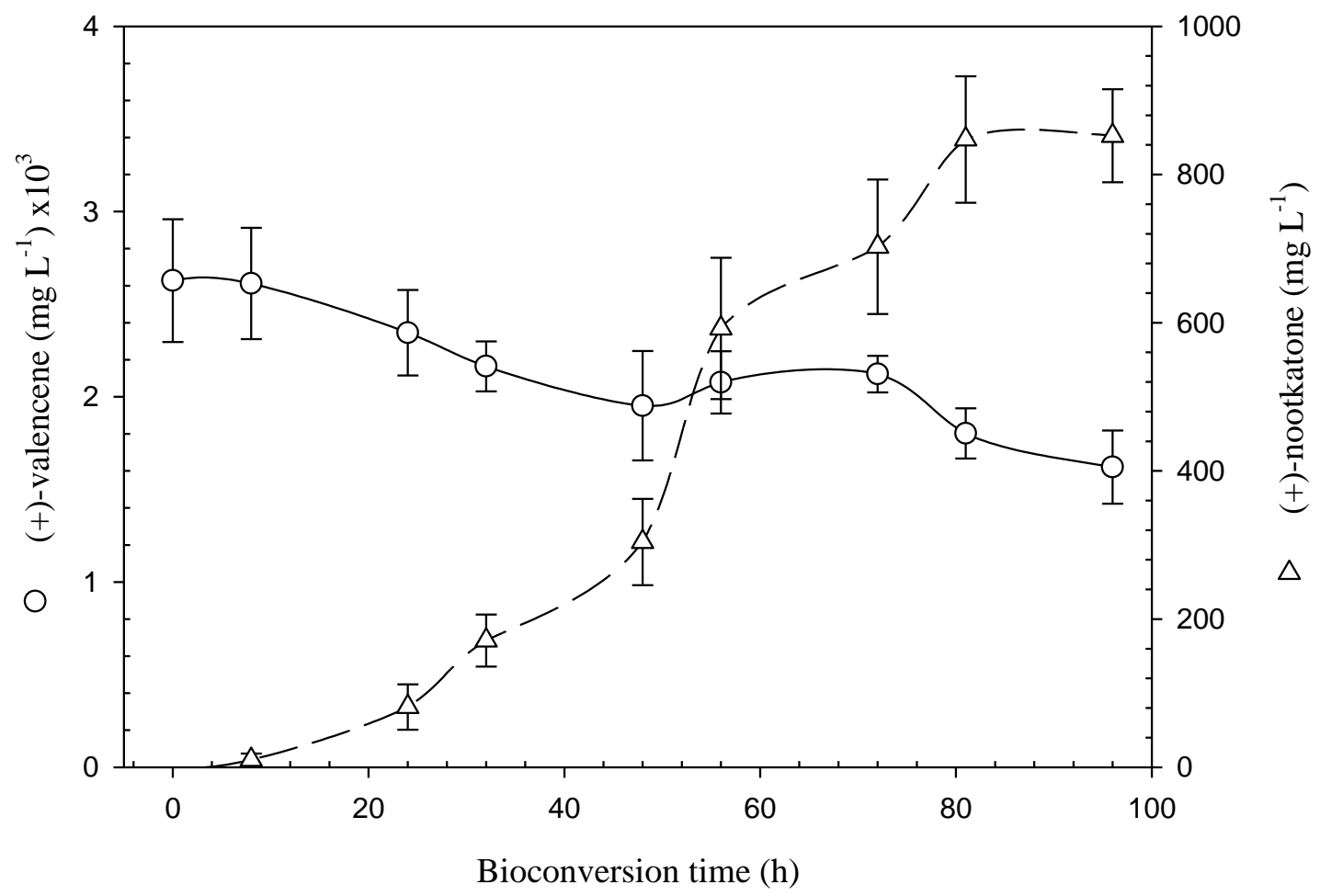

Figure 5.7. Bioconversion of (+)-valencene to (+)-nootkatone in a three-phase system using $Y$. lipolytica. Zero time corresponds to $33 \mathrm{~h}$ of growth. 
Wriessnegger et al. ${ }^{8}$ generated a strain of $P$. pastoris co-expressing the premnaspirodiene oxygenase of Hyoscyamus muticus (HPO) and the Arabidopsis thaliana cytochrome P450 reductase (CPR) that hydroxylated extracellularly added (+)-valencene. Two-phase cultivations of $P$. pastoris resulted in the production of trans-nootkatol, which was oxidized to (+)-nootkatone by an intrinsic microbial activity. Additional over expression significantly enhanced the (+)-nootkatone yield to $208 \mathrm{mg} \mathrm{L}^{-1}$ cell culture with $0.5 \mathrm{~g} \mathrm{~L}^{-1}$ of (+)-valencene in bioreactor cultivations fed-batch in $108 \mathrm{~h}$ of bioconversion of final time, the (+)nootkatone is recovered in situ with $10 \%(\mathrm{v} / \mathrm{v})$ of n-dodecane as the organic phase. Girhard et al. ${ }^{16}$ also studied this bioconversion process using a two-phase system with $10 \%$ dodecane as the organic phase with a recombinant strain of Escherichia coli. An initial concentration of $409 \mathrm{mg} \mathrm{L}^{-1}$ of (+)-valencene was used in a relatively short time $(8 \mathrm{~h}), 94.2 \mathrm{mg} \mathrm{L}^{-1}$ of (+)nootkatone was produced with a total bioconversion of $23 \%$. As much as $80 \%$ cell death was observed using other organic solvents such as isooctane and n-octane, due to the significant toxicity of these solvents. In contrast, cell viability remained at $90 \%$ during the bioconversion process upon use of organic solvent dodecane. Comparing the results of our three-phase system using a partitioning bioreactor with those of Fraatz et al. ${ }^{4}$ and those obtained in our study using a two-phase system, it is evident that partitioning bioreactor is a promising technology for scaled up in the production of (+)-nootkatone on Y. lipolytica. This study highlighted the advantage of using three-phase partitioning bioreactor to enhance productivity of (+)-nootkatone overcoming its inhibition effects. Moreover, a non-previously studied wild-type $Y$. lipolytica strain was used for the production of an important flavor/fragrance compound, namely (+)-nootkatone. Nowadays, Y. lipolytica is one of the most extensively studied yeasts ${ }^{49}$, capable of producing important metabolites and with an interesting enzymatic machinery, among them Cytochrome P450, which is one of the enzymes involved in the biotransformation process. ${ }^{7}$

Furthermore, experiments were carried out to find the effect of biomass increment on the bioconversion process. The biomass increased up to $32.41 \mathrm{~g} \mathrm{~L}^{-1}$ and the results are summarized in Table 5.2. 
Table 5.2. Biomass concentration effect on the (+)-nootkatone bioconversion using $Y$. lipolytica in a three-phase partitioning bioreactor at $30{ }^{\circ} \mathrm{C}, 200 \mathrm{rpm}$ and $0.5 \mathrm{vvm}$.

\begin{tabular}{|c|c|c|c|c|c|}
\hline $\begin{array}{c}\text { Initial } \\
\text { biomass } \\
\left(\mathrm{g} \mathrm{L}^{-1}\right)\end{array}$ & $\begin{array}{c}\text { Reaction rate } \\
(\mathrm{mg} \text { nootkatone } \\
\left.\mathrm{L}^{-1} \mathrm{~h}^{-1}\right)\end{array}$ & $\begin{array}{c}\text { Bioconversion } \\
(\%)\end{array}$ & $\begin{array}{c}\text { Volumetric } \\
\text { productivity } \\
\left(\mathrm{mg} \mathrm{L}^{-1} \mathrm{~h}^{-1}\right)\end{array}$ & $\begin{array}{c}\text { Yield } \\
\text { Nootkatone/biomass } \\
\left(\mathrm{mg} \mathrm{g}^{-1}\right)\end{array}$ & $\begin{array}{c}\text { Final } \\
\text { nootkatone } \\
\text { concentration } \\
\left(\mathrm{mg} \mathrm{L}^{-1}\right)\end{array}$ \\
\hline $11.7 \pm 1.4$ & $4.9 \pm 1.7$ & $38.8 \pm 13.1$ & $3.4 \pm 0.1$ & $27.8 \pm 3.1$ & $326.3 \pm 9.9$ \\
\hline $22.0 \pm 0.5$ & $12.9 \pm 1.9$ & $77.9 \pm 19.4$ & $8.8 \pm 0.6$ & $38.2 \pm 3.2$ & $852.2 \pm 62.8$ \\
\hline $32.4 \pm 1.3$ & $7.6 \pm 0.7$ & $64.9 \pm 6.4$ & $6.2 \pm 0.3$ & $18.4 \pm 1.0$ & $599.6 \pm 33.6$ \\
\hline
\end{tabular}

As expected initial biomass has an important effect on bioconversion variables, nevertheless, those initial biomass values 11.7 and $32.41 \mathrm{~g} \mathrm{~L}^{-1}$ leaded to lower reaction rate, bioconversion, volumetric productivity, yield and final nootkatone concentration than when $22 \mathrm{~g} \mathrm{~L}^{-1}$ of initial biomass was used during the bioconversion.

\subsection{CONCLUSIONS}

This work reported a natural method of synthesis to convert (+)-valencene to (+)-nootkatone using cells of a non-previously studied $Y$. lipolytica in a stirred tank partitioning bioreactor. Cell membrane permeabilization with CTAB and cofactor NADH regeneration with Niacin enhanced the bioconversion. Three phase partitioning technology (organic- aqueous-air) is compared to two-phase (aqueous-air) technology. The addition of organic phase, i.e., orange essential oil containing a cheap source of (+)-valencene, overcame bioconversion inhibition from (+)-nootkatone or (+)-valencene observed in the two-phase technology. From these results, the three phase portioning reactor is a potential technology for industrial production and in situ extraction of (+)-nootkatone.

\section{REFERENCES}

1. Ladaniya M, Citrus fruit: Biology, Technology and Evaluation, First Edition, USA, Ed. Elsevier. 176-177 (2010). 
2. Wilson CW and Shaw PE, Synthesis of nootkatone from valencene. J Agr Food Chem 26:1430-1432 (1978).

3. Salvador JAR and Clark JH, The allylic oxidation of unsaturated steroids by tert-butyl hydroperoxide using surface functionalised silica supported metal catalysts. Green Chem 4:352-356 (2002).

4. Fraatz MA, Berger RG and Zorn H, Nootkatone-a biotechnological challenge. Appl Microbiol Biotechnol 83:35-41 (2009).

5. Schmid A, Dordick JS, Hauer B, Kiene A, Wubbolts M and Witholt B, Industrial biocatalysis today and tomorrow. Nature 409:258-266 (2001).

6. Tufvesson P, Fu W, Skibsted, JJ and Woodley JM, Process considerations for the scale-up and implementation of biocatalysis. Food Bioprod Process 88:3-11 (2010).

7. Gavira C, Höfer R, Lesot A, Lambert F, Zucca J and Werck-Reichhart D, Challenges and pitfalls of P450-dependent (+)-valencene bioconversion by Saccharomyces cerevisiae. Metab Eng 18:25-35 (2013).

8. Wriessnegger T, Augustin P, Engleder M, Leitner E, Müler M, Kaluzna I, Schümann M, Mink E, Zellnig G, Schwab H and Pichler H, Production of the sesquiterpenoid (+)nootkatone by metabolic engineering of Pichia pastoris. Metab Eng 24:18-29 (2014).

9. Oppermann V, Stein F and Kragl U, Ionic liquids for two-phase systems and their application for purification, extraction and biocatalysis. Appl Microbiol Biotechnol 89:493-499 (2011).

10. Doig SD, Avenell PJ, Bird PA, Gallati P, Lander KS, Lye GJ, Wohlgemuth R and Woodley JM, Reactor operation and scale-up of whole cell Baeyer-Villiger catalysed lactone synthesis. Biotechnol Progr 18:1039-1046 (2002).

11. Torres-Martínez D, Melgarejo-Torres R, Gutiérrez-Rojas M, Aguilera-Vazquez L, Micheletti M, Lye GJ and Huerta-Ochoa S, Hydrodynamic and oxygen mass transfer studies in a threephase (air-water-ionic liquid) stirred tank bioreactor. Biochem Eng J 45:209-217 (2009).

12. De Gonzalo G, Rodriguez C, Rioz-Martinez A and Gotor V, Improvement of the biocatalytic properties of one phenylacetone monooxygenase mutant in hydrophilic organic solvents. Enzyme Microbiol Technol 50:43-49 (2012).

13. Berger RG, Krings U and Zorn H, Biotechnological flavor generation. In A. J. Taylor (Ed.), Food Flavor Tech. Weimar: C.H.I.P.S Press. 60-104 (2002).

14. Maróstica MR and Pastore GM, Production of R-(+)- $\alpha$-terpineol by the biotransformation of limonene from orange essential oil, using cassava waste water as medium. Food Chem 101:345-350 (2007). 
15. Tsigie YA, Wang CY, Kasim NS, Diem QD, Huynh LH, Ho QP, Truong CT and Ju YH, Oil production from Yarrowia lipolytica Po1g using rice bran hydrolysate. J Biomed Biotechnol 1:1-10 (2012).

16. Girhard M, Machida K, Itoh M, Schmid R, Arisawa A and Urlacher V, Regioselective biooxidation of (+)-valencene by recombinant E. coli expressing CYPI09BI from Bacillus subtilis in a two-liquid-phase system. Microbial Cell Factories 8:1-12 (2009).

17. Kaspera R, Krings U, Nanzad $T$ and Berger RG, Bioconversion of (+)-valencene in submerged cultures of the ascomycete Chaetomium globosum. Appl Microbiol Biotechnol 67:477-483 (2005).

18. Malik M, Ganguli A and Ghosh M, Modeling of permeabilization process in Pseudomonas putida G7 for enhanced limonin bioconversion. Appl Microbiol Biotechnol 95:223-231 (2012).

19. Ming An Y, Yu Meng W, Ling Z, Lan J and Xiao B, Bioconversion of ethyl 4-chloro-3oxobutanoate by permeabilized fresh brewer's yeast cells in the presence of allyl bromide. $J$ Ind Microbiol Biot 34:151-156 (2007).

20. Wong E and Vaillant-Barka F, Synergistic effect of sonication and high osmotic pressure enhances membrane damage and viability loss of Salmonella in orange juice. Food Res Int 45:1072-1079 (2012).

21. Melgarejo-Torres R, Torres-Martínez D, Gutiérrez-Rojas M, Gómez de Jesús A, Lye GJ and Huerta-Ochoa S, Regime analysis of a Baeyer-Villiger bioconversion in a three-phase (airwater-ionic liquid) stirred tank bioreactor. Biochem Eng J 58:87-95 (2011).

22. Hong W, ChunyongT, Xiaokai S, Chuang L, Dong Y and ZhongyiJ, Methods for the regeneration of nicotinamide coenzymes. Green Chem 15:1773-1789 (2013).

23. Miller GL, Blum R, Glennon WE, Burton AL, Measurement of carboxymethylcellulase activity. Anal Biochem 2:127-132 (1960).

24. Bonora A and Mares D, A simple colorimetric method for detecting cell viability in cultures of eukaryotic microorganisms. Curr Microbiol 7:217-222 (1982).

25. Bradford MM, A rapid sensitive method for the quantitation of microgram quantities of protein utilizing the principle of protein-dye binding. Anal Biochem 72:248-254 (1976).

26. Becerra M, Rodríguez E, Esperanza M and González MI, Extraction of intracellular proteins from Kluyveromyces lactis.Food Technol Biotech 39:135-139 (2001).

27. Del Río JA, Ortuño A, Puig DG, Iborra JL and Sabater F, Accumulation of the sesquiterpenes nootkatone and valencene by callus cultures of Citrus paradisi, Citrus limonia and Citrus aurantium. Plant Cell Rep 10:410-413 (1991). 
28. Espina L, Somolinos M, Loran S, Conchello P, Garcia D and Pagan R, Chemical composition of commercial Citrus fruit essential oils and evaluation of their antimicrobial activity acting alone or in combined processes. Food Control 22:896-902 (2010).

29. Elston V, Lin J and Rouseff R, Determination of the role of valencene in orange oil as a direct contributor to aroma quality. Flavour Frag J 20:381-386 (2005).

30. Liu K, Chen Q, Liu Y, Zhou X and Wang X, Isolation and biological activities of decanal, linalool, valencene, and octanal from sweet orange oil. J Food Sci 77:C1156-1161 (2012).

31. Sharon-Asa L, Shalit M, Frydman A, Bar E, Holland D, Or E, Lavi U, Lewinsohn E and Eyal Y, Citrus fruit flavour and aroma biosynthesis: isolation, functional characterization, and developmental regulation of Cstps1, a key gene in the production of the sesquiterpene aroma compound valencene. Plant J 36:664-674 (2003).

32. Manter DK, Kelsey RG and Karchesy JJ, Antimicrobial activity of extractable conifer heart wood compounds to ward Phytophthora aramorum. J Chem Ecol 33:2133-2147 (2007).

33. Mustafa U, Filiz U, Aysun S and Sadık D, Research on antifungal and inhibitory effects of DL-limonene on some yeasts. Turkish Journal of Agriculture \& Forestry 36, 576-582 (2012).

34. Vögeli $U$ and Chappell J, Induction of sesquiterpene cyclase and suppression of squalene synthetase activities in plant cell cultures treated with fungal elicitor. Plant Physiol 88:12911296 (1988).

35. Yokose T, Katamoto K, Park S, Matsuura H and Yoshihara T, Anti-fungal sesquiterpenoid from the root exudate of Solanum abutiloides. Biosci Biotech Bioch 68:2640-2642 (2004).

36. Huffaker A, Kaplan F, Vaughan MM, Dafoe NJ, Ni X, Rocca JR, Alborn HT, Teal PEA and Schmelz, EA, Novel acidic sesquiterpenoids constitute a dominant class of pathogen-induced phytoalexinsin maize. Plant Physiol 156:2082-2097 (2011).

37. Guerlava P, Izac V, Tholozan JL, Comparison of different methods of cell lysis and protein measurements in Clostridium perfringens: Application to the cell volume determination. Curr Microbiol 36:131-135 (1998).

38. Milik TV, Rakin M and Marincovik S, Utilization of baker's yeast (Saccharomyces cerevisiae) for the production of yeast extract: effects of different enzymatic treatments on solid, protein and carbohydrate recovery. J Serb Chem Soc 72:451-457 (2007).

39. Papanikolaou S, Gortzi O, Margeli E, Chinou I, Galiotou-Panayotou M and Lalas S, Effect of citrus essential oil addition upon growth and cellular lipids of Yarrowia lipolytica yeast. Eur J Lipid Sci Tech 110:997-1006 (2008). 
40. Alonso FOM, Oliveira EBL, Dellamora-Ortiz GM and Pereira-Mirelles FV, Improvement of lipase production at different stirring speeds and oxygen levels. Braz J Chem Eng 22:9-18 (2005).

41. Liu Y, Li F, Hu W, Wiltberger K and Ryll T, Effects of bubble-liquid two-phase turbulent hydrodynamics on cell damage in sparged bioreactor. Biotechnol Progr 30:48-58 (2014).

42. Krügener S, Krings U, Zorn $\mathrm{H}$ and Berger RG, A dioxygenase of Pleurotus sapidus transforms (+)-valencene regio-specifically to (+)-nootkatone via a stereo-specific allylic hydroperoxidation. Bioresource Technol 101:457-462 (2010).

43. Sikkema J, De Bont JA and Poolman B, Interactions of cyclic hydrocarbons with biological membranes. J Biol Chem 269:8022-8028 (1994).

44. Sikkema J, De Bont JA, Poolman B, Mechanisms of membrane toxicity of hydrocarbons. Microbiol Rev 59:201-222 (1995).

45. Galabova D, Tuleva B, Spasova D, Permeabilization of Yarrowia lipolytica cells by Triton X-100. Enzyme Microbiol Technol 18:18-22 (1996).

46. Naina N, Gowda LR and Bhat SG, Preparation of NADH/NADPH using cetyltrimethylammonium bromide permeabilized baker's yeast cells. Anal Biochem 196:234237 (1991).

47. Sowden RJ, Yasmin S, Rees NH, Bell SG and Wong, LL, Biotransformation of the sesquiterpene (+)-valencene by cytochrome P450cam and P450BM-3. Org Biomol Chem 3:57-64 (2005).

48. Furusawa M, Hashimoto T, Noma Y and Asakawa Y, Biotransformation of Citrus Aromatics Nootkatone and Valencene by Microorganisms. Chem Pharm Bull 53:1423-1429 (2005).

49. Coelho MAZ, Amaral PFF and Belo I, Yarrowia lipolytica: An industrial workhorse. In: Méndez-Vilas A. (Ed), Curr Res, Technol Educ Top, App Microbiol Microb Biotechnol, 930944 (2010). 


\section{CHAPTER VI}

EFFECT OF HYDRODYNAMIC STRESS AND BIOMASS CONCENTRATION ON THE BIOCONVERSION OF (+)-VALENCENE TO (+)-NOOTKATONE WITH YARROWIA LIPOLYTICA 


\title{
EFFECT OF HYDRODYNAMIC STRESS AND BIOMASS CONCENTRATION ON THE BIOCONVERSION OF (+)-VALENCENE TO (+)-NOOTKATONE WITH YARROWIA LIPOLYTICA
}

\author{
D.M. Palmerín-Carreño, O.M. Rutiaga-Quiñones, J.R. Verde Calvo, S. Huerta-Ochoa*
}

\begin{abstract}
In whole cell bioconversion processes, cell viability and cell concentration are important factors. Process performance might be affected by the hydrodynamic stress caused by the conditions of aeration and agitation on cells growing in stirred bioreactors. The aim of this work was to evaluate the effect of hydrodynamic stress and biomass concentration on the bioconversion of (+)-nootkatone of yeast $Y$. lipolytica 2.2ab in a stirred tank partitioning bioreactor. Orange essential oil was used as a source of (+)-valencene, for the production of (+)nootkatone. The bioconversion was enhanced using $2 \mathrm{X}$ initial biomass concentration reaching a (+)-nootkatone concentration of $803.1 \mathrm{mg} \mathrm{L}^{-1}$ and $67.1 \%$ of bioconversion at $0.25 \mathrm{vvm}$ and $100 \mathrm{rpm}$. Reducing hydrodynamic stress loss of cell viability decreased; however, (+)-nootkatone yield was not improved compared to that observed at $200 \mathrm{rpm}$ and $0.5 \mathrm{vvm}$.
\end{abstract}

Keywords: hydrodynamic stress; increase biomass bioconversion; partition bioreactor

\subsection{Introduction}

The nootkatone is a natural ingredient of high value for the flavor and fragrance industry because of its flavor/aroma of grapefruit, low sensory threshold and low availability. However, the microbial sesquiterpene allylic oxidation of (+)-valencene (Figure 6.1) offers an attractive route for obtaining this coveted fragrance [1].

In the whole cell bioconversion processes product yield is affected by stress caused by the hydrodynamic conditions of aeration and agitation of the cells cultured in stirred bioreactors [3]. Another important factor in bioconversion processes is the effect of biomass concentration on bioconversion.

The aim of this work was to evaluate the effect of hydrodynamic stress and biomass concentration on the bioconversion of (+)-valencene to (+)-nootkatone using yeast $Y$. lipolytica $2.2 \mathrm{ab}$ in a stirred tank partitioning bioreactor. 


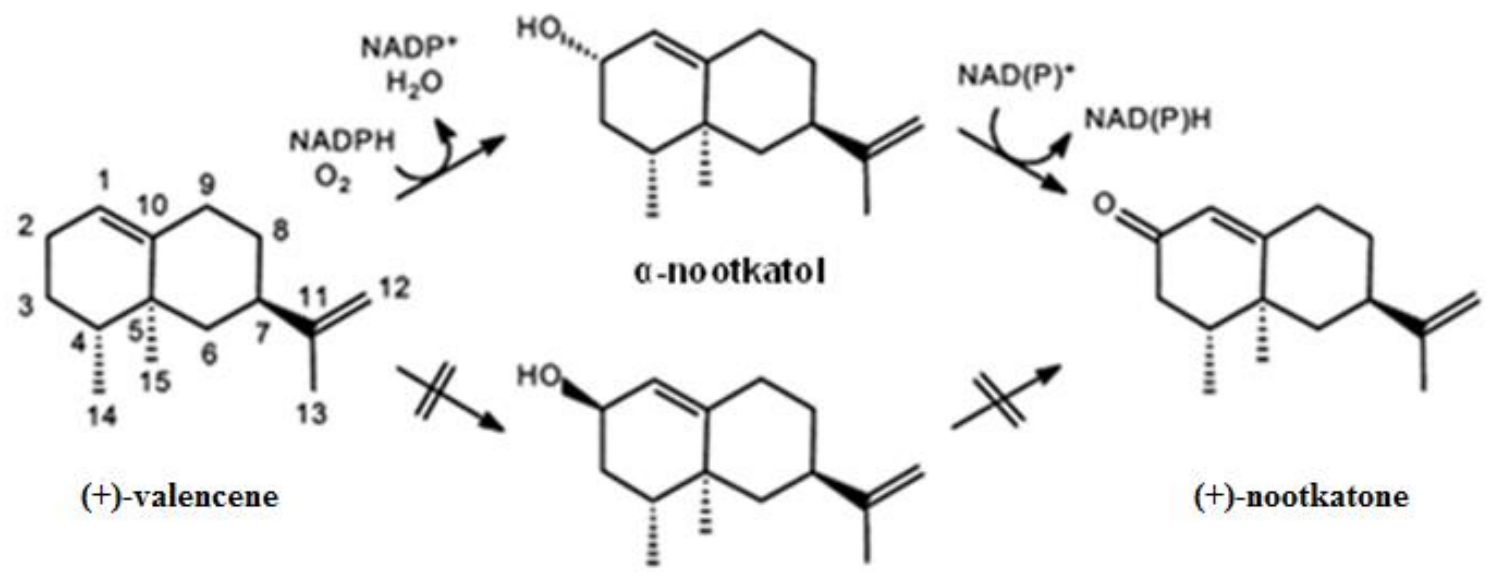

B-nootkatol

Fig. 6.1. Bioconversion of (+)-valencene to (+)-nootkatone [2].

\subsection{Materials and Methods}

The growth of $Y$. lipolytica $2.2 \mathrm{ab}$ was performed by inoculating a final concentration of $1 \times 10^{6}$ cells $\mathrm{mL}^{-1}$ to $350 \mathrm{~mL}$ of liquid medium containing $\left(\mathrm{g} \mathrm{L}^{-1}\right)$ : $\mathrm{Na}_{2} \mathrm{MoO}_{4}, 0.2 ; \mathrm{MnSO}_{4}, 0.4 ; \mathrm{FeCl}_{3}$, 0.2; KI, 0.1; $\mathrm{CuSO}_{4}, 0.04 ; \mathrm{H}_{2} \mathrm{BO}_{3}, 0.5 ; \mathrm{CaCl}_{2}, 0.1 ; \mathrm{NaCl}, 0.1 ; \mathrm{MgSO}_{4} * 7 \mathrm{H}_{2} \mathrm{O}, 0.5 ; \mathrm{KH}_{2} \mathrm{PO}_{4}$, 1; $\mathrm{ZnSO}_{4}, 0.4 ;\left(\mathrm{NH}_{4}\right)_{2} \mathrm{SO}_{4}, 5$; Yeast extract, 4004 [4], $30 \mathrm{~g} \mathrm{~L}^{-1}$ glucose; with an initial pH of 5.5 at $30^{\circ} \mathrm{C}$ in a stirred tank reactor final volume of $1 \mathrm{~L}$; with an agitation of 100 and 200 rpm and aeration of $0.5 \mathrm{vvm}$ and 0.25 respectively.

After 33 hours of growth, biomass concentration $2 \mathrm{X}\left(22 \mathrm{~g} \mathrm{~L}^{-1}\right)$ and $3 \mathrm{X}\left(34 \mathrm{~g} \mathrm{~L}^{-1}\right)$, previously treated with $2 \mathrm{mM}$ Niacin concentration and $0.2 \% \mathrm{w} / \mathrm{v}$ CTAB to regenerate the cofactor $\mathrm{NADPH}^{+}$and Membrane permeabilization, respectively were added [5], to the bioconversion media containing $350 \mathrm{~mL}$ orange essential oil [6]. Subsequently, kinetics of glucose [7], cell viability [8], (+)-valencene and (+)-nootkatone concentration in the organic phase were obtained by gas chromatography [2]. Each experiment was performed in triplicate. The results obtained were analyzed by the Tukey HSD $(p \leq 0.05)$ method with the SAS System package (Version 9).

\subsection{Results and Discussions}

Hydrodynamic stress experiments were carried out without the addition of orange essential oil as control. Figure 6.2 shows that at lower agitation and aeration (100 rpm, and $0.25 \mathrm{vvm})$ 
the loss of cell viability decreases reaching $60 \%$ of viable cells,-: Under these operation conditions, the cell viability was improved compared to the operating conditions of $200 \mathrm{rpm}$ and $0.5 \mathrm{vvm}$. These results suggest that $Y$. lipolytica $2.2 \mathrm{ab}$ strain might be sensitive to oxidative or mechanical stress [3].

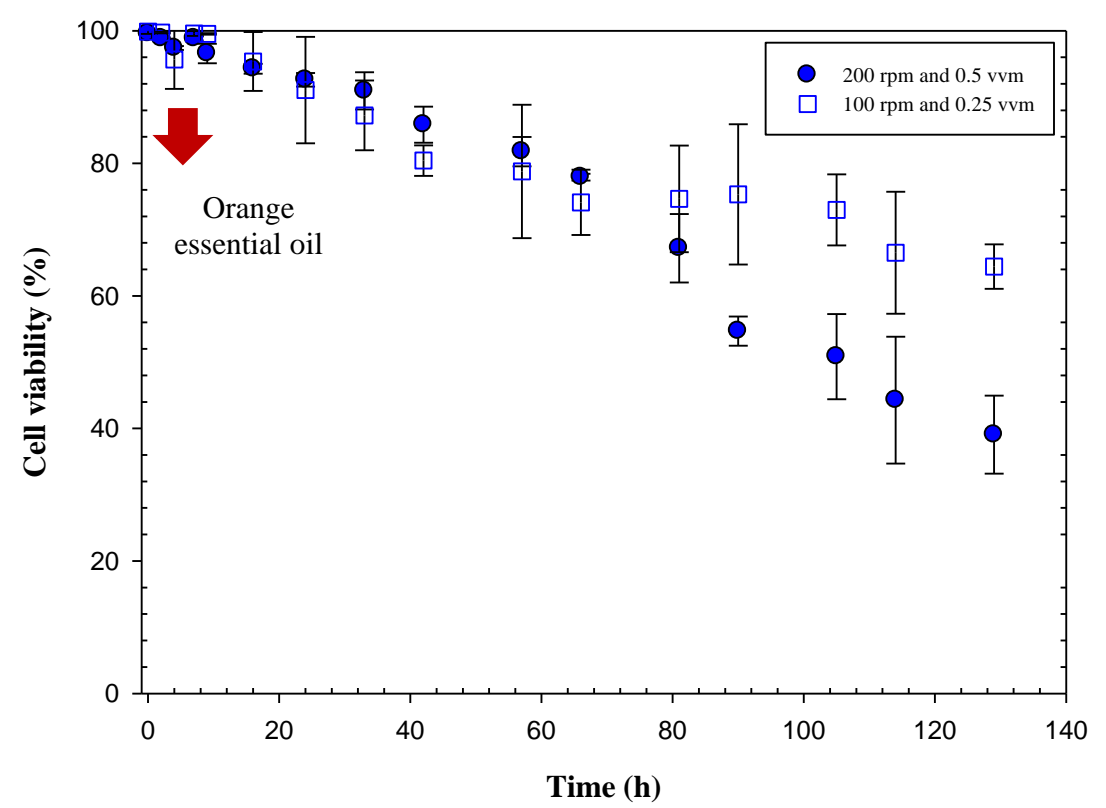

Fig. 6.2. Cell viability kinetics of $Y$. lipolytica $2.2 \mathrm{ab}$ incubated without the addition of (+)valencene at two operation conditions ( $200 \mathrm{rpm}$ and $0.5 \mathrm{vvm}$; and $0.25 \mathrm{vvm}$ and $100 \mathrm{rpm}$ ).

Another strategy to increase (+)-nootkatone production is increasing the amount of biomass during bioconversion. Then experiments increasing biomass concentration at $100 \mathrm{rpm}$ and $0.25 \mathrm{vvm}$, in a three phase bioconversion system using orange essential oil (found 1:1 v/v) as dispersed phase were conducted. Figure 6.3 shows bioconversion kinetics using different biomass concentrations $1 \mathrm{X}, 2 \mathrm{X}$ and $3 \mathrm{X}$. At a biomass concentration of $2 \mathrm{X}$, the highest (+)nootkatone concentration, $803.1 \pm 70.1 \mathrm{mg} \mathrm{L}^{-1}$, with a bioconversion of $67.1 \%$ and reaction rate of $12.5 \mathrm{mg} \mathrm{L}^{-1} \mathrm{~h}^{-1}$ were reached. 


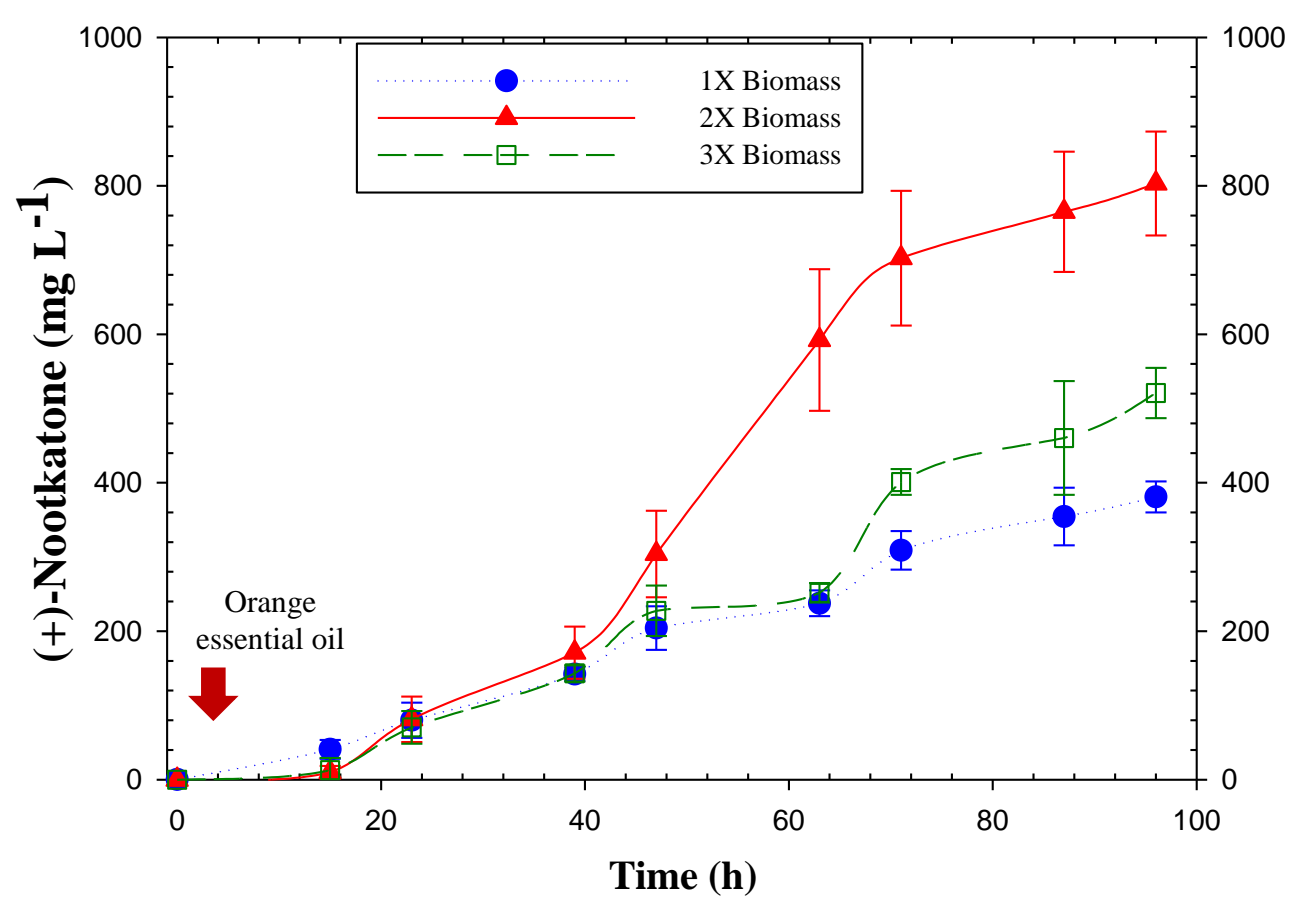

Fig. 6.3. Kinetic of (+)-nootkatone bioconversion at different initial biomass concentrations in a three phase system using $Y$. lipolytica $2.2 \mathrm{ab}$ at $100 \mathrm{rpm}$ and $0.25 \mathrm{vvm}$.

No statistical difference was observed on cell viability using $1 X$ and $2 X$ biomass concentration (Figure 6.4); however, using a biomass concentration of $3 \mathrm{X}$, the (+)nootkatone concentration decreased due to a reduction in cell viability, which reached a value of $40 \%$ after 96 hours of bioconversion. The highest loss of cell viability might be due the increment in oxygen demand as shown in Figure 6.4. Previous results in our laboratory showed an increment of (+)-nootkatone up to $852.3 \mathrm{mg} \mathrm{L}^{-1}$ at $200 \mathrm{rpm}$ and $0.5 \mathrm{vvm}$ with $2 \mathrm{X}$ biomass [5]. A stationary phase was observed after $72 \mathrm{~h}$ of bioconversion. At this point, nonhigher concentrations of (+)-nootkatone were reached probably due to an enzymatic deactivation process. Under these operating conditions a greater supply of oxygen was observed, so a bioconversion experiment was performed with the same operating conditions but using a biomass concentration of $3 \mathrm{X}$ in order to observe a possible increase in the concentration of (+)-nootkatone. Despite of the increment of dissolved oxygen and biomass concentration, similar results in (+)-nootkatone production were observed. 


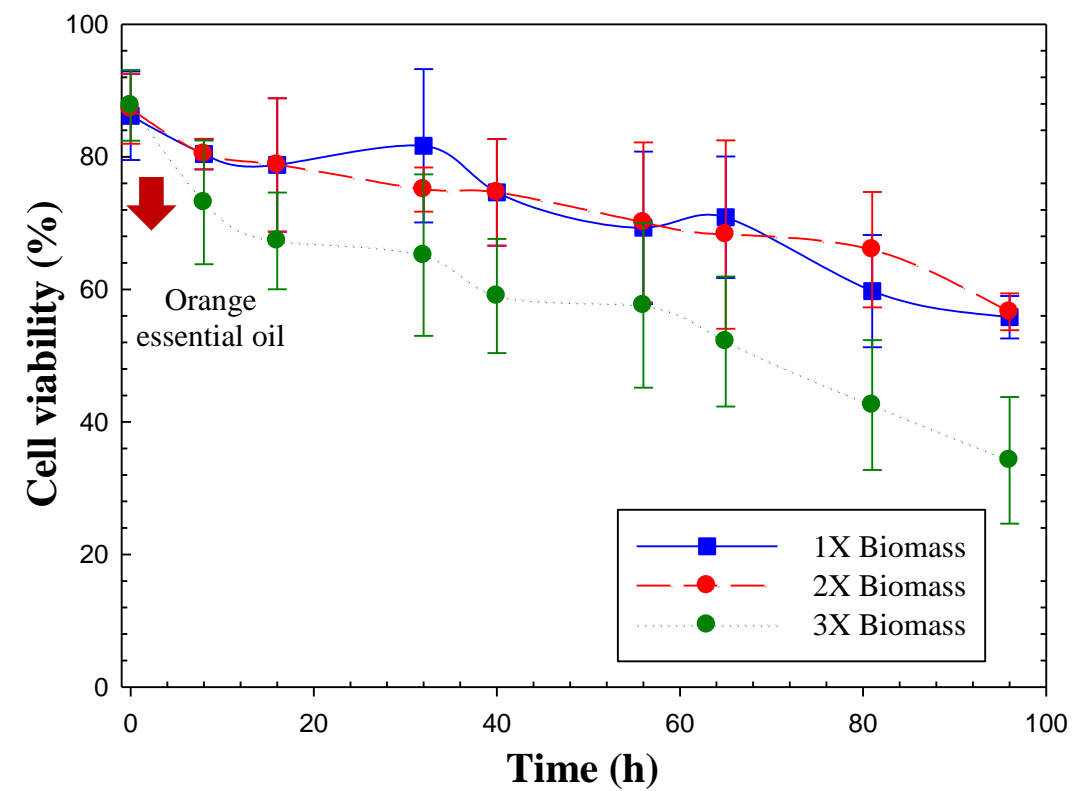

Fig. 6.4. Cell viability kinetics of $Y$. lipolytica $2.2 \mathrm{ab}$ with $1 \mathrm{X}, 2 \mathrm{X}$ and $3 \mathrm{X}$ biomass at $100 \mathrm{rpm}$ and $0.25 \mathrm{vvm}$.

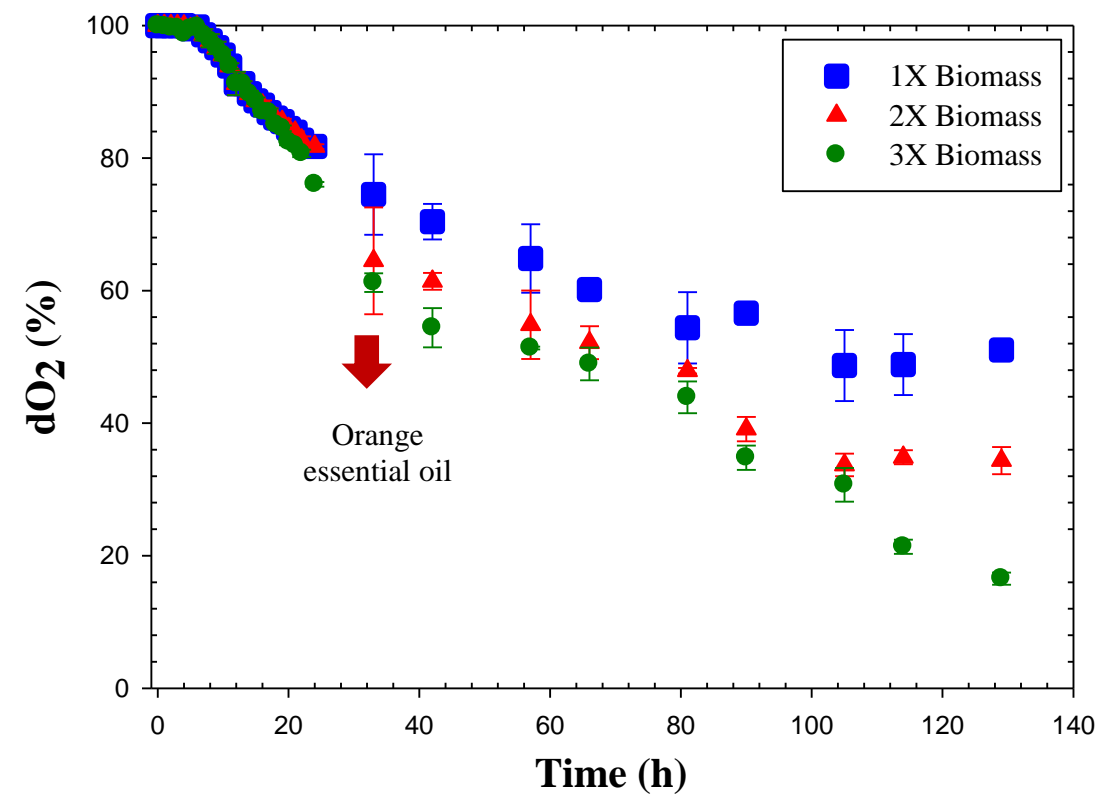

Fig. 6.5. Dissolved oxygen kinetics of $Y$. lipolytica $2.2 \mathrm{ab}$ with $1 \mathrm{X}, 2 \mathrm{X}$ and $3 \mathrm{X}$ biomass at $100 \mathrm{rpm}$ and $0.25 \mathrm{vvm}$. 
Table 6.1. Bioconversions in a three-phase system at $100 \mathrm{rpm}$ and $0.25 \mathrm{vvm}$.

\begin{tabular}{|c|c|c|c|c|c|}
\hline $\begin{array}{c}\text { Biomass } \\
\left(\mathrm{g} \mathrm{L}^{-1}\right)^{\mathrm{i}}\end{array}$ & $\begin{array}{c}\text { Reaction rate } \\
(\mathrm{mg} \mathrm{Nootkatone} \\
\left.\mathrm{L}^{-1} \mathrm{~h}^{-1}\right)^{\mathrm{iii}}\end{array}$ & $\begin{array}{c}\text { Bioconversion } \\
(\%)^{\mathrm{ii}}\end{array}$ & $\begin{array}{c}\text { Volumetric } \\
\text { productivity } \\
\left(\mathrm{mg} \mathrm{L}^{-1} \mathrm{~h}^{-1}\right)^{\mathrm{iii}}\end{array}$ & $\begin{array}{c}\text { Nootkatone/ } \\
\text { biomass Yield } \\
\left(\mathrm{mg} \mathrm{g}^{-1}\right)\end{array}$ & $\begin{array}{c}\text { Maximum } \\
\text { Nootkatone } \\
\left(\mathrm{mg} \mathrm{L}^{-1}\right)^{\mathrm{iv}}\end{array}$ \\
\hline $11.4 \pm 0.8(\mathrm{c})$ & $4.76 \pm 0.4(\mathrm{c})$ & $31.7 \pm 3.8(\mathrm{c})$ & $3.96 \pm 0.21(\mathrm{c})$ & $33.52 \pm 4.55(\mathrm{a})$ & $380.91 \pm 20.9(\mathrm{c})$ \\
\hline $22.0 \pm 0.5$ (b) & $12.5 \pm 2.1(\mathrm{a})$ & $67.1 \pm 15.6(\mathrm{a})$ & $8.36 \pm 0.72(\mathrm{a})$ & $36.77 \pm 3.96(\mathrm{a})$ & $803.14 \pm 70.0(\mathrm{a})$ \\
\hline $33.4 \pm 0.6$ (a) & $7.1 \pm 0.9$ (b) & $46.0 \pm 7.1$ (b) & $5.42 \pm 0.35(\mathrm{~b})$ & $15.34 \pm 0.99$ (b) & $520.88 \pm 33.8$ (b) \\
\hline
\end{tabular}

${ }^{\mathrm{i}}$ Concentration of initial biomass in the growth medium of $Y$. lipolytica.

ii Percentage of (+)-nootkatone produced relative to (+)-valencene consumed based on molecular masses.

iii $\mathrm{mg}$ of nootkatone $\mathrm{L}^{-1}$ produced between 24 and $48 \mathrm{~h}$.

${ }^{\text {iv }} \mathrm{mg}$ of maximum nootkatone $\mathrm{L}^{-1}$ produced after $96 \mathrm{~h}$.

${ }^{v}$ values represent mean \pm standard deviation.

Same letters represent no significant differences ( $\mathrm{p} \leq 0.05$; Tukey, SAS System Version 9).

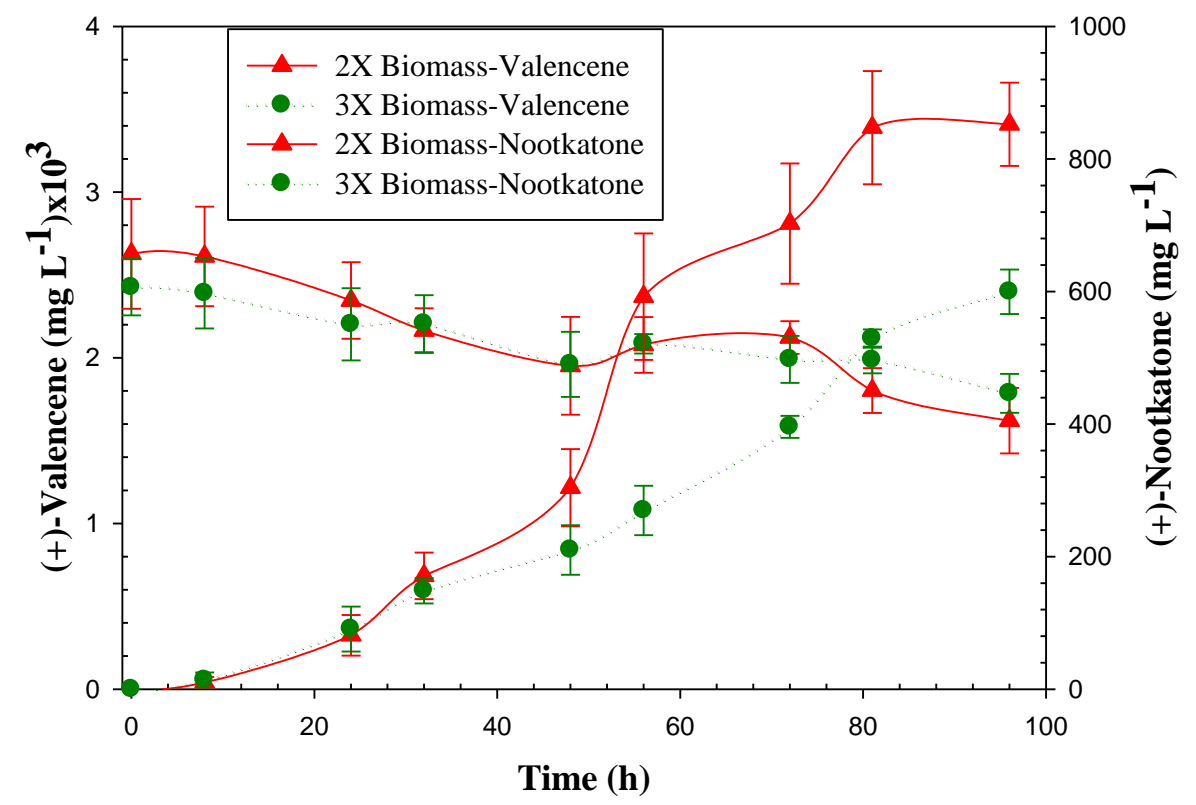

Fig. 6.6. Bioconversion of (+)-valencene to (+)-nootkatone in a three phase system using $Y$.

lipolytica $2.2 \mathrm{ab}$ at $200 \mathrm{rpm}$ and $0.5 \mathrm{vvm}$. 


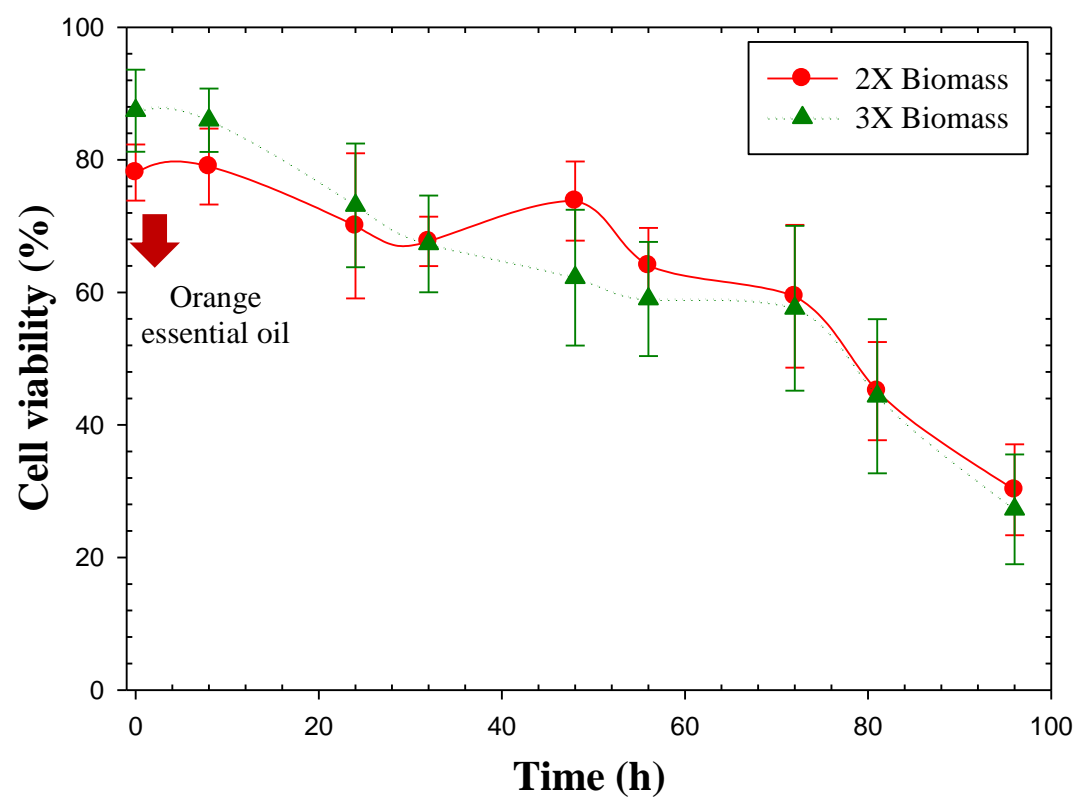

Fig. 6.7. Cell viability kinetics of $Y$. lipolytica $2.2 \mathrm{ab}$ with $2 \mathrm{X}$ and $3 \mathrm{X}$ biomass at $0.5 \mathrm{vvm}$ and 200 rpm.

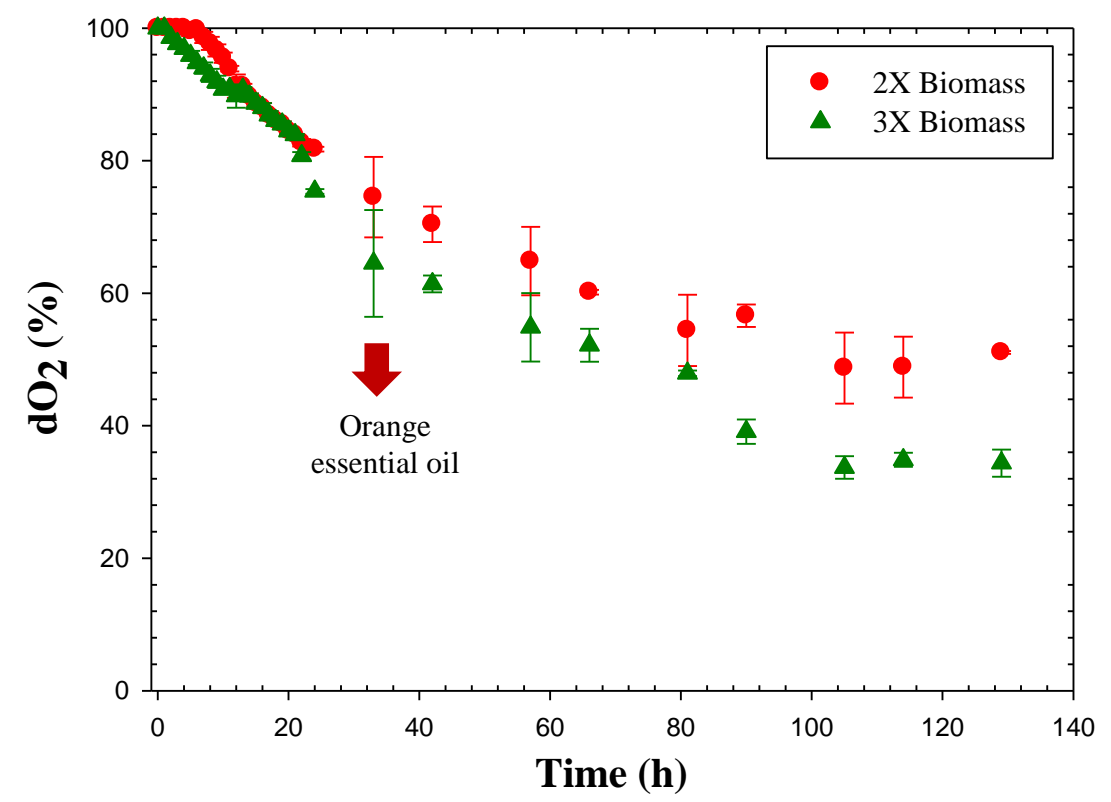

Fig. 6.8. Dissolved oxygen kinetics of $Y$. lipolytica $2.2 \mathrm{ab}$ with $2 \mathrm{X}$ and $3 \mathrm{X}$ biomass at $200 \mathrm{rpm}$ and $0.5 \mathrm{vvm}$. 
In Table 6.2, the results obtained from three-phase experiments are shown. Significantly, at a concentration of $22 \mathrm{~g} \mathrm{~L}^{-1}$ of biomass the maximum bioconversion was reached, this fact confirmed that there is a demand of oxygen by increasing the biomass concentration, which inhibited the bioconversion of substrate. Hsieh et al., [9] used olive oil for the production of biomass and polysaccharides at Grifola frondosa at high levels of aeration at reactor level, they observed a decrease of dissolved oxygen up to $10 \%$ with $30 \mathrm{~g} \mathrm{~L}^{-1}$ of initial biomass. In our study, a similarity decay of dissolved oxygen up to $20 \%$ at the end of the bioconversion with $34 \mathrm{~g} \mathrm{~L}^{-1}$ of initial biomass, the excess of biomass during the bioconversion limits oxygen supply.

Table 6.2. Bioconversions in a three-phase system at $200 \mathrm{rpm}$ and $0.5 \mathrm{vvm}$.

\begin{tabular}{|c|c|c|c|c|c|}
\hline $\begin{array}{c}\text { Biomass } \\
\left(\mathrm{g} \mathrm{L}^{-1}\right)\end{array}$ & $\begin{array}{c}\text { Reaction rate } \\
(\mathrm{mg} \mathrm{Nootkatone} \\
\left.\mathrm{L}^{-1} \mathrm{~h}^{-1}\right)^{\mathrm{iii}}\end{array}$ & $\begin{array}{c}\text { Bioconversion } \\
(\%)^{\mathrm{ii}}\end{array}$ & $\begin{array}{c}\text { Volumetric } \\
\text { productivity } \\
\left(\mathrm{mg} \mathrm{L}^{-1} \mathrm{~h}^{-1}\right)^{\mathrm{iii}}\end{array}$ & $\begin{array}{c}\text { Nootkatone/ } \\
\text { Biomass } \\
\text { Yield }\left(\mathrm{mg} \mathrm{g}^{-1}\right)\end{array}$ & $\begin{array}{c}\text { Maximum } \\
\text { Nootkatone } \\
\left(\mathrm{mg} \mathrm{L}^{-1}\right)^{\mathrm{i}}\end{array}$ \\
\hline $22.0 \pm 0.5(\mathrm{~b})^{\mathrm{i}, \mathrm{v}}$ & $12.9 \pm 2.0(\mathrm{a})$ & $78.0 \pm 19.5(\mathrm{~b})$ & $8.87 \pm 0.65(\mathrm{a})$ & $38.23 \pm 3.25(\mathrm{a})$ & $852.3 \pm 62.8(\mathrm{a})$ \\
\hline $32.4 \pm 1.4(\mathrm{a})^{\mathrm{i}, \mathrm{v}}$ & $7.7 \pm 0.8(\mathrm{~b})$ & $64.9 \pm 6.5(\mathrm{a})$ & $6.24 \pm 6.46(\mathrm{~b})$ & $18.5 \pm 1.0(\mathrm{~b})$ & $599.6 \pm 33.7(\mathrm{~b})$ \\
\hline
\end{tabular}

${ }^{\mathrm{i}}$ Concentration of initial biomass in the growth medium of $Y$. lipolytica.

ii Percentage of (+)-nootkatone produced relative to (+)-valencene consumed based on molecular masses.

iii $\mathrm{mg}$ of nootkatone $\mathrm{L}^{-1}$ produced between 24 and $48 \mathrm{~h}$.

${ }^{\text {iv }} \mathrm{mg}$ of maximum nootkatone $\mathrm{L}^{-1}$ produced after $96 \mathrm{~h}$.

${ }^{\mathrm{v}}$ values represent mean \pm standard deviation.

Same letters represent no significant differences ( $\mathrm{p} \leq 0.05$; Tukey, SAS System Version 9).

\subsection{Conclusions}

The study of the effect of biomass concentration on the bioconversion process led to-obtain a maximum production of (+)-nootkatone at $2 \mathrm{X}, 200 \mathrm{rpm}$ and $0.5 \mathrm{vvm}$. It was observed that using lower agitation and aeration rates the hydrodynamic stress was reduced, which was observed by decreasing the loss of cell viability; however, the product yields were not improved. These results provide the basis to establish operating windows for oxidative bioconversions.

\section{References}

1. Gavira C., R. H Höfer, A. Lesot, F. Lambert, J. Zucca, D. Werck-Reichhart. Challenges and pitfalls of P450-dependent (+)-valencene bioconversion by Saccharomyces cerevisiae. Metabolic Engineering, Vol. 18, p. 25-35, 2013. 
2. Marco Girhard, Kazuhiro Machida, Masashi Itoh, Rolf Schmid, Akira Arisawa and Vlada Urlacher. Regioselective biooxidation of (+)-valencene by recombinant E. coli expressing CYPI09BI from Bacillus subtilis in a two-liquid-phase system. Microbial Cell Factories, Vol. 8, No. 36, p 1-12, 2009.

3. Liu, Y., Li, F., Hu, W., Wiltberger, K., Ryll, T. Effects of bubble-liquid two-phase turbulent hydrodynamics on cell damage in sparged bioreactor. Biotechnol. Prog, Vol.30, p 48-58, 2014.

4. Yeshitila Asteraye Tsigie, Chun-Yuan Wang, Novy S. Kasim, Quy-Do Diem, Lien-Huong Huynh, Quoc-Phong Ho, Chi-Thanh Truong and Yi-Hsu Ju. Oil Production from Yarrowia lipolytica Po1g Using Rice Bran Hydrolysate. J of Biomedicine and Biotechnology, Vol. 1, p 1-10, 2012.

5. D.M. Palmerín-Carreño, C.O. Castillo-Araiza, O.M. Rutiaga-Quiñones, J.R. Verde Calvo, G.M. Trejo-Aguilar, Abhishek Dutta, S. Huerta-Ochoa. Whole cell bioconversion of (+)-valencene to (+)-nootkatone by Yarrowia lipolytica using a three phase partitioning bioreactor. Journal of Chemical Technology and Biotechnology, Doi: 10.1002/jctb.4702, (2015).

6. Dulce Palmerín Carreño, Rutiaga Quiñones O., Verde Calvo R., Huerta Ochoa S. Bioconversion of (+)-nootkatone by Botryodiplodia theobromae using a membrane aereated biofilm reactor. Revista Mexicana de Ingeniería Química, Vol. 13, No. 3, p 757-764, 2014.

7. Gail Lorenz Miller, Robert Blum, William E. Glennon, y Anne L. Burton. Measurement of Carboxymethylcellulase Activity. Analytical Biochemistry, Vol. 2, No. 2, p 127-132, 1960.

8. Angelo Bonora and Donatella Mares. A Simple Colorimetric Method for Detecting Cell Viability in Cultures of Eukaryotic Microorganisms. Current Microbiology, Vol. 7, No. 7, p 217-222, 1982.

9. Chienyan Hsieh, Chia-Jang Liu, Mei-Hua Tseng, Chaur-Tsuen Lo, Yuan-Chang Yang. Effect of olive oil on the production of mycelial biomass and polysaccharides of Grifola frondosa under high oxygen concentration aeration. Enzyme and Microbial Technology, Vol. 39, p 434-439, 2006. 


\section{CHAPTER VII}

WHOLE CELL (+)-NOOTKATONE BIOCONVERSION IN AN ORGANIC PHASE (ORANGE ESSENTIAL OIL) SYSTEM USING YARROWIA LIPOLYTICA

D.M. Palmerín-Carreño, C.O. Castillo Araiza, O.M. Rutiaga-Quiñones, J.R. Verde Calvo,

A. Prado-Barragán, S. Huerta-Ochoa*

In preparation for publication. 


\title{
WHOLE CELL (+)-NOOTKATONE BIOCONVERSION IN AN ORGANIC PHASE (ORANGE ESSENTIAL OIL) SYSTEM USING YARROWIA LIPOLYTICA
}

\author{
D.M. Palmerín-Carreño ${ }^{a}$, C.O. Castillo-Araiza ${ }^{b}$, O.M. Rutiaga-Quiñones ${ }^{c}$, J.R. Verde \\ Calvo $^{\text {a }}$, A. Prado-Barragán ${ }^{\mathrm{a}}$, S. Huerta-Ochoa ${ }^{{ }^{*}}$ \\ aDepartamento de Biotecnología, Universidad Autónoma Metropolitana. \\ P.A. 55-535, 09340 Iztapalapa, México D.F., MÉXICO, sho@xanum.uam.mx \\ ${ }^{\mathrm{b}}$ Grupo de Procesos de Transporte y Reacción en Sistemas Multifásicos. Dpto. de IPH, Universidad \\ Autónoma Metropolitana. P.A. 55-535, 09340 Iztapalapa, México D.F., México. coca@xanum.uam.mx \\ 'Departamento de Química-Bioquímica, Instituto Tecnológico de Durango, Durango. e-mail: \\ omrutiaga@itdurango.edu.mx
}

\begin{abstract}
The aim of this work was to assess whole cell bioconversion of (+)-valencene to (+)-nootkatone in an organic phase (orange essential oil) using a stirred tank bioreactor. Yarrowia lipolytica 2.2ab was used to carry out the bioconversion experiments; $700 \mathrm{~mL}$ of orange essential oil were inoculated with $22.5 \mathrm{~g} \mathrm{~L}^{-1}$ of permeabilized biomass using $0.2 \%$ (w/v) of CTAB, and enriched with $2.0 \mathrm{mM}$ of niacin. Experiments were conducted at 200 rpm, $0.5 \mathrm{vvm}$ and $30{ }^{\circ} \mathrm{C}$. The highest (+)-nootkatone production was $773 \mathrm{mg} \mathrm{L}^{-1}$ after 4 days of conversion. It was observed that there was no statistical difference to the value reported previously using a three-phase partitioning bioreactor. However, bioconversion percent and volumetric productivity was enhanced to $82.3 \%$ and $9.5 \mathrm{mg} \mathrm{L}^{-1} \mathrm{~h}^{-1}$, respectively.
\end{abstract}

Key words: Bioconversion; orange essential oil; (+)-valencene; (+)-nootkatone; Yarrowia lipolytica

\subsection{INTRODUCTION}

The sesquiterpene (+)-nootkatone has a fruity, typically grapefruit odour and is one of the most commonly compounds used in fragrance industry. This compound is mainly produced by chemical processes and thus, commercially available at a relatively high price. Besides, this compound can also be produced via biological processes and, thus, can be sold as natural product $[1,2]$. Different efforts have been focused to enhance whole cell bioconversion of $(+)$-valencene to (+)-nootkatone. Classical genetics approach [3] or metabolic engineering [4] have been reported. Moreover, due to this bioconversion presents substrate and product inhibition [5], the addition of a second liquid phase (organic) has been extensively studied $[5,6]$. Bioconversion of (+)-valencene to (+)-nootkatone has been described, using a wide 
range of microorganisms as catalysts: Botryodiplodia theobromae 1368 [7]; Yarrowia lipolytica 2.2ab [5]; a recombinant $P$. pastoris co-expressing the premnaspirodiene oxygenase of Hyoscyamus muticus (HPO) and the Arabidopsis thaliana cytochrome P450 reductase (CPR) that hydroxylated extracellularly added (+)-valencene [4]; a recombinant strain of E. coli [6], plant enzymes expressed in Saccharomyces cerevisiae [8], Pleurotus sapidus [9], Chaetomium globosum [10], a dioxygenase of Pleurotus sapidus [11] among others.

In recent years, there has been an increasing trend towards valorization of components from essential oils. Amongst these studies, the production of R-(+)- $\alpha$-terpineol by Penicillium sp. 2025, Aspergillus sp. 2038, Fusarium oxysporum 152B from orange essential oil [12], biotransformation of limonene by fungi and red yeast from citrus [13], production of $\alpha$ terpineol by Penicillium digitatum NRRL 1202 from orange peel oil [14], increase bioavailability of orally administered pharmaceutical compounds from essential oils [15], production of peach flavour and lactones by Yarrowia lipolytica from ricinoleic acid [16,17].

The use of whole cells in organic-media biocatalysis provides a way to regenerate cofactors and carry out bioconversions or fermentations requiring multi-step metabolic pathways. [18]. This type of bioprocesses overcome the problem of the low volumetric productivity of the reaction system; besides, the organic phase has a positive effect on the stability of the biocatalyst $[19,20]$. Furthermore, the more hydrophobic solvents manifest less toxicity to whole cells [21].

The aim of this work was to evaluate the performance of $Y$. lipolytica 2.2ab during the bioconversion of (+)-nootkatone in an organic phase (orange essential oil) comparing its volumetric productivity using this organic phase to those reported previously.

\subsection{MATERIALS AND METHODS}

\subsubsection{Chemicals}

(+)-Valencene (CAS 75-05-6) and (+)-nootkatone (CAS 93-78-5) with a purity $>70 \%$ and $>85 \%$, respectively were purchased from Fluka (Switzerland) and used as standards. 
Analytical grade orange essential oil (Citrus aurantium, var. Amara) was purchased from a local drugstore in Mexico City) and used as an organic phase to carry out bioconversion studies.

\subsubsection{Microorganism, culture media and inoculum}

The yeast Yarrowia lipolytica 2.2ab was selected for its potential in the bioconversion of (+)valencene to (+)-nootkatone under different bioconversion conditions [22]. The strain was maintained in potato dextrose agar (PDA, Bioxon-Dickinson, México) at $30^{\circ} \mathrm{C}$. Y. lipolytica 2.2ab was propagated in PDA and incubated at $30^{\circ} \mathrm{C}$ for 3-7 days. Cells were harvested with $25 \mathrm{~mL} 0.01 \%$ Tween-80 and counted using a Neubauer chamber. $100 \mu \mathrm{L}$ of $Y$. lipolytica cell suspension $\left(1 \times 10^{6}\right.$ cells $\left.\mathrm{mL}^{-1}\right)$ were used to inoculate $250 \mathrm{~mL}$ conical flask containing 100 $\mathrm{mL}$ of culture medium. Flasks were incubated at $30{ }^{\circ} \mathrm{C}$ for 4 days on a rotary shaker at 200 rpm. Later biomass was washed and permeabilized using $0.2 \%$ (w/v) of CTAB [5].

\subsubsection{Stirred tank bioreactor for organic phase bioconversions}

A of $1.0 \mathrm{~L}$ glass stirred tank bioreactor (model ADI 1025, Applikon) was used for bioconversion processes. Agitation and the air flow rate for the bioconversion were maintained at $200 \mathrm{rpm}$ and $0.5 \mathrm{vvm}$, respectively. Temperature was maintained at $30^{\circ} \mathrm{C}$. The $\mathrm{pH}$ was monitored and controlled at $5.5 \mathrm{using} 2 \mathrm{M} \mathrm{HCl}$. A refrigerant was located at the air exit to avoid sesquiterpenes evaporation from the bioreactor [5]. Bioconversion studies were conducted adding $22.5 \mathrm{~g} \mathrm{~L}^{-1}$ of permeabilized biomass enriched with $\mathrm{NADPH}^{+}$as a cofactor regeneration to $700 \mathrm{~mL}$ of orange essential oil ( $3.2 \mathrm{~g} \mathrm{~L}^{-1}$ of (+)-valencene) to the bioreactor [5]. Every day, $5 \mathrm{~mL}$ of sample from the bioconversion media was taken and centrifuged at $5000 \mathrm{rpm}$ for $10 \mathrm{~min}$. Then, sesquiterpene extraction was carried out using $500 \mu \mathrm{L}$ of sample and $500 \mu \mathrm{L}$ of ethyl acetate. The mixture was vortexed twice for $20 \mathrm{~s}$ in a vortex, and settled until phase separation occurred, after that $1 \mu \mathrm{L}$ of the ethyl phase was injected to CG [5].

\subsubsection{Analytical techniques}

Biomass determination was carried out by measuring the dry weight of cells. Samples of 5.0 $\mathrm{mL}$ were dried to a constant weight in metal plates which had been previously weighed after being left in an oven at $90{ }^{\circ} \mathrm{C}$ overnight. 
Glucose consumption of Y. lipolytica was determined by analysing the glucose concentration in the medium using the dinitrosalicylic acid method described by Miller et al [23] for reducing sugar, and a UV spectrophotometer at a wavelength of $550 \mathrm{~nm}$.

Cell viability during process was determined by measuring the concentration of living cells using the methylene blue (MB) dye, as described by Bonora and Mares [24]. Culture samples (around $5 \mathrm{~mL}$ ) were aseptically centrifuged at 8,000 rpm for $10 \mathrm{~min}$. Cells were suspended and centrifuged in an equal amount of phosphate buffered saline $\mathrm{pH} 8$ (PBS). PBS was used as a diluent. The MB dye was added to sample during 6 min and suspended again in PBS at the same conditions. The living cells were calculated using time course measurement mode at $640 \mathrm{~nm}$.

The concentrations of (+)-valencene and (+)-nootkatone were determined by gas chromatography (GC-FID) using a Perkin Elmer Auto System XL Gas Chromatograph equipped with a flame ionization detector (Cyclosil-b capillary column; $30 \mathrm{~m} \mathrm{x} 0.32 \mathrm{~mm}$ x $0.25 \mu \mathrm{m} ; \mathrm{J}-\&-\mathrm{W}$ Scientific Inc., CA), using the chromatographic method described previously [5]. Compounds in the samples were identified by comparison of mass spectra with that of pure compounds.

\subsection{RESULTS AND DISCUSSION}

Kinetics of biomass, glucose consumption and cell viability were obtained during the bioconversion in the organic-phase system using orange essential oil (Figure 7.1). It was observed a decrease of cell viability up to $30 \%$ at $96 \mathrm{~h}$ of the bioconversion. Similar results were observed by Palmerín-Carreño et al. [5] in a three-phase system using $50 \%$ (v/v) of orange essential oil as dispersed phase. The prolonged productivity in the organic system

depends on cell viability, in this sense $Y$. lipolytica $2.2 \mathrm{ab}$ shows acceptable tolerance to orange essential oil. Some parameters used for correlation with solvent toxicity are associated with their physicochemical properties such as: the dielectric constant $(\varepsilon)$, dipole moment $(\mu)$, and polarizability $(\alpha)$, all related to the polarity of the solvent; however, available data are not enough to test their validity [25]. 
A progressively decreases of microorganism activity after $8 \mathrm{~h}$ to $10 \%$ was also observed by Cabral et al., [20] using Gluconobacter oxydans which is able to convert isoamyl alcohol to isovalver aldehyde from isooctane. This decrement was possibly due to shear molecular toxicity of the organic phase or the intrinsic deactivation. Viable cells of Rhodococcus erythropolis DCL14 were naturally capable of regenerating the cofactor using n-dodecane as organic phase in order to convert carveol to carvone [2]. Brault et al. [26] reported a wholecell biocatalyst using an $E$. coli showing excellent tolerance to alcohol and short-chain fatty acid denaturation in a micro-aqueous media during the synthesis of a short-chain ester flavour.

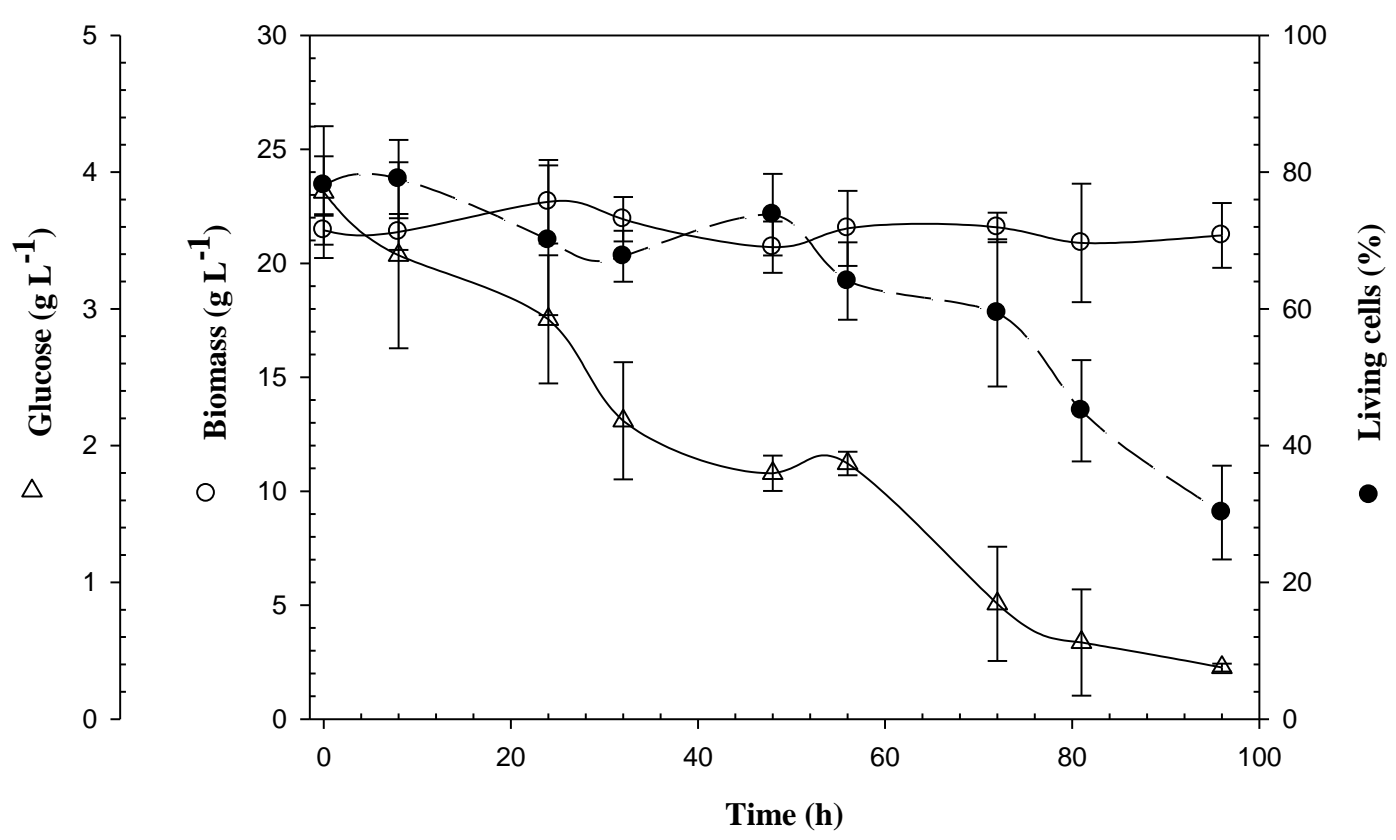

Figure 7.1. Kinetics of biomass $(\circ)$, glucose consumption $(\Delta)$ and cell viability $(\bullet)$ during the bioconversion in an organic-phase system using orange essential oil containing $3.2 \mathrm{~g} \mathrm{~L}^{-1}$ of (+)valencene.

The kinetics of (+)-valencene consumption and (+)-nootkatone production during the bioconversion in the organic-phase system are plotted in Figure 7.2. A nootkatone production of $774 \mathrm{mg} \mathrm{L}^{-1}$ was obtained at $96 \mathrm{~h}$, with an approximate consumption of $0.9 \mathrm{~g} \mathrm{~L}^{-1}$ of (+)valencene. A product/substrate yield of $0.86 \mathrm{~g}(+)$-nootkatone per $\mathrm{g}$ of $(+)$-valencene was achieved. This value was $60 \%$ larger than that obtained in a three-phase system [5]. 
Maróstica and Pastore [12] used Fusarium oxysporum 152B, to convert R-(+)-limonene to $\mathrm{R}$-(+)- $\alpha$-terpineol, yielding nearly $450 \mathrm{mg} \mathrm{L}^{-1}$ after 3 days of transformation in the presence of a solution of $1.0 \%$ orange essential oil in $250 \mathrm{ml}$ conical flasks containing $50 \mathrm{ml}$ of liquid medium. Pseudomona putida cells exposed to very high concentrations of phenol led to an increase in the trans acid [27]. They found that the bioconversion ratio increased around tenfold both for 16:1 and 18:1 fatty acids.

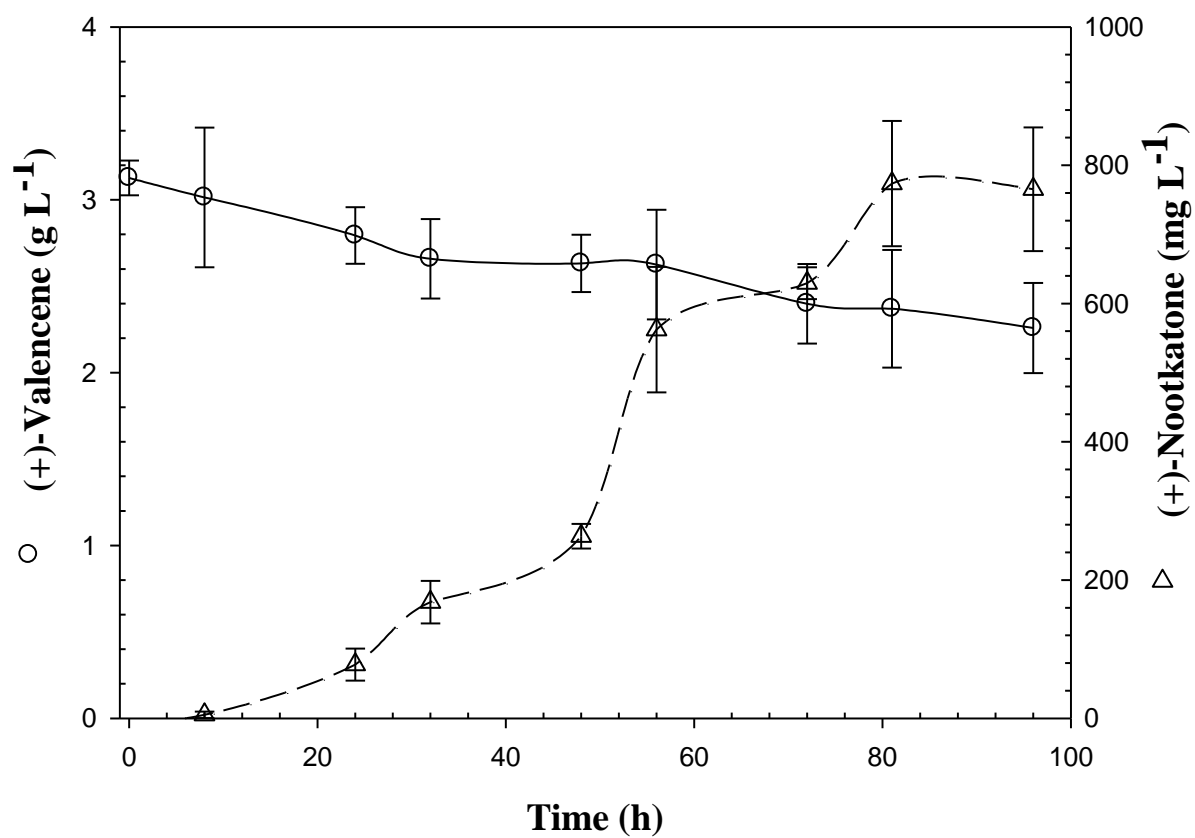

Figure 7.2. Kinetics of $(+)$-valencene consumption $(\circ)$ and $(+)$-nootkatone production $(\Delta)$ during the bioconversion in an organic-phase system using $Y$. lipolytica 2.2ab.

In Table 7.1, bioconversion results are compared to those previously reported in two and three-phase systems [5]. Authors demonstrated that using a two-phase system bioconversion was inhibited by product. However, when a three-phase system was used $852 \mathrm{mg}(+)$ nootkatone $\mathrm{L}^{-1}$ were obtained in the organic phase, $50 \% \mathrm{v} / \mathrm{v}$. The (+)-nootkatone concentration in the organic phase system is slightly lower than those obtained by PalmerínCarreño et al. [5] using $50 \%(\mathrm{v} / \mathrm{v})$ of orange essential oil; however, overall volumetric productivity is higher. This result demonstrated that the substrate concentration in a saturated organic phase was not inhibitory for Y. lipolytica. One possible hypothesis is that this event presents two parallel $Y$. lipolytica metabolism for (+)-valencene distribution, one could lead 
to an intermediary bioconversion to produce energy and another pathway could lead to the formation of (+)-nootkatone. This has previously been reported in some strains of the genus Pseudomonas during the production of terpineol [26].

Tabla 7.1. Overall volumetric productivity in two-phase, three-phase and organic phase systems

\begin{tabular}{|c|c|c|c|c|}
\hline System & $\begin{array}{c}\text { Bioconversion } \\
(\%)^{\mathrm{i}}\end{array}$ & $\begin{array}{c}\text { Final nootkatone } \\
\text { concentration } \\
\left(\mathrm{mg} \mathrm{L}^{-1}\right)^{\mathrm{ii}}\end{array}$ & $\begin{array}{c}\text { Overall volumetric } \\
\text { productivity } \\
\left(\mathrm{mg} \mathrm{L}^{-1} \mathrm{~h}^{-1}\right)^{\mathrm{iii}}\end{array}$ & Reference \\
\hline Aqueous-phase & $77.2 \pm 11.3(\mathrm{~b})$ & $619.8 \pm 33.9(\mathrm{c})$ & $6.46(\mathrm{~b})$ & Palmerín-Carreño \\
& & & $8.06(\mathrm{a})$ & This work \\
\hline Organic-phase & $82.3 \pm 19.3(\mathrm{a})$ & $773.5 \pm 32.6(\mathrm{a}, \mathrm{b})$ & & Palmerín-Carreño \\
\hline Three-phase & $77.9 \pm 19.4(\mathrm{c})$ & $852.2 \pm 62.8(\mathrm{a})$ & $4.44(\mathrm{a})$ & \\
\hline
\end{tabular}

${ }^{i}$ Percentage of (+)-nootkatone produced relative to (+)-valencene consumed based on molecular masses.

ii $\mathrm{mg}$ of maximum nootkatone $\mathrm{L}^{-1}$ produced after $96 \mathrm{~h}$.

iii $\mathrm{mg}$ of nootkatone per liter of bioreactor per hour

Same letters represent no significant differences ( $\mathrm{p} \leq 0.05$; Tukey, SAS System Version 9).

\subsection{CONCLUSIONS}

Finally, in this paper a method for converting (+)-valencene into high concentrations of (+)nootkatone was presented. We report for the first time the (+)-valencene to (+)-nootkatone bioconversion in an organic phase (orange essential oil) using $Y$. lipolytica. It was demonstrated that the use of vegetable oils as organic phase is especially useful in the aforementioned reactions since it inhibited the concurrent oxidative metabolism, enabling to obtain higher (+) nootkatone yield (0.86 $\mathrm{g}(+)$-nootkatone per $\mathrm{g}$ of $(+)$-valencene) at a bioconversion close to $82 \%$ than that observed from conventional two-phase and three phase reaction systems.

\section{REFERENCES}

1 Berger, R G (Ed.). Aroma biotechnology. Berlin-Heidelberg: Springer-Verlag (1995). 
2 Carvalho, CCC R, and Fonseca, MMR, Maintenance of cell viability in the biotransformation of (+)-carveol with whole cells of Rhodococcus erythropolis. Journal of Molecular Catalysis B: Enzymatic 19:389-398 (2002).

3 Omarini, AB, Plagemann I, Schimanski S, Krings U, Berger RG, Crosses between monokaryons of Pleurotus sapidus or Pleurotus florida show an improved biotransformation of (+)-valencene to (+)-nootkatone. Bioresource Technology, 171:113-119 (2014).

4 Wriessnegger T, Augustin P, Engleder M, Leitner E, Müler M, Kaluzna I, Schümann M, Mink E, Zellnig G, Schwab H and Pichler H, Production of the sesquiterpenoid (+)-nootkatone by metabolic engineering of Pichia pastoris. Metab Eng 24:18-29 (2014).

5 Palmerín Carreño DM., CO Castillo A, OM Rutiaga Q, JR Verde C, GM Trejo A, Abhishek Dutta, S Huerta Ochoa, Whole cell bioconversion of (+)-valencene to (+)-nootkatone by Yarrowia lipolytica using a three phase partitioning bioreactor. Journal of Chemical Technology and Biotechnology Doi: 10.1002/jctb.4702, (2015a).

6 Girhard M, Kazuhiro M, Masashi I, Rolf S, Akira Ar and Vlada U, Regioselective biooxidation of (+)-valencene by recombinant E. coli expressing CYPI09BI from Bacillus subtilis in a twoliquid-phase system. Microbial Cell Factories 8:1-12 (2009).

7 Palmerín Carreño DM, Rutiaga Quiñones O, Verde Calvo R, Huerta Ochoa S, Bioconversion of (+)-nootkatone by Botryodiplodia theobromae using a membrane aereated biofilm reactor. Revista Mexicana de Ingeniería Química 13:757-764 (2014).

8 Gavira C, R H Höfer, A Lesot, F Lambert, J Zucca, D Werck-Reichhart, Challenges and pitfalls of P450-dependent (+)-valencene bioconversion by Saccharomyces cerevisiae. Metabolic Engineering 18:25-35 (2013).

9 Fraatz MA, Berger RG and Zorn H, Nootkatone-a biotechnological challenge. Appl Microbiol Biotechnol 83:35-41 (2009).

10 Kaspera R, Krings U, Nanzad T and Berger RG, Bioconversion of (+)-valencene in submerged cultures of the ascomycete Chaetomium globosum. Appl Microbiol Biotechnol 67:477-483 (2005).

11 Krügener S, Krings U, Zorn H and Berger RG, A dioxygenase of Pleurotus sapidus transforms (+)-valencene regio-specifically to (+)-nootkatone via a stereo-specific allylic hydroperoxidation. Bioresource Technol 101:457-462 (2010).

12 Maróstica MR and Pastore GM, Production of R-(+)- $\alpha$-terpineol by the biotransformation of limonene from orange essential oil, using cassava waste water as medium. Food Chem 101:345350 (2007). 
13 Noma, Y and Y Asakawa, Biotransformation of limonene and related compounds by newly isolated low temperature grown citrus pathogenic fungi and red yeast. Book of Abstract of the $38^{\text {th }}$ ISEO, p.7, 2007a.

14 Badee, AZM, Shahinaz A Helmy, Nashwa FS Morsy, Utilisation of orange peel in the production of a-terpineol by Penicillium digitatum (NRRL 1202). Food Chemistry 126:849-854 (2011).

15 Benet Leslie Z, Vincent J Wacher, Reed M Benet, Use of essential oils to increase bioavailability of orally administered pharmaceutical compounds. US 6121234 A (2000).

16 Endrizzi A, Pagot Y, Le Clainche A, Nicaud JM, Belin JM, Production of lactones and peroxisomal $\beta$-oxidation in yeasts. Crit Rev Biotechnol 16:301-329 (1996).

17 Waché Y, Aguedo M, LeDall MT, Nicaud JM, Belin JM, Optimization of Yarrowia lipolytica's $\beta$-oxidation pathway for lactones production. J Mol Catal B Enzym 153:347-351 (2002).

18 León R, P Fernandez, H M Pinheiro, and J M S Cabral, Whole-cell biocatalysis in organic media. Enzyme and Microbial Technology 23:483-500 (1998).

19 Cantone S, Ulf Hanefeldb and Alessandra Basso, Biocatalysis in non-conventional media-ionic liquids, supercritical fluids and the gas phase. Green Chemistry 9:954:971 (2007).

20 Cabral JMS, MR Aires Barros, H Pinheiro, DMF Praze, Biotransformation in organic media by enzymes and whole cells. Journal of Biotechnology 59:133-143 (1997).

21 Nikolova Penka and Owen P Ward, Whole cell biocatalysis in nonconventional media. Journal of Industrial Microbiology, 12:76-86 (1993).

22 Palmerín-Carreño D.M., Rutiaga-Quiñones O.M., Verde Calvo J.R., Prado-Barragán A., HuertaOchoa S. Screening of microorganisms for bioconversion of (+)-valencene to (+)-nootkatone. LWT-Food Science and Technology. 64:788-793 (2015b).

23 Miller GL, Robert B, William E G, and Anne L Bu, Measurement of Carboxymethylcellulase Activity. Analytical Biochemistry 2:127-132 (1960).

24 Bonora A and Mares D, A Simple Colorimetric Method for Detecting Cell Viability in Cultures of Eukaryotic Microorganisms, Current Microbiology 7:217-222 (1992).

25 León R, Fernandes P, Pinheiro HM and Cabral JMS, Whole-cell biocatalysis in organic media. Enzyme and Microbial Technology 23:483-500 (1998).

26 Brault G, F Shareck, Y Hurtubise, F Lépine, N Doucet, Short-chain flavor ester synthesis in organic media by an E. coli whole-cell biocatalyst expressing a newly characterized heterologous lipase, PLoS ONE, 9(3):1-9 (2014).

27 Bicas JL, Fontanille P, Pastore GM, Larroche C, Characterization of monoterpene biotransformation in two pseudomonads. J Appl Microbiol 105:1991-2001 (2008). 


\section{CHAPTER VIII}

HYDRODYNAMIC AND OXYGEN MASS TRANSFER STUDIES IN A THREEPHASE (AIR-WATER-ORANGE ESSENTIAL OIL) STIRRED TANK BIOREACTOR FOR THE BIOCONVERSION OF (+)-VALENCENE WITH YARROWIA LIPOLYTICA

Palmerín-Carreño D.M., Castillo-Araiza C.O., Rutiaga-Quiñones O.M., Verde-Calvo J.R. Huerta-Ochoa S.

In preparation for publication. 


\title{
HYDRODYNAMIC AND OXYGEN MASS TRANSFER STUDIES IN A THREE- PHASE (AIR-WATER-ESSENTIAL ORANGE OIL) STIRRED TANK BIOREACTOR FOR THE BIOCONVERSION OF (+)-VALENCENE WITH YARROWIA LIPOLYTICA
}

\author{
Palmerín-Carreño D.M. ${ }^{1}$, Castillo-Araiza C.O. ${ }^{2}$, Rutiaga-Quiñones O.M. ${ }^{3}$, Verde-Calvo \\ J.R. ${ }^{1}$, Huerta-Ochoa S. ${ }^{1}$ \\ ${ }^{I}$ Departamento de Biotecnología, Universidad Autónoma Metropolitana. \\ P.A. 55-535, 09340 Iztapalapa, México D.F., MÉXICO, e-mail:sho@xanum.uam.mx \\ ${ }^{2}$ Grupo de Procesos de Transporte y Reacción en Sistemas Multifásicos. Dpto. de IPH, Universidad \\ Autónoma Metropolitana. P.A. 55-535, 09340 Iztapalapa, México D.F., México. coca@xanum.uam.mx \\ ${ }^{3}$ Departamento de Química-Bioquímica, Instituto Tecnológico de Durango, Durango. e-mail: \\ omrutiaga@itdurango.edu.mx
}

\begin{abstract}
The productivity of the bioconversion of (+)-valencene to (+)-nootkatone by Yarrowia lipolytica 2.2ab in a multiphase system can be limited by mass transport. The aim of this work was to characterize the hydrodynamic and oxygen mass transfer in a three phase (gas-water-orange essential oil) partitioning bioreactor. Firstly, a central composite experimental design was used to investigate the interaction of three operational factors i.e. agitation (300, 400, $500 \mathrm{rpm})$, aeration rates $(0.5,0.75,1.0 \mathrm{vvm})$, and orange essential oil volume fraction (20, $35,50 \%)$, on two response variables i.e., the Sauter mean droplet diameter $\left(d_{32}\right)$ and the volumetric oxygen transfer coefficient $\left(k_{L} a\right)$. The hydrodynamic and mass transfer studies led to $k_{L} a$ and $d_{32}$ values of $53.76 \mathrm{~h}^{-1}$ and $10.09 \mu \mathrm{m}$, respectively. Secondly, the substrate $\left(k_{S}\right)$ and product $\left(k_{P}\right)$ global mass transfer coefficients were determined in a modified Lewis cell. The maximum $k_{S}$ and $k_{P}$ values obtained were $3.02 \times 10^{-5}$ and $2.81 \times 10^{-5} \mathrm{~m}$ $\mathrm{s}^{-1}$, respectively. The volumetric mass transfer coefficients $\left(k_{S} A\right.$ and $\left.k_{P} A\right)$ were calculated using interfacial areas $(A)$ of the dispersed phase (orange essential oil) estimated from the "Sauter" mean drop diameter $\left(d_{32}\right)$ in one liter stirred tank partitioning bioreactor. Finally, from a regime analysis it was observed that the characteristic time obtained for oxygen uptake rate $\left(94 \mathrm{~s}^{-1}\right)$ was among the characteristic times determined for oxygen transfer $\left(67 \mathrm{~s}^{-1}\right)$ at $200 \mathrm{rpm}$ and $0.5 \mathrm{vvm}$ as operating conditions, suggesting that the oxygen transfer rate under certain operating conditions could be a limiting step in the bioconversion process.
\end{abstract}

Keywords: Multiphase bioreactor; hydrodynamics; oxygen mass transfer; (+)-nootkatone; Yarrowia lipolytica 


\subsection{INTRODUCTION}

The compound (+)-nootkatone is a valuable sesquiterpenoid which possesses an intense grapefruit-like taste that are exploited by the fragrance and flavour industries (Ladaniya, 2010). Industry and academia are interested on this biocatalytic process using whole cells, which involves the selection of an optimal cellular enzyme, reaction engineering, product recovery and scaling-up. Different efforts have been focused to enhance whole cell bioconversion of (+)-valencene to (+)-nootkatone. Classical genetics approach (Omarini et al., 2014) or metabolic engineering (Wriessnegger et al., 2014) have been reported. Girhard et al. (2009) described the conversion of (+)-valencene by recombinant E. coli expressing CYP109B1 from Bacillus subtilis in a two-liquid-phase system. Recently, in previous work the bioconversion of (+)-valencene to (+)-nootkatone with Yarrowia lipolytica in a partitioning bioreactor using orange essential oil as the dispersed phase was successfully evaluated (Palmerín-Carreño et al., 2015). The addition of orange essential oil as second liquid phase as a substrate reservoir and in situ product extracting agent overcame substrate and product inhibition increasing process performance. Orange essential oil used in this type of bioprocess has concentrations of (+)-valencene and (+)-nootkatone of $3.2 \mathrm{~g} \mathrm{~L}^{-1}$ and 0.94 mg L ${ }^{-1}$, respectively (Palmerín-Carreño et al., 2015). These concentrations are known to be dependent from the harvest and fruit species.

Multiphase partitioning bioreactors conception seems to have a great potential in enhancing the productivity of many bioprocesses by overcoming issues of poor substrate solubility and toxicity (Melgarejo-Torres et al., 2015). However, the productivity of oxidative bioconversions in a multiphase system (Doig et al., 2002) could be limited by low mass transfer rates across the inter-phases (gas-liquid and/or liquid-liquid). Substrate, product and oxygen transfer rates will also depend on the fluid physicochemical properties, temperature, pressure, media composition, agitation conditions, oxygen superficial gas velocity and the configuration of the bioreactor. Physicochemical properties influence thermodynamic equilibrium of substrate and product in the interface observed in the partition coefficient. The high (+)-nootkatone partition coefficient (22.5) reported by Palmerín-Carreño et al. (2015) implies a good affinity of (+)-nootkatone for orange essential oil (organic phase), which is advantageous for in situ recovery in the partitioning bioreactor. 
Mass transfer rates in a multiphase system are functions of the Sauter mean drop size diameter $\left(d_{32}\right)$, oxygen volumetric mass transfer coefficient $\left(k_{L} a\right)$, substrate partition coefficient, and the oxygen solubility into the medium. For a specific partitioning bioreactor and medium, it is normally possible to increase the liquid-liquid interfacial area and $k_{L} a$, and consequently mass transfer rates, using high agitation and aeration rates. However, this causes high power consumption and significantly increasing operation costs. High stirring rates also present a limitation when applied to cells that are sensitive to hydrodynamic stress and can promote stable emulsion formation leading to downstream processing problems. Hydrodynamic studies in two-phase partitioning bioreactors have focused on elucidation of the interfacial area available form ass transfer in order that substrate supply (normally from the non-aqueous phase) does not become the rate limiting step of the process. The interfacial area has previously been correlated to the dispersed phase hold-up fraction and the Weber number (Quadros and Baptista, 2003). The interfacial area available for mass transfer $(a)$ is given by:

$a=\frac{6 \phi}{d_{32}}$

where $d_{32}$ is the Sauter mean drop diameter and $\phi$ is the volume fraction of the dispersed phase. Accurate knowledge of the effect of bioreactor operating conditions on $d_{32}$ is therefore very important. Besides, knowledge of $d_{32}$ can give an early indication of the stability of the liquid-liquid dispersion created. The physicochemical properties of the media can influence both mean drop size and drop size distribution. If dispersed-phase viscosity, $\mu_{d}$, is low, the force resisting drop break-up comes only from surface tension (Nienow, 2004). The majority of studies have used organic solvents as the second phase; however, these pose additional toxicity and flammability problems. Recently, the use of essential oils has been reported as a safe alternative for the bioconversion of pharmaceutical and terpenes (Krings and Berger, 2010).

The aim of this work was to characterize the hydrodynamic and oxygen mass transfer in a three phase gas-water-orange essential oil dispersion and determine substrate and product global mass transfer coefficients in three biphasic water-orange essential oil system. This 
work will be useful for the purposes of bioreactor design and scale-up and will inform our ongoing studies of oxidative bioconversions in multiphase systems.

\subsection{MATERIALS AND METHODS}

\subsubsection{Chemicals}

(+)-Valencene (CAS 75-05-6) and (+)-nootkatone (CAS 93-78-5) with a purity $>70 \%$ and $>85 \%$, respectively were purchased from Fluka (Switzerland) and used as standards. Ethyl acetate (99.5\%) used for sesquiterpene extraction was purchased from Quimex (Mexico). Analytical grade orange essential oil (Citrus aurantium, var. Amara) was purchased from a local drugstore in Mexico DF, and used as an organic dispersed phase.

\subsubsection{Measurement of physicochemical properties of two-phase system}

\subsubsection{Determination of viscosity}

The apparent viscosity of orange essential oil was measured using a modular compact rheometer Physica MCR 300 (Brookfield Engineering Laboratories, Germany). Samples of $20 \mathrm{~mL}$ were placed in a PP glass, doing the reading with a LV2 geometry. Temperature was controlled with a Peltier (TEL $150 \mathrm{P}-\mathrm{C}$ ) at $30^{\circ} \mathrm{C}$. Measurements were performed in triplicate.

\subsubsection{Measurement of the density of orange essential oil}

A hydrometer DMA 35 (Anton Paar, Austria) was used to determine the amount of mass contained in a certain volume of orange essential oil.

\subsubsection{Measurement of interfacial tension}

Interfacial tension was measured using a Tensiometer (Fisher, Model 20) at $30^{\circ} \mathrm{C}$. A sample of $20 \mathrm{~mL}$ of mineral medium were placed in a clean container glass (4 cm diameter) and 4 $\mathrm{cm}$ in height, and $20 \mathrm{~mL}$ of orange essential oil was added carefully, taking care not to disturb the interface between two fluids. Then, platinum ring $(0.6 \mathrm{~mm}$ diameter $)$ was placed below the interface. Then, the ring was elevated at a constant speed until a thin interface film was formed; tension measurements were taken until the thin film was broken. Calibration is performed using distilled water as reference. Measurements were performed in triplicate. 


\subsubsection{Stirred tank bioreactor description}

A 1.0 L glass stirred tank bioreactor (model ADI 1025, Applikon) was used for hydrodynamic and mass transfer characterization. The bioreactor had an inside diameter of $9.5 \mathrm{~cm}$ and an operation volume of $0.7 \mathrm{~L}\left(\mathrm{H}_{\mathrm{L}} / \mathrm{D}_{\mathrm{T}}=0.96\right)$. The bioreactor was equipped with a single Rushton turbine with 6 paddles, $\mathrm{D}_{\mathrm{i}}=4.53 \mathrm{~cm}\left(\mathrm{D}_{\mathrm{i}} / \mathrm{D}_{\mathrm{T}}=0.46\right)$, located $4.53 \mathrm{~cm}$ from the base of the container. The bioreactor had 2 equidistant deflectors of $1.0 \mathrm{~cm}$ in width to improve liquid-liquid mixing. Temperature and agitation were maintained at $30^{\circ} \mathrm{C}$ and 300 rpm, respectively. The $\mathrm{pH}$ was monitored using an AppLiSens Z001023511 pH electrode (Applikon) and controlled at 5.5 using 2M NaOH. Atmospheric air entering the system was filtered through a sterile $0.22 \mu \mathrm{m}$ filter. The air flow rate in the bioreactor was $0.5 \mathrm{vvm}$ through a perforated "L" tube with seven holes of $1.0 \mathrm{~mm}$ in diameter.

\subsubsection{Aerated power consumption $\left(P_{g}\right)$}

Aerated power consumption was measured using the methodology reported by Ascanio et al. (2004). The method is based on electrical measurements (Watts and amperes) carried out directly on the motor shaft of the bioreactor impeller. To consider the losses occurring in the agitation system, electrical measurements were also obtained when the bioreactor was empty. All measurements were performed in triplicate.

\subsubsection{Determination of oxygen mass transfer coefficient $\left(k_{L} a\right)$}

Oxygen mass transfer coefficient $\left(k_{L} a\right)$ was determined according to the dynamic method reported by Koizumi and Aiba (1984) using dissolved oxygen electrode (AppLiSens Z010032520, Applikon). Oxygen electrode was attached to a controller Bio IDA 1010 (Applikon). Dissolved oxygen concentrations were taken every 5 seconds. The effect of operating conditions: agitation rate $(300,400$, and $500 \mathrm{rpm})$, aeration rate $(0.5,0.75$ and 1.0 vvm), and orange essential oil fraction $(20,35$ and $50 \% \mathrm{v} / \mathrm{v})$ on the volumetric oxygen transfer coefficient was studied.

\subsubsection{Measurement of Sauter mean drop diameter ( $\left.d_{32}\right)$}

The Sauter mean drop diameter $\left(d_{32}\right)$ was measured using a particle Analyzer, Optical Reflectance Meter (3D ORM, MTS, Messtechnic Schwartz) (Jaradat et al., 2010; Ahosseini 
et al., 2010). Two thousand automatic determinations of the drop diameter $\left(d_{i}\right)$ for each measurement were taken, that allows the calculation of $d_{32}$, as defined in equation (2):

$d_{32}=\frac{\sum d_{i}^{3} n_{i}}{\sum d_{i}^{2} n_{i}}$

Mean drop diameter and drop diameter distribution were obtained in situ and on-line in all experiments. Since the 3D-ORM equipment measures the drop size by optical reflectance of a laser beam and the fact that gas bubbles do not have reflectance properties, it was assumed that gas bubbles did not interfere with the measures of the drop size of orange essential oil. This was confirmed measuring the size of ion exchange beads at different agitation and aeration rates as a positive control. Therefore, droplet size measurements were taken directly from the three-phase system. With the aim that the drop size distribution reach the equilibrium, measurements were taken 15 minutes after agitation had begun.

\subsubsection{Lewis cell}

A modified Lewis cell was used, consisting of a jacketed glass vessel $11.8 \mathrm{~cm}$ high and with an internal diameter of $6.7 \mathrm{~cm}$ (Melgarejo-Torres et al., 2012). Each phase had a volume of $182 \mathrm{~mL}$. Two independent marine propellers $\left(\mathrm{d}_{\mathrm{i}}=3.5 \mathrm{~cm}\right)$, each one located inside a suction glass tube (internal diameter $4 \mathrm{~cm}$ and height $3.5 \mathrm{~cm}$ ) supported by six baffles producing a radial and tangential flow motion to a constant interfacial area $\left(a_{\text {cell }}\right)$ of $18.5 \mathrm{~m}^{2} \mathrm{~m}^{-3}$. Temperature of both liquids inside the Lewis cell was kept at $30^{\circ} \mathrm{C}$ by passing water through the cell's jacket from a water bath. Different agitation rates (40,60 and $80 \mathrm{rpm})$ in the organic phase were settled, allowing different liquid velocities $\left(V_{S}\right)$ in each phase near the interface. The aqueous phase was constant $(60 \mathrm{rpm})$. To determine $V_{S}$, small bead particles were made from silicon and epoxy resin with the same fluid density. Time required for the small bead to go around the internal tube at different agitation rates in each phase was measured and an arithmetic average was obtained, and this value was used to calculated fluid velocity (LizardiJiménez and Gutiérrez-Rojas, 2011). Then, global mass transfer coefficients could be estimated at liquid velocity values close to those obtained in a dispersion system. 


\subsubsection{Experiments in the Lewis cell}

In the experiments using orange essential oil, only the organic phase was agitated. Aqueous phase agitation rate was $60 \mathrm{rpm}$ for the water-orange essential oil system. Therefore, the aqueous phase was prepared as follow: $3.2 \mathrm{~g} \mathrm{~L}^{-1}$ of nootkatone was dissolved in a $0.1 \mathrm{M}$ phosphate buffer adjusted to $\mathrm{pH}$ 7.5. Also, the organic phase was orange essential oil containing $3.2 \mathrm{~g} \mathrm{~L}^{-1}$ of (+)-valencene. Samples of $1.0 \mathrm{~mL}$ were taken from the organic phase at different time intervals from $\mathrm{t}=0$ to $3 \mathrm{~h}$; this time was necessary to reach equilibrium. The samples were analysed by gas chromatography (GC) and a standard curve was used to determine substrate and product concentration in the organic phase. Substrate and product concentrations in the aqueous phase were calculated from mass balance.

\subsubsection{Sesquiterpene analysis}

The concentrations of (+)-valencene and (+)-nootkatone were determined by gas chromatography (GC-FID) using a Perkin Elmer Auto System XL Gas Chromatograph equipped with a flame ionisation detector (Cyclosil-B capillary column; $30 \mathrm{~m} \mathrm{x} 0.32 \mathrm{~mm}$ x $0.25 \mu \mathrm{m} ; \mathrm{J}-\&-\mathrm{W}$ Scientific Inc., CA). The temperatures of the injector and detector were constant at $250{ }^{\circ} \mathrm{C}$ to $270{ }^{\circ} \mathrm{C}$, respectively. During the analysis $1 \mu \mathrm{L}$ of sample was automatically injected with a split ratio of 1:4, using helium gas as a carrier. The oven

temperature was initially set to $120{ }^{\circ} \mathrm{C}$ for 4 min then ramped up to $250{ }^{\circ} \mathrm{C}$ at a rate of $10{ }^{\circ} \mathrm{C}$ per min and maintained at $250{ }^{\circ} \mathrm{C}$ for $5 \mathrm{~min}$, using the technique reported by Girhard et al.(2009). Analyses were performed in triplicate, and concentrations were determined using external calibration curves of (+)-valencene and (+)-nootkatone.

\subsubsection{Estimation of mass transfer coefficients}

Solute transfer rate through the interface water-ionic liquid can be expressed in a general form by the equation (2):

$$
\frac{d S}{d t}=-k a_{\text {Cell }}\left(S-S_{f}\right)
$$

where: $d S / d t$ is the mass transfer rate in the interface, $k$ is the global mass transfer coefficient, $a_{\text {Cell }}$ is the interfacial area, $S$ is the substrate or product concentration in the bulk aqueous 
phase, and $S_{f}$ is the solute equilibrium concentration in the aqueous phase. Solving Equation

(1) at $t=0 \quad S=S_{0}$ and at $t=t S=S$ :

$\ln \frac{\left(S-S_{f}\right)}{\left(S_{0}-S_{f}\right)}=-k a_{\text {Cell }} t$

The concentration $S_{f}$ can be expressed as a function of the initial solute concentration, $S_{0}$, and its partition coefficient, $K_{p}$ :

$S_{f}=\frac{S_{o}}{K_{p}+1}$

\subsubsection{Experimental design of response surface}

To study the effect of three operation variables (aeration and agitation rates, and the dispersed volume fraction) on two response variables $\left(k_{L} a\right.$ and $\left.d_{32}\right)$, a central composite design (Montgomery, 2005) was used. Experiments were carried on in the bioreactor with three independent factors, each one with three levels, three central points and 11 replications. A second order polynomial model provided the best fit to the experimental data. For response surface methodology (RSM), design of experiments software "Fusion Pro" (version 6.7.0, USA) was used for the regression analysis and the graphs of the experimental results.

\subsection{RESULTS AND DISCUSIONS}

\subsubsection{Physicochemical properties of orange essential oil and biocompatibility}

The physicochemical properties and biochemical characteristic of the orange essential oil evaluated in this work (Citrus aurantium var. amara) are shown in Table 8.1.

Table 8.1. Physicochemical properties and biochemical characteristic of the orange essential oil used.

\begin{tabular}{cc}
\hline Property & Value \\
\hline Density $\left(\mathrm{Kg} \mathrm{m}^{-3}\right)$ & 836 \\
Dynamic Viscosity $\left(\mathrm{Kg} \mathrm{m}^{-1} \mathrm{~s}^{-1}\right)$ & 0.12 \\
Interfacial tension $\left(\mathrm{Kg} \mathrm{s}^{-2}\right)^{\mathrm{a}}$ & 0.0059 \\
$(+)$-valencene partition coefficient & 6.37 \\
\hline
\end{tabular}


(+)-nootkatone partition coefficient ${ }^{\mathrm{b}} \quad 22.50$

${ }^{a}$ Saturated with growth medium for Y. lipolytica at $30^{\circ} \mathrm{C}$.

${ }^{b}$ Saturated with phosphate buffer solution 0.1M at pH 7.5.

\subsubsection{Power consumption and Sauter mean drop diameter $\left(d_{32}\right)$}

The results obtained for the hydrodynamic experiments using orange essential oil are shown in the Table 8.2. All experiments were considered to be within the turbulent flow regime based on the calculated Reynolds numbers and visual observation of the fluid flow. The Reynolds numbers calculated were based on the viscosity of the continuous phase and ranged among 6,000 and 10,000. For the orange essential oil, a positive effect of increasing agitation rate on $P_{g} / V$ value was observed as expected. On the other hand, $P_{g} / V$ values decreased as aeration rates increased as would be expected for a single liquid phase. In the range studied, there was not observed any effect of dispersed volume fraction on $P_{g} / V$ values. Despite these similar patterns for the three fractions of dispersed orange essential oil phases, it was observed that experimental $P_{g} / V$ values were affected by the physicochemical properties of the oil used (Table 8.2). The order of magnitude of $P_{g} / V$ values was similar to those obtained by Nielsen et al. (2003) using a 2-L New Brunswick Bioflo I bioreactor $\left(H_{L} / D_{T}=0.96 ; D_{i} / D_{T}=\right.$ 0.45 ) with a working volume of $1 \mathrm{~L}$ and two phase liquid dispersions comprising water and $n$-hexadecane when agitated with two six-blade Rushton turbine impellers.

The relationship between inertial forces and cohesion forces, as represented by the Weber number $\left(N_{W e}\right)$, was among $390<N_{W e}<10,000$ for the orange essential oil. The differences in $\sigma$ and oil viscosity probably led to a different balance in droplet break-up and coalescence phenomena for dispersed orange essential oil phase. The relationships between the measured $d_{32}$ values for oil as a function of agitation and aeration rate are shown in the Table 8.2. The values of $d_{32}$ for the different fractions of orange essential oil are lower when stirring and the fraction of dispersed phase increases. The maximum value of $d_{32}$ was observed for 0.20 disperse phase fraction (Table 8.2). For both fractions 0.35 and 0.50 a general decrease in $d_{32}$ values was observed with increasing dispersed phase volume fraction. The physicochemical properties of the dispersed phase modified the relationship of inertial and cohesion forces which controls break-up of the droplets. Dispersed phase viscosity has a profound influence on both mean drop size and drop size distribution (Maaß et al., 2012). Torres-Martínez et al. 
(2009) found that the viscosity of the various ionic liquid phases appeared to be the most critical physical parameter governing mass transfer rate in a multiphase bioreactor system, while density and interfacial tension were found to be of lesser importance.

\subsubsection{Oxygen mass transfer coefficient $\left(k_{L} a\right)$}

The effect of bioreactor operating conditions and dispersed phase volume fraction on experimentally determined $k_{L} a$ values for the orange essential oil is shown in the Table 8.2. For three oil fractions $k_{L} a$ values generally increased as agitation and aeration rates increased as expected from conventional biphasic gas-liquid system studies. $k_{L} a$ values were around $26 \mathrm{~h}^{-1}$ at a dispersed phase volume fraction of $35 \%$, which was significantly lower value than that $k_{L} a$ obtained at a dispersed phase volume fraction of $50 \%$, which was $>116 \mathrm{~h}^{-1}$. For all three fractions, the measured $k_{L} a$ values were observed to increase as the oil volume fraction increased. Nielsen et al. (2003) examined the effect of increasing volume fraction on $k_{L} a$ using $n$-hexadecane as the second liquid phase. These authors found that oxygen mass transfer rates actually increased when the organic phase volume fraction was increased. This was attributed to the addition of a second immiscible phase with a much higher solubility of oxygen compared to water, increasing the general level of oxygen solubility in the system.

In a revised approach (Nielsen et al., 2005) considering the same aqueous-organic phase system, the authors using a more fundamental two-phase mass transfer model, it was demonstrated the potential for oxygen mass transfer enhancement by organic phase addition which was one of the motivations for employing a distinct second phase in a partitioning bioreactor. Gomes et al. (2007) claimed that the presence of oil in the medium increases the overall $k_{L} a$ value of the system, but this effect is opposite when the medium contains surfactant (Tween 80). On the other hand, Quijano et al. (2009) worked with a three-phase system (gas-water-silicone oil) and found to silicone oil had a positive effect on the overall oxygen transfer.

\subsubsection{Substrate and product global mass transfer coefficients obtained in the Lewis cell}

The substrate and product global mass transfer coefficients ( $k_{S}$ and $k_{P}$, respectively) were estimated from the resulting slopes, early defined in (Eq. (3)), of the logarithmic profile of 
solute concentration against removal time divided by mass transfer area $\left(18.5 \mathrm{~m}^{2} \mathrm{~m}^{-3}\right)$ of the Lewis cell. The $k_{S}$ and $k_{P}$ plotted against the superficial velocity $\left(V_{S}\right)$ of organic phase in the water-orange essential oil system are shown in Figure 8.1.

Table 8.2. Operational variables and experimental results obtained for orange essential oil.

\begin{tabular}{|c|c|c|c|c|c|c|c|}
\hline$\phi$ & $\begin{array}{c}\text { rpm } \\
\left(\min ^{-1}\right)\end{array}$ & $\begin{array}{c}\text { vvm } \\
\left(\min ^{-1}\right)\end{array}$ & $\begin{array}{c}P_{g} / V \\
\left(\mathrm{~W} \mathrm{~m}^{-3}\right)\end{array}$ & $\begin{array}{c}d_{32} \\
(\mu \mathrm{m})\end{array}$ & $\begin{array}{l}k_{L} a \\
\left(h^{-1}\right)\end{array}$ & $N_{W e}$ & $N_{R e}$ \\
\hline \multirow[t]{3}{*}{0.20} & 300 & 0.50 & $1784 \pm 0.20$ & $13.05 \pm 0.32$ & $47.27 \pm 0.42$ & 392 & 5746 \\
\hline & 400 & 1.00 & $2429 \pm 0.08$ & $13.49 \pm 0.21$ & $53.04 \pm 0.33$ & 697 & 7653 \\
\hline & 500 & 0.75 & $3225 \pm 0.12$ & $14.10 \pm 0.15$ & $59.83 \pm 0.21$ & 1090 & 9573 \\
\hline \multirow[t]{5}{*}{0.35} & 300 & 0.75 & $1828 \pm 0.30$ & $18.93 \pm 0.30$ & $24.65 \pm 0.13$ & 392 & 5746 \\
\hline & 400 & 0.50 & $2431 \pm 0.04$ & $14.75 \pm 0.05$ & $16.63 \pm 0.51$ & 697 & 7653 \\
\hline & 400 & 0.75 & $2490 \pm 0.11$ & $14.25 \pm 0.13$ & $27.45 \pm 0.34$ & 697 & 7653 \\
\hline & 400 & 0.75 & $2437 \pm 0.15$ & $15.49 \pm 0.08$ & $24.65 \pm 0.22$ & 697 & 7653 \\
\hline & 500 & 1.00 & $3055 \pm 0.06$ & $12.35 \pm 0.21$ & $47.92 \pm 0.15$ & 1090 & 9573 \\
\hline \multirow[t]{3}{*}{0.50} & 300 & 1.00 & $1829 \pm 0.05$ & $8.27 \pm 0.11$ & $62.21 \pm 0.72$ & 392 & 5746 \\
\hline & 400 & 0.75 & $2540 \pm 0.12$ & $9.26 \pm 0.08$ & $88.51 \pm 0.51$ & 697 & 7653 \\
\hline & 500 & 0.50 & $3433 \pm 0.32$ & $7.98 \pm 0.20$ & $116.44 \pm 0.44$ & 1090 & 9573 \\
\hline
\end{tabular}

Global mass transfer coefficients are influenced by hydrodynamics near the interface. It can be seen in Figure 8.1 that the increase in the $V_{S}$ of organic phase increased the $k_{S}$ value. Where $k_{S}$ values showed a direct linear relationship to $V_{S}$ of the aqueous phase. The $k_{S}$ values increased almost 10 fold up to $3.02 \times 10^{-5} \mathrm{~m} \mathrm{~s}^{-1}$ when the $V_{S}$ increased 4 fold (from 0.006 to $\left.0.025 \mathrm{~m} \mathrm{~s}^{-1}\right)$.

The increment of the inertial forces decreased the thickness of the boundary layers of the liquids, probably diminishing resistance to the mass transport. It can also be seen in the same Figure that the highest values of $k_{P}$ were obtained with the lower $V_{S}$. Variations in the $k_{P}$ values in the range tested did not let us to observe a tendency with respect to $V_{S}$ of the organic 
phase, the maximum $k_{P}$ value $\left(2.81 \times 10^{-5} \mathrm{~m} \mathrm{~s}^{-1}\right)$ was obtained at $V_{S}$ of $0.005 \mathrm{~m} \mathrm{~s}^{-1}$. On the other hand, the maximum $k_{P}$ value was 0.21 times lower than that obtained for $k_{s}$. Maximum $k_{S}$ and $k_{P}$ values of $3.02 \times 10^{-5}$ and $2.81 \times 10^{-5} \mathrm{~m} \mathrm{~s}^{-1}$, respectively, were obtained.

Molecular diffusivities for the substrate and the product $\left(8.33 \times 10^{-10}\right.$ and $7.99 \times 10^{-10} \mathrm{~cm} \mathrm{~s}^{-1}$, respectively) in the organic phase were estimated using Wilke-Chang correlations (Bird et al., 2010). On the other hand, analyzing the role of operating condition on mass transfer during liquid-liquid extraction through dimensional analysis (Tudose and Lisa, 2003) it was showed the effect of density and viscosity of the orange essential oil on mass transfer coefficients.

Mass transfer coefficients obtained in this work were on the same order of magnitude as those reported in similar Lewis cells. For example, Melgarejo-Torres et al., (2012) obtained $k$ values of $1.2 \times 10^{-5}-4.3 \times 10^{-5} \mathrm{~m} \mathrm{~s}^{-1}$ for a bicyclic cetone (Bicyclo[3.2.0]hept-2-en-6-ona) transferred from an organic phase ([MeBuPyrr][BTA]) to an aqueous phase composed of phosphate buffer. The agitation rates in the organic phase were 0-205 rpm. Srivastava et al. (2000) reported $k$ values of $1.1 \times 10^{-5}$ and $1.2 \times 10^{-5} \mathrm{~m} \mathrm{~s}^{-1}$ for a limonene/water/heptanoic acid system, where heptanoic acid was the molecule transferred from the aqueous phase to the organic phase (limonene). Baldascini et al. (2001) obtained $k$ values of $2.3 \times 10^{-5} \mathrm{~m} \mathrm{~s}^{-1}$ for epoxide hydrolase transferred from its own organic phase to an aqueous phase composed of phosphate buffer with n-octane. The agitation rates in both phases were 150-200 rpm. These studies noted that by increasing the agitation rate in both phases, the thickness of the boundary layer of the interface is reduced, leading to an increase of the mass transfer coefficient. 


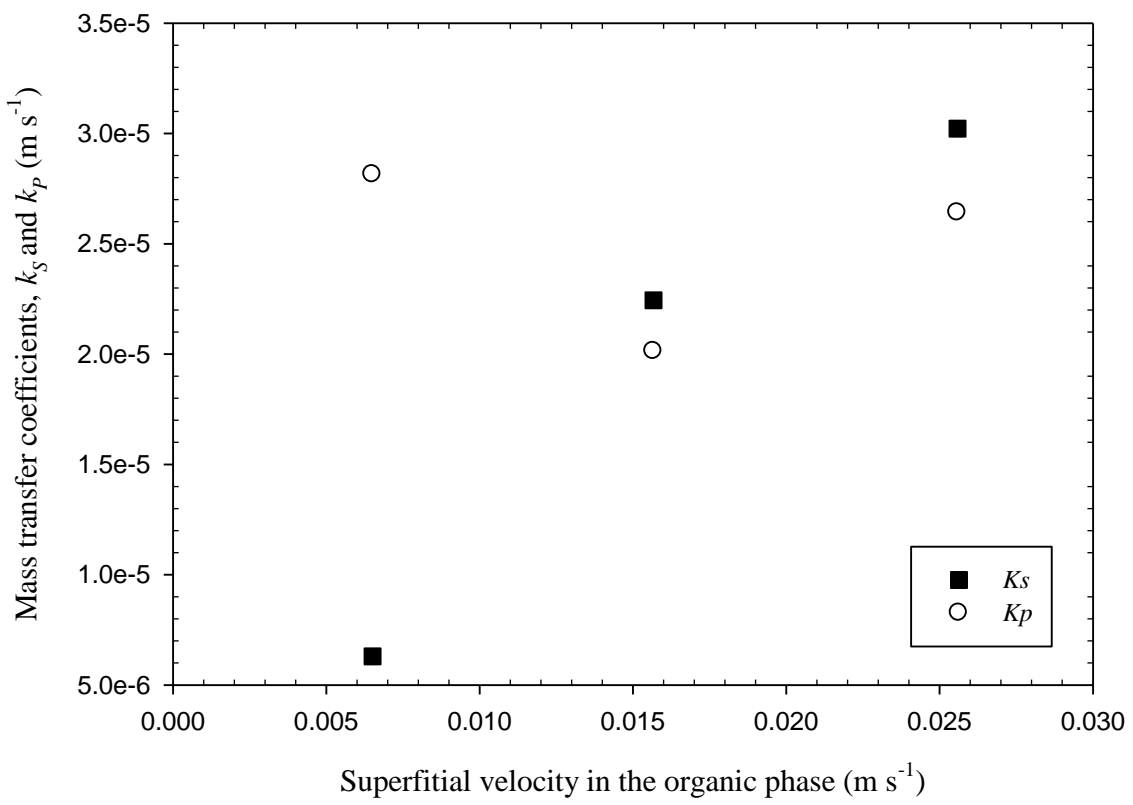

Figure 8.1. Global mass transfer coefficients versus superficial velocity of the organic phase for the phosphates buffer- orange essential oil system: (匹) substrate, $k_{S}$; and (०) product, $k_{P}$.

Global mass transfer coefficients are not only influenced by hydrodynamics near the interface, but also by the thermodynamics. Global mass transfer coefficients values in relation to the physicochemical properties of orange essential oil (interfacial tension, viscosity, density) and the partition coefficients of the compounds extracted (Table 8.1) were analysed.

It was observed that the viscosity of the oil showed a direct linear relationship to $k_{S}$. The increment of mass transfer coefficients due to the increment in viscosity of the organic phase (tri-n-butyl phosphate) has also been reported by Bandyopadhyay et al. (1996) for the extraction of tellurium (IV) using a biphasic system. Interfacial tension also showed a direct linear relation-ship to $k_{S}$. However, the influence of interfacial tension has mainly been related to droplet breakage and coalescence mechanisms (Jaradat et al., 2010) rather than mass transfer resistances. More molecules of the orange essential oil dissolved in the aqueous phase probably influence molecular diffusivity through the aqueous phase boundary layer; therefore, mass transfer was reduced. It has been reported the study of a biphasic system using orange essential oil and n-octanol, which are partially soluble. The authors claimed that 
concentration influenced phase equilibrium, and interfacial physical properties (Maróstica and Pastore, 2007).

Besides, interfacial tension values of the biphasic system are much lower than the surface tension of pure ionic liquids (Hanczyc et al., 2007). Therefore, these results show an important influence of the physicochemical properties of essential oils phase on mass transfer.

\subsubsection{Volumetric mass transfer coefficients in a stirred tank partitioning bioreactor}

The lower values $k_{S}$ and $k_{P}$ measured in the modified Lewis cell in both biphasic systems were multiplied by the mass transfer volumetric areas $(A)$ of the dispersed orange essential oil phases obtained under different operation conditions (oil fraction, agitation and aeration rates) in a stirred tank partitioning bio-reactor, as reported by Torres-Martínez et al. (2009). In this respect, volumetric mass transfer coefficients for the substrate and the product $\left(k_{S} A\right.$ and $k_{P} A$ )were obtained, since they are useful when studying this type of partitioning bioreactors. The obtained range values were: $k_{S} A\left(6732 \mathrm{~h}^{-1}\right)$ and $k_{P} A\left(21492 \mathrm{~h}^{-1}\right)$ in the biphasic system. Melgarejo-Torres et al. (2012) reported a $k_{S} A\left(7.5-36 \mathrm{~h}^{-1}\right)$ and $K_{P} A(2.8-12$ $\mathrm{h}^{-1}$ ) for the water-[OMA][BTA] system. This difference in several orders of magnitude might be due to Melgarejo et al. (2012) used a dispersed phase fraction of $5 \%$, ten times lower than those used in this work and also the physicochemical properties of [OMA][BTA].

A regime analysis based on characteristic times of the mass transfer mechanisms involved using parameters obtained in this work and reaction parameters from previous work (Palmerín-Carreño et al., 2015) was carried on (Table 8.3). This analysis has been used to obtain a quantitative estimate of bioreactor performance (Melgarejo-Torres et al., 2011).

It was observed that the characteristic times for substrate and product transfer mechanism were about the same order of magnitude, less than one second, indicating that they were the fastest. This fact was probably due to both the physicochemical characteristic of the orange essential oil and the high volume fraction used allowing high liquid-liquid interfacial areas. On the other hand, the characteristic times for oxygen transfer and oxygen consumption are 
about the same order of magnitude, oxygen transfer is almost $40 \%$ faster than oxygen consumption. This means that under the operation conditions oxygen transfer was not limiting the bioconversion process. Finally, it was observed that the characteristic time for substrate consumption was the largest time, so bioconversion was limited by reaction.

Table 8.3. Characteristic times in a three-phase stirred tank bioreactor

\begin{tabular}{|ccc|}
\hline Mechanism & Definition & Value (s) \\
\hline Substrate transfer & $t_{S}=\frac{1}{k_{S} A}$ & 0.53 \\
Product transfer & $t_{P}=\frac{1}{k_{P} A}$ & 0.16 \\
Oxygen transfer & $t_{O_{2}}=\frac{1}{k_{L} a}$ & 66.96 \\
Oxygen consumption* & $t_{\mathfrak{R}_{O_{2}}}=\frac{C_{O_{2}}}{X \Re_{O_{2}}}$ & 94.23 \\
Substrate consumption* & $t_{\mathfrak{R}_{S}}=\frac{[S]_{0}}{X \Re_{S} Y_{S}}$ & 85096 \\
\hline
\end{tabular}

*Estimated from data obtained by Palmerín-Carreño et al. (2015)

Melgarejo-Torres et al. (2011) reported a regime analysis of a Baeyer-Villiger bioconversion in a three-phase stirred tank partitioning bioreactor using [MeBuPyrr][BTA] as dispersed phase. The authors found that the characteristic time for oxygen transfer and oxygen consumption were similar in the interval studied and therefore oxygen mass transfer might be the limiting step of the bioconversion.

\subsection{CONCLUSIONS}

A regime analysis of the mass transfer phenomena and reaction rates allowed us to establish possible limiting steps during the bioconversion process. The characteristic time obtained for oxygen uptake rate $\left(94 \mathrm{~s}^{-1}\right)$ was among the characteristic times determined for oxygen transfer $\left(67 \mathrm{~s}^{-1}\right)$ under $200 \mathrm{rpm}$ and $0.5 \mathrm{vvm}$ operating conditions, suggesting that the oxygen transfer rate under certain operating conditions could be a limiting step in the bioconversion process. 


\section{References}

[1]. Ahosseini A., B. Sensenich, L.R. Weatherley, A.M. Scurto, Phase equilibrium, volumetric, and interfacial properties of the ionic liquid, 1-hexyl-3- methylimidazolium bis(trifluoromethylsulfonyl)amide and 1-octene, J. Chem. Eng. Data 55 (2010) 1611-1617.

[2]. Ascanio G., B. Castro, E. Galindo, Measurement of power consumption in stirred vessels: a review, Trans IChemE, Part A: Chem. Eng. Res. Des. 82 (2004) 1282-1290.

[3]. Baldascini H, Ganzeveld KJ, Janssen DB, Beenackers AACM, Effect of mass transfer limitations on the enzymatic kinetic resolution of epoxides in a two-liquid-phase system. Biotechnol. Bioeng. 73 (2001) 44-54.

[4]. Bandyopadhyay M., S. Datta, S.K. Sanya, Correlation of mass transfer coefficient for tellurium (IV) extraction with instantaneous reaction in modified Lewis cell, Hydrometallurgy 42 (1996) $115-123$.

[5]. Bird B., W. Stewart, E. Lightfoot, Fenómenos de Transporte, 2nd edn., Limusa- Wiley, México, (2010) 615-631.

[6]. Bonora A., D. Mares, A Simple Colorimetric Method for Detecting Cell Viability in Cultures of Eukaryotic Microorganisms, Curr. Microbiol. 7 (1982) 217-222.

[7]. S.D. Doig, P.J. Avenell, P.A. Bird, P. Gallati, K.S. Lander, G.J. Lye, R. Wohlgemuth, M.J. Woodley, Reactor operation and scale-up of whole cell Baeyer-Villiger catalyzed lactone synthesis, Biotechnol. Prog. 18 (2002) 1039-1046.

[8]. Girhard M., K. Machida, M. Itoh, R. Schmid, A. Arisawa and V. Urlacher, Regioselective biooxidation of (+)-valencene by recombinant E. coli expressing CYPI09BI from Bacillus subtilis in a two-liquid-phase system, Microbial Cell Factories, 8 (2009) 1-12.

[9]. Gomes N., M. Aguedo, J. Teixeira, I. Belo, Oxygen mass transfer in a biphasic medium: influence on the biotransformation of methyl ricinoleate into decalactone by the yeast Yarrowia lipolytica, Biochem. Eng. J. 35 (2007) 380-386.

[10]. Hanczyc, M., Toyota, T., Ikegami, T., Fatty Acid Chemistry at the Oil Water Interface: SelfPropelled Oil Droplets. J. Am. Chem. Soc. 129 (2007) 9386-9391.

[11]. Jaradat M., M. Attarakih, H.J. Bart, Effect of phase dispersion and mass transfer direction on steady state RDC performance using population balance modeling, Chem. Eng. J. 165 (2010) $379-387$.

[12]. Koizumi J., S. Aiba, Reassessment of the dynamic $k_{L} a$ method, Biotechnol. Bioeng. 26 (1984) 1131-1133.

[13]. Krings U and Berger RG, Terpene bioconversion--how does its future look? Natural Product Communications, 5(9) (2010) 1507-1522. 
[14]. Ladaniya, M. Citrus fruit: Biology. Technology and Evaluation. First Edition, USA, ed. Elsevier. (2010) 176-177.

[15]. Lizardi-Jiménez M.A., M. Gutiérrez-Rojas, Assessment of the local hydrodynamic zones in a three-phase airlift reactor: looking for the lowest liquid-phase Re, Rev. Mex. Ing. Quim. 10 (2011) 59-65.

[16]. Maaß S., Niklas Paul, Matthias Kraume, Influence of the dispersed phase fraction on experimental and predicted drop size distributions in breakage dominated stirred systems, Chem. Eng. Sci. (2012)

[17]. Maróstica M.R. and Pastore G.M., Production of R-(+)- $\alpha$-terpineol by the biotransformation of limonene from orange essential oil, using cassava waste water as medium. Food Chem 101 (2007) 345-350.

[18]. Melgarejo-Torres R., D. Torres-Martínez, M. Gutiérrez-Rojas, A. Gómez de Jesús, G.J. Lye, S. Huerta-Ochoa, Regime analysis of a Baeyer-Villiger bioconversion in a three-phase (airwater-ionic liquid) stirred tank bioreactor, Biochem. Eng. J. 58-59 (2011) 87-95.

[19]. Melgarejo-Torres R., D. Torres-Martínez, C.O. Castillo-Araiza, C. Arriaga-Juárez, M. Gutiérrez-Rojas, P. Esponda-Aguilar, G. Aroca, G.J. Lye, S. Huerta-Ochoa, Mass transfer coefficient determination in three biphasic systems (water-ionic liquid) using a modified Lewis cell, Chem. Eng. J. 182 (2012) 702-707.

[20]. Melgarejo-Torres R., Carlos O. Castillo-Araiza, Abhishek Dutta, Guido Bény, Daniel TorresMartinez, Mariano Gutiérrez-Rojas, Gary J. Lye, Sergio Huerta-Ochoa, Mathematical model of a three phase partitioning biorreactor for conversion of ketones using whole cells. Chemical Engineering Journal 260 (2015) 765-775.

[21]. Montgomery D.C., Design and Analysis of Experiments, sixth edition, John Wiley \& Sons, (2005).

[22]. Nielsen D.R., A.J. Daugulis, P.J. McLellan, A novel method of simulating oxygen mass transfer in two-phase partitioning bioreactors, Biotechnol. Bioeng. 83 (2003) 735-742.

[23]. Nielsen D.R., J. Daugulis, J. McLellan, A restructured framework for modeling oxygen transfer in two-phase partitioning bioreactor, Biotechnol. Bioeng. 91 (2005) 773-777.

[24]. Nienow A.W., Break-up, coalescence and catastrophic phase inversion in turbulent contactors, Adv. Colloid Interface 108-109 (2004) 95-103.

[25]. Omarini A.B., Ina Plagemann, Silke Schimanski, Ulrich Krings, Ralf G. Berger. Crosses between monokaryons of Pleurotus sapidus or Pleurotus florida show an improved biotransformation of (+)-valencene to (+)-nootkatone. Bioresource Technology 171 (2014) 113-119. 
[26]. Palmerín-Carreño D.M., Castillo-Araiza C.O., Rutiaga-Quiñones O.M., Verde Calvo J.R., Trejo-Aguilar G.M., Dutta A., Huerta-Ochoa S. Whole cell bioconversion of (+)-valencene to (+)-nootkatone by Yarrowia lipolytica using a three phase partitioning bioreactor. Journal of Chemical Technology and Biotechnology, (2015), DOI: 10.1002/jctb.4702

[27]. Quadros P.A., C.M.S.G. Baptista, Effective interfacial area in agitated liquid-liquid continuous reactors, Chem. Eng. Sci. 58 (2003) 3935-3945.

[28]. Quijano G., S. Revah, M. Gutiérrez-Rojas, L.B. Flores-Cotera, F. Thalasso, Oxygen transfer in three-phase airlift and stirred tank reactors using silicone oil as transfer vector, Process Biochem. 44 (2009) 619-624.

[29]. Srivastava P., O. Hahr, R. Buchholz, M. Worden, Enhancement of mass transfer using colloidal liquid aphrons: measurement of mass transfer coefficients in liquid-liquid extraction, Biotechnol. Bioeng. 70 (5) (2000) 525-532.

[30]. Torres-Martinez D., R. Melgarejo-Torres, M. Gutierrez-Rojas, L. Aguilera-Vazquez, M. Micheletti, G.J. Lye, S. Huerta-Ochoa, Hydrodynamic and oxygen mass transfer studies in a three-phase (air-water-ionic liquid) stirred tank bioreactor, Biochem. Eng. J. 45 (3) (2009) 209-217.

[31]. Tsigie Y.A., Ch-Y. Wang, N.S. Kasim, Quy-Do Diem, Lien-Huong Huynh, Quoc-Phong Ho, Chi-Thanh Truong y Yi-Hsu Ju, Oil Production from Yarrowia lipolytica Po1g Using Rice Bran Hydrolysate, J. Biomed. Biotechnol. 1 (2012) 1-10.

[32]. Tudose R.Z. and G. Lisa, The determination of individual mass transfer coefficients in liquidliquid extraction, Chem. Ind. 57 (9) (2003) 393-398.

[33]. Wriessnegger T, Augustin P, Engleder M, Leitner E, Muler 1 M, Kaluzna I, Schumann M, Mink E, Zellnig G, Schwab H and Pichler H, Production of the sesquiterpenoid (+)-nootkatone by metabolic engineering of Pichia pastoris. Metab Eng 24 (2014) 18-29. 


\section{CHAPTER IX}

\section{GENERAL CONCLUSIONS AND PERSPECTIVES}




\section{GENERAL CONCLUSIONS}

A screening method to evaluate the potential ability of the strains to biotransform (+)valencene to (+)-nootkatone in different bioconversion systems was developed. Two different physiological and morphological strains (B. theobromae 1368 and $Y$. lipolytica 2.2ab) were selected due to they were able to produce higher (+)-nootkatone concentrations in all bioconversion systems. Membrane aerated biofilm reactor (MABR) using $B$. theobromae 1368 showed being an attractive technological alternative; however, further studies of operation and optimization of biofilm reactor are needed to enhance bioconversion. The physiological characterisation of whole cell biocatalysis using Yarrowia lipolytica 2.2ab for the bioconversion of $(+)$-valencene to $(+)$-nootkatone in a partitioning bioreactor demonstrated that this bioconversion system presents an interesting way to produce and recover (+)-nootkatone. Permeability of cell membrane with CTAB, NADPH cofactor regeneration with Niacin and increasing twice the biomass concentration enhanced the production of (+)-nootkatone up to product inhibition concentrations. The addition of organic phase, i.e., orange essential oil containing a cheap source of (+)-valence in a three-phase partitioning bioreactor, overcame the bioconversion inhibition.Despite of under lower hydrodynamic stress (lower agitation and aeration rates) cell viability loss was diminished; the (+)-nootkatone production yields were not improved.

Finally, whole cell bioconversion of $Y$. lipolytica $2.2 \mathrm{ab}$ in an organic phase (orange essential oil) to produce (+)-nootkatone was successfully assessed, as it was observed during the screening method.

This thesis promises to be an important step in the analysis of process performance in bioconversions using a TPPB and useful tool in the understanding and evaluation of the design of bioconversions in this type of bioreactors. 


\section{PERSPECTIVES}

Identify the enzyme or enzymes involved in the bioconversion.

Modify genetically the $Y$. lipolytica $2.2 \mathrm{ab}$ and $B$. theobromae 1368 strains to enhance (+)nootkatone production.

This work could be a starting point to establish the window of operation for commercial exploitation involving bioconversion of sesquiterpenes in a three phase partitioning bioreactor. 
ANNEXES 


\section{Figures annexed of Chapter VI.}

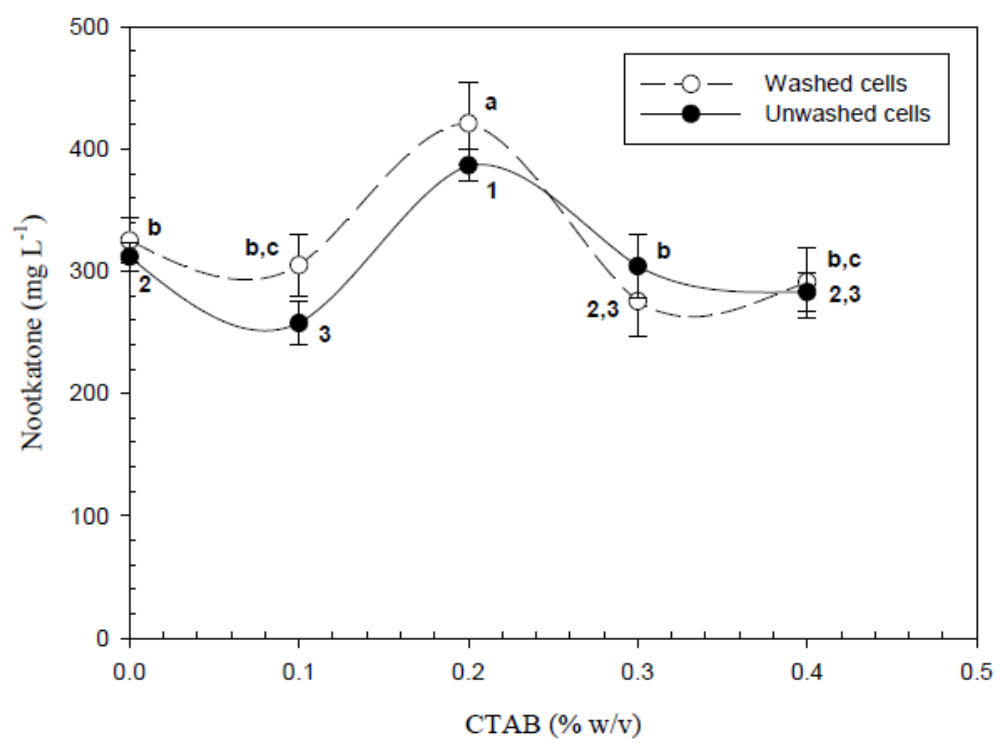

Figure A1. Effect of CTAB concentration on the bioconversion process using washed $(0)$ and unwashed cells $(\bullet)$ of $Y$. lipolytica. Same letters for washed cells represent no significant differences, and same numbers for unwashed cells represent no significant differences ( $\mathrm{p} \leq 0.05$; Tukey, SAS System Version 9$)(\mathrm{p} \leq 0.05$; Tukey, SAS System Version 9).

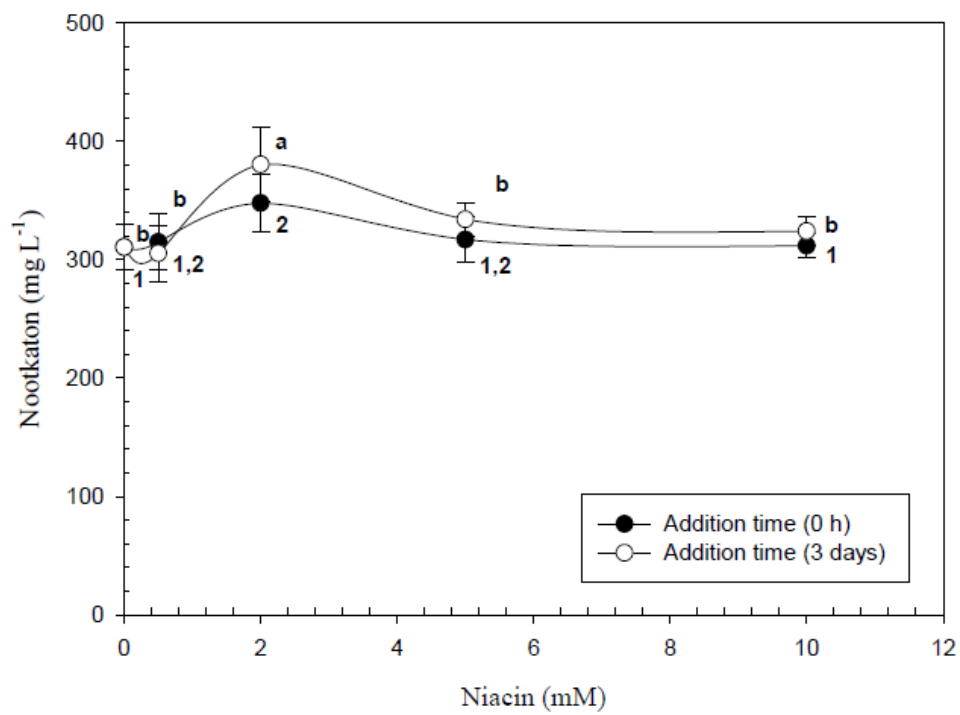

Figure A2. Effect of niacin concentration on the bioconversion process using Y. lipolytica. Niacin addition at $0 \mathrm{~h}(\bullet)$ and after 3 days (०) of inoculation time. Same letters for addition time after 3 days represent no significant differences, and same numbers for addition time at $0 \mathrm{~h}$ represent no significant differences $(\mathrm{p} \leq 0.05$; Tukey, SAS System Version 9) ( $\mathrm{p} \leq 0.05$; Tukey, SAS System Version 9). 


\section{DERIVATIVE WORKS OF THIS THESIS}

\section{INTERNATIONAL SCIENTIFIC INDEXING - (ISI).}

1. Palmerín-Carreño D.M., Rutiaga-Quiñones O.M., Verde Calvo J.R., Prado-Barragán A., Huerta-Ochoa S. Screening of microorganisms for bioconversion of (+)-valencene to (+)nootkatone. LWT- Food Science and Technology, (2015), 64(2): 788-793.

2. Palmerín-Carreño D.M., Rutiaga-Quiñones O.M., Verde Calvo J.R., Huerta-Ochoa S. Bioconversion of (+)-valencene by Botryodiplodia theobromae using a membrane aerated biofilm reactor. Revista Mexicana de Ingeniería Química, (2014), 13(3): 1-8.

3. D.M. Palmerín-Carreño, C.O. Castillo-Araiza, O.M. Rutiaga-Quiñones, J.R. Verde Calvo, G.M. Trejo-Aguilar, Abhishek Dutta, S. Huerta-Ochoa. Whole cell bioconversion of (+)valencene to (+)-nootkatone by Yarrowia lipolytica using a three phase partitioning bioreactor. Journal of Chemical Technology and Biotechnology (2015). Doi: $10.1002 /$ jctb. 4702

4. Palmerín-Carreño D.M., Castillo Araiza C.O., Rutiaga-Quiñones O.M., Verde Calvo J.R., Prado-Barragán A., Huerta-Ochoa S. Whole cell (+)-Nootkatone bioconversionin an organic phase (orange essential oil) system using Yarrowia lipolytica (In preparation).

5. Palmerín-Carreño D.M., Castillo-Araiza C.O., Rutiaga-Quiñones O.M., Verde Calvo J.R., Huerta-Ochoa S. Hydrodynamic and oxygen mass transfer studies in a three-phase (airwater-essential orange oil) stirred tank bioreactor for the bioconversion of (+)-valencene with Yarrowia lipolytica. (In preparation). 


\section{PARTICIPATION IN CONGRESS:}

\section{INTERNATIONALS}

1. Carlos Castillo-Araiza, Dulce Palmerín-Carreño, Miguel Arellano, Abhishek Dutta, Arely Prado-Barragán and Sergio Huerta-Ochoa. An Approach to Develop a Kinetic Model from a Stirred Tank Reactor accounting for the Role of Hydrodynamics: (+)Nootkatone Bioconversion, The 9th International Conference on Chemical Kinetics, June 28 to 02 July, 2015. Ghent, Belgium. (Modality Oral).

\section{NATIONALS}

1. Dulce María Palmerín Carreño, José Ramón Verde Calvo, Olga Miriam Rutiaga Quiñones and Sergio Huerta Ochoa, Efecto del estrés hidrodinámico y la concentración de biomasa en la bioconversión de (+)-nootkaton con Yarrowia lipolytica, XXXVI Encuentro Nacional, AMIDIQ, Retos de la Ingeniería Química en la Globalización. May 05 to 08, 2015, in Cancún QR, México. (Modality Oral).

2. Dulce María Palmerín Carreño, José Ramón Verde Calvo, Olga Miriam Rutiaga Quiñones and Sergio Huerta Ochoa, Mejoramiento de la bioconversión de (+)valenceno a (+)-nootkaton con Yarrowia lipolytica, XXXV Encuentro Nacional, AMIDIQ, La interdisciplinariedad en la Ingeniería Química. May 06 to 09, 2014, in Puerto Vallarta, Jalisco, México. (Modality Oral).

3. Dulce María Palmerín Carreño, José Ramón Verde Calvo, Olga Miriam Rutiaga Quiñones and Sergio Huerta Ochoa, Bioconversión microbiana de (+)-valencene a (+)-nootkatone en un biorreactor de partición, XXXIV Encuentro Nacional, AMIDIQ, La Ingeniería Química en la Biotecnología y la Energía. May 07 to 10, 2013, in Mazatlán Sinaloa, México. (Modality Oral).

4. Dulce María Palmerín Carreño, Olga Miriam Rutiaga Quiñones, José Ramón Verde Calvo and Sergio Huerta Ochoa, Screening of selected microorganisms for bioconversion of (+)-valencene to (+)-nootkatone, XV Congreso Nacional de la 
SMBB, 2013, June 23-28, in Cancun QR, México. (Third place at Biotechnology, Modality Poster).

5. Dulce María Palmerín Carreño, Olga Miriam Rutiaga Quiñones, José Ramón Verde Calvo and Sergio Huerta Ochoa, Hydrodynamic and oxygen mass transfer studies in a three-phase (air-water-orange oil) stirred tank bioreactor, XV Congreso Nacional de la SMBB, 2013, June 23-28, in Cancun QR, México. (Modality Poster).

6. Dulce María Palmerín Carreño, Olga Miriam Rutiaga Quiñones, José Ramón Verde Calvo and Sergio Huerta Ochoa, Bioconversion of (+)-valencene to (+)-nootkatone using a membrane-aerated biofilm reactor, XV Congreso Nacional de la SMBB, 2013, June 23-28, in Cancún QR, México. (Modality Oral).

\section{HUMAN RESOURCES TRAINING}

Coach Masters student Hanne De Crits with the thesis: KinETICS OF THE (+)-NOOTKATONE BIOCONVERSION USING WHOLE CELLS OF YARROWIA LIPOLYTICA. Chemical Engineering, Faculty of Engineering Technology, Campus Group T Leuven, Belgium. 
These annexes shows the published papers from this thesis.

\section{ANNEXE III}

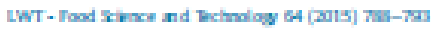

\begin{tabular}{|c|c|c|}
\hline & Comems liass awailable at Science Drect & LWT- \\
\hline & LWT - Food Science and Technology & \\
\hline AFVIFR & journal homepages www.eb evier scom/locat e/lwh & \\
\hline
\end{tabular}

\section{Screening of microorganisms for bioconversion of $(+)$-valencene to} (+)-nootkatone

\section{D.M. Palmerín-Carreño a , O.M. Rutiaga-Quiñones ', J.R. Verde Calvo a , A. Prado-Barragán * ,} S. Huerta-Ochoa ${ }^{2}$

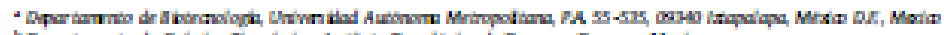

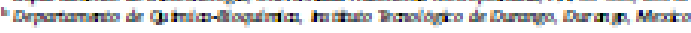

\section{A R TICLE I N F O}

\section{Antik himory}

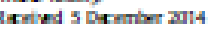

lentiod $n$ rwased him

$27 \mathrm{May}$ 2ins

Acropted 25 yne ans

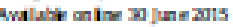

Nrywats

Semining

Sorian atus

Oran gommination

(t) ramesan

Chanian' compoundr mad ind th athr attide

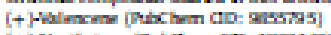

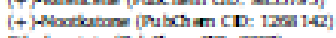

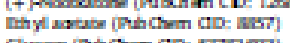

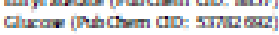

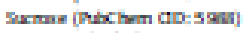

Tween in (RubCh an CD: 52 51965 )

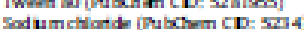

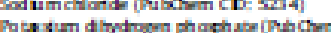

CD: 51251$]$

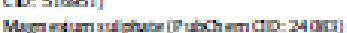

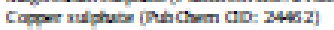

\begin{abstract}
A B STRACT

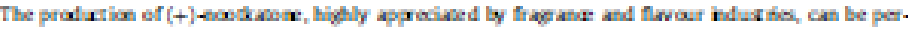

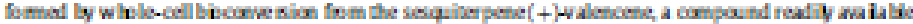

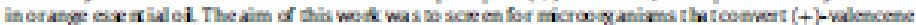

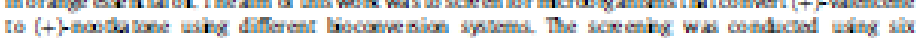

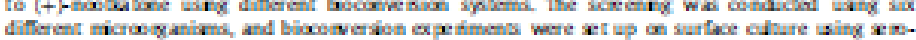

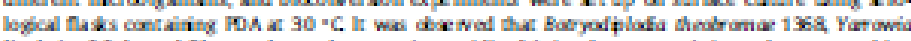

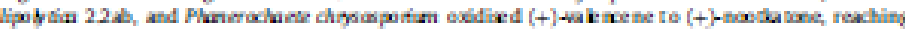

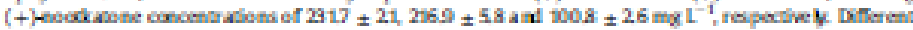

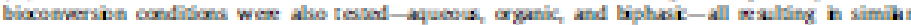

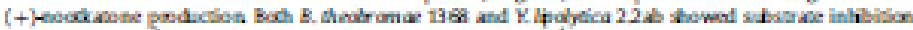

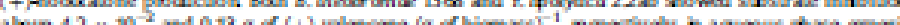

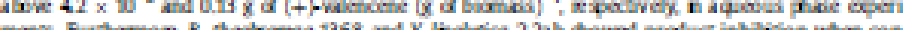

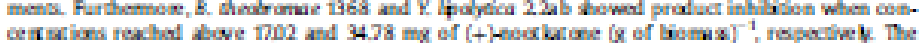

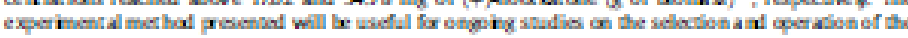
proper biose acox af ifferent biocomersiba condilions.
\end{abstract}

o 2015 Flevier lat. M righs reseved.

\section{Introduction}

Flawours and aromas are highly valued in food, cosmetc, chemical, and pharmxeutical industites. Most of the aramatic cam pounds avallable are oba ined by chemical synthesis or solvent extracton. However, consumes' growing avertion trwards synthese chemicals added to foods, carmescs, and other household products has encouraged research efforts towards the production of aromatic and flwouring compounds using biologeal organisms

\footnotetext{
- Camrequand ne waher

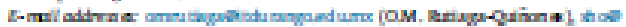

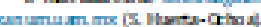

(Mardistica \& Pastore, 2007). The sesquiterpene molecul es and their congenated derhatwes are widdy used in the amma industry. Of particular interest is (+)-valencene $((2 R)-8,8,8$, trimethyl-2-prop1-en-2-y-12,3,4,67-hexahydronaphthalene) the main bicydic sesquiterpene found in orange ped oll (Fiston, Iin sa Rouseft, 2005) Sesquiterpenes are low-piticed compounds commonly used za substrates for the biocomversion $\alpha$ various aromas (Misawa et al. 2011). The production $\alpha(+)$-nooscatone has been conducted by chemical synthesis ma inly from the sesquiterpene $(++$ valencene,

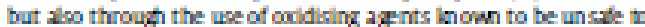
the exvironment, such as tert-buty peraceate (Wilson \& Shaw. 1978) or tert-butyl hydroperoodide in combinato on with medal cat. alysts supported on sllica (Sahador \& Clark, 2002), As such, the 


\section{ANNEXE IV}

\section{Revista Mexicana de Ingeniería Química}

Vol. 13, No. 3 (2014) xxx-xxx

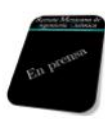

BIOCONVERSION OF (+)-NOOTKATONE BY Botryodiplodia theobromae USING A MEMBRANE AERATED BIOFILM REACTOR

BIOCONVERSIÓN DE (+)-NOOTKATON POR Botryodiplodia theobromae UTILIZANDO UN REACTOR DE BIOPELÍCULA DE MEMBRANA AIREADA

D.M. Palmerín-Carreño ${ }^{1}$, O.M. Rutiaga-Quiñones ${ }^{2}$, J.R. Verde-Calvo ${ }^{1}$, S. Huerta-Ochoa ${ }^{1 *}$ ${ }^{1}$ U Departamento de Biotecnología, Universidad Autónoma Metropolitana. P.A. 55-535, 09340 Iztapalapa, México D.F., México.

${ }^{2}$ Departamento de Química-Bioquímica, Instituto Tecnológico de Durango, Durango. Received July 17, 2014; Accepted October 19, 2014

\section{Abstract}

The aim of this work was to evaluate the bioconversion of (+)-valencene to (+)-nootkatone by B. theobromae using a membrane aerated biofilm reactor (MABR) in a two liquid phase system with orange essential oil as the organic phase. In the aqueous phase system, a (+)-nootkatone production rate up to $3.98 \mathrm{mg} \mathrm{L}^{-1} \mathrm{~h}^{-1}$ was achieved, obtaining a final product concentration of $398.08 \mathrm{mg} \mathrm{L}^{-1}$ with a bioconversion of $62 \%$. A two liquid phase system, using orange essential oil as the dispersed phase, was also studied and a final (+)-nootkatone concentration of $310.37 \mathrm{mg} \mathrm{L}^{-1}$ was achieved in the organic phase, with a bioconversion of $30.5 \%$ and a production rate of $2.46 \mathrm{mg} \mathrm{L}^{-1}$ day ${ }^{-1}$. The lower performance obtained using the two phase system was probably due to mass transfer limitations. The present work is the first report on an MABR for the bioconversion of (+)-valencene to $(+)$-nootkatone. Further studies on bioconversion products and optimization of biofilm reactor operations are needed to enhance bioconversion.

Keywords: bioconversion, (+)-nootkatone, Botryodiplodia theobromae, orange essential oil, membrane aerated biofilm reactor.

Resumen

El objetivo de este trabajo fue evaluar la bioconversión de (+)-valenceno a (+)-nootkaton por $B$. theobromae usando un reactor de biopelícula de membrana aireada (MABR) en un sistema de dos fases líquidas con aceite esencial de naranja como fase orgánica. En el sistema de fase acuosa, se logró una tasa de producción de (+)-nootkaton de hasta $3.98 \mathrm{mg}$ $\mathrm{L}^{-1} \mathrm{~h}^{-1}$, obteniendo una concentración de producto final de $398.08 \mathrm{mg} \mathrm{L}^{-1}$ con una bioconversión de $62 \%$. También se estudió un sistema de dos fases líquidas, utilizando aceite esencial de naranja como fase dispersa, y se alcanzo una concentración final de (+)-nootkaton en la fase orgánica de $310.37 \mathrm{mg} \mathrm{L}^{-1}$, con una bioconversión de $30.5 \%$ y una tasa de producción de $2.46 \mathrm{mg} \mathrm{L}^{-1}$ día $^{-1}$. El menor rendimiento obtenido mediante el sistema de dos fases fue probablemente debido a las limitaciones de transferencia de masa. El presente trabajo es el primer reporte utilizando un MABR para la bioconversión de (+)-valenceno a (+)-nootkaton. Se necesitan estudios adicionales sobre los productos de bioconversión y la optimización de las condiciones de operación del reactor de biopelícula para mejorar la bioconversión.

Palabras clave: bioconversión, (+)-nootkaton, Botryodiplodia theobromae, aceite esencial de naranja, reactor de biopelícula de membrana aireada.

\section{Introduction}

The compound (+)-nootkatone is a sesquiterpenoid which possesses an intense grapefruit-like taste and other valuable properties that are highly appreciated by the fragrance and flavor industries (Ladaniya, 2010). The production of (+)-nootkatone is performed via chemical synthesis, mainly from the sesquiterpene

*Corresponding author: E-mail: sho@xanum.uam.mx 


\title{
ANNEXE V
}

Research Article

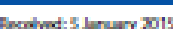

Deruect 12 March ngs

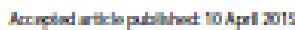

Rubihed animo in Wiry Orline litury:

(wileyonlinslibrarycom) DOI 10.1002/jttb.4702

\section{Whole cell bioconversion of (+)-valencene to (+)-nootkatone by Yarrowia lipolytica using a three phase partitioning bioreactor}

\author{
Dulce M Palmerín-Carrefío, ${ }^{a}$ Carlos O Castillo-Araiza, ${ }^{b}$ Olga M

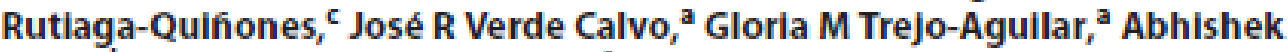

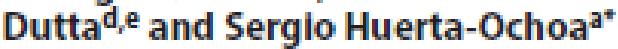

\begin{abstract}
BACKGROUND: Low permeability of substrates across the cell membrane, cofactor regeneration and product inhibition are some drawbacks of $(++$-nootkatone bloconversion. The alm of this work was to evaluate and enhance the bloconversion of $(+)$-valencene to $(+)$-nootkatone with Yarrowia lipolytica in a partitioning bioreactor using orange essential oil as the dispersed phase.

RESULTS: Preliminary experiments in shake flasks allowed enhancing (+)-nootkatone biocomversion to obtain favorable operating conditions ( $0.2 \%$ w/v of CTAB, 2.0 mmol L-1 of niacin and $11.5 \mathrm{~g} \mathrm{~L}^{-1}$ of biomsss) to produce $420.9 \mathrm{mg} \mathrm{L}^{-1}$. Biloreactor experiments in a two-phase system using $0.2 \%$ (w/v) of $C \mathrm{TAB}, 2.0 \mathrm{mmol} \mathrm{L}^{-1}$ of niacin and $22.5 \mathrm{~g} \mathrm{~L}^{-1}$ of biomass produced a maximum ( + -nootkstone concentration of $619.8 \mathrm{mg} \mathrm{L}^{-1}$ which was around the product inhibition concentration. Nevertheless, the partitioning three-phase system using orange essentisl ofl overcame product inhibition, obtaining concentrations up to $852.3 \mathrm{mg} \mathrm{L}^{-1}$

CONCLUSIONS: This is the first report of a wild type Y. Mpolytica with the enzymatic machinery to carry out this biocomversion. The multi phase partitioning bloresctor concept seems to have good potential for enhancing the productivity of $1+1$-nootkatone. The blocomversion approach presents an attractive way to produce and recover $(+)$-nootkatone in situ using a natural $(+)$-valencene source.

2015 Society of Chemical Industry
\end{abstract}

Keywords: biocomwersion; partitioning bioraactor; (+)-nootkatone; orange essential oit yoast; product inhibition

\section{INTRODUCTION}

The compound $(+)$-nootkatone is a sesquiterpenoid which possesses an intense grapefinit-like taste and other valuable prop. erties that are exploited by the frogrance and flawour industries. The peoduction of $(+)$-nootkatone is performed vis chemica synthesis, mainly from the sesquiterpene (+)-valoncene, which is readly avalable from the orange industry and also through the use of ervironmentaly unfrisndly oxidising sgents, such 3 tert-butyl peracetate ${ }^{2}$ and tert butyl hydroperoxide in combina tion with catalytic metal supported on slica. "However, the resulting (+1)-nootkatone produced via chamical synthesis cannot be marketed as a "natural' product and does not satisfy increasing market demands for natural aromatic compounds. In order to meet this demand, efforts have been focused on the use of biotechnological processes with bacteria, fungi or plants." Some researchers hawe investigated gensticaly modified microorganisms, and seweral published reviews ${ }^{\text {to }}$ have provided an owsrviow of recently acquired knowledge about whole cell bioconversions and future industrial applications. In particular, industry and acadomia are interested in a biocatalytic peocess using whole cells which involves the selection of an optimal cellular enryme, rasction engineering product recovsry and scaling-up
Gavira et al. ${ }^{7}$ reported a bicconversion process for (t)-nootkatone production using plant enrymes expressed in Saccharomyces cerevisiae. However, the peocess was inhibited by both the substrate $\left(3.4 \mathrm{gL}^{-1}\right)$ and the product $\left(1.0 \mathrm{gL}^{-1}\right)$ as woll

- Comapondance ta: Seygo Fusrla-Ochoa, Departamento de Botecnologla, Unvaridad Autónoma Matropolitana, Mtelco Cry, Mosica. E-mal-shovearumaumerm

a Departaments de Blorechologla, Uniwssidod Astohomo Motropoitrana, PA 55. 535, 03340 Litapalepa, MGrico DF, MGrico

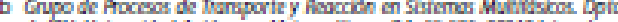

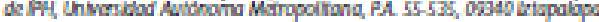
Maco DF, Mbxico

c. Departananto de Quimica Eloquimica, Instltuto Fecnoldgico de Duxinga Dunanga, Morico

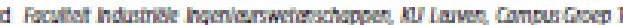
Laven, Anches Vesalusstoat 13, 8.3900 Lever, Beiglum

- Departement Materioallunde, KJ Laven, Kasteclpark Averbarg 44 bus 2450 B.3001 Hoveroe Lewan, Belgium 